Edited by Malcolm Cooper, Abhik Chakraborty and Shamik Chakraborty

\title{
Rivers and Society
}

Landscapes, Governance and Livelihoods

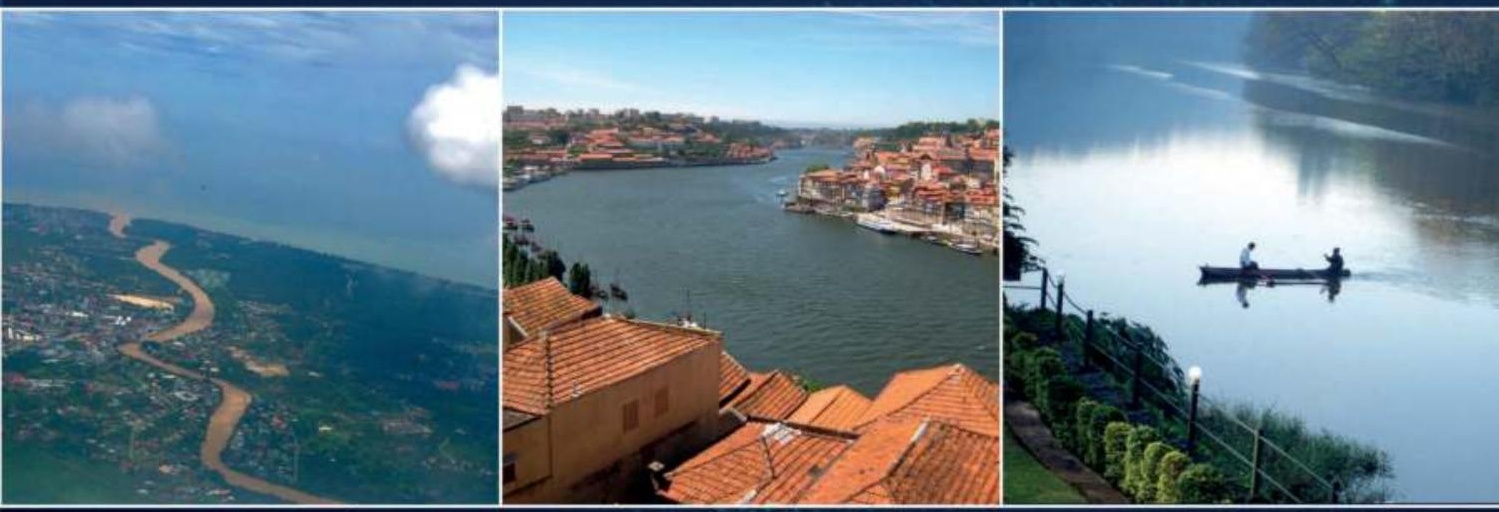




\section{Rivers and Society}

Rivers and their watersheds constitute some of the most dynamic and complex landscapes. Rivers have sustained human communities, and human societies have utilized and altered river flows in a number of ways for millennia. However, the level of human impact on rivers, and on watershed environments, has become acute during the last hundred years or so.

This book brings together empirical research and theoretical perspectives on the changing conditions of a range of river basin environments in the contemporary world, including the history and culture of local societies living in these river basins. It provides theoretical insights on the patterns and nature of the interaction between rivers and their use by human communities. The chapters are written from a variety of positions, including environmental science, hydrology, human ecology, urban studies, water management, historical geography, cultural anthropology and tourism studies.

The case studies span different geographical regions, providing valuable insight on the multifaceted interactions between rivers and our societies, and on the changing riverscapes in different parts of the world. Specific detailed examples are included from Australia, Brazil, France, India, Iran, Japan, the Netherlands, New Zealand, South Africa, UK and USA.

Malcolm Cooper PhD is Emeritus Professor, College of Asia Pacific Studies, Ritsumeikan Asia Pacific University, Japan.

Abhik Chakraborty PhD is Lecturer in the Center for Tourism Research, Wakayama University, Japan.

Shamik Chakraborty $\mathrm{PhD}$ is a Postdoctoral Research Fellow at the Institute for the Advanced Study of Sustainability, United Nations University, Tokyo, Japan, and a Visiting Research Fellow at the Integrated Research System for Sustainability Science, Japan. 


\section{Earthscan Studies in Water Resource Management}

\section{Water Policy, Imagination and Innovation}

Interdisciplinary Approaches

Edited by Robyn Bartel, Louise Noble, Jacqueline Williams and Stephen Harris

Rivers and Society

Landscapes, Governance and Livelihoods

Edited by Malcolm Cooper, Abhik Chakraborty and Shamik Chakraborty

Transboundary Water Governance and International Actors in South Asia The Ganges-Brahmaputra-Meghna Basin

Paula Hanasz

The Grand Ethiopian Renaissance Dam and the Nile Basin

Implications for transboundary water cooperation

Edited by Zeray Yihdego, Alistair Rieu-Clarke and Ana Cascao

Freshwater Ecosystems in Protected Areas

Conservation and management

Edited by Max C. Finlayson, Jamie Pittock and Angela Arthington

Participation for Effective Environmental Governance

Evidence from European Water Framework Directive Implementation

Edited by Elisa Kochskämper, Edward Challies, Nicolas W. Jager and Jens Newig

China's International Transboundary Rivers

China's International Transboundary Rivers

Lei Xie and Jia Shaofeng

For more information and to view forthcoming titles in this series, please visit the Routledge website: www.routledge.com/books/series/ECWRM/ 


\section{Rivers and Society}

Landscapes, Governance

and Livelihoods

Edited by Malcolm Cooper, Abhik Chakraborty and Shamik Chakraborty 
First published 2018

by Routledge

2 Park Square, Milton Park, Abingdon, Oxon OX14 4RN

and by Routledge

711 Third Avenue, New York, NY 10017

Routledge is an imprint of the Taylor $\mathcal{E}$ Francis Group, an informa business

(C) 2018 selection and editorial matter, Malcolm Cooper, Abhik

Chakraborty and Shamik Chakraborty; individual chapters, the contributors

The right of Malcolm Cooper, Abhik Chakraborty and Shamik

Chakraborty to be identified as the authors of the editorial material, and of the authors for their individual chapters, has been asserted in accordance with sections 77 and 78 of the Copyright, Designs and Patents Act 1988.

With the exception of Chapter 11, no part of this book may be reprinted or reproduced or utilised in any form or by any electronic, mechanical, or other means, now known or hereafter invented, including photocopying and recording, or in any information storage or retrieval system, without permission in writing from the publishers.

Chapter 11 of this book is available for free in PDF format as Open Access from the individual product page at www.routledge.com. It has been made available under a Creative Commons Attribution-Non Commercial-No Derivatives 4.0 license.

Trademark notice: Product or corporate names may be trademarks or registered trademarks, and are used only for identification and explanation without intent to infringe.

British Library Cataloguing-in-Publication Data

A catalogue record for this book is available from the British Library

Library of Congress Cataloging-in-Publication Data

A catalog record for this book has been requested

ISBN: 978-1-138-93090-2 (hbk)

ISBN: 978-1-315-68008-8 (ebk)

Typeset in Goudy

by Apex CoVantage, LLC 


\section{Contents}

List of figures vii

List of tables $\quad$ ix

Preface $\quad x$

Acknowledgements $\quad$ xi

Contributors xii

1 Introduction: the rivers and society debate revisited 1 ABHIK CHAKRABORTY

2 Rivers as socioecological landscapes 9 ABHIK CHAKRABORTY AND SHAMIK CHAKRABORTY

3 Rivers and communities: can we drought proof a catchment or an entire country?

RONNIE MCKENZIE

4 Arid lands, saline lands: water in the form of a major river under stress, the Murray-Darling system in Australia MALCOLM COOPER

5 Life, identity and work in an arid river basin: the case of the Zayandeh-Rud (life-giving river) in central Iran KAZEM VAFADARI MEHRIZI

6 Rivers and water security: supply adaptation strategies in the city of Chennai, India SHARANYA SETHURAM AND MALCOLM COOPER

7 The Velho Chico: perceptions and conflicts 
vi Contents

8 Rivers as vernacular landscapes: place and experience in making the Clutha River, New Zealand ANDREA FARMINER

9 Keep it flowing: the restoration ecology of indigenous culture and language along the Missouri River DEAN P. GOOD EAGLE FOX AND ALESIA MALTZ

10 The end of the Los Angeles River: a paradox T.S. MCMILLIN

11 The river's embrace: the Rhine-Meuse delta (re)imagined 169 EVELINE R. DE SMALEN

12 Art custodians of our rivers: Basia Irland, Daniel McCormick and Mary O'Brien

VALERIE BEHIERY

13 Hydrocitizenship: concepts and insights from the Lee Valley, UK

GRAEME EVANS

14 River Tourism MALCOLM COOPER

15 Social landscape and environment: the Hérault River in Southern France

JEREMY S. EADES

16 Concluding remarks and the way forward 246 SHAMIK CHAKRABORTY, ABHIK CHAKRABORTY, AND MALCOLM COOPER

Index 


\section{Figures}

2.1 Map of Kizu River Watershed showing the Biwako Yodogawa Watershed (right) and its location in the Japanese Archipelago

2.2a The Taki River Basin is known for lush natural vegetation cover and numerous waterfalls and is an important habitat for the giant salamander

2.2b However, large artificial structures such as bridges and roadways that impede material flow and fragment the river basin are conspicuous at the downstream parts of the Kizu watershed 16

2.3 Map of the Takatsu River Watershed and its location in the Japanese Archipelago

2.4a A boat floats along the water's edge at the Takatsu River Basin. During the 20th century's economic development, most of the notable rivers in Japan were dammed, and comparatively free-flowing rivers such as the Takatsu are rare

2.4b The Common Oriental Clam: this humble creature is an important marker species for downstream watershed health $\quad 19$

3.1 Indicative single mass plot for rainfall 30

3.2 Reducing rainfall record: Orange River Catchment 30

3.3 Typical 2-basin water resource system 31

$\begin{array}{ll}3.4 & \text { Naturalizing a stream flow record }\end{array}$

3.5 The critical period for a storage system 35

3.6 Calculation of the risk of failure and reliability 37

3.7 The actual seven-year performance of a storage system
compared to the expected

$\begin{array}{lll}3.8 & \text { Hydrology and resource system analyses } & 39\end{array}$

3.9 Typical stages in the analysis process 41

3.10 Example of a simple inter-basin transfer for drought proofing the Bloemfontein Area of South Africa 43

3.11 High level system schematic of Figure 3.10 44

4.1 Murray-Darling Basin 48

5.1 Map of the Zayandeh/Gavkhouni drainage basin 61

5.2 The Shahrestan Bridge, Esfahan 73

6.1 The water resources of Chennai 84 
6.2 Chennai's population growth, water demand, and supply gaps

6.3 Chennai's water supply system for many people - storage of water for two or three days in jars

7.1 Sao Francisco River, Brazil

7.2 The Sao Francisco River Watershed 95

$\begin{array}{ll}7.3 \text { Hydropower stations: past } & 97\end{array}$

$\begin{array}{lll}7.4 & \text { Infrastructure for irrigation } & 98\end{array}$

7.5 Percentage of water volume available (volume útil) in

Sobradinho reservoir during two years of extreme droughts: 2001 and 2015

7.6 The civil society against the Inter-basin water transfer project: protests in Brasília

8.1 The Clutha River system, Otago, New Zealand

8.2 Personal placescapes layering the Clutha River vernacular landscape - a well-worn picnic bench, heritage board and old bridge abutment overlooking the Clutha River in the Beaumont Gorge

10.1 The Mouth of the Los Angeles River

10.2 Sign at the end of the Los Angeles River

10.3 Lower Los Angeles River near Willow Street 158

10.4 Confluence with the Rio Hondo 162

10.5 The beginning of the end 164

12.1 Basia Irland. Ice Book TOME II at Dusk 191

12.2 River guide adds water to the Canteen 192

12.3 River Fork Ranch Flood Plain Wall 198

13.1 Lee Valley and Neighbouring Towns 205

13.2 Cultural Ecosystem Mapping, Hackney Wick, lower Lee Valley 212

13.3 Graffiti and floating cinema Hackney Wick, lower Lee Valley 215

14.1 A simplified illustration of the range of factors that affect the ability of the tourism industry to use rivers for touristic purposes 


\section{Tables}

3.1 Reservoir yields for different record lengths 36

4.1 Murray-Darling Basin long-term annual inflow and water use 52

7.1 Geography and demographic characteristics 93

$\begin{array}{lll}7.2 & \text { Hydropower Stations } & 100\end{array}$

7.3 Changing River Flows 104

13.1 Stewards and stakeholders in the Lee River system 207

14.1 The use of river systems for tourism and other industries 224 


\section{Preface}

Rivers constitute some of the most dynamic and complex environmental, economic and socio-cultural landscapes on the planet. To aid understanding of this complexity we have assembled a wide range of contributors to consider the implications of the current patterns of river basin governance for more effective environmental conservation within the current patterns of socio-economic and cultural use of their water resources by the communities that live in them. In the introductory chapter, we outline the book's aims, overall perspective and central argument. Rivers have sustained human communities for thousands of years, and human societies have utilized and altered river flows in many ways for millennia.

However, the level of human impact on rivers, and on watershed environments, has become acute during the last 100 years or so. Recent evidence shows that freshwater ecosystems, which support $40 \%$ of all fish species world-wide, are becoming increasingly threatened; nearly 10,000 freshwater and estuarine species have become extinct in the past 100 years or are endangered due to human impact on these environments. This is a result of a combination of factors: the rampant construction of dams and weirs in freshwater landscapes, over-extraction of water, the alteration of river flow patterns, increases in pollution and changes in the way human societies interact with these landscapes in tourism activities, for example. One major impact has been the 'fragmentation' of river systems, either from flow regulation through dams and other direct impacts, or from conversion of flood plains through increases in the built environment in river basins, leading to a decline in landscape diversity. The net result has been a decline in ecological and visual diversity in river basins, an increase in transboundary and riparian rights issues and the concretizing and straightening of river channels; these changes are having adverse impacts on local societies in many cases, as well as on the availability of the water that the rivers carry. The chapters have been chosen to highlight these hydrological, environmental, social, cultural, governmental and economic themes throughout the book. We emphasize that the sustainable use of riverine systems is most appropriately viewed as an increasingly pivotal factor at the intersection of a broad range of social patterns and processes in the 21 st century.

Finally, we hope this book will be a first but important step towards co-creating values for rivers and society through collaboration in the private and public sectors. In this way, we will co-create and innovate by unleashing the full potential of our rivers within the sustainable development of our communities. 


\section{Acknowledgements}

The editors would firstly like to acknowledge all the people involved in this project at Earthscan/Routledge, and Malcolm Cooper and Shamik Chakraborty would like to thank their respective institutions Ritsumeikan Asia Pacific University and the United Nations University. Without their active support, this book would not have become a reality. Secondly, the editors would like to thank each one of the authors for their contributions; please accept our sincere thanks for your time and expertise. Lastly, we want to thank our families and friends, whose quiet support kept the project alive.

Shamik Chakraborty would also like to specifically thank Dr. Alexandros Gasparatos for the thought-stimulating discussions about ways to look into humannature systems, these discussions, although not always about rivers, stimulated him in the writing, editing and synthesizing of this book. Warm thanks also go to Dr. Pankaj Kumar and Dr. Binay Kumar Mishra for discussion regarding freshwater issues. He would also like to thank colleagues and fellow researchers at the Institute for the Advanced Study of Sustainability, United Nations University, for the research facilities and continuous support that helped him complete his work for this book. He would also welcome readers of this volume to share their thoughts on how to conserve and restore our rivers. 


\section{Contributors}

Valerie Behiery PhD is Assistant Professor of Art History at Princess Nourah bint Abdulrahman University in Riyadh, Saudi Arabia. Prior to this, she taught at Necmettin Erbakan University in Konya, Turkey. A Canadian graduate of McGill University in Montreal, she has published widely in peerreviewed journals, academic reference works and art catalogues on the history and impact of art.

Abhik Chakraborty $\mathrm{PhD}$ is a Lecturer in the Centre for Tourism Research, Wakayama University, Japan. His research interests include complex environmental systems, landscape change and holistic nature conservation.

Shamik Chakraborty $\mathrm{PhD}$ is a Postdoctoral Research Fellow at the Institute for the Advanced Study of Sustainability, United Nations University, Tokyo, Japan, and a Visiting Research Fellow at the Integrated Research System for Sustainability Science, Tokyo, Japan.

Malcolm Cooper $\mathrm{PhD}$ is Emeritus Professor in the Tourism and Hospitality Cluster at Ritsumeikan Asia Pacific University, Beppu, Japan. He is a former Vice President of APU, and has held several senior positions in Universities in Australia, Sri Lanka and New Zealand. He has published over 150 books and papers.

Eveline R. de Smalen has a background in English and Comparative Literature and is currently working on her $\mathrm{PhD}$ in Environmental Humanities at the Rachel Carson Center, Ludwig-Maximilians-Universität München, Germany, as an Early Stage Researcher as part of the Marie Skłodowska-Curie ENHANCE ITN. Her work embodied in this chapter received funding from the European Union's Horizon 2020 research and innovation programme under the Marie Skłodowska-Curie grant agreement No 642935.

Jeremy S. Eades PhD is Emeritus Professor of Ritsumeikan Asia Pacific University, Beppu, Japan and Visiting Professor at SOAS, London, United Kingdom. He continues to work on collecting and systematizing the academic anthropological and sociological tourism literature of the Asia Pacific Region in conjunction with colleagues from around the world. 
Graeme Evans $\mathrm{PhD}$ is Professor of Urban Cultures \& Design in the Faculty of Arts \& Creative Industries at Middlesex University, London, United Kingdom. He also holds the Chair in Culture \& Sustainable Development at Maastricht University. He has recently completed a three-year research project: Towards Hydrocitizenship, funded by the UK Arts \& Humanities Research Council.

Andrea Farminer PhD is Principal Archaeologist at Origin Consultants Ltd, Queenstown, New Zealand. She gained her PhD at Otago University, New Zealand, and her research focused on a deeper understanding of how people and place relationships are created and expressed through river experiences.

Dean P. Good Eagle Fox, died on Thanksgiving Day 1999, at the age of 44. He had an abiding commitment to the revitalization of Mandan, Hidatsa and Arikara cultures and was instrumental in reintroducing the Okipa ceremony and the Grass Dance. Aware of the role of media and myth in protecting indigenous culture, Dean asked Alesia Maltz to publish these ideas about media, language, story and the Missouri River at the proper time. Today, as the MHA Nation faces the aftermath of development from the dam and the fracking boom, and as the Standing Rock encampments protect the waters of the Missouri, may the words in this book serve, as Dean hoped they would, as medicine.

Alesia Maltz PhD is core faculty in the Environmental Studies Department at Antioch University New England and has taught at both Fort Berthold and Sitting Bull Tribal Colleges. Her research interests are in indigenous knowledge, public health and environmental history, with a focus on environmental justice, food and water. She teaches environmental history, environmental arts, and environmental justice. Her current research interest in the history of nutrition focuses on the relationship between nutrition and the environment. Her forthcoming book traces the history of Vitamin D in Great Britain and the interplay between indigenous dietary knowledge and the scientific discovery of vitamins in the creation of national public health policy.

Ronnie Mckenzie PhD is the Chair of the International Water Association's Specialist Group on Water Loss, and Managing Director of WRP P/L, Durban, South Africa. Ronnie is a specialist in Water Demand Management, Hydrology, Water Resource Planning, Management and Operation, with more than 30 years of experience in these fields. Ronnie was a key member of the Vaal River System Analysis team which pioneered the water resources conservation techniques which are now used throughout South Africa. He was responsible for the overall management of the second phase of the development of an Integrated Water Resource Development Plan for the Orange River basin.

T.S. McMillin PhD is Professor of English at Oberlin College and Conservatory, Ohio, United States. He is the author of The Meaning of Rivers: Flow Eु Reflection in American Literature (American Land \& Life Series, University of Iowa Press, 2011) and Our Preposterous Use of Literature: Emerson 8 the Nature of 
Reading (University of Illinois Press, 2000). Most recently, his essay "Strange Waters - Confluences in the Los Angeles Basin" appeared in The Politics of Fresh Water: Access, Conflict and Identity, eds. Catherine Ashcroft and Tamar Mayer (Studies in Water Resource Management Series, Routledge, 2016).

Lucigleide Nery Nascimento PhD holds a BS in Economics, a MS in Natural Resources - Environmental Conservation and a PhD in Natural Resources and Environmental Studies, and is Especialista em Produção de Informações Econômicas, Sociais e Geoambientais at Superintendência de Estudos Econômicos e Sociais da Bahia, Brazil.

Sharanya Sethuram $\mathrm{PhD}$ was at UCLA as a researcher in the Environmental LA Grand Challenge Project, Los Angeles, United States, at the time this chapter was written based on her earlier PhD work at Ritsumeikan Asia Pacific University, Beppu, Japan.

Kazem Vafadari Mehrizi PhD is an Associate Professor and Head of the Tourism and Hospitality Cluster at Ritsumeikan Asia Pacific University, Beppu, Japan. His previous positions include Research Fellow, Institute of Nature and Environmental Technology, Kanazawa University 2011-present and JSPS. UNU Post-Doctoral Research Fellow, United Nations University, Institute of advanced Studies UNU-IAS, Kanazawa City, Japan, 2008-2010. 


\title{
1 Introduction \\ The rivers and society debate revisited
}

\author{
Abhik Chakraborty
}

\section{Encountering a river}

A weak stream that barely moves. A waterbird stands on the barely perceptible flow, perhaps looking a bit confused. On the banks, and floating on the stream, are different types of garbage; plastic catches the eye, but there is more discarded stuff from our everyday lives. This is how the Yamato River near the large metropolis of Osaka looks like on an average day. I have a chance to meet this river frequently, yet I must say, I do not know it enough: how did the river come to this state? What are the sources of its ills? Is there any way to possibly re-engineer the river to a more natural state? Although it is a snapshot framed by a particular glance at a particular time, it sums up a disturbing reality of our rivers today. That reality is this: though the nature of their plight differs from one place to the other and the scales and complexities involved are widely different, rivers have a troubled existence. And this has profound repercussions on our society.

To paraphrase Tim Ingold (2015): to be a river is a verb. Rivers are always in motion, cutting across landforms and landscapes and societies. While rivers provide us with vital life-supporting services such as water, fertile soil, and food (fish and other aquatic creatures), their flow is regulated by geological, geomorphological, and climatic conditions; and therefore, rivers do not exist out of a necessity to sustain life. The river's motion does not exist for anthropocentric, nor even biocentric reasons; the motion exists because it connects spatial change with time, across multiple levels of landforms and landscapes. However, the nature of rivers is poorly understood by human societies, and this incomplete understanding gives rise to schemes that seek to 'control' rivers. Rivers and their flows become value-laden in the process, they can be misconstrued as agents of sustenance or equilibrium defined by human stakeholders; and that is why, from time to time, the river's needs come in conflict with ours. Humans may try to alter rivers when our needs and the reality of a river's nature clash; but the river in the long run will always have its say. If it is trapped behind concrete walls it might start to withhold the very function of sustenance which we humans try to reserve for our society. Newson (1992) observes that the need to maximally exploit a river's capacity to provide benefit for our society through artificial means, and then regret when 


\section{Abhik Chakraborty}

the environmental costs pile up is a consistent trend throughout the history of civilizations. In this sense, the plight of the river and the plight of humans can be seen as an almost perpetual, self-repeating process.

\section{From control to comprehension?}

The urge to control the unpredictable and mind-bogglingly complex flow of rivers is an ancient one in human society. Biswas (1967) notes how, nearly 4000 years ago, the Babylonian king Hammurabi laid down strict rules for managing dams in his landmark 'codes': if a dam did not work properly and the river flooded cornfields, the person in charge of the dam was liable to pay a high amount in reparations. Wittfogel (1957) termed complex agricultural civilizations that prospered in large river valleys as 'hydraulic civilizations', which according to him were primarily based in the orient (Asia and Africa) where early technologies to harness rivers evolved and were aided with the ability of the centralized state to utilize labor. During the twentieth century, the Tennessee Valley Authority (TVA) type river management possibly marked an equally significant way of harnessing rivers. The TVA style management is characterized by the 'parceling' of rivers and their watershed components into sections based on a reductive logic of their functions, and mobilizing a complex web of landscape designing and urban-industrial development agendas with tightly controlled feedback loops (Downs 2014; Newson 1992). Hargrove (1994), in his authoritative analysis of the complexity that eventually came to be associated with the nature of the Tennessee project, has a note of caution: those tightly controlled feedback loops are a myth, a discourse created to suit a society's agenda, and can be prisoners of their own time and style.

Unfortunately, while it is relatively easy to criticize the idea behind 'controlling' rivers, it is not equally easy to offer solutions. The lack of feasible alternatives is, at least to a part, what drives the continued damming and course alterations of rivers around the world today. McCully (2001) narrates how large dams have silenced rivers and their natural rhythms; generating a complex cascade of problems. Based on the World Commission of Dams' analyses, Scudder (2006) examines the impact of large dams; a more detailed account on large dams and development is available in the two-set volume by Berga et al. (2006).

Despite these clear lessons of the loss of ecological connectivity and cultural diversity from several large dam projects, the quest to harness rivers for the sake of 'economic development' continues. The number of dams on the planet's watercourses is poised to see a net increase with dams planned on the watersheds of the Mekong, the Congo, and the Amazon; each of those basins housing many species unknown to modern science. Out of the debated terrain shaped by claims of benefits and services secured by damming rivers, and claims of irreversible environmental damage caused in the process, an issue of fundamental import to the well-being of human society stands out: it is the issue of uprooting of native culture, vernacular landscapes, and the diversity of local value systems, which are, along with the geological and geomorphological aspects, vital assets for comprehending rivers. 
Such 'river cultures' or 'river experiences' are place-specific, so when we lose one of them it is nearly impossible to fully replace it. While these are essentially human accounts based on subjective experiences of the environment and may be shaped, to an extent, by an emotive response; the inherent heterogeneity of such accounts directly stems out of the diversity of each river they are attached with. Indeed, the value systems and the associated local knowledge of rivers are as diverse as rivers themselves: they can range from local perceptions of glaciers (Cruikshank 2005) that are in essence 'frozen' rivers that flow in a different timescale; to a consciousness shaped by an iconic tree species that is in turn influenced by patterns in ancient floodplains, drought-and-flood pulses, and forest fires in an arid environment (Colloff 2014); to the always fluid dynamics of forest and cultures in the gigantic Amazon basin (Davies 2014).

As we enter the Anthropocene (Davies 2016), the effect of human control of rivers for the benefit of our society, and whether this notion itself is an elaborate yet myopic myth, must come under renewed focus. A notable point of inquiry is the river as a geomorphological agent and the mountain-watershed-coast continuum (which includes fluxes as well as contiguous processes). The report from a large-scale study is already available on this issue; derived from research on this set of interactions based on case studies under the UNESCO International Geosphere-Biosphere Programme (IGBP) (Crossland et al. 2005). The report devotes a section on 'The Catchment to Coast Continuum'. A question of import in this arguably 'new' geological epoch is: whether our actions and their accumulated impacts have fundamentally altered the biophysical processes of watersheds which in turn will affect land-formation and landscaping mechanisms that in turn will impact biodiversity. A related, but equally important, question is this: how those actions and impacts have altered our ways of interacting with rivers, i.e. how the rivers and society interaction is being transformed from within.

While scientists will assume the key role of deciphering the signs and magnitude of change in the biophysical continuum, social scientists have an equally important and complementary role in deciphering how the society itself is undergoing change even as it changes the river. Analyzing how modernity, or industrial and urban development specifically, shapes our needs and gives rise to evaluation, management and conservation discourses (and the value system engendered therein) on rivers is therefore both timely and important. What is the rupture that modernity has caused to rivers? Is it a rupture of landscapes where biophysical units are fragmented from one another? Or is it also a fracture in our knowledge system, symbolizing our increasing inability to coexist with geological and geomorphological forces and a growing chasm between our species and the rest of the geo-biosphere that will arise as a logical consequence? Does our present relationship with rivers forebode a troubled future for humanity? These are some questions that merit urgent attention by river scientists, sociologists, and planners.

Fortunately, there is a growing amount of scholarship that aims to understand the modern society's relationship with rivers with a critical perspective, and this allows us to hold out hope that rivers will not end up being contested spaces for 


\section{Abhik Chakraborty}

the extraction of resources and the exercise of power but they will be valued as a unifying force for an ecologically conscious humanity.

\section{The river as a system or entity}

A simplistic, but analytically powerful way to comprehend a river is to conceptualize it as a system consisting of mutually interacting components (or subsystems) over a spatial unit. The system has one or multiple 'key function/s'. Schumm's (1977) influential work, 'The Fluvial System', marks a milestone in this regard: his representation of the watershed (with a main river and its tributaries) as a sediment transfer system remains a powerful analytical tool. The system can undergo change over time. Change can be fundamental and irreversible, such as the formation of the rift-valley of Africa due to the break-up of ancient continental landmasses and separation of the Nile system from the Congo system (Wohl 2011), or it could be episodic such as the flood and drought cycle of the Nile (Ortileb 2004; Sutcliffe 2009). Episodic changes in the river regime can be integrally linked with ecosystem responses (Benke 2001; Tockner et al. 2003), and social dynamics and human well-being. The river can be the backbone of a 'socioecological system', a complex dynamic web of adaptive interactions where surprise and change are part-and-parcel of the system dynamic; the system periodically undergoes swift (apparently destructive) release of energy but reconfigures itself due to its 'memory' etched in the landscape over time. (For more, see Gunderson and Holling 2001; Gunderson et al. 2009.) Increasingly ecologists are recognizing sudden, abrupt change as an inherent part of the river system (Tiegs et al. 2005; Middleton 2002; Espinola et al. 2014); such 'shocks' facilitate landscape level heterogeneity, ecological diversity, and capacity of regeneration (resilience); rivers in this sense are truly systems in perpetual flux.

The idea that the river forms a riverscape over time and across a large spatial unit is another influential one for understanding its functions. Haslam's (2008) work remains a milestone in this regard. The opening sentence of her seminal book reads: "The riverscape and the river share the sheet of water which covers the land: in whole or in part, permanently or intermittently" (Haslam 2008, 1). The riverscape thus encapsulates many apparently contradictory scales and processes; it is shaped by, and it shapes, the water body of the river. It has the three characteristics of "structure, function and change" (Haslam 2008, 2) and it can be generally conceived of as a three-tiered landscape comprising the river itself (and aquatic biota), the riverside (and riparian biota and relief) and "the land beyond" (which can be mountains, forests or pastures; Haslam 2008, 3). It is clear from this observation that the riverscape is as much a product of our comprehension as much it is a natural entity. Haslam points out that the riverscape is also a working or cultural entity, and its appearance and identity (and thus its value) can change with the transformation of social interaction pathways (Haslam 2008, 4). The riverscape therefore is very much a pathscape of interactions.

Another equally important viewpoint is to comprehend water itself as an entity. This is done mainly through anthropocentric meaning-making processes, but 
such explorations eventually expand into awareness about the other and how that other is related to the self in the waterscape. One of the most notable treatises on this type of reflexive inquiry is Strang's The Meaning of Water (2004). As this work eloquently shows, while each water-body and the value systems attached therewith is different, there are issues of common importance and general applicability. The river in this sense is a source of knowledge, which can assume different forms such as scientific and ethno-ecological knowledge. A related lesson stands out from Strang's work: even a little known, unassuming river has a wealth of information in the richness of its landscape, fluvial patterns, biota, and history of human interactions that is waiting to be discovered. In our volume, several chapters touch upon this important realization.

\section{The changing river landscape and implications for governance and livelihoods}

The 'riverscape' and 'meaning of water' ideas converge around the issue of fragmentation of rivers in our times. Haslam cites Rackham (1986) who argued that the landscape of the UK witnessed more destruction in four decades beginning from 1945 compared to the previous 1,000 years. Strang (2015) also writes about the drastic change in our relationship with water. Once a source of spiritual sustenance, the society's view of water underwent phase transitions over time; and today the fate of this precious resource appears uncertain due to agricultural and industrial consumption patterns and contested claims for control. The WWF reports that only 64 out of the 177 rivers that are over $1000 \mathrm{~km}$ in length flow undammed today, and only 21 of those are allowed to flow directly into the sea (WWF n.d.). A related report mentions that $20 \%$ of the nearly 10,000 species that live in freshwater environments have either gone extinct in the last few decades or are facing extinction today (Ibid). River damming - especially its twentieth-century variant of large concrete dams - has been singled out as causing the biggest impact on a river's connectivity with its basin environment. Van Cappellen and Maavara (2016) warn that by 2030, as much as $90 \%$ of all streams and rivers across the world could be controlled by damming, leading to far-reaching effects in the planet's geo-biosphere. Large dams such as the Sardar Sarovar in India are highly controversial and became a touchstone for local anti-dam movements (Leslie 2005). The WWF (2004) explicitly states: "Dams disconnect rivers from their floodplains and wetlands. The damage to freshwater ecosystems is devastating and can be difficult to undo" (8). As industrial and urban development, agriculture and recreational activities continue to consume water, and as human actions change the fundamental bio-geochemical pathways of the planet; these figures may well be conservative estimates of the impending change.

Yet, at the same time, humans cannot afford to move away from water and let rivers flow without any intervention at all. Better management of rivers and robust governance schemes that seek to preserve the diversity, quality of environment and ecological resilience of river basins, and more enlightened interaction pathways at the level of every individual is therefore needed more than ever. Efforts are already 
on in some of the high profile and most ecologically diverse river basins like the Mekong to move towards transboundary cooperation even when the stakeholders possess conflicts of interest (Haefner 2016). The plight of the Colorado, one of the most iconic rivers of North America that now fails to reach the sea, has prompted calls for living with less water (Fleck 2016). Scholars of different disciplines are increasingly drawn together in collaborative works about rivers resulting in comprehensive chronicling of the threats on some of the last wild rivers (Stromberg and Tellman 2012). There are also a few bold schemes aiming to free rivers; the removal of dams for restoration of watersheds is gaining momentum (Hawley 2011).

In the highly mobile contemporary society, river tourism (Prideaux and Cooper 2009) is likely to become a key activity that will facilitate a sense of river-heritage and play an increasingly important role in making informed decisions about rivers. However even as such positive beacons appear on the horizon, much is still being lost at an alarming rate. Responsible and innovative governance of river basins is urgently needed because healthy rivers are associated with healthy livelihoods. In addition, river governance in the twenty-first century (and beyond) is not solely about rivers, it is also about wetlands, forests, mountains, and coasts. A matter of critical importance is how much open space is available for the geomorphological and biological processes once an artificial structure fragments the upstreamdownstream connectivity of a large watershed or when built surfaces prevent the river from reaching out to its floodplain. The emerging science of open spaces (Curtin 2015) offers us a useful analytical tool in this regard. Finally, each river and its basin is a 'place'; which necessitates applying ideas such as the ecology of place (Billick and Price 2011) with special attention given to vernacular landscapes, tangible and intangible heritage in the landscape and local society, biocultural diversity found in the local linguistic resources, and empathy (local emotional attachment) with the river. The pertinence to revisit the rivers and society debate lies precisely here: in the pressing need to find solutions for our better future with rivers, and the need to continuously explore them as complex systems, homes (for creatures many of which we do not yet know), and a planetary force that connects mountains to seas, snowmelt to forests, and raindrops to our bodies.

\section{A note on the chapters of this book}

The chapters that follow analyze rivers and their connections from different but complementary angles. Rivers are analyzed as dynamic socioecological systems, as providers of water and shapers of water policies in arid watersheds, as contested spaces, as vernacular landscapes and as increasingly important spaces for recreation (tourism). The contributors provide analyses from different perspectives, and they also highlight the present conditions in different river systems in the process. While some rivers are well known for their importance in international or national level water management, some case studies focus on smaller waterways that nevertheless carry important meaning for the local societies. The book is not divided into formal sections but is loosely grouped in a progression from theory to case study practice that will assist in our major aim of integrating rivers and society. 


\section{References}

Benke, A. C. 2001. "Importance of Flood Regime to Invertebrate Habitat in an Unregulated River - Floodplain Ecosystem." Journal of the North American Benthological Society 20: 225-240.

Berga, L., Buil, J. M., Bofill, E., De Cea, J. C., Garcia Perez, J. A., Manueco, G., Polimon, J., and Yaguee, J. eds. 2006. Dams and Reservoirs: Societies and Environments in the 21st Century, I, II. Boca Raton, FL: CRC Press.

Billick, I., and Price, M. V. 2011. The Ecology of Place: Contributions of Place-Based Research to Ecological Understanding. Chicago, IL: The University of Chicago Press.

Biswas, A. K. 1967. "Hydrologic Engineering Prior to 600 BC." Proceedings of the American Society for Civil Engineers Journal Hydraulics Division HY5: 118-131.

Colloff, M. 2014. Flooded Forest and Desert Creek: Ecology and History of the River Red Gum. Collingwood, VIC: CSIRO Publishing.

Crossland, C. J., Kremer, H. H., Lindeboom, H. J., Marshall Crossland, J. I., and Le Tissier, M. D. A. eds. 2005. Coastal Fluxes in the Anthropocene: The Land-Ocean Interactions in the Coastal Zone Project of the International Geosphere-Biosphere Programme. Heidelberg: Springer.

Cruikshank, J. 2005. Do Glaciers Listen? Local Knowledge, Colonial Encounters, and Social Imagination. Washington, DC: University of Washington Press.

Curtin, C. G. 2015. The Science of Open Spaces: Theory and Practice for Conserving Large Complex Systems. Washington, DC: Island Press.

Davies, J. 2016. The Birth of the Anthropocene. Oakland, CA: University of California Press.

Davies, W. 2014. One River: Explorations and Discoveries in the Amazonian Rainforest. New York: Vintage.

Downs, M. L. 2014. Transforming the South: Federal Development in the Tennessee Valley 1915-1960. Baton Rouge, LA: LSU Press.

Espinola, L. A., Amsler, M. L., Paira, A. R., Drago, E. E., Blettler, M. C. M., and Agostinho, A. A. 2014. "Effects of Decadal Changes in the Hydrological Regime of the Middle Reach of the Paraná River (Argentina) on Fish Densities." Environmental Biology of Fishes 97(7): 757-771.

Fleck, U. 2016. Water Is For Fighting Over: And Other Myths About Water in the West. Washington, DC: Island Press.

Gunderson, L. H., Allen, C. R., and Holling, C. S. eds. 2009. Foundations of Ecological Resilience. Washington, DC: Island Press.

Gunderson, L. H., and Holling, C. S. eds. 2001. Panarchy: Understanding Transformations in Human and Natural Systems. Washington, DC: Island Press.

Haefner, A. 2016. Negotiating for Water Resources: Bridging Transboundary River Basins. New York: Routledge.

Hargrove, E. C. 1994. Prisoners of the Myth: The Leadership of the Tennessee Valley Authority 1933-1990. Princeton, NJ: Princeton University Press.

Haslam, S. M. 2008. The Riverscape and the River. Cambridge, UK: Cambridge University Press.

Hawley, S. 2011. Recovering a Lost River: Removing Dams, Rewilding Salmon, Revitalizing Communities. Boston, MA: Beacon Press.

Ingold, T. 2015. A Life of Lines. London: Routledge.

Leslie, J. 2005. Deep Water: The Epic Struggle Over Dams, Displaced People, and the Environment. New York: Farrar, Strauss and Giroux.

McCully, P. 2001. Silenced Rivers: The Ecology and Politics of Large Dams. London: Zed Books. 
Middleton, B. A. (Ed). 2002. Flood Pulsing in Wetlands: Restoring the Natural Hydrological Balance. New York: John Wiley and Sons.

Newson, M. D. 1992. Land, Water and Development: River Basin Systems and Their Management. London: Routledge.

Ortileb, L. 2004. "Historical Chronology of ENSO and the Nile Flood Record." In Past Climate Variability Through Europe and Africa, edited by R. W. Battarbee, F. Gasse, and C. E. Stickley, 257-278. Dordrecht: Springer.

Prideaux, B., and Cooper, M. eds. 2009. River Tourism. Wallingford: CABI International. Rackham, O. 1986. The History of the Countryside. London: J. M. Dent and Sons.

Schumm, S. A. 1977. The Fluvial System. New York: Wiley.

Scudder, T. 2006. The Future of Large Dams. London: Earthscan.

Strang, V. 2004. The Meaning of Water. Oxford: Berg.

Strang, V. 2015. Water: Nature and Culture. London: Reaktion Books.

Stromberg, J. A. C., and Tellman, B. 2012. Ecology and Conservation of the San Pedro River. Tucson, AZ: University of Arizona Press.

Sutcliffe, J. V. 2009. "The Hydrology of the Nile Basin." In The Nile: Origin, Environment, Limnology and Human Use, edited by H. J. Dumont. Dordrecht: Springer.

Tiegs, S. D., O'leary, J. F., Pohl, M. M., and Munill, C. L. 2005. "Flood Disturbance and Riparian Species Diversity on the River Delta." Biodiversity $\mathcal{E}$ Conservation 14(5): 1175-1194.

Tockner, K., Ward, J. V., Arscott, D. B., Edwards, P. J., Kollmann, J., Gurnell, A. M., Petts, G. E., and Maiolini, B. 2003. "The Taglimento River: A Model Ecosystem of European Importance.” Aquatic Sciences 65: 239-253.

Van Cappellen, P., and Maavara, T. 2016. "Rivers in the Anthropocene: Global Scale Modifications of Riverine Nutrient Fluxes by Damming.” Ecohydrology $\mathcal{E}$ Hydrobiology 16(2): 106-111.

Wittfogel, K. A. 1957. Oriental Despotism: A Comparative Study of Total Power. New Haven, CT: Yale University Press.

Wohl, E. 2011. A World of Rivers: Environmental Change on Ten of the World's Great Rivers. Chicago, IL: The University of Chicago Press.

WWF. 2004. Rivers at Risk: Dams and the Future of Freshwater Ecosystems. http:// d2ouvy59p0dg6k.cloudfront.net/downloads/riversatriskfullreport.pdf.

WWF. n.d. Threats to Rivers, Lakes $\mathcal{E}$ Watersheds. http://wwf.panda.org/about_our_earth/ about_freshwater/freshwater_problems/. 


\title{
2 Rivers as socioecological landscapes
}

\author{
Abhik Chakraborty and Shamik Chakraborty
}

\section{Introduction: rivers as complex adaptive systems and the socioecological angle}

Rivers constitute one of the most dynamic geomorphic agents on earth, and they are also one of the most recognizable and powerful cultural symbols. Rivers as geomorphic agents can be defined at multiple levels (scales): Fryirs and Brierley (2012) mention that a river system can be defined in terms of its imposed boundary conditions, which could include tectonic settings and lithology, and flux boundary conditions such as flow and sediment transport rate that can be controlled by climatic factors. It readily follows that the relationship between these boundary conditions - and therefore catchment level processes - form a nested hierarchy whereby the flux boundary conditions are inset within the imposed boundary conditions: faster changing components are defined in terms of their relation to slower changing components, and components also occupy different spatial scales (faster components are associated with small spatial scales and slower changes occur at larger spatial scales) (Fryirs and Brierley 2012, 9-13). For more on rivers as geomorphological systems and hierarchical descriptions of catchment processes see Schumm (2007), Robert (2003), and Gupta (2008).

There is another type of system that provides good description of rivers, starting from tiny rills on mountainsides to some of the greatest watercourses on our planet: they are Complex Adaptive Systems (CAS). As Levin (1998) notes, a CAS is a self-organizing system with nonlinear change pathways where initial conditions do not always lead to same outcomes, and the system can self-organize in a process that provides opportunities for multiple possible outcomes. Typically, a CAS shows emergence of new patterns at higher levels that are shaped by processes operating at the lower levels. Both initial constraints (environmental conditions) and localized interaction pathways are important for understanding such nonlinear - and at times transformative - changes to the system. CASrelated analysis of ecological systems and environmental change has flourished over the last three decades; see Gunderson and Holling (2001), Armitage et al. (2008), Berkes et al. (2008), and Gunderson et al. (2010) for more on the theoretical aspects of complex ecological systems. To sum up, a complex adaptive system is nonlinear, and it is extremely difficult to accurately predict how the 
system will behave after it is subjected to some form of control or stimulus that has the potential to re-organize local level interactions. CAS modeling typically offers a 'range' of possible outcomes, i.e. it is possible to predict a 'bandwidth' within which changes might occur, if such systems are studied in detail and over time. CAS also typically involve a great number of variables many of which are obscure to the casual observer or are imperfectly understood by planners; for this reason, human governance of such systems must be flexible, reflective, and one that retains the complexity angle (Stirling 2010).

Socioecological systems (SES) are a special type of CAS; they have both 'ecological' (i.e. natural) and 'social' components. The term 'natural and social' does not need to be a simple dualistic concept; it marks that the processes operating in the SES are of both human and non-human origin and that they are 'coupled'. In his seminal paper, Holling (1973) describes why ecological systems are not amenable to equilibrium-based management schemes: it is because the inherent complexity and perpetual change in the ecological variables could result in a unstable yet highly resilient system. In addition, Holling mentions that ecological systems exhibit the property of spatial heterogeneity (mosaic), from this observation we can further assume that interaction pathways between different system components are not uniform and could feature fluctuations. Such fluctuations, or non-uniform interaction patterns make it extremely challenging to make reductive models of SES, and the challenge becomes even more daunting when we understand that such fluctuations are not perturbations to the system but are inherent mechanisms of system resilience. Holling (1996) also observes that ecological change is not continuous but episodic, ecosystems do not have single equilibria, and therefore management schemes that focus on single outcomes or force the system to a stable state can be detrimental for its resilience (Holling 1996, 52-53). Ecosystem management therefore can be categorized into two alternating (but mutually exclusive) approaches: stability-based (Pimm 1984, which is termed 'engineering resilience' by Holling (1986, 1996), and resilience-based (Holling 1996). Highly engineered ecosystems such as watersheds can result in a loss of functional diversity and resilience, and the system can shift into a state of irreversible change due to myriad different changes taking place in the hydrological, ecosystem, and mutual interaction processes (Holling et al. 1995). At the social level, such degradation of resilience can enhance a decision-making gridlock that favors static management, especially when high economic returns - even though short-term - are available (Gunderson et al. 1995).

Across the world, examples of degradation of resilience in coupled humannature watershed systems (SES) are common. It can be argued that the standard aim of modern-day river basin management is that of maximizing yield and stabilizing watersheds (thereby reducing functional variability and diversity), and the standard response from the SES at the landscape level has been degradation of heterogeneity and resilience, which is eventually translated into reduced yield and associated ecosystem services from the system. In advanced industrialized countries, rivers such as the Colorado (US) and the Danube (Germany) are notable examples. Apart from carving out the deepest canyon on the planet 
that also serves as a fascinating record-book of deep time, the Colorado once flowed as a mighty river that supported great spatial diversity. It was also a place that indigenous people called home thousands of years before John Wesley Powell 'discovered' the majesty of the wild Colorado; thus, the river has a socioecological history of several millennia. The environmental impact of large dams in the watershed such as the Hoover and Glen Canyon, transformation in the landscape, and emerging efforts to restore some parts of the watershed system are analyzed in Farmer (1999), Waterman (2010), Davies (2013), and Adler (2007). The standout message of these studies is that of the depletion of the multiplicity of interaction pathways between the ecological and human components, a rise in stasis, and decrease in resilience within the system. Gorman and Stone (1999) point out that the humpback chub (Gila cypha), an indigenous species that was once found all over the Colorado watershed but is now restricted to a handful of breeding populations in the deep canyons, requires a complex mosaic of landform and hydrological components for spawning. The species may soon become extirpated as global warming favors predatory species upriver into its last refuges (National Geographic 2011). The Columbia River Basin once supported the planet's most productive salmon run, but overfishing and damming have combined to reduce returning fish to a meager $1 \%$ of the historic past (Hawley 2012). By focusing on salmon as a key indicator, Hawley (2012) analyzes the degradation of resource flow, watershed level heterogeneity and ecological resilience in the Snake River Basin, a part of the wider Columbia watershed.

Similar accounts of loss of spatial heterogeneity resulting in the loss of watershed functions are found from Europe. Winiwarter et al. (2013) describe the long history of human intervention in the Danube basin and the transformation of socioecological properties of the watershed. In the past, the flood-prone Danube had a propensity to flow in alternating channels and the watershed maintained a high level of spatial heterogeneity at the expense of stability. During the late 18th century a series of damaging floods became the catalyst for major control structures on the river that delivered heightened stability at the expense of ecological resilience. The damage was paralleled by extirpation of signature fish species such as the European Sturgeon (Huso huso).

While there are some efforts to rehabilitate excessively designed rivers and allow the ecosystem to reclaim its territory, the lack of understanding of their dynamic system properties continues to affect rivers worldwide. Indeed, it could be argued that the stakes are now higher as some of the most dynamic and richest basin ecosystems face uncertainty and degradation, as the wave of industrialization rolls into watersheds that were formerly considered 'wild' and hostile. The largest waterway on the planet, Amazon, is witnessing a significant phase of dam construction with 437 finished and planned dam projects, and the projected ecological footprint of these on the watershed is poised to go upward dramatically (Lees et al. 2016). The largest of the proposed dams, the Belo Monte in the Xingu tributary watershed, has already attracted significant media coverage including documentaries (for more see/watch The Guardian 2014; D'Elia 2012; Southgate 
2016), and criticism from environmental scientists (Fearnside 2008, 2015, 2016). Lees et al. (2016) point out that an estimated $4000-5000 \mathrm{~km}^{2}$ of forest cover will be lost due to processes related to the construction of the Belo Monte. In addition, the dam will cut off $80 \%$ of the natural water supply to a $100 \mathrm{~km}$ stretch of the river known as the 'Big-bend', a distinct geomorphological feature that has aided the evolution of specialized ecological niches and endemic species, including newly discovered ones. By cutting off water flow and converting lotic environments to lentic ones, dams disrupt upstream-downstream connectivity of the watershed system and biota such as the rheophilic fish species that depend on fast and turbulent flow of water are most directly affected (Lujan and Conway 2015). In addition, the landscape is affected at wider scales: for example, the forest in the Uatuma tributary watershed has undergone a sweeping qualitative change (i.e. change in species composition and taxonomic loss) after the construction of the Balbina Dam (Benchimol and Peres 2015; Lees et al. 2016). Lees et al. (2016) note that management solutions such as fish ladders and other types of structural interventions cannot offset such losses in a meaningful way.

The Congo, a river that is second only to the Amazon in terms of flow volume, will also soon be similarly affected by hydroelectric projects. The watershed remained out of reach for development for years, due to the dense rainforest and a series of cataracts downstream that hinder navigation. Recent archaeological research suggests that the indigenous Bantu had traveled deep inside the rainforest thousands of years ago (Wohl 2011), and possibly settled in some parts of it. The British explorer H. M. Stanley noted that indigenous people had devised novel ways of catching rheophilic fish in the turbulent waters near the cataracts; and the remarkable linguistic diversity (several hundred dialects spoken by the basin inhabitants) hints at unique socioecological landscapes that are still poorly understood (Wohl 2011). Wohl also notes how seemingly transient features such as elephant footmarks create egg-laying space for fish species in the watershed, and notes that relatively little scientific research has been done on the Congo. All this could change dramatically due to a series of planned hydroelectric projects on the river, the biggest of which, the Grand Inga Dam, will dwarf the Three Gorges Dam in China, currently the largest river dam in the world. Showers (2009) analyzes how this short-sighted dam project (and the lack of consideration of geomorphological and ecological features of the watershed) could lead to serious depletion of mineral and carbon supplies to the tropical Atlantic and trigger global-level environmental consequences.

In the next section, we look at two river basins in Japan: while the first study, the Biwako-Yodogawa watershed shows the effect of extensive engineering in the form of dams and channel alteration schemes, the second of the Takatsu River highlights the fragility of basin environments even where there is minimal direct impact on the river itself. Intriguingly, in both cases, watershed functions continue to be degraded. Together, these two cases deliver the message that river basins as socioecological landscapes have lost their vital functions only in the very recent past; that is why it is pertinent to compare rivers of advanced industrialized countries with relatively free flowing rivers. Such comparative 
assessments can provide a sobering realization of how little we know about even the most familiar rivers and their inhabitants, and such realization has obvious and important repercussions for holistic basin governance.

\section{Socioecological change in the Biwako-Yodogawa Watershed}

The Yodo River Basin is one of the most important watersheds of Japan. The major components of the watershed are Biwako (the largest freshwater lake in Japan) and three rivers of Uji, Katsura, and Kizu (Yodo is the name given to the combined flow of these three rivers downstream). The combined area of the Biwako-Yodo River Basin is $8240 \mathrm{~km}^{2}$ and nearly 12 million people live in this watershed. Biwako forms the main water-source: it is a $27.5 \mathrm{~km}^{3}$ body of freshwater with a four-million year geomorphological and ecological history (Mother Lake Database n.d.). The initial cavity - referred to as the Ko-Biwako - formed near the present day Iga Basin. The present lake, which formed about 400,000 years ago, collects water from 460 small and moderate sized rivers, but there is only one main artery (Uji River) for water to flow out of Lake Biwako. Historically, the watershed was flood prone owing to this single outflowing natural conduit, and due to the mountainous topography of the adjacent Kizu and Katsura sub-basins.

Floods were a major hindrance for the development of urban and industrial infrastructure in the basin; they were perceived as particularly troublesome when urban and industrial development became a national goal in the late 19thcentury Japan (Tipton 2002). It is worth noting here that major watersheds of Japan had already witnessed deforestation through logging on a massive scale well before Japan's European-style modernization began (Totman 1998), and that basin hydrology and ecology had already been degraded significantly prior to this phase. It is possible that loss of old growth vegetation in major watersheds contributed to rising flood damage in the late 19th century.

Along with the Yodo River Basin, the Tone River Basin in the Kanto area (near Tokyo), and the Chikugo River Basin of Kyushu were subjected to extensive flood control engineering in the late 19th and early 20th centuries, and the government of Meiji Japan called on Dutch engineers Johannis de Rijke and Cornelis van Doorn to design flood protection for major river systems (Takahashi 2004; Stalenberg and Kikumori 2008). The Yodo River basin witnessed a long and damaging flood in late April to early May 1868, which prompted the Meiji state to call on the services of de Rijke; and even as the Dutch engineer was exploring several low-impact schemes, another massive flood affected more than a hundred administrative units in 1885 leading to calls for comprehensive flood control (Kawauchi 2007). The Biwako Canal (sosui) project to supply water to Kyoto city began in 1890, and the Araizeki, a multipurpose weir on the Uji River that became a catalyst for a wave of dam building, was erected in 1905. Although there were notable benefits for urban dwellers - the first hydroelectric power station started operating in 1891 and the nation's first electric train in Kyoto followed - the fate of Ogura Ike, a small freshwater lake adjacent to the Uji River, offers a stark example of the degradation of the socioecological landscape. This small freshwater body sustained 43 species of fish and 150 species of plants and numerous 


\section{Abhik Chakraborty and Shamik Chakraborty}

water-birds (Kyoto Chigaku Kyoiku Kenkyukai 1988), but as the Uji River was made to flow a slightly different course, the lake became dissociated from its water source and deteriorated rapidly. It disappeared completely in 1941 when a reclamation project of developing rice paddies and housing took full effect (Uemura and Ueno 1999).

Unfortunately, apart from such sporadic reports, no comprehensive historical ecology based account of socioecological degradation exists, and we can only assume how widespread the fragmentation of the socioecological landscape must have been during the late 19th and early 20th centuries. After World War II Japan swiftly emerged as an industrialized and urbanized nation; and the flood control discourse was strengthened at the expense of other discourses on water. A powerful typhoon left 82 people dead in 1953 in the Yodo River basin, leading to the formulation of a 'basic' flood control plan for the watershed in 1954; this was followed by a comprehensive plan for regulating the flow volume and dynamics of nearly all major streams in the basin (Bamba 2011). The Ise-Bay Typhoon, the deadliest storm on record in modern Japan in terms of mortality and property-loss, made landfall in an adjacent prefecture in 1959 (Oka 2009) and caused severe flooding in different parts of the Yodo River Basin. Typhoon damage thus became a rallying point for river engineers, and is still used to justify ongoing flood control and dam-building projects even as the evidence of ecological degradation in the watershed continues to mount.

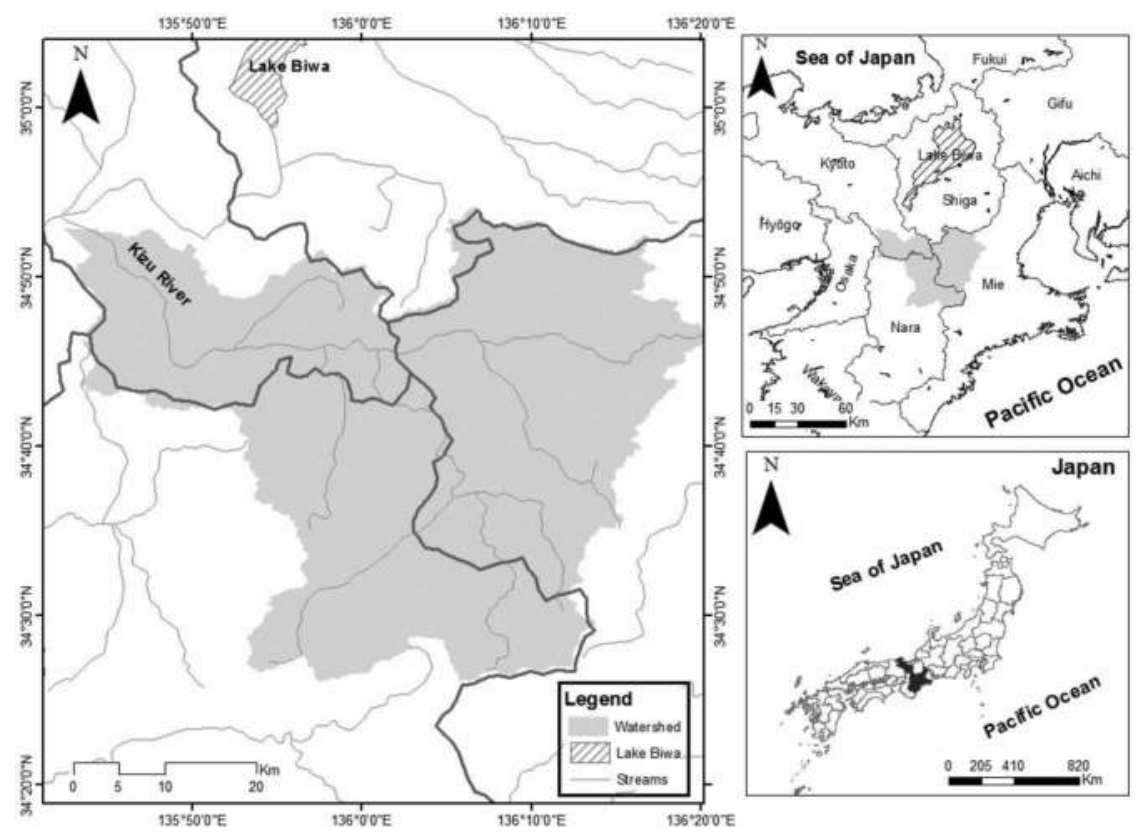

Figure 2.1 Map of Kizu River Watershed showing the Biwako Yodogawa Watershed (right) and its location in the Japanese Archipelago.

Map courtesy Mohamed Kefi. 
The first author of this chapter carried out a research project for nearly three years in the Yodo River Basin, and data on change in the watershed landscape functions were collected from residents, experts, and river engineers, with a specific focus on the Kizu River sub-basin (see Figure 2.1). While the Yodo River Watershed has been affected by large-scale deforestation and conversion of logged forest landscapes to monoculture of coniferous species since pre-modern times, the Kizu sub-basin retained its broadleaf forest cover in places until the 1980s. Today there are five dams in this sub-basin, and their combined effect has been a net reduction of the silt and water budget of the rivers. In addition, a complex network of channelization, embankment construction, and check weirs extend into and affect smaller streams coming out of the mountains. These problems are compounded by pesticide and household sewage runoff where streams flow across the small plains where agriculture is the mainstay for small rural communities. Also, there have been several cases of citizens protesting the dumping of industrial waste in the upstream areas of the basin. In upstream Nabari City, residential blocks and shopping centers are located inside the floodplain of the Nabari River, the largest tributary of the Kizu. In downstream areas however, long-term residents report a steady decrease of sand washed downriver, and a resulting increase in turbidity of the flow since the construction of the Takayama Dam on the Nabari River began (in 1959). This indicates that damming a main tributary just above the confluence point has interfered with the sand and water regime of the entire sub-basin.

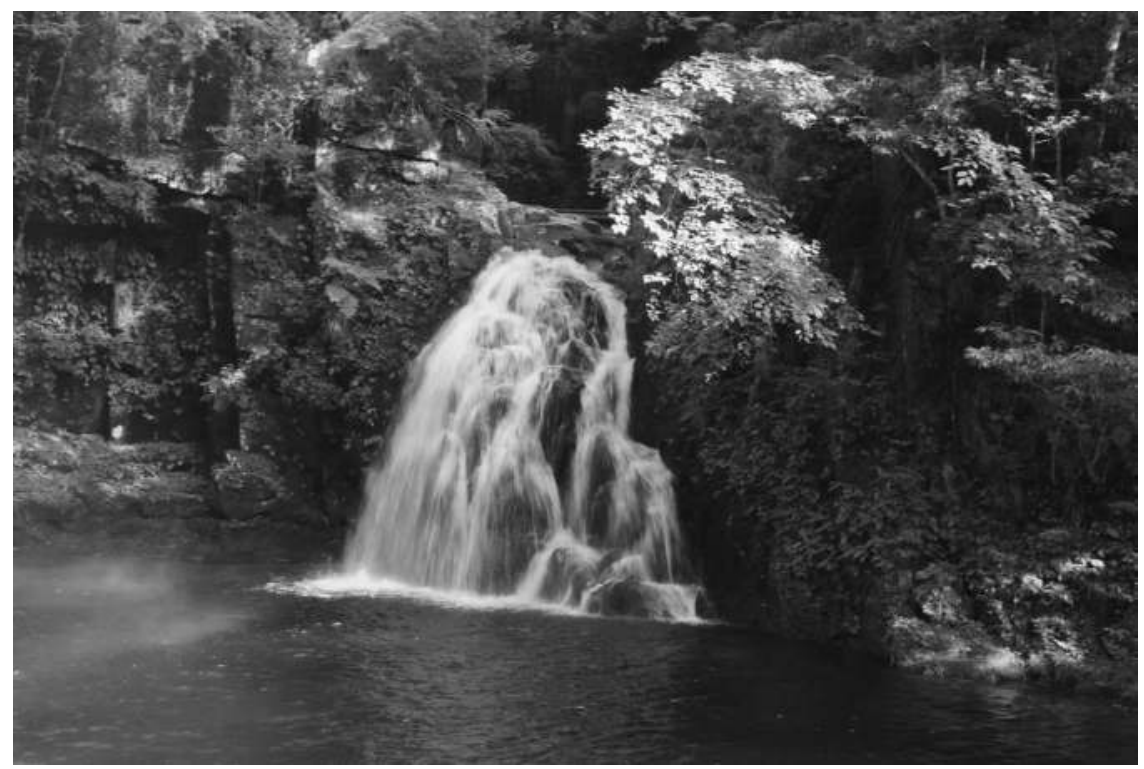

Figure 2.2a The Taki River Basin is known for lush natural vegetation cover and numerous waterfalls and is an important habitat for the giant salamander. 


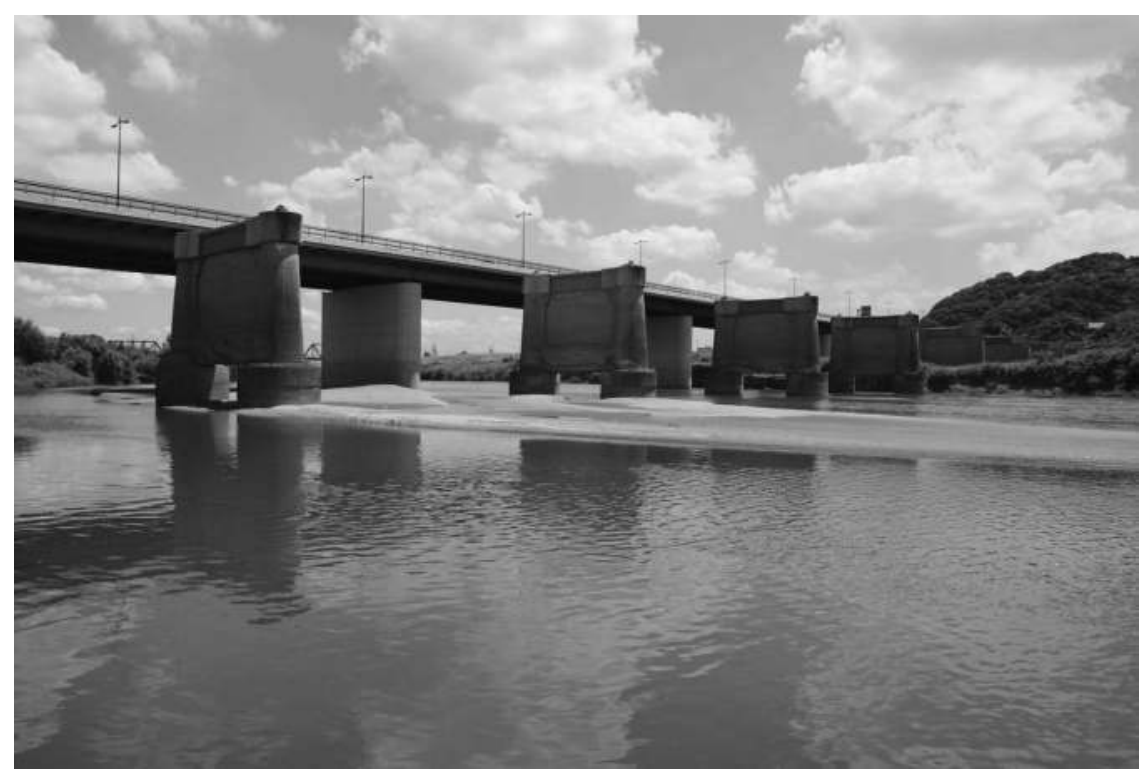

Figure 2.2b However, large artificial structures such as bridges and roadways that impede material flow and fragment the river basin are conspicuous at the downstream parts of the Kizu watershed.

An instructive example of the decline of the ecological resilience caused by these changes can be seen from the condition of the Japanese giant salamander (Andrias japonicas), which was once found all over the Kizu River Basin, but is now confined to the upstream parts such as the Taki River (part of the Nabari sub-basin) and the Maefukase-Kawakami River sub-basins (see Figures 2.2a,b). The giant salamander is one of the largest salamander species on the planet; it can grow over a meter long. The giant salamander is nearly fully aquatic, it waits quietly at the riverbed to prey on fish with the help of its powerful jaws. The species needs clear water to survive (IUCN Red List 2004), and is extremely sensitive to changes in the physical and chemical properties of water. For the Kizu River Basin, its swift decline during the past three decades indicates a significant change in the physical properties of the river system, brought on by increased turbidity and loss of fish species from flow control (dams), deforestation, and other related mechanisms. Though the species is recognized as a target for preservation at the national level and is preserved through captive breeding in various places, their habitat and food bases have changed dramatically.

Currently the salamanders face a new threat in the form of the planned construction of the Kawakami Dam at the Maefukase River sub-basin. While dam engineers claim that the salamander will survive in temporary 'salamander pits', it is hard to see how the species could fare well as the river on which it depends 
is being converted into a shallow lake, and the fish that it feeds on face an insurmountable obstacle in the dam wall. Although managers spoke of their 'commitment' to preserve the salamander, it is effectively a scheme to save a species in an ecological vacuum in the absence of the physical conditions needed for survival. Meanwhile, the Kawakami Dam, an unfinished project dating back to 1982, is purported to provide 'safety' from floods to a mountainous community that has rapidly shrunk to just a few households due to depopulation. Local environmental activists and scientists had voiced opposition to the dam.

The case of the giant salamanders offers an important insight of how the ecological resilience of socioecological landscapes is degraded. This has obvious repercussions for the 'social' aspect of the system. The giant salamander is not only important for its own sake, it is also important for the chain of ecological interaction it helps construct with fish and vegetation and abiotic components such as water properties and the type of riverbed. Typically, in complex adaptive socioecological landscapes, precise interaction patterns are often obscure, and species that do not apparently have important functions may play the crucial role of 'redundancy' or 'overlap' (multiple species for the same function increases robustness). However, such species are dependent on the biophysical environment, and have evolved with it for thousands or millions of years, while sudden change in these environments typically thrust the CAS into a lower resilience threshold within a few years. During interviews and interactions with the local people it became clear that public 'association' with the river has also changed to that of a lower intensity one: with the loss of shining sand, clear water, fish and navigable stretch downstream, the river's presence is 'diminished' in local life. In the adjacent Katsura River Basin, this sense of diminution is even more palpable. The Katsura cuts a beautiful gorge in its upstream where its emerald waters are known as the Hozu River; but it abruptly becomes stagnant, polluted, and constrained near the urban agglomeration of Kyoto. To many visitors and residents, the beautiful Hozu and the troubled Katsura appear as two different rivers. This is yet another example of how watersheds are 'parceled' into components that have value for different aspects, implying a negative correlation for the overall ecological connectivity.

\section{Recent change in the Takatsu River Watershed and River Mouth areas}

The Takatsu River (length $81 \mathrm{~km}$, basin area $1090 \mathrm{~km}^{2}$ ) (see Figure 2.3) is one of the few remaining undammed rivers in Japan. Most of the watershed is 'mountainous' and does not have a major industrial complex in its upstream or downstream parts. Lack of economic opportunities led to a steady out-migration of younger people from the area during the latter half of the 20th century; making the watershed one of the demographically 'shrinking' rural regions of Japan (for more on rural depopulation in Japan, see Matanle, Rausch with the Shrinking Regions Research Group 2011). However, while much attention has been directed at 'depopulation' and 'economic decline' of the region (Seki and 


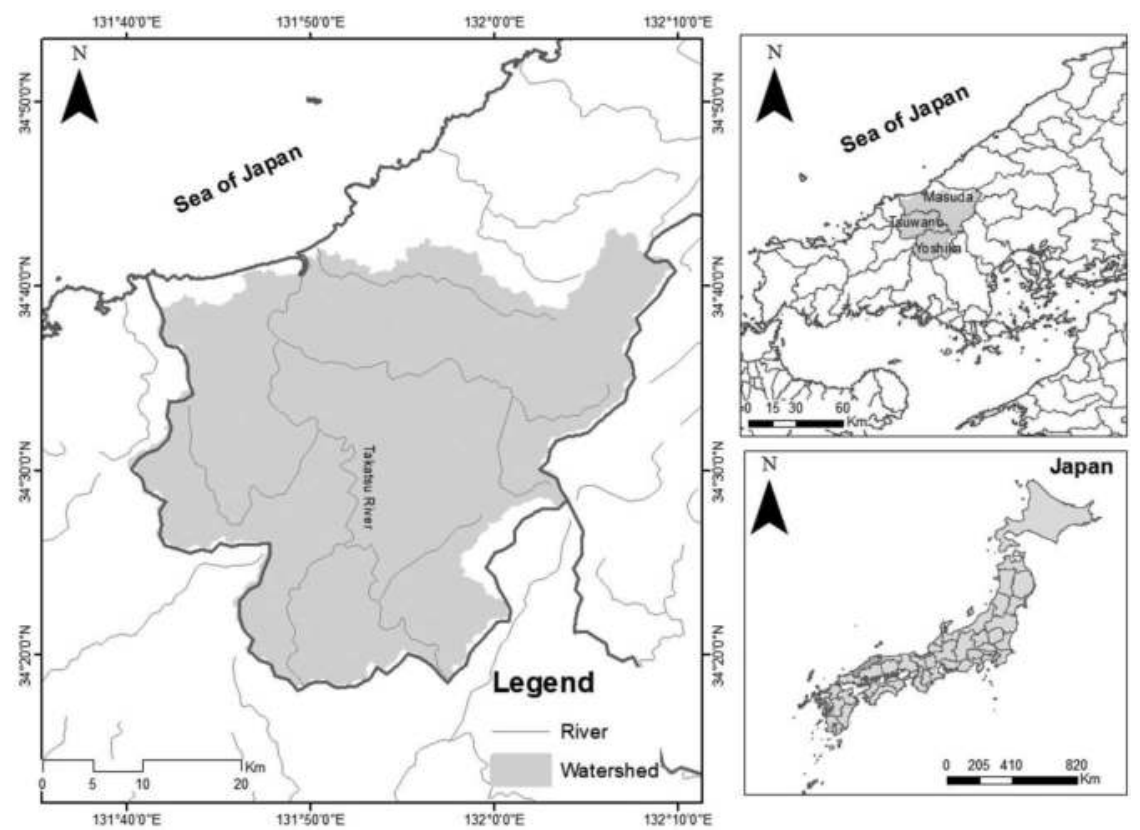

Figure 2.3 Map of the Takatsu River Watershed and its location in the Japanese Archipelago

Map courtesy Mohamed Kefi.

Matsunaga 2009, 2010) - the watershed is seen by some scholars as the starting point of rural depopulation in Japan - there is surprisingly little analysis of environmental change. The watershed has attracted attention for sporadic research on 'stream capture', and differential erosion rates leading to fragmentation of a large network of rivers (Machida 1984), but detailed mechanisms for such events remain under-researched to date (Yamauchi and Shiraishi 2010). Also, as the western seaboard of Japan is geologically older than the accretionary-prism dominated eastern seaboard, the watershed possibly offers evidence of past crustal deformation and deposition events, the rates of which have remained debated (Nakata 1996).

Unlike the other major rivers of Japan that are being flood-prone, the Takatsu has a 'gentle' image, possibly in part due to the hydrological characteristics of its watershed. The river flows without concretized stretches for most of its journey, and broadleaf forests remain in the basin (see Figure 2.4a). The few studies that have been done on the ecological properties of the watershed report a natural 'flux' of sandbar deposition, washout, and replenishment by flood and sea waves (Ono et al. 2013), a gradual loss of sediment influx due to concretization and weir construction in the tributary streams which also affect sweetfish (Plecoglossus altivelis) migration (Terakado et al. 2015), and an increasing pollution load from 


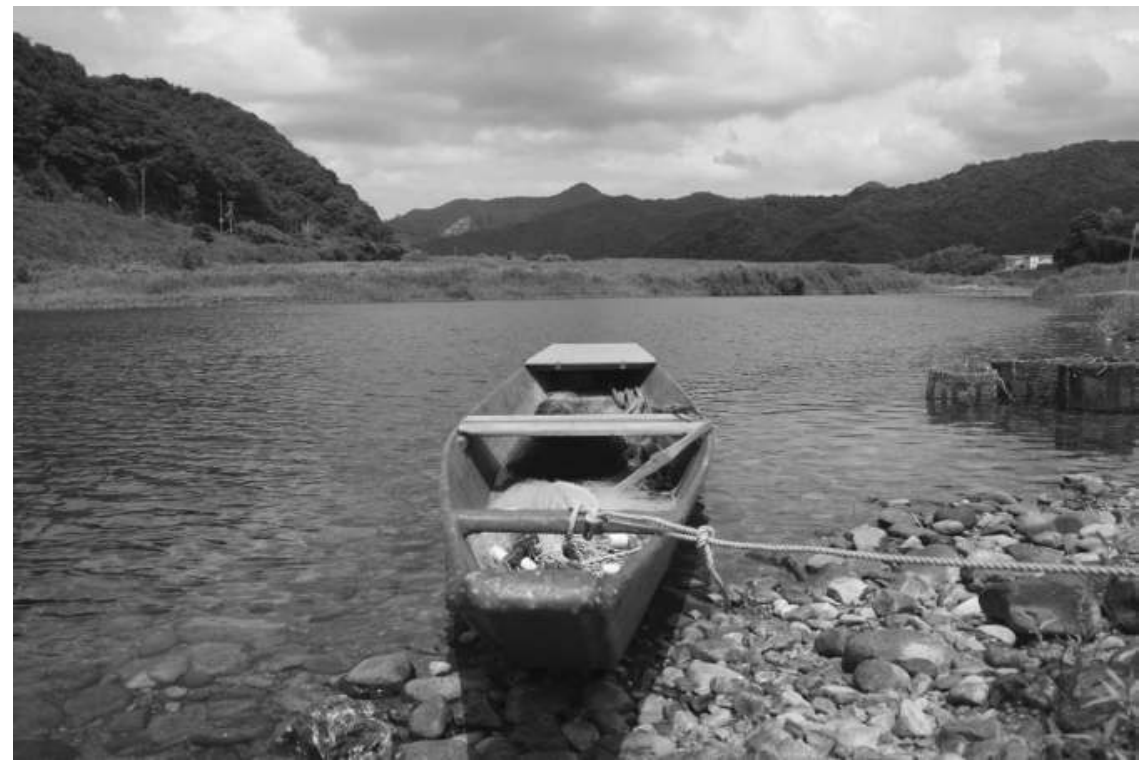

Figure 2.4a A boat floats along the water's edge at the Takatsu River Basin. During the 20th century's economic development, most of the notable rivers in Japan were dammed, and comparatively free-flowing rivers such as the Takatsu are rare.

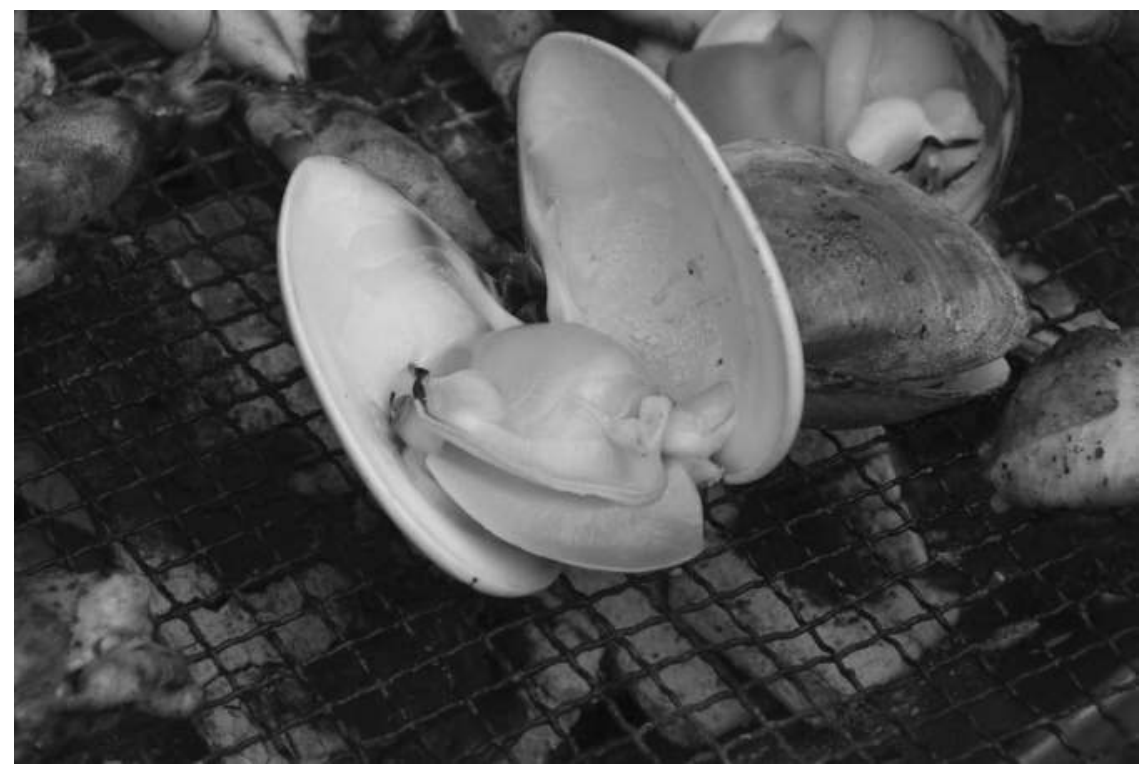

Figure 2.4b The Common Oriental Clam: this humble creature is an important marker species for downstream watershed health. 
the Tsuwano River (one of the two main tributaries of the Taktasu), leading to an increase in phosphorus and nitrogen contaminants and consequent ecological degradation downstream (Hodoki et al. 2007). We observed the watershed over a period of two years, variously engaging in foot-transects of the length of the river, in-depth interviews with local stakeholders in the watershed and the adjacent sub-basins and coastal locations, and participant observation with a local nonprofit organization (NPO) that has organized volunteer surveys of the ecological landscape of the watershed spanning two decades.

While the sweetfish remains a 'symbol of nature' of the Takatsu River, numerous small weirs currently prevent upstream migration of the species. Because the sweetfish is an 'economically valuable' resource - it brings high returns as a sportfishing commodity - it is artificially released in large numbers in the upstream to mimic the natural cycle of the fish through the watershed. But even this solution has begun to show diminishing returns. In 2016, the local fishing cooperative had to call off the sport-fishing season early, citing 'unnaturally low' numbers of the fish (Takatsu River Fishing Cooperative 2016). While this one species attracts attention, there are more silent casualties: residents spoke of a recent 'qualitative' change in the upstream forest cover, with a steady decline of older broadleaf vegetation and increases in anthropogenic disturbance. The combined effect of changes in forest cover and weirs disrupting the normal water-sediment budget is reflected in the increased erosion in the river mouth. This has altered the habitat conditions of the Common Oriental Clam (Meretrix lamarckii) (see Figure 2.4b). The Japanese name of this clam is 'hamaguri' - literally meaning 'bay chestnut' reflecting both the shape and the habitat preference of the species.

The Takatsu River Mouth was once well known for its rich production of this species, but the situation changed abruptly in the 1980s, when the catch level dropped to near zero - prompting temporary bans on catching. According to a local fisheries expert who has led the volunteer survey of the oriental clam, the history of catch in this river mouth goes back to the feudal Edo (1603-1868) period, and the shells of large specimens were popular as chips for the Japanese traditional game 'Go' (Sasaki 2016, personal correspondence). While no statistical data is available prior to the 1980 s, older fishermen recounted particularly large catches in the 1950s. The catch level declined to a meager $2 \mathrm{~kg} /$ year in 1989, when the first statistical data were gathered. Despite being a familiar species to fishermen, the life cycle and ecology of the oriental clam is poorly documented. This plankton feeder favors the region of the river mouth where saltwater and freshwater mix, and sustains itself on the nutrients carried by rivers and artesian springs (groundwater) of the coastal ecotone. Thus, the species requires a 'narrow band' of geomorphological and ecological conditions to thrive. The oriental clam shows an affinity to the inward wall of coastal sandbars; experienced fishermen described the 'right kind' of environment for the species as the one with 'loose and slightly moving' sand. The clam is sensitive to disturbances like fishermen sticking their instruments into the sand and altering its configuration.

While there is no scientific dataset on the correlation between landscape level change and the river mouth population of the oriental clam in this watershed, 
anecdotal evidence strongly suggests ongoing degradation of the socioecological system of which this species is a part. Recent rises in impervious (concretized) surface areas in the coast and pesticide runoff were reported, and the water quality of the adjacent Masuda River that empties into the same coastal section is distinctly poor. The ecological transformation of this coastal species indicates that even managing a river without large dams is not adequate for safeguarding ecological resilience of the watershed, especially if the river is dissociated from its floodplain. During the late 20th century, construction of weirs on rivers, dykes at the coast, and other land use-related changes effected near complete change of habitats in many river mouths in the Japanese Islands, leading to drastic reduction of clam populations. In this sense, the Takatsu River case speaks for a general change in the coastal ecology of contemporary Japan. In addition, a local expert spoke of the sea becoming a 'desert' with the degradation of healthy seagrass beds, suggesting a cascade of changes that are underway as land-sea interaction patterns change (Sasaki 2016, personal correspondence). Local volunteers monitoring the clam in this river mouth report a partial recovery - currently the catch amounts to 5-6 tons/year - but the Takatsu River Mouth population is still fragile and is mostly comprised of young individuals.

Apart from the condition of such species, the watershed in general shows change from a high natural disturbance-low stability-high ecological resilience condition to a high anthropogenic disturbance-high stasis-low ecological resilience one. During our numerous trips to the watershed we found that the natural rifflepool sequence of the Takatsu River has changed over the years: large pools have become rarer due to the net reduction of water-sediment budgets along the flow, and even where they occur they are possibly altered by thermal pollution and turbidity, judging from local anecdotes of the 'different' appearance of the pools. While specific details are unknown, these changes have significant impact on the biota and the socioecological characteristics of the watershed.

\section{Discussion}

While socioecological landscapes are formed and maintained through natural and human components and processes through 'coupling', precise interaction pathways are not easy to describe, and in cases where processes operate in large spatial units such as river basins over a long temporal scale, it is difficult to pinpoint an 'origin' and a 'transformation point', mainly due to the fact that the long history of human interaction with rivers has generally favored the maximum extraction of available resources and a highly stable or 'controlled' environment. However, a highly stable environment means loss of ecological resilience and ultimately results in diminishing returns from the watershed; this was seen in each of the cases described earlier.

The two case studies from Japan show how the socioecological landscape underwent multiple changes. Significant depletion of old growth forests had occurred in the pre-industrial past, but industrial modernization and urban development resulted in an arguably more profound 'rupture' of ecological connectivity. In the 
case of the Biwako-Yodogawa watershed, floods constituted a natural and vital 'pulse' of the socioecological system partly due to the 'imposed' condition of a singular outflow from the lake, and the riparian environment had adapted to this periodic disturbance. Human intervention occurred in the form of dams and weirs, beginning from the late 19th century, floods at that point invoked a strong response from a centralized government that prioritized urban and industrial development as a national agenda. European river engineering was introduced and subsequent flooding and urban water demand resulted in near total control of the watershed mechanisms through reductionist approaches. Curiously, while science was looked up to as a source of objective information, engineers and developers came up with a poor objective assessment of the river system: various structural interventions from this point indicate a thorough and amplified 'subjective' response to one specific function (flooding) detached from its associated functions (silt transport, riparian ecosystems, habitat diversity). The urge to protect newly urbanized settlements from flooding resulted engineers and policy makers simplifying natural systems and ignoring their dynamic equilibrium.

The adverse effects of such reductionist solutions have accumulated over time, and the plight of marker species such as the giant salamander shows how widespread the degradation is. Besides, the role of the river as a landscape feature has diminished; both resulting in and reflecting further loss of ecological connectivity of a complex adaptive system. From the case of the Takatsu River Basin we gain insights on how even undammed and apparently ecologically rich rivers can hide extensive ongoing degradation at the watershed level. The key 'marker' species here is the oriental clam, and changes in its population dynamics hint at a cascade of changes in land-water interactions. The oriental clam is extremely sensitive and adapted to a range of dynamic changes in the coastal environment, so an increase of stasis and stability directly affects this species. The sweetfish migration upriver is also significantly affected due to changes in hydrological patterns.

As river basin systems transform into lower ecological resilience states, the engineering discourse of hazard management may be followed by the ideological project of 'harmonizing' nature's patterns to human needs. But socioecological systems are dynamic and function due to the inherent capacity of the system to adapt to disturbance; thus, any meaningful governance of such systems must take notice of the spatial heterogeneity and the long temporal factor that combine to create their complex web of interactions. Rather than stability and harmony, change and disturbance are the hallmarks of such systems, and these aspects are particularly important for the ecological resilience of rivers. Therefore, a meaningful lesson can be drawn by comparing highly altered river systems to relatively wilder ones and the broad contours of system transformation can be better understood in the process.

\section{Conclusions}

Research on rivers as complex adaptive systems is still at a formative stage. Humans have increasingly emerged as a powerful landscape level agent in the Anthropocene. As examples from all over the world show; rivers as socioecological landscapes are marked by an increase of human-induced 'stability' of the 
regime but a consequent decline of ecological resilience. This deterioration is manifested through the drastic decline of aquatic species, which can perform the role of 'markers' of change. The two cases we described in detail in this chapter offer the important insight that even in industrialized countries river basin degradation is a comparatively recent event. The drivers and pathways of change differ from river basin to river basin but in most cases, a contrasting 'before' and 'after' scenario is reported, which reflects one or multiple tipping points for the resilience threshold. Although once the system undergoes this critical transition, further structural management actions are unlikely to restore its original ecological diversity, degraded socioecological riverscapes are important study materials for the lessons they offer on the recentness and swiftness of change. Those lessons are instructive for the relatively unmodified and naturally diverse river basins in other parts of the world.

Acknowledgment: The authors thank Mohamed Kefi, JSPS-UNU Postdoctoral Fellow at the Institute for the Advanced Study of Sustainability, United Nations University, Tokyo, for kindly composing the GIS based maps of the Kizu and Takatsu River Basins.

\section{References}

Adler, R. W. 2007. Restoring Colorado River Ecosystems: A Troubled Sense of Immensity. Washington, DC: Island Press.

Armitage, D., Berkes, F., and Doubleday, N. eds. 2008. Adaptive Co-Management: Collaboration, Learning, and Multi-Level Governance. Vancouver: University of British Columbia Press.

Bamba, Y. 2011. Integrated Basin Management in the Lake Biwa and Yodo River Basin. http:// wldb.ilec.or.jp/data/ilec/WLC13_Papers/S13/s13-4.pdf.

Benchimol, M., and Peres, C. A. 2015. "Edge-Mediated Compositional and Functional Decay of Tree Assemblages in Amazonian Forest Islands After 26 Years of Isolation." Journal of Ecology 103(2): 408-420.

Berkes, F., Folke, C., and Colding, J. eds. 2008. Navigating Social-Ecological Systems: Building Resilience for Complexity and Change. Cambridge, UK: Cambridge University Press.

Davies, W. 2013. River Notes: A Natural and Human History of the Colorado. Washington, DC: Island Press.

D'Elia, A. 2012. Belo Monte: Anúncio de uma Guerra (Belo Monte: Announcement of a War). Documentary Film. www.youtube.com/watch?v=ZoRhavupkfw\& feature=youtu.be.

Farmer, J. 1999. Gen Canyon Dammed: Inventing Lake Powell and the Canyon Country. Tucson: University of Arizona Press.

Fearnside, P. M. 2008. The Roles and Movements of Actors in the Deforestation of Brazilian Amazonia. Ecology and Society 13(1): 23.

Fearnside, P. M. 2015. "Amazon Dams and Waterways: Brazil's Tapajos Basin Plans." Ambio 44(5): 426-439.

Fearnside, P. M. 2016. “Tropical Dams: To Build or Not to Build?" Science 351: 426-439.

Fryirs, K. A., and Brierley, G. J. 2012. Geomorphic Analysis of River Systems: An Approach to Reading the Landscape. Chichester: Wiley-Blackwell.

Gorman, O. T., and Stone, D. M. 1999. "Ecology of Spawning Humpback Chub in the Little Colorado River Near Grand Canyon, Arizona." Environmental Biology of Fishes 55: 115-133. 


\section{Abhik Chakraborty and Shamik Chakraborty}

The Guardian (Jonathan Watts Correspondent). 2014. Belo Monte, Brazil: The Tribes Living in the Shadow of a Megadam. www.theguardian.com/environment/2014/dec/16/ belo-monte-brazil-tribes-living-in-shadow-megadam.

Gunderson, L. H., Allen, C. R., and Holling, C. S. 2010. Foundations of Ecological Resilience. Washington, DC: Island Press.

Gunderson, L. H., and Holling, C. S. 2001. Panarchy: Understanding Transformations in Human and Natural Systems. Washington, DC: Island Press.

Gunderson, L. H., Holling, C. S., and Light, S. 1995. Barriers and Bridges to Renewal of Ecosystems and Institutions. New York: Columbia University Press.

Gupta, A. ed. 2008. Large Rivers: Geomorphology and Management. Chichester: John Wiley \& Sons.

Hawley, S. 2012. Recovering a Lost River: Removing Dams, Rewilding Salmon, Revitalizing Communities. Boston: Beacon Press.

Hodoki, Y., Ohbayashi, K., Minato, T., and Ishiga, H. 2007. Assessment of River Environments From Analysis of Environmental Components and Ayu, Plecoglossus altivelis in the Takatsu River, Shimane, Japan (In Japanese). Geoscience Report of Shimane University.

Holling, C. S. 1973. "Resilience and Stability of Ecological Systems." Annula Review of Ecology and Systematics 4: 1-23.

Holling, C. S. 1986. "The Resilience of Terrestrial Ecosystems: Local Surprise and Global Change." In Sustainable Development of the Biosphere, edited by W. C. Clark and R. E. Munn, 292-320. Cambridge, UK: Cambridge University Press.

Holling, C. S. 1996. "Engineering Resilience Versus Ecological Resilience.” In Engineering Within Ecological Constraints, edited by P. C. Schulze, 31-44. Washington, DC: National Academies Press.

Holling, C. S., Schindler, D. W., Walker, B., and Roughgarden, J. 1995. "Biodiversity in the Functioning of Ecosystems: An Ecological Primer and Synthesis." In Biodiversity Loss: Ecological and Economic Issues, edited by C. Perrings, K. G. Maler, C. Folke, C. S Holling, and B. O. Janson. Cambridge, UK: Cambridge University Press.

IUCN Red List. 2004. Andrias japonicas. www.iucnredlist.org/details/1273/0.

Kawauchi, A. 2007. Yodogawa Monogatari (The Tale of the Yodo River). Tokyo: Yomiuri Rengo Hokokusha.

Kyoto Chigaku Kyoiku Kenkyukai. 1988. Kyoto Shizen Kiko (Kyoto: Almanac of Nature). Kyoto: Jinbun Shoin.

Lees, A. C., Peres, C. A., Fearnside, P. M., Schneider, M., and Zuanon, J. A. S. 2016. "Hydropower and the Future of Amazonian Biodiversity." Biodiversity and Conservation 25: 451-466.

Levin, S.A. 1998. Ecosystems and the Biosphere as Complex Adaptive Systems. Ecosystems 1(5): 431-436.

Lujan, N. K., and Conway, K. W. 2015. "Life in the Fast Lane: A Review of Rheophily in Freshwater Fishes." In Extremophile Fishes, edited by R. Riesch, 107-307. Geneva: Springer International Publishing.

Machida, S. 1984. Chikeigaku (Geomorphology). Osaka: Taimeido.

Matanle, P., and Rausch, A., with the Shrinking Regions Research Group. eds. 2011. Japan's Shrinking Regions in the 21st Century: Contemporary Responses to Depopulation and Socioeconomic Decline. New York: Cambria Press.

Mother Lake (Shiga Prefecture Homepage). n.d. www.pref.shiga.lg.jp/d/biwako-kankyo/ lberi/01shiru/01-04biwako/01-04biwako.html. 
Nakata, T. 1996. "Toko Danmen no Chikei kara mita Nion Retto no Chikaku Hendo" (Crustal Deformation in the Japanese Islands From the Cross-Sectional Profiles of Island Arc Systems). In Chikeigaku no Furotia (Frontiers of Geomorphology), edited by K. Fujiwara. Osaka: Taimeido.

National Geographic Society. 2011. National Parks Collection (Expanded Edition) DVD. Washington, DC: National Geographic Media.

Oka, K. 2009. Ise Wan Taifu: Suigai no Zensen ni Natta Mura (Ise Bay Typhoon: Villages That Bore the Brunt). Nagoya: Yuipo-oto.

Ono, N., Kuroki, K., Ishimoto, K., and Ito, Y. 2013. "Numerical Simulations of Chanel Infilling and Sand Bar Deformation Around Mouth of Takatsu River (in Japanese)." Doboku Gakkai Ronbunshu (Proceedings of Japanese Civil Engineering society) B2: 621-625.

Pimm, S. L. 1984. "The Complexity and Stability of Ecosystems." Nature 307: 321-326.

Robert, A. 2003. River Processes: An Introduction to Fluvial Dynamics. New York: Routledge.

Schumm, S. A. 2007. River Variability and Complexity. Cambridge, UK: Cambridge University Press.

Seki, M., and Matsunaga, K. 2009. Chusankan Chiiki no No-Sho-Ko Renkei: Shimane ken Chugoku Chiho no Genjo to Kadai (Agriculture-Handicraft-Industry Collaboration in Mountainous Regions: Examples From Chugoku Region of Shimane Prefecture). Tokyo: Shinhyoron.

Seki, M., and Matsunaga, K. 2010. No to Monozukuri no Chusankan Chiiki: Shimane ken Takatsugawa Ryuiki no Kurashi to Sangyo (Agriculture and Branding in Mountainous Regions: A Case Study of the Takatsu River Basin in Shimane Prefecture). Tokyo: Shinhyoron.

Showers, K. B. 2009. Congo River's Grand Inga Hydroelectricity Scheme: Linking Environmental History, Policy and Impact. Water History 1(1): 31-58.

Southgate, T. 2016. Belo Monte: After the Flood. Documentary Film. Berkeley, CA: International Rivers, Amazon Watch and Cultures of Resistance.

Stalenberg, B., and Kikumori, Y. 2008. "Historical Floods With Responding Flood Control." In Urban Water in Japan, edited by R. D. Graaf and F. Hooimeijer, 89-100. Leiden: Taylor and Francis.

Stirling, A. 2010. "Keep It Complex.” Nature 468: 1029-1031.

Takahashi, Y. 2004. Public-Private Partnership as an Example of Flood Control Measurements in Japan. Water Resources Development 20(1): 97-106.

Takatsu River Fishing Cooperative. 2016. www.takatugawa.or.jp.

Terakado, H., Murayama, T., Soeda, H., and Tanaka, S. 2015. Takatsugawa ni okeru Ayu Sanranjo no Bunpu to Kasho Jotai no Hensen (Distribution of Sweetfish Breeding Grounds and Change in Riverbed Structure in Takatsu River). Report of Shimane Prefecture Aquaculture Research. http://agriknowledge.affrc.go.jp/RN/2010891800.pdf.

Tipton, E. K. 2002. Modern Japan: A Social and Political History. London: Routledge.

Totman, C. 1998. The Green Archipelago: Forestry in Pre-industrial Japan. Athens, OH: Ohio University Press.

Uemura, Y., and Ueno, H. eds. 1999. 1999 Kyôto Chizu Monogatari (Maps of Kyoto Prefecture, 1999). Tokyo: Kokon Shoin.

Waterman, J. 2010. Running Dry: A Journey From Source to Sea Down the Dying Colorado River. Washington, DC: National Geographic Books.

Winiwarter, V., Schmid, M., Hohensinner, S., and Haidvogl, G. 2013. "The Environmental History of the Danube River Basin as an Issue of Long-Term Socio-Ecological 


\section{Abhik Chakraborty and Shamik Chakraborty}

Research.” In Long Term Socio-Ecological Research, edited by S. J. Singh, H. Haberl, M. Chertow, M. Mirtl, and M. Schmidt, 103-122. Dordrecht: Springer.

Wohl, E. 2011. A World of Rivers: Environmental Change on Ten of the World's Great Rivers. Chicago, IL: The University of Chicago Press.

Yamauchi, K., and Shiraishi, K. 2010. "Chugoku Sanchi Seibu Nishikigawa Suikei Usagawa ni okeru Kasen Sodatsu” (Stream Capture in USA River, Nishiki River Watershed in Chugoku Region). Ritsumeikan Chirigaku. Geography Bulletin of Ritsumeikan University 22: 39-57. 


\title{
3 Rivers and communities \\ Can we drought proof a \\ catchment or an entire country?
}

\author{
Ronnie Mckenzie
}

\section{Introduction}

Analyzing the water resource potential of an area or a system is a complex and often time-consuming process which can involve the input of hydrologists, engineers, water resource planners, agricultural engineers, climatologists, environmentalists, groundwater engineers, geologists, various other specialists, and local communities. But it is necessary if we are to implement effective governance of existing and potential water resources, and specifically, to attempt to droughtproof our communities and their natural environments, while at the same time protecting the riverine environments that these resources often come from. This chapter outlines how a country (South Africa) and its communities coped in a practical way with the water supply stressors discussed in other chapters of this book.

The methodology described here was developed through the combined input of many specialists from around the world, including the UK, USA, Canada and South Africa (Sigvaldason 1976; DWAF 1986; Pegram and Mckenzie 1991; Gleick 1993; Rademeyer, van Rooyen and McKenzie 1997). While catchment models have been continually upgraded, and improved to take advantage of the latest developments in computer hardware and software, the basic underlying methodology remains unchanged, and has proven to be reliable and robust through its 30-year use (Rademeyer, van Rooyen, and McKenzie 1997). This, in turn has allowed water managers to propose policies to cope with the various drought events in significant river catchments, and to seek to avoid the necessity of introducing severe water restrictions at any time after the engineering solutions are first implemented. Thus, it is possible to say, at the technical level, yes we can both drought-proof communities and protect the environmental health of our rivers if such time-tested procedures are followed, but only if such actions are economically and socially feasible (DWAF 1986; Rademeyer, van Rooyen, and McKenzie 1997; Madani and Mariño 2009).

It should be understood though, that in the context of this book this chapter is about a specific practical aspect of river governance, or more precisely, the distribution of water resources in a more equitable way across a national or regional landscape; it is not about determining the socio-cultural and/or economic 
frameworks for making such decisions. Of course, the governance policies that determine both the assessment of those resources in terms of their suitability for extraction, and whether a technological solution can be found for resource scarcity within the competing demands of communities (Haefner 2016), are determined in the political, socio-cultural and economic environments of the communities that may be affected (Coughlan et al. 2003; Chakraborty Chapter 1 this volume). This overview of one appropriate methodology for water resource assessment leading to the ability to make policy on drought proofing is presented here solely to highlight the key aspects of an engineering approach (Holling 1996: engineering resilience) to the problem of differentiated drought (oversupply in one area and drought in another), without delving into too much technical detail, or perhaps more importantly, not explicitly considering the range of social and environmental aspects of water supply and use (Schumm 2007; Wohl 2011; Strang 2015) that are covered in other chapters.

The approach taken here is well documented in various government technical reports across the world (UNEP 2012), and in other publications (especially from South Africa), which can be consulted if additional detail is sought. Equally, more sophisticated methodologies for determining the desired outcomes before embarking on changes to water supply systems can of course be used to derive the basic assumptions underlying the water diversion processes reported on here (for example, CAS [Complex Adaptive Systems analysis]; Gunderson. 2010). The various computer models used here were developed by the South African Government, and can be obtained from that country's Department of Water and Sanitation for use by communities outside of South Africa as required.

\section{The hydrological background to drought-proofing communities}

If a community intends to use river-based water supplies available in one area to drought-proof another, it needs to know the capacity and performance of that supply (the hydrology) in relation to the outcomes desired (Rademeyer, van Rooyen, and McKenzie 1997; Molle, Ghazi, and Murray-Rust 2009). Here, while streamflow is the critical issue when dealing with water resource assessment and environmental protection in a river catchment (Sutcliffe 2009), rainfall is often the key data source upon which hydrological analyses are based (Newson 1992). This is primarily because, in many parts of the world, streamflow records are relatively new and often inaccurate (Sutcliffe 2009), which creates problems when trying to undertake water resource analyses. Rainfall records are easier to collect because virtually every agricultural and urban area in every country has a rain gauge, with the result that rainfall records tend to be readily available in both rural and urban areas, and can often span 100 years or more. It is for this reason that "simulated" streamflow records are often generated from rainfall data using some form of rainfall-runoff model in those cases where the existing streamflow records are short or deemed to be unreliable. 


\section{Rainfall}

When using rainfall records, it is important to check that the record is reliable and consistent. If gaps in the record exist, they should be infilled using some form of patching software (Pegram and Mckenzie 1991). Most countries have their own patching software, which will typically range in complexity from simple regression analysis to more complicated surface fitting models. For example, in South Africa a very rigorous approach was developed to infill and even extend the monthly rainfall records that have been used in many hydrological analyses across that country (Pegram and Mckenzie 1991; Basson et al. 1994). Nevertheless, whether simple or complicated models are used, the hydrologist should always carefully examine any infilled values to ensure that they look realistic and make sense, as if the infilling procedure is not reliable, any subsequent rainfallrunoff modelling using the infilled rainfall data will be compromised (Bakker and Allen 2012).

Another important issue when examining rainfall is the issue of climate change, which is often raised as a key problem when dealing with hydrology (UN Water 2006; IPCC 2008; Back and King 2009; Huhne and Slingo 2009; Bakker and Allen 2012). Interestingly, many hydrologists view data showing a break in continuity as evidence of climate change (Bakker and Allen 2012). However, if a rainfall record depicts such an abrupt break, this has most likely been caused by some other factor such as gauges being moved or gauges being replaced. If there is influence of climate change on a rainfall record, it will be a gradual influence and will ultimately be evident not only in a single rainfall record but on every rainfall record in a region.

A basic method for recording and checking the stationarity and reliability of rainfall data is the single mass plot (Figure 3.1). This is simply a plot of the cumulative annual rainfall over a given period. If the record is sufficiently long, the natural cycles of wet and dry periods will not be strongly evident, and a straight line can be drawn. It is important to note that if a short record of 10 to 20 years is analyzed using the mass plot method, it is likely that the wet and dry cycles will be more pronounced, and in extreme cases may appear to suggest a break in continuity. However, any such break can only be determined if the record is of sufficient length to include several dry and wet cycles (Rademeyer, van Rooyen, and McKenzie 1997; Bakker and Allen 2012).

To make the analysis more precise and useful, monthly rainfall values as well as reservoir storage volumes (\% full) are necessary. At the start of the attempt to drought-proof a region, these data must be recorded to highlight climate change. This was done for the Orange River region of South Africa over the period 1991 to 2010 (Pitman 2011), and suggested that rainfall (average annual precipitation) in that region was steadily declining (Figure 3.2). These data also showed that reservoir storage responds to average annual precipitation in a lagged way over time (storage values drop only after a prolonged period of low precipitation), and this behavior must also be taken into account when designing a droughtproofing system. 


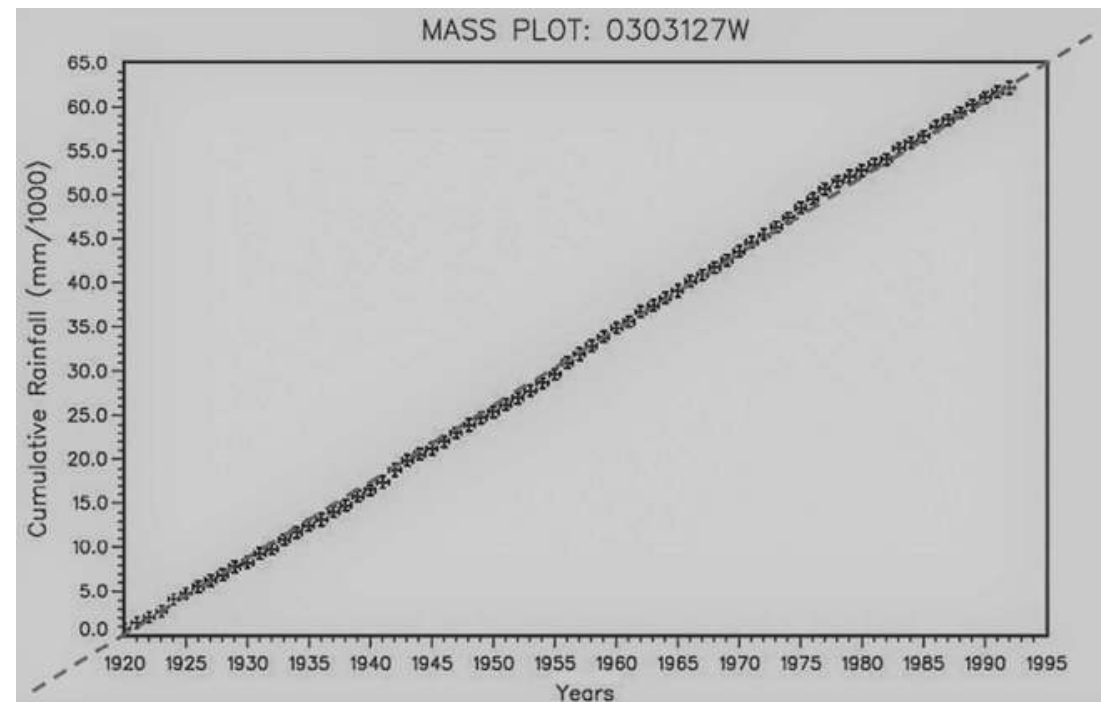

Figure 3.1 Indicative single mass plot for rainfall.

Source: the Author

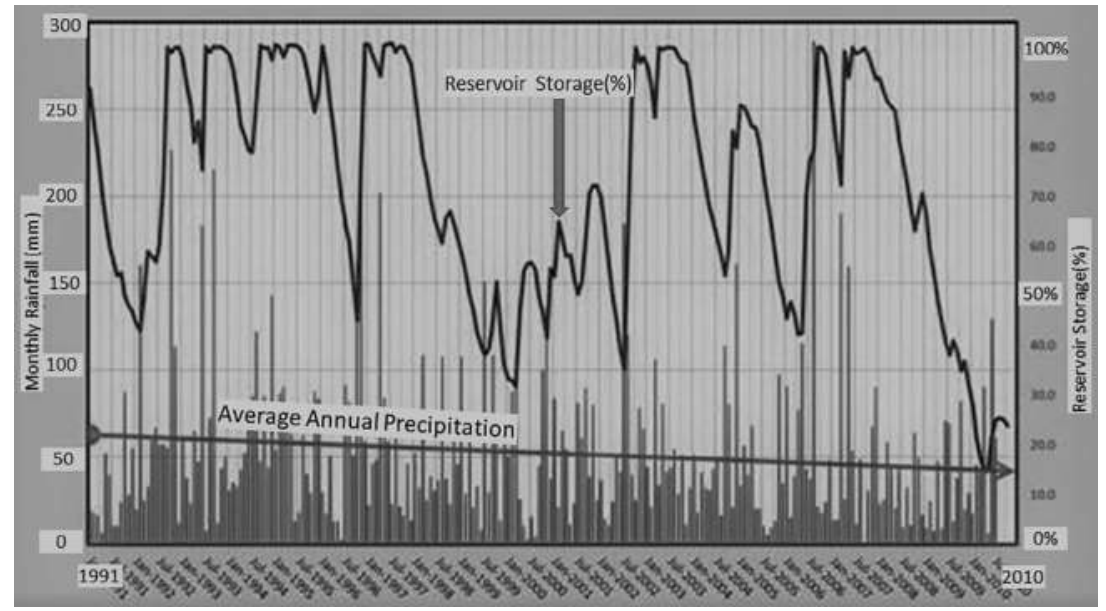

Figure 3.2 Reducing rainfall record: Orange River Catchment.

Source: the Author 


\section{Streamflow and inter-basin transfers of water}

Streamflow is the most important variable to be considered when undertaking any form of water resource analysis as it is the basis for any real-world water supply scheme, reservoir design, or abstraction potential assessment (inter-basin transfer). Once rainfall and streamflow have been considered as a dynamic system and recorded, data are available for the consideration of water resource protection policies, such as the water supply augmentation scheme being discussed in this chapter, as the potential for abstraction from a catchment can then be reliably assessed (Molle, Ghazi, and Murray-Rust 2009). Figure 3.3 shows a typical water resource system which includes two adjacent catchment areas, each with a reservoir; one of which is used to provide an inter-basin transfer to its adjacent catchment. In this scenario, the river system in the donor catchment area has effectively been developed with the primary aim of supporting the water demands in the adjacent receiving basin, where there are several competing demands for water (Sutcliffe 2009). This is a typical situation found all over the world where the water demand in a specific area has outgrown the ability of local resources; with the result that unused resources in another area are diverted through some form of transfer scheme, which will normally involve a pipeline or tunnel, and may also include pumps, depending on the topography faced (Rademeyer, van Rooyen, and McKenzie 1997; Molle, Ghazi, and Murray-Rust 2009).

In this type of situation, the streamflow as measured at the catchment outlets (points $\mathrm{B}$ and $\mathrm{C}$ ) will be influenced by various developments occurring upstream of the gauging

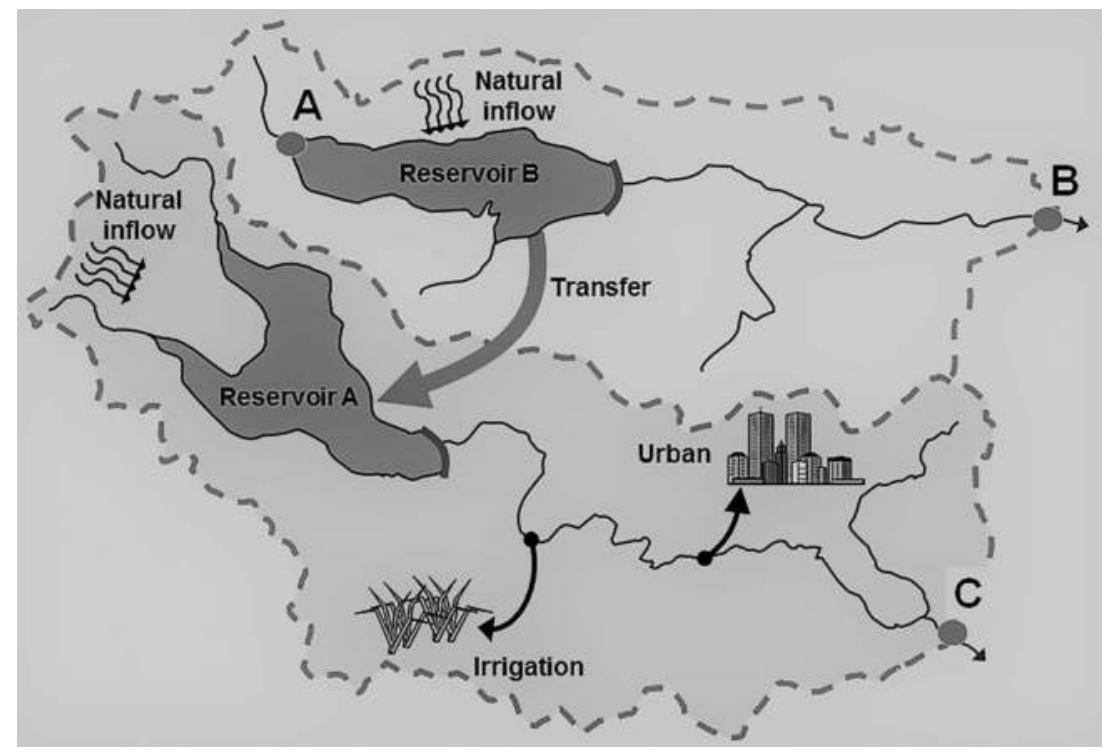

Figure 3.3 Typical 2-basin water resource system.

Source: the Author 


\section{Ronnie Mckenzie}

points. Obviously if a gauging point is upstream of any development, the flow at that point (here, Point A) will remain "natural," as it is not influenced in any way by that development. Thus, it is always important to establish and try to quantify any existing and future development in the catchment being considered as a source of additional water for another catchment, so that the demands from this can be factored into any subsequent water resource analysis (Rademeyer, van Rooyen, and McKenzie 1997).

Quantifying these demands can be challenging (Sutcliffe 2009) as it is often not simply a case of estimating the demand for water from local communities and the environment, and adding this back onto the recorded streamflow record. This is particularly relevant when dealing with afforestation, "run of river" irrigation pressure on water resources or urban-based demand pressures. There are many programs that can be used to estimate such requirements, but it is important to also take the water used by natural vegetation into account when adding the irrigation demands back onto the streamflow record to determine natural streamflow. It is also important to ensure that if irrigation demands have been cut during drought periods, the reduced irrigation consumption is added to the recorded streamflow to properly simulate natural flows, otherwise there may be problems when assessing the likely yield from the system under later drought conditions (Rademeyer, van Rooyen, and McKenzie 1997).

The influence of any reservoirs should also be considered when trying to establish natural river flow. This can usually be achieved quite simply by adding back the difference between the reservoir inflow and the reservoir outflow. This difference accommodates any abstractions from the reservoir, as well as the evaporation and rainfall onto or from the reservoir surface. It also takes the change in storage into account. An alternative approach is to identify each of the water balance components separately and add or subtract them one at a time. In the case of an inter-basin transfer, the water demand will often be continuous at a constant flow rate, although it can also be an intermittent demand at a variable flow rate if not required all the time. In either case the actual transfer will usually be recorded, and can simply be added or subtracted as necessary to create the natural streamflow record for policy purposes (Rademeyer, van Rooyen, and McKenzie 1997; Molle, Ghazi, and Murray-Rust 2009).

\section{Naturalized streamflow, or the water that is likely to be available in the future}

Once the engineering team has identified and quantified the various existing development impacts on streamflow from the community and natural environment, as in the Orange River context, it is then possible to re-create the "natural" streamflow record, which represents the streamflow that would have occurred in a river had there been no impact from human communities (Figure 3.4). At this point we have the most reliable measure of what the system under study can produce in the way of water resources for the calculation of augmentation potential. This does not however include the likely impact of climate change, which is a separate issue involving a more complicated and rigorous process (Huhne and Slingo 2009; Gunderson 2010).

A simplified example of the naturalization process is shown in Figure 3.4. Here different catchment-use requirements have been added back to the recorded streamflow to generate the natural streamflow record, or "virgin flow conditions". The 


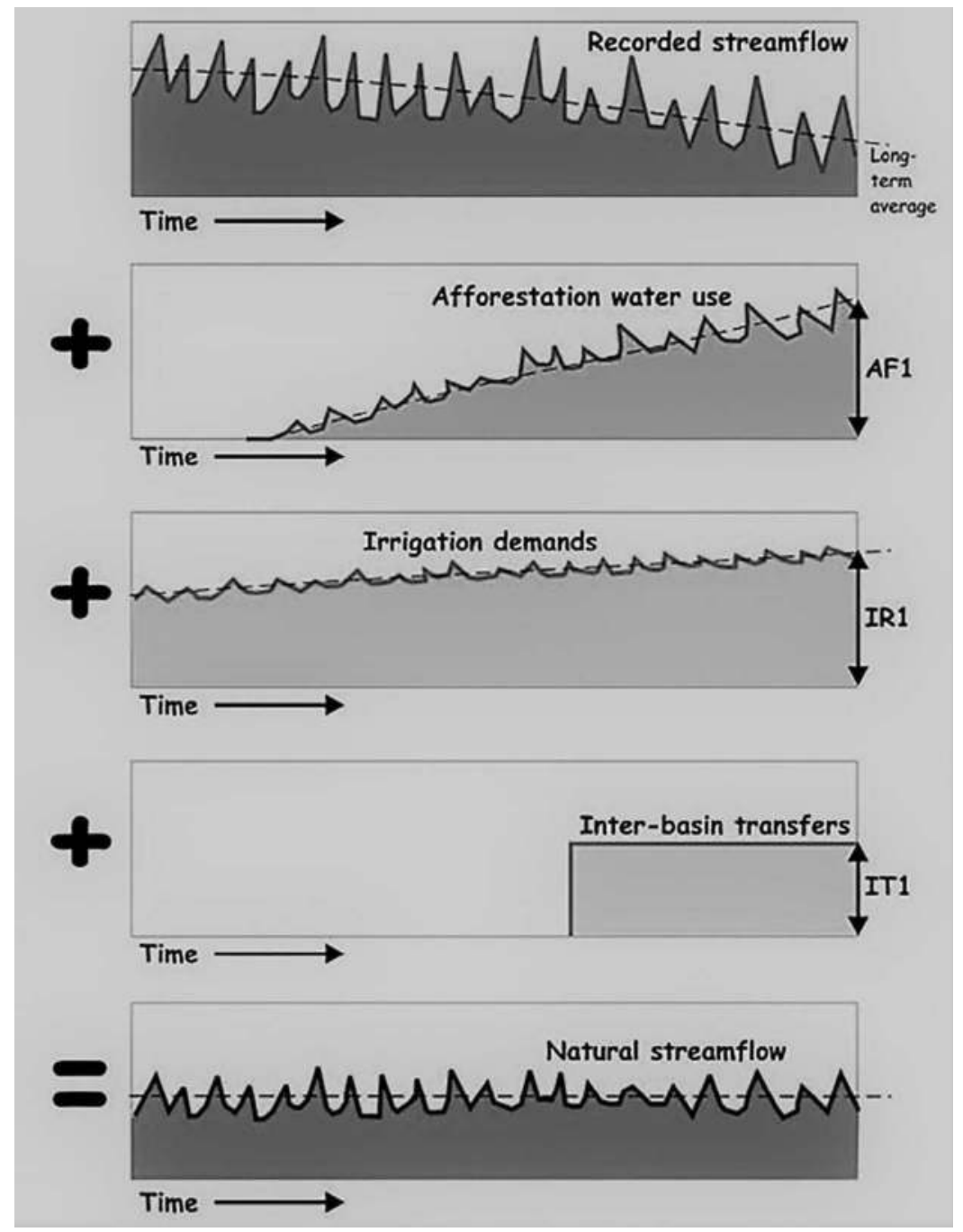

Figure 3.4 Naturalizing a streamflow record.

Source: the Author

significance of the streamflow record based on current development levels can be understood by considering a simple example (Rademeyer, van Rooyen, and McKenzie 1997; Molle, Ghazi, and Murray-Rust 2009). Suppose a catchment has experienced a severe drought early in the data record (say, 80 years previously), and again towards the end of the present study period. Let us also suppose that the drought at the end of the record created huge problems and severe water restrictions, while the drought 80 years earlier caused no real problem. At first glance, the more recent 


\section{Ronnie Mckenzie}

drought would thus be considered the more severe event due to the hardship and restrictions that it caused. If, however, the earlier drought had occurred at the time when the development demands were much higher as with the last one, it may well have caused even more hardship (Rademeyer, van Rooyen, and McKenzie 1997).

Thus, in many cases, what appears to have been the worst drought on record may well have been mild compared to an earlier event, which was not considered to be severe because catchment demand at the time was significantly lower. It is therefore important to recognize the need to "naturalize" streamflow records, and then deduct the current demands from the whole record when undertaking any reliable yield assessment, or the results may be over optimistic, and lead to incorrect policy decisions being taken (Holling 1996; Gunderson 2010).

In other words, the demands that we subtract from the natural flow record are considered to have existed since the start of the record, but are based on current demand, in any catchment. Thus, Figure 3.4 shows that the resulting streamflow record is no longer reducing in time, but is stationary at a much lower average level. It is this level that should determine the policy response to the question of re-distribution of water to another catchment: our drought-proofing agenda (Rademeyer, van Rooyen, and McKenzie 1997; Molle, Ghazi, and Murray-Rust 2009; Haefner 2016).

\section{Yield Assessment}

The key purpose of community water catchment policy is to store water during periods of surplus so that these reserves can sustain supply during drought periods. In very general and simplistic terms, areas with greater and consistent runoff will experience shorter drought events, while arid areas which tend to experience very erratic runoff will experience longer drought events (Huhne and Slingo 2009; Molle, Ghazi, and Murray-Rust 2009; Bakker and Allen 2012). Storage systems are primarily created in this scenario to even out supplies. If more than one storage is connected to support a specific demand center, a system is created which can become very complicated, and in some cases, can include several hundred reservoirs connected by pipelines, tunnels, and river sections. In relation to the previous discussion on streamflow, as a system grows, the critical period required for stream flow observations to cover all contingencies relating to water supplies for a community will also increase, and in extreme cases can extend beyond 10 or 15 years in length. The critical period is usually defined as the time in months or years from the storage system being full to the time that system reaches the dead storage level, under normal drawdown - i.e. the storage level at which the demands on the system cannot be met. This is shown in Figure 3.5.

As discussed in the introduction, one of the key functions of any water resource analysis is to assess the available yield that can be drawn from a system compared with the expected demands placed on it (Pegram and Mckenzie 1991; Basson et al. 1994; Pitman 2011). This needed to determine if the system will be able to meet the demands under adverse conditions such as a drought, or if it is likely to fail at this point. Most yield analyses undertaken around the world are based on a historical streamflow record which will typically be 20 to 100 years in length. 


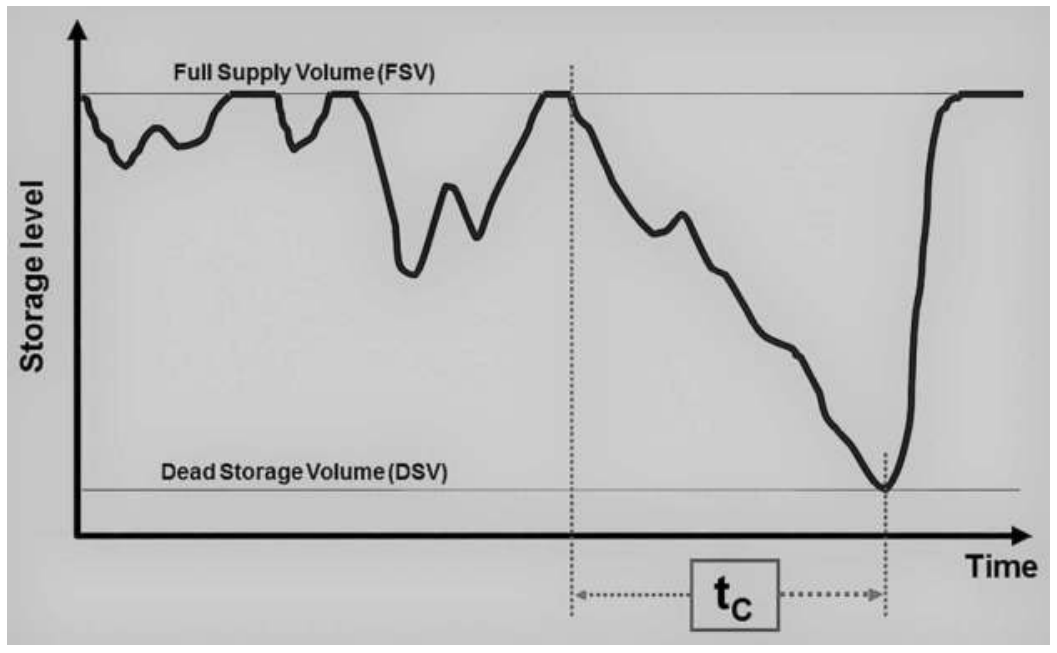

Figure 3.5 The critical period for a storage system.

Source: the Author

While such analyses do provide some idea of what yield can be provided from a system, the results can be very misleading as they often ignore the whole issue of reliability, which is an integral part of any yield figure. For example, saying that the yield from a system is 100 million $\mathrm{m}^{3} /$ annum is meaningless unless the figure is presented together with the risk of failure, since a yield of 100 million $\mathrm{m}^{3} /$ annum at a risk of failure of 1 in 2 years is completely different from a yield of 100 million $\mathrm{m}^{3}$ /annum at a risk of failure of 1 in 200 years. To highlight this issue the yields from a typical storage system are presented in Table 3.1 for a range of different streamflow analysis periods (Pegram and Mckenzie 1991; Pitman 2011).

As can be seen from the table, if the five-year record 1930 to 1934 were the only one to be considered, a yield of 81 million $\mathrm{m}^{3} /$ annum from this water resource system would be expected. If the record length is doubled to 10 years, the yield that can be drawn drops to 69 million $\mathrm{m}^{3} /$ annum. If another 10 years of record are added, it remains the same, and it even does not change when another 20 years of record are added. However, when the last 20 years of record is added,

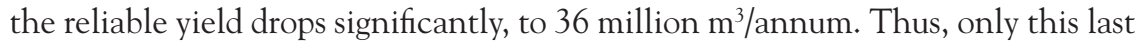
amount of water can be relied on from that catchment in all scenarios (Mckenzie and van Rooyen 1998).

This simple and theoretical example helps to highlight a very important issue when undertaking any yield analysis based on the historical streamflow sequence in a water catchment prior to deciding on the potential for development, or determining the amount that can be extracted to support another area's development; which yield result is correct (Basson et al. 1994; Pegram and Mckenzie 1991; Pitman 2011)? The answer is of course that all are correct. 
Table 3.1 Reservoir yields for different record lengths.

\begin{tabular}{lcl}
\hline $\begin{array}{l}\text { Period of analysis (hydrological } \\
\text { years) }\end{array}$ & Number of years & Firm yield (million $\left.\mathrm{m}^{3} / \mathrm{a}\right)$ \\
\hline $1930-1934$ & 5 & 81 \\
$1930-1939$ & 10 & 69 \\
$1930-1949$ & 20 & 69 \\
$1930-1969$ & 40 & 69 \\
$1930-1989$ & 60 & 36 \\
\hline
\end{tabular}

Source: the Author

They also all lack the one key piece of information that must be included whenever using the "historical" yield analysis that we are advocating here information on the reliability of the data, or alternatively, the risk of failure (Rademeyer, van Rooyen, and McKenzie 1997; Haefner 2016). In this example, the initial yield of 81 million $\mathrm{m}^{3}$ /annum is the correct yield from the system at a 1 in 5-year risk of failure (Mckenzie and van Rooyen 1998). The 36 million $\mathrm{m}^{3}$ /annum is also the correct yield from the system, but it will be at a lower risk of failure, perhaps 1 in 60 years or even 1 in 100 years. Thus, without specifying the risk of failure associated with a specific yield figure, only half the picture is being presented (Basson et al. 1994).

\section{Yield and reliability calculations}

As mentioned previously the yield from a water resource system is influenced by the record length of the streamflow sequence being analyzed, and it is therefore important to attach a reliability or alternatively a risk of failure to any specific yield figure that is being used in any form of water resource analysis (Mckenzie and van Rooyen 1998). The aim of the analyses is to identify the likely risk of failure based on certain demand forecasts and specific operating rules. If the analyses suggest that the risk of failure of the collection and storage system is higher than can be accepted, the operating rules may be changed or certain demands may be curtailed after which the model can be re-run to assess if the changes are sufficient to bring the risk of failure down to an acceptable level.

To explain this rather complicated issue, it is again best to use an example (Mckenzie and van Rooyen 1998). In this example, a small water resource system is described, where the yield from the system was found to be 45 million $\mathrm{m}^{3} / \mathrm{yr}$ based on the analysis of a 60-year long naturalized historical streamflow sequence. The question that remains to be answered is this: "what is the reliability of risk of failure associated with that yield figure?" This may be calculated at a 1 in 10-year risk of failure, or at a 1 in 200-year risk of failure, or anywhere in between. Figure 3.6 shows the reliability of supply calculation from this catchment based on simulations of stream flow (in 19 years out of 60 , stream flow failed to reach the yield estimate). 
- $\mathbf{R}_{\mathbf{n}}=$ Long-term risk of failure

$=[$ Failure sequences +1$] /[$ Total sequences $]$

$=(19+1) / 41$

$=0.488$

$=48.8 \%$

- $E_{p}=$ Long-term reliability of supply

$=1-R_{\mathrm{n}}$

$=51.2 \%$

- $\quad \mathrm{RI}=$ Recurrence interval of failures

$=1 /\left(1-E_{p}^{1 / n}\right)$

$=90.18$ years

Figure 3.6 Calculation of the risk of failure and reliability.

Source: the Author

\section{Drought management using stream flow analyses}

One of the most important uses of streamflow sequences is in the prediction of possible water supply problems moving into the future (Tallaksen and Van Lanen 2004). Streamflow sequences represent plausible future scenarios, some of which may be very positive with regards to water supply while others may be very pessimistic (Mckenzie and van Rooyen 1998). By generating and analyzing comparative sequences, it is possible to develop a 5 - or 10 -year projection into the future to indicate the likelihood of failure. Technically, it is possible to create projections of 50 or 100 years into the future, but in practice, a 5 -to-20-year window is more than sufficient in most cases. Normally the analysis "window" is re-analyzed each year so that a moving window is created; from this a water supply authority can assess whether the situation is deteriorating or improving. If the situation is deteriorating, then the aim is to identify the risks, and to act early on in a drought period, rather than allowing things to become so bad that severe restrictions are necessary. In many droughts, it is possible to avoid the most severe restrictions if low level restrictions are introduced at an early stage (Pegram and Mckenzie 1991; Molle, Ghazi, and Murray-Rust 2009).

Mckenzie and van Rooyen (1998) developed a typical seven-year risk analysis as shown in Figure 3.7, where the heavy black line represents what happened 


\section{Ronnie Mckenzie}

over that seven-year period. As can be seen, the storage continued to drop, and, after six years, was at the drought restriction level, at which point restrictions were introduced. In this example, the drought was broken in the following year and the restrictions were lifted. It is interesting to note that with hindsight it was not necessary to introduce the restrictions, since the floods filled the reservoir storages, and no doubt some politicians would have criticized the water managers for introducing the restrictions. If the drought had not broken and the situation had worsened, the same politicians would probably have criticized the water managers for not introducing restrictions earlier in the drought cycle! Thus, the important issue is to develop realistic and pragmatic operating rules that must be observed during drought events, and when the operating rules suggest that restrictions should be introduced, that they are implemented with full political support, or the consequences may be dire (Gunderson 2010; Haefner 2016).

\section{Drought proofing our communities}

Should a community or communities in a river basin wish to use this approach with a view to the augmentation of existing supplies to alleviate or to prevent

\section{Monthly Projected Reservoir Levels}

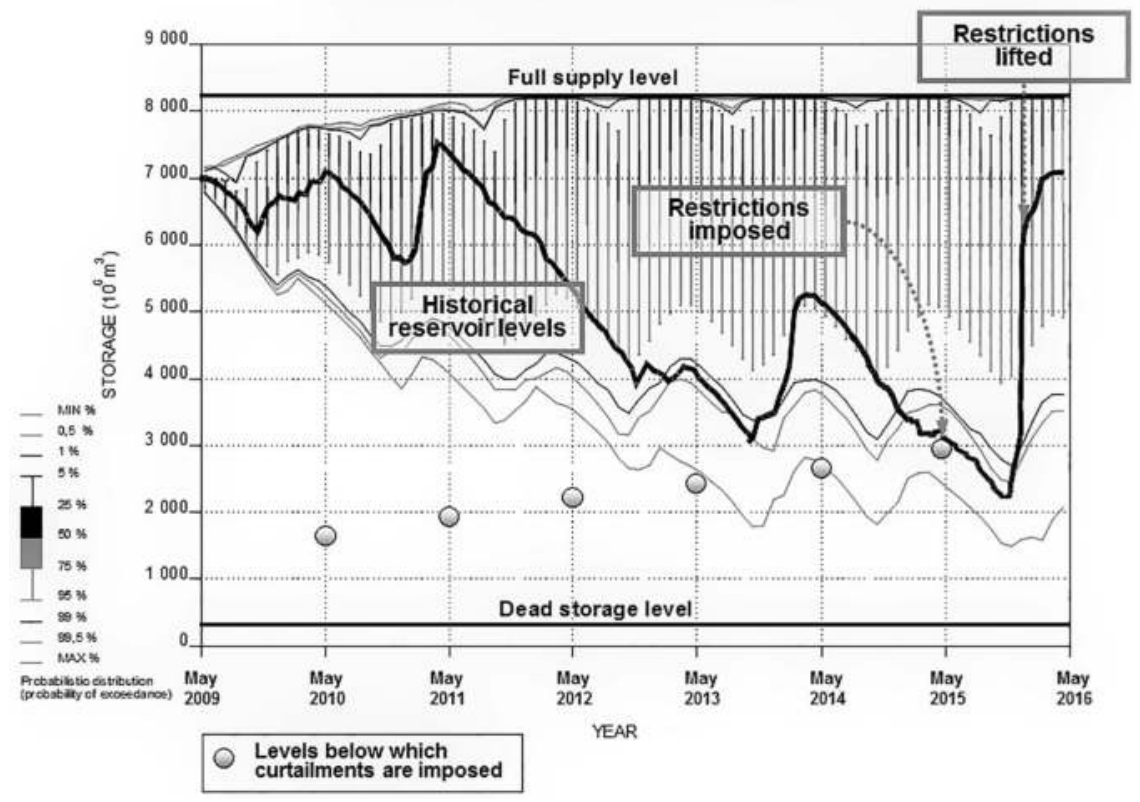

Figure 3.7 The actual seven-year performance of a storage system compared to the expected.

Source: the Author 
drought conditions from developing, completion of the data verification process to this stage would allow for this important next step.

\section{Modelling the water resource system as the starting point}

There is of course no single approach to water system analysis that can be applied to every drought risk or conservation situation in the world (Caviedes and Muller 1994; Tallaksen and Lanen 2004; Gleick 2009; Marengo 2009; Gleick 2016), but we have now established that the most useful forms of data needed to attempt the modelling of the water resource system may be obtained using the streamflow analysis methods discussed in this chapter (Pegram and Mckenzie 1991). Most countries that have large water resource systems to operate and manage have developed their own models and management practices over the past 30 to 40 years, during which time advances in computing power have been staggering (Haefner 2016). In this next part of the chapter, some general concepts and principles of water resource modelling are discussed that are relevant to many of the situations riverine communities experience around the world. The technology and methodologies put forward are to a large degree based on the more than 30 years of modelling development that has been undertaken in South Africa, which has one of the largest and most integrated water resource networks in the world, in one of the driest areas in the world (Pegram and Mckenzie 1991; Pitman 2011).

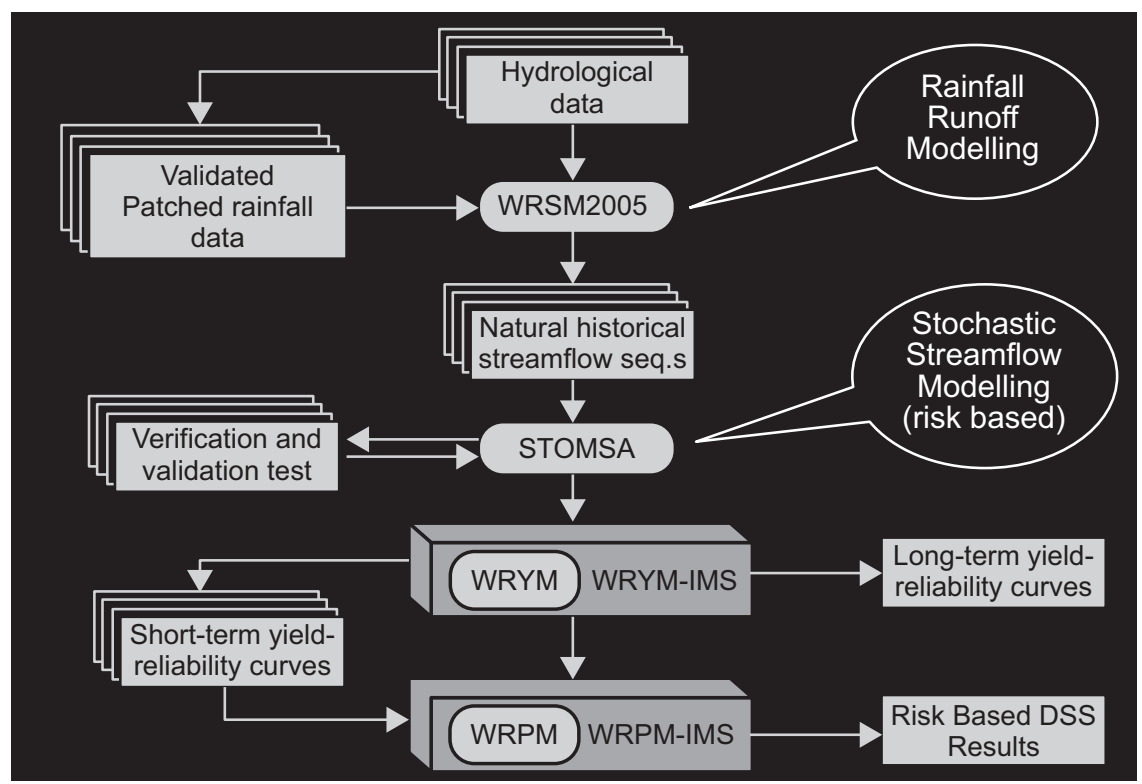

Figure 3.8 Hydrology and resource system analyses.

Source: the Author 
The system analyzes techniques currently used in South Africa, which are based on the combined experience and expertise from around the world, with particular emphasis on the pioneering work undertaken in Canada in the late 1970s by Sigvaldason (1976), which helped to create this platform. The original model was imported into South Africa in 1985, and was modified over a period of 10 years for use in arid areas through the combined efforts of many experts from the USA, Canada, the UK and South Africa (Mckenzie and van Rooyen 1998). The models have continually been upgraded and enhanced since 1985 to take advantage of the latest advances in both software and computer hardware. Full details of the analytical techniques are provided by Basson et al. (1994); while those wishing to understand the actual engine room of the model can find the details of the "Out of Kilter" algorithm in Jensen and Barnes (1987).

As can be seen in Figure 3.8, the first stage in the process is to sort out the hydrology as described earlier, and relate that to stream flow. Establishing a solid and reliable hydrological data set is essential for any water resource analysis, since the resulting system yields and estimated risks of failure are based on this (Mckenzie and van Rooyen 1998). This is often a difficult and time-consuming process that can take many years when dealing with a large system (Pitman 2011). For example, the hydrological analysis of the Orange River System in South Africa that this chapter is based on took more than five years to prepare, as it has a catchment area of over 1 million $\mathrm{km}^{2}$, and involves more than 200 individual hydrological inflow points.

Figure 3.9 lists the models used in the South African context. It can be seen that the WRSM2005 Model has been used to generate the rainfall/runoff data, and the STOMSA Model used to generate the stochastic streamflow sequences based on these data (Jensen and Barnes 1987; Basson et al. 1994). The WRSM2005 Model (Pitman 2011) is a basic South African derivative of the famous Stanford Watershed Model (Crawford and Linsley 1974), which was the first deterministic rainfall-runoff model ever developed, and remains one of the most significant advances in hydrology to this day. The two water resource models shown at the final stages of the flowchart can effectively be considered as a single model that has two key functions (Pitman 2011). The initial function of the model is to establish the existing yield capability of a specific system based on a set of operating rules (Crawford and Linsley 1974; Gunderson and Holling 2001). During this process, the historical streamflow record is used (naturalized with current day development demands in place) supported by stochastically generated streamflow sequences. The initial analyses establish the yield capability of the system (long-term yield/reliability curves), as well as the short-term yield reliability characteristics (short-term yield reliability curves) for the system based on different starting storages for the system (Mckenzie and van Rooyen 1998).

The second function of the models is for future planning purposes and for drought management support (Tallaksen and Van Lanen 2004). By using the 
short-term yield/reliability curves for the system together with the expected future demands at each demand center for each year (or month) of the analysis, the risk of failure to supply the demand can be assessed. This analysis then forms the basis for the operation of the system, and allows a systematic and pragmatic approach to the introduction of water restrictions early on in a drought cycle. While no two analyses are the same, Figure 3.9 provides some idea of the typical elements that can be included in a detailed water resource analysis for any community (Mckenzie and van Rooyen 1998).

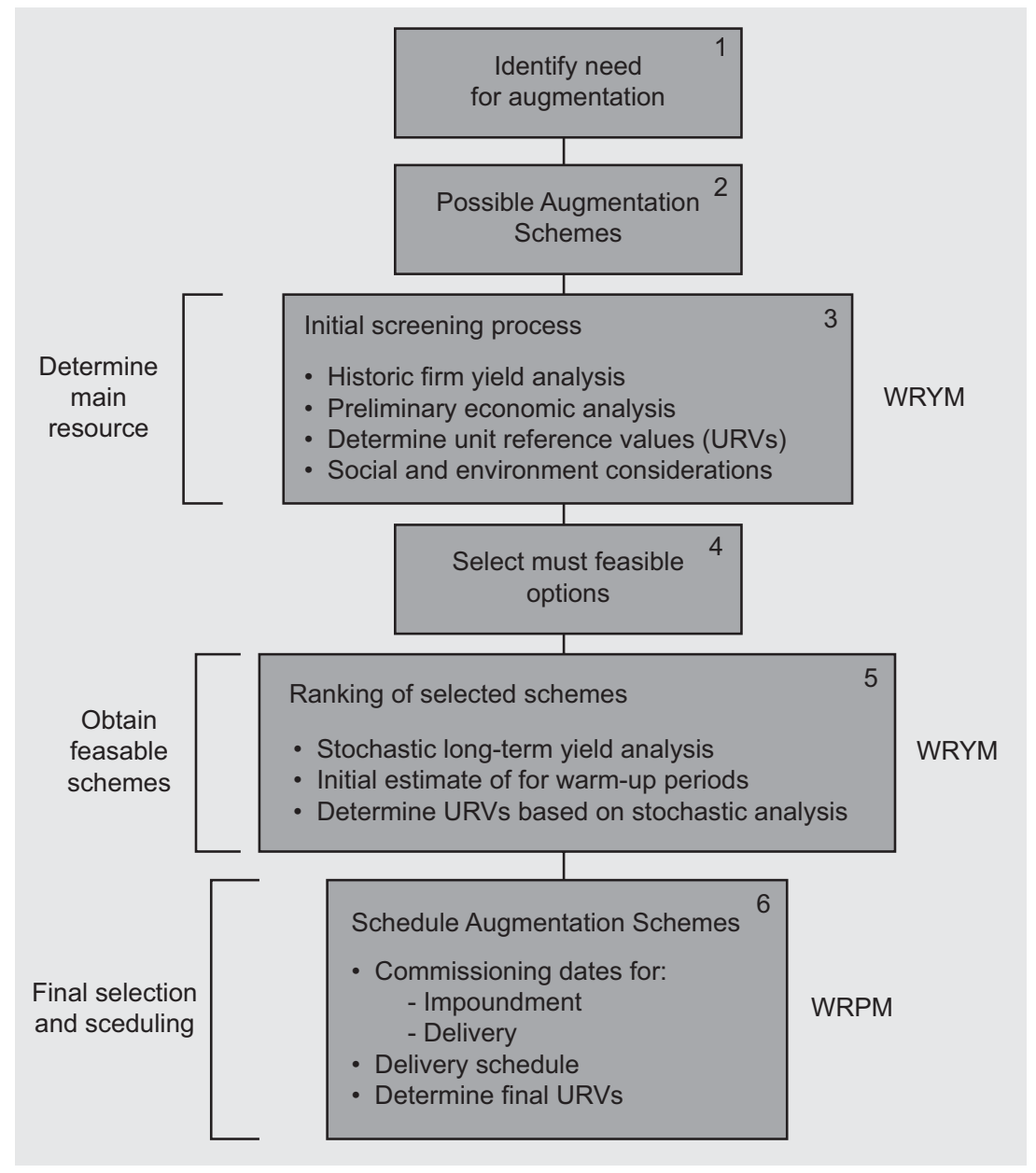

Figure 3.9 Typical stages in the analysis process.

Source: the Author 


\section{Ronnie Mckenzie}

\section{Pulling it all together}

The system modelling techniques used to generate the basin transfer policies discussed in this chapter are based on a form of Linear Programming that utilizes a powerful network solver called the "Out-of-kilter" algorithm to predict community water resources under conditions of drought. The outof-kilter algorithm is a statistical technique that computes solutions to the minimum-cost flow problem in a flow network (Fulkerson 1961; Jensen and Barnes 1987). The name of the algorithm reflects the fact that each phase of an operation either satisfies the optimality conditions for that operation (and we say that it is are in-kilter) or does not (and we say that it is outof-kilter). That is, a time of drought is "out of kilter", and a time of normal or better flow is "in kilter". However, all that needs to be considered in the present discussion is that the physical system of rivers, reservoirs, pipelines, inflows, demands and so on that is required to supply communities with sufficient water must be converted to a "virtual" network (algorithm) in which the operating rules are defined by community policy. That algorithm is then used to analyze each time step in the supply of water (typically monthly, but can be weekly or daily), and to identify the "least-cost" solution in respect of the use of water from the system for policy purposes. Thus, we can safeguard environmental flows and consumption patterns in a river basin(s) that is being considered as a possible donor to another basin, while at the same time determining the amount of water that can be passed on to the basin in need, and the extent of infrastructure works that will be required to achieve this outcome.

In simple terms, the operating rules define which demands are supplied, and those that are not supplied, for a specific storage system and extraction situation (Fulkerson 1961; Jensen and Barnes 1987; Tallaksen and Van Lanen 2004). If the operating rules have been defined in such a manner that there can be no confusion regarding which demands are to be supplied under a specific stream flow/storage scenario, the method reported on here will identify the optimal network solution (Rademeyer, Van Rooyen, and McKenzie 1997; Mckenzie and van Rooyen 1998). To explain the process in setting up a system model, and allocating cost and penalty structures, a slightly more complicated model is presented. Once again, the starting point is a real system, as shown in Figure 3.10. This example is from one of the small water resource basins within the Orange River system, with a few demand centers and an inter-basin transfer system that includes several reservoirs, centered on the Bloemfontein area of South Africa (Mckenzie and van Rooyen 1998).

The final stage in the network analysis is to convert the map of the real system into a high-level network model as shown in Figure 3.11 using the algorithm outlined earlier (Mckenzie and van Rooyen 1998). Having established the high-level network model, the water manager must create the 


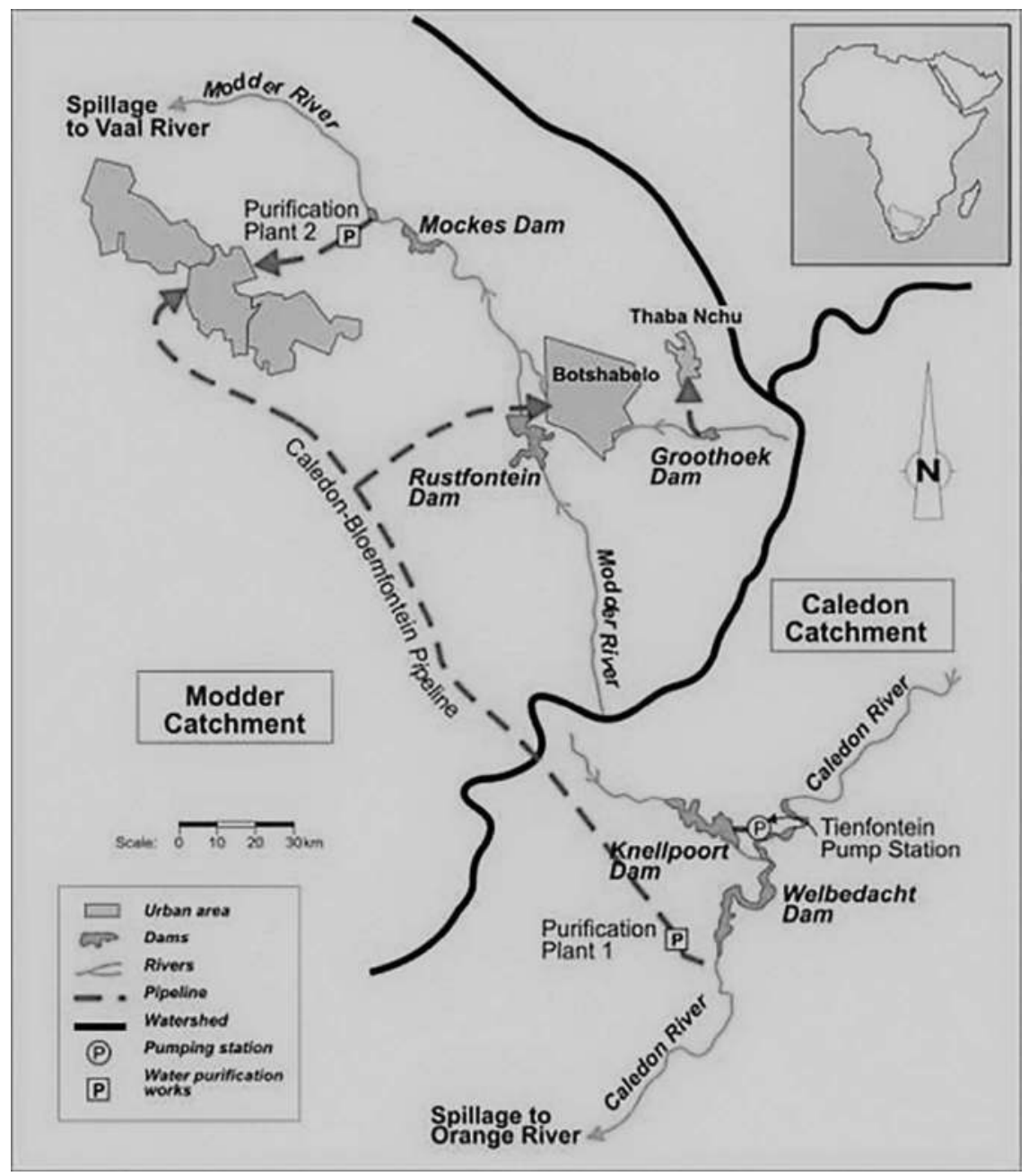

Figure 3.10 Example of a simple inter-basin transfer for drought proofing the Bloemfontein Area of South Africa.

Source: the Author

penalty structures to define the operating rules to be used in the analysis. Flows are then calculated and allocated to the storage, extraction and environmental flow parts of the system as shown. The operating rules for the network system are then specified and the model run to determine the best policy response. 


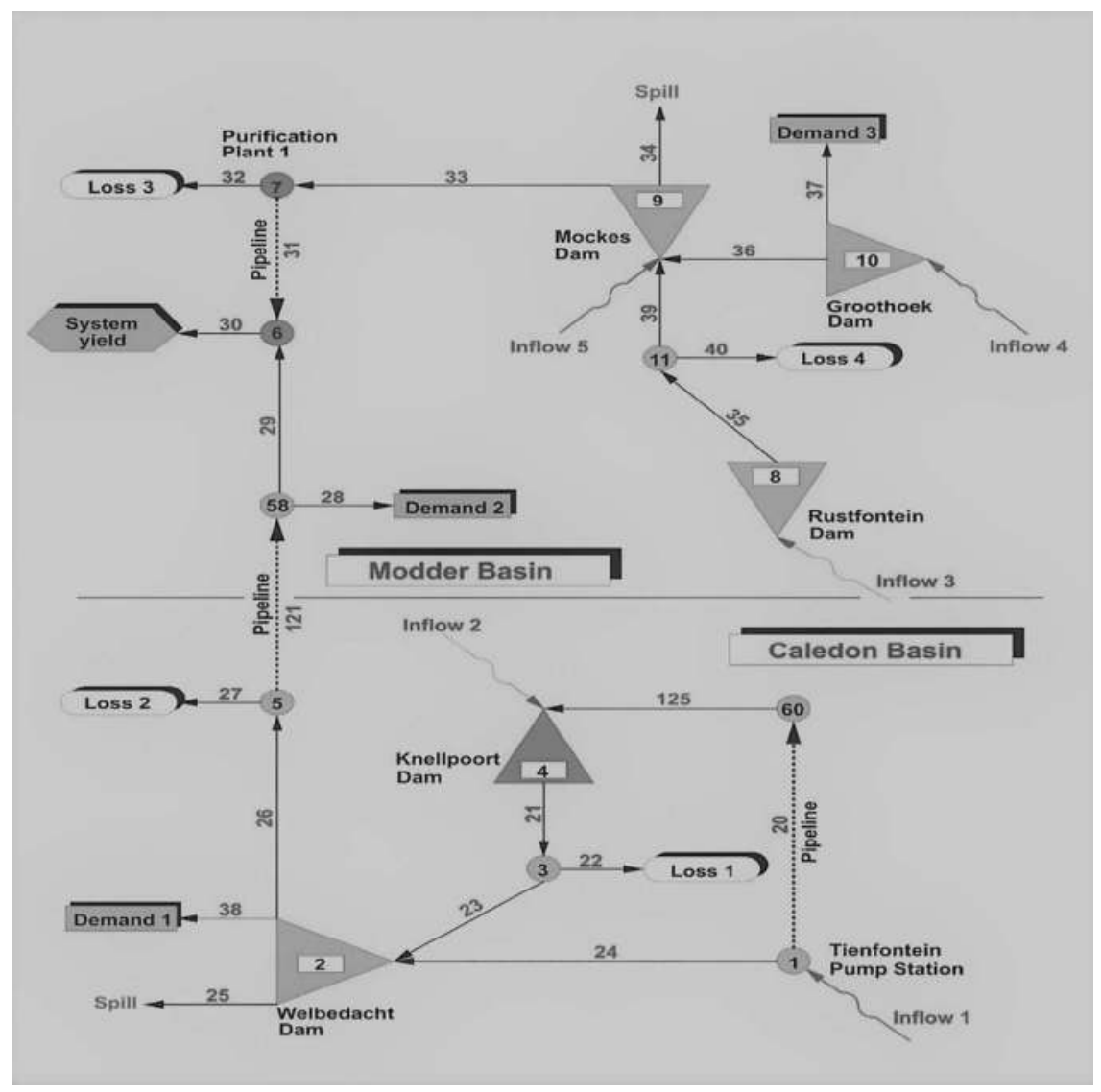

Figure 3.11 High level system schematic of Figure 3.10.

Source: the Author

\section{Conclusions}

Ensuring that there is a sufficient supply of good quality water for urban, agricultural and industrial use is arguably the most important issue facing the world's population in the next few years (UN Water 2006; Pitman 2011; UNEP 2012). Already, countries like South Africa and Australia are unable to supply enough water to many areas in times of drought unless there has been significant and effective investment in water transfer schemes, and it is estimated that over one billion people throughout the world face the prospect of having to somehow make do with unsafe water in the absence of effective distribution schemes.

This chapter has outlined the methodology used in South Africa to develop the very effective drought-proofing policies, and design the physical systems required to implement them (DWAF 1986; Government Gazette 1988; Rademeyer, Van 
Rooyen, and McKenzie 1997), used in that country to implement the decision to pipe water from the relatively wet coastal areas of South Africa to the inland high country, where much of the urban population resides (Pegram and Mckenzie 1991; Pitman 2011). This transfer system has been spectacularly successful as an engineering project, and can provide a good model for other systems and regions to achieve the same outcome, but there are increasing concerns about the environmental health of the origin river systems, and a rising level of stress in the origin communities related to the adequacy of the remaining water flows within their purview as climate change bites harder (Coughlan et al. 2003; Marengo 2009; Strang 2015). These factors need closer attention as important variables that must be included when using the network modelling approach described here (Bakker and Allen 2012; Strang 2015). This will allow communities and nations to develop the most efficient, and environmentally and socially responsible, droughtproofing scenarios to solve geographical differences in water supplies using existing river resources (Bakker and Allen 2012; Gleick 2016; Haefner 2016).

\section{References}

Back, M., and King, J. 2009. The Atlas of Water: Mapping the World's Most Critical Resources. Los Angeles: University of California Press.

Bakker, K., and Allen, D. 2012. Water Security: Governance and Climate Change Challenges From a Canadian Perspective. Vancouver: Pacific Institute for Climate Solutions (PICS).

Basson, M. S., Allen, R. B., Pegram, G. G. S., and van Rooyen, J. A. 1994. Probabilistic Management of Water Resource and Hydropower Systems. Highlands Ranch, CO: Water Resource Publications.

Caviedes, C. N., and Muller, K. D. 1994. "Fruticulture and Uneven Development in Northeast Brazil." Geographical Review 84(4): 380-93.

Coughlan, M., Jones, D., Plummer, N., Watkins, A., Trewin, B., and Dawkins, S. 2003. "Impacts of 2002/2003 El Niño on the Australian Climate." In Proceedings of Droughtcom Workshop: Improving the Communication of Climate Information, edited by N. Plummer, M. Flannery, C. Mullen, B. Trewin, A. Watkins, W. Wright, T. Powell and S. Power, 2, 7-12. Melbourne: CSIRO.

Crawford, N. H., and Linsley, R. K. 1974. Continuous simulation models in urban hydrology Geophysical Research Letters, 1(1): 59-62.

DWAF. 1986. Management of the Water Resources of the Republic of South Africa. Pretoria: Department of Water Affairs and Forestry.

Fulkerson, D. R. 1961. “An Out-of-Kilter Method for Minimal-Cost Flow Problems.” Journal of the Society for Industrial and Applied Mathematics 9(1): 18-27.

Gleick, P. H. 1993. Water Crisis. Oxford: Oxford University Press.

Gleick, P. H. 2009. The World's Water 2008-2009: The Biennial Report on Freshwater Resources. Washington: Island Press.

Gleick, P. H. 2016. Impacts of California's Ongoing Drought: Hydroelectricity Generation 2015 Update. Oakland, CA: Pacific Institute.

Gunderson, L. H. 2010. Ecological and Human Community Resilience in Response to Natural Disasters. Ecology and Society 15(2): 18.

Gunderson, L. H., and Holling, C. S. eds. 2001. Panarchy: Understanding Transformations in Human and Natural Systems. Washington, DC: Island Press.

Haefner, A. 2016. Negotiating for Water Resources: Bridging Transboundary River Basins. New York: Routledge. 
Holling, C. S. 1996. "Engineering Resilience Versus Ecological Resilience.” In Engineering Within Ecological Constraints, edited by P. C. Schulze, 31-44. Washington, DC: National Academies Press.

Huhne, C., and Slingo, J. 2009. Climate: Observations, Projections and Impacts. Department of Energy and Climate Change India, Met Office, Hadley Centre; University of Nottingham, UK; Walker Institute; Centre for Ecology and Hydrology; University of Leeds; Tyndall Centre for Climate Change. Nottingham: Met Office, UK.

IPCC. 2008. Climate Change and Water. UK, Germany, China, Australia: IPCC Working Group II. Geneva: WMO and UNEP.

Jensen, P. A., and Barnes, J. W. 1987. Network Flow Programming. 2nd ed. Operations Research Group, University of Texas, Austin, USA. Austin: Krieger Publishing.

Madani, K. \& Mariño, M. A. 2009. System dynamics analysis for managing Iran's Zayandeh-Rud river basin. Water Resource Management 23(11): 2163-2187.

Marengo, J. A. 2009. "Impactos de extremos relacionados com o tempo e o clima - impactos sociais e econômicos." Boletim do Grupo de pesquisa em mudanças Climáticas, Cachoeira paulista, SP 8, 01-05. http://mudancasclimaticas.cptec.inpe.br/ rmclima/pdfs/ newsletters/boletim_no8_port.pdf

Mckenzie, R. S., and van Rooyen, P. G. 1998. Water Resources Yield Model User Guide. Department of Water Affairs and Forestry Report No P0000/00/001/98. Pretoria: Department of Water Affairs and Forestry.

Molle, F., Ghazi, I., and Murray-Rust, H. 2009. "Buying Respite: Esfahan and the Zayandeh Rud River Basin, Iran." In River Basin Trajectories: Societies, Environments and Development, edited by F. Molle and P. Wester, 196-213. Wallingford: CABI.

Newson, M. D. 1992. Land, Water and Development: River Basin Systems and Their Management. London: Routledge.

Pegram, G. G. S., and Mckenzie, R. S. 1991. Synthetic Streamflow Generation in the Vaal River System Study. Proceedings of the SA Institute of Civil Engineers, 15-24 January.

Pitman, W. V. 2011. "Overview of Water Resource Assessment in South Africa: Current State and Future Challenges." Presented to the Water Research Commission 40-Year Celebration Conference, Kempton Park, 31 August-1 September 2011.

Rademeyer, J. I., van Rooyen, P. G., and McKenzie, R. S. 1997. Water Demand and Demand Management. Proceedings of the South African Institute of Civil Engineers, September, $13-14$.

SA Government Gazette. 1988. Water Act, Number 19182. August. Pretoria: Government Printer.

Schumm, S. A. 2007. River Variability and Complexity. Cambridge, UK: Cambridge University Press.

Sigvaldason, O. T. 1976. A Simulation Model for Operating a Multipurpose, MultiReservoir System. Water Research 12(2): 263-278.

Strang, V. 2015. Water: Nature and Culture. London: Reaktion Books.

Sutcliffe, J. V. 2009. "The Hydrology of the Nile Basin." In The Nile: Origin, Environment, Limnology and Human Use, edited by H. J. Dumont. Dordrecht: Springer.

Tallaksen, L. M., and Van Lanen, H. A. J. eds. 2004. Hydrological Drought: Processes and Estimation Methods for Streamflow and Groundwater. Amsterdam: Elsevier.

UN Water. 2006. UN Water. New York: United Nations. www.unwater.org/downloads/ Water_facts_and_trends.pdf.

UNEP. 2012. United Nations Status Report on the Application of Integrated Approaches to Water Resource Management. Rome: UNEP.

Wohl, E. 2011. A World of Rivers: Environmental Change on Ten of the World's Great Rivers. Chicago, IL: The University of Chicago Press. 


\title{
4 Arid lands, saline lands \\ Water in the form of a major river \\ under stress, the Murray-Darling \\ system in Australia
}

\author{
Malcolm Cooper
}

\section{Introduction}

The management of the water resources in the Murray-Darling system has been of concern to the communities living along its banks and using its water for a very long time. Post colonization, the health and use of the river devolved at the political level to each of the Colonies involved (MDBA 2017), but centralized jurisdiction over the system was not achieved. At the 1897 Federation Convention and the 1898 Melbourne Constitutional Convention, the South Australian and Victorian Premiers both suggested:

we ought to give the federal parliament which we propose to call into existence the power to legislate on the river to remove this fertile source of conflict and friction between the colonies.

(MDBA 2017)

However, it took the severe Federation Drought (1895-1902), so named because it coincided with the deliberations about forming the country of Australia from several self-governing States, to bring the stakeholders together on the management of the system. After several failures, the first River Murray Waters Agreement was signed in 1914. Fifteen iterations later, it is now the Murray-Darling Basin Agreement, making it possibly Australia's longest standing inter-governmental agreement (Guest 2017). The initial agreement was primarily about safeguarding the economic value of the Basin's water resources (MDBA 2017), although some recognition was given to their social and cultural importance. That economic value involved extracting as much water for irrigation, industry and communities in the basin, while at the same time trying to ensure that sufficient water was available for the river's transport function and to supply the City of Adelaide in South Australia (not in the basin but directly supplied by it). Thus, while the water resource in the river basin became highly regulated to try to cope with the shortage of water in the system, there was little attention given to environmental flows in the early days of the agreement (MDBA 2017). However, by 1968, the level of concern about the quality of the Basin environment impacts was rising as water quality had also deteriorated. This led to discussions about further regulations on extraction. 


\section{Malcolm Cooper}

State government control during the 1970s to the 1990s saw attempts being made to manage land and water in parts of the basin, but it became obvious that the intergovernmental approach that the River Murray Waters Agreement had failed to deliver was needed. This was first formulated in 1987, when the Murray-Darling Basin Commission (MDBC), which later morphed into the MDBA (MDBA 2017), was established.

\section{The geography, geology and hydrology of the Basin}

The Basin includes the catchments of the Murray and Darling rivers and their tributaries (Figure 4.1). The Basin extends over 1 million $\mathrm{km}^{2}$; covering $75 \%$ of New South Wales, more than 50\% of Victoria, significant parts of Queensland and South Australia, and all the Australian Capital Territory. More than

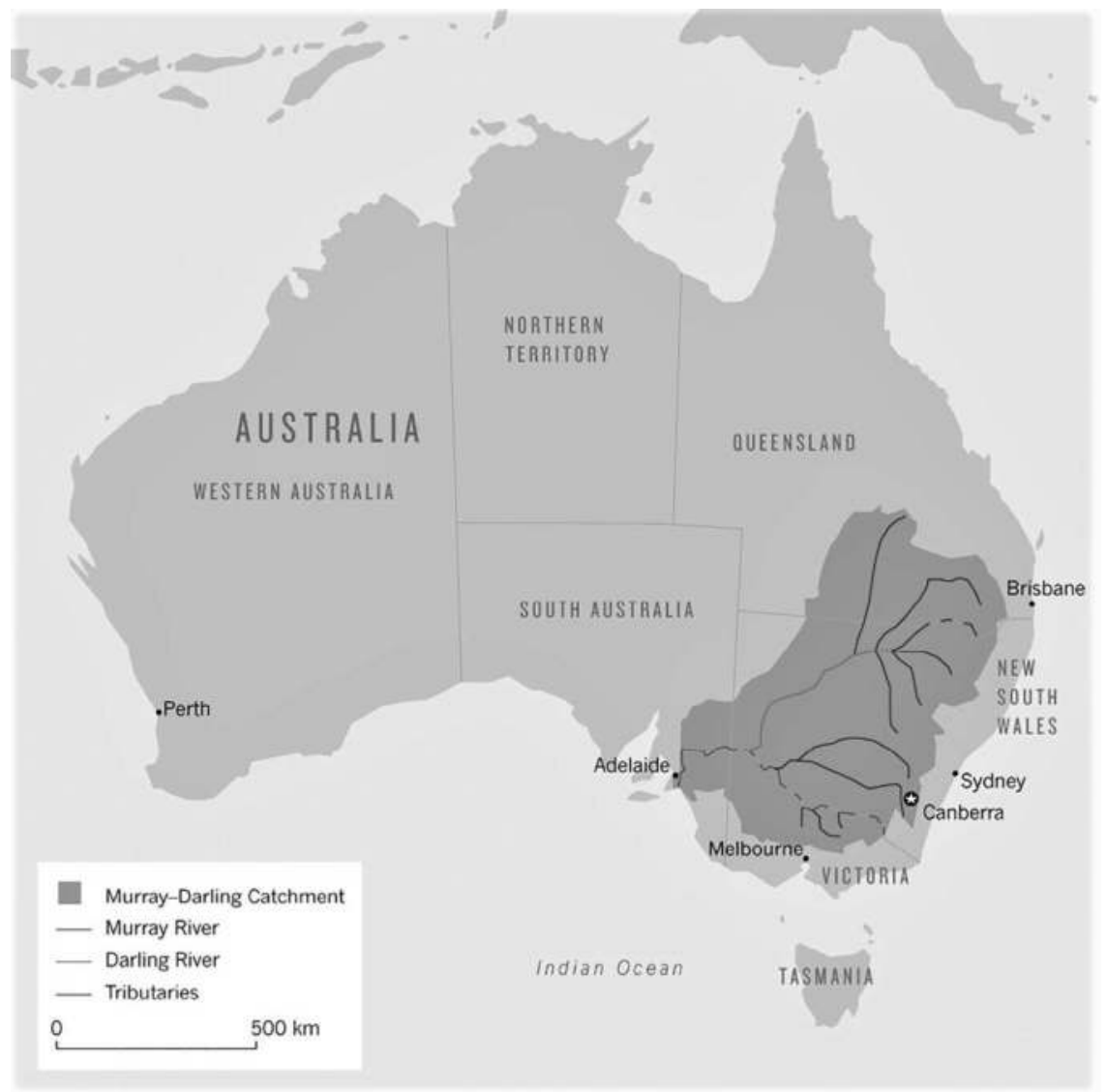

Figure 4.1 Murray-Darling Basin.

Source: Martyman, CC BY-SA 3.0, https://commons.wikimedia.org/w/index.php?curid=7888890 
$75,000 \mathrm{~km}$ of streams and rivers in 23 main river valleys make up the catchment (Crabb 1997), and an estimated 30,000 wetlands, of which 11 are registered under the RAMSAR agreement, are included. The major rivers within the basin are the Murray $(2,575 \mathrm{~km})$, Darling $(2,740 \mathrm{~km})$, Condamine-Balonne, Gwydir, Macquarie, Lachlan and the Murrumbidgee (MDBA 2017).

However, many of the watercourses, particularly in the north, are highly ephemeral, and the main river system also periodically ceases to flow. This is because around $94 \%$ of all the rainfall captured by the basin is lost through evaporation or transpiration. Thus, less than 6 of the estimated 530,618 gigaliters (GL) of rain per year in the basin reaches its rivers (Roderick and Farquhar 2011; MDBA 2010b). This means the average annual inflows into the Basin rivers (including the inter-basin transfers lower down in the system) is only of the order of 32,500 GL (Crabb 1997; MDBA 2011c). Offsetting this problem, the Basin includes large shallow groundwater resources (estimated to be about 10.13 million GL; CSIRO 2010b). Sedimentary alluvial and porous rocks cover a considerable part of the Basin, but while storage in the aquifers within them is important, not much of this is accessible and its often of poor quality. Finally, the entire basin is on top of Australia's greatest stored water resource, the deeper Great Artesian Basin. However, while this is a major resource, its management is not influenced by the Basin Plan, as the Federal Water Act of 2007 excluded this water from the definition of Murray-Darling Basin water resources.

\section{Connectivity within the basin}

The collection and use of rainfall and groundwater resources is thus difficult within the Basin, but this is not the only problem: the natural hydrologic connectivity is also highly variable between basin sub-regions, and within both wet and dry periods. For example, three of the major subsidiaries in the Murray-Darling system do not reach the main river at all, instead they end in floodplain wetlands (CSIRO 2008). Conversely, in very wet periods, the main river channels spread out over the wide floodplains. Because these floodplains are flat, this results in slow flood water-travel times, high amounts of evaporation and few opportunities to impound the water for later use. In the Basin, the connectivity between surface and groundwater is also variable. For example, there is a strong connection in the Peel River basin, but no connections at all in other areas (Tomlinson 2011; MDBA 2012a).

\section{Climatic variability}

The climate of the Basin also varies considerably from sub-region to sub-region, and from time to time (MDBA 2017). Rainfall is summer-dominant in the north and winter-dominant in the south (CSIRO 2008). This is a major factor in the variations in the annual inflow to its rivers. In the 114 years since records commenced, inflow has varied from a high of 117,907 GL in 1956, to a low of 6,740 GL in 2006 (MDBA 2010a, 2010b). Because of the variations in 
inflow, the flow reaching the sea in South Australia has also varied widely. The river has experienced the massive droughts described earlier, but also very wet periods during the 1950s and 1970s. The historical patterns of annual stream flow are evidence of these events: the flow in the wettest 15 -year sequence (1950-1964) was 42\% higher than the long-term average, while the flow in the driest 15-year sequence (1995-2009) was 32\% lower than the long-term average (MDBA 2010b).

The research for the creation of the Murray-Darling Basin Plan also shows that the weather systems across the basin are changing (MDBA 2017). If these changes continue they will have significant impact on the Basin, and may lead to a warmer and drier climate in south-eastern Australia (CSIRO 2010a), further reducing the water available in this system.

\section{Condition of the water resources}

\section{Surface water}

The quality and amount of surface water resources thus varies across the Basin, but also depends on other factors, including the level of development, management arrangements and local levels of use. Within these patterns, changes to the flow regimes over time have affected the ecosystems within the Basin (Boulton 1999; Kingsford 2000; Kingsford and Thomas 2004). It is not surprising therefore that the National Land and Water Resources Audit (2011) assessment of the condition of Australian rivers indicated that the ecological health of the Basin is now less than what is required for its long-term future (Davies et al. 2008; CSIRO 2012).

An important indicator of river health is the continued existence of a native ecosystem (Lintermans 2007), and in this regard, native fish populations are in serious decline. It is estimated that these communities are at about $10 \%$ of the level they were at before European settlement. Replacing the native species to some extent though, 11 alien species now comprise $80-90 \%$ of fish biomass at many sites in several of the rivers, so the problem is not entirely to do with water quality (Lintermans 2007). Also, the large wetlands in the Murray-Darling Basin are among the most important their type in Australia for maintaining native ecosystems (Kingsford et al. 1999; Kingsford and Auld 2005). However, the number of water birds, and the frequency of breeding in these areas, has also been reduced from pre-European settlement levels (Kingsford and Thomas 1995; Kingsford and Johnson 1998). Finally, the riparian and wetland vegetation along the river, which is important for its ecological health, has also declined in quality and amount. For example, $80 \%$ of the surviving river red gums in the floodplain are partially stressed, and 20-30\% are severely stressed (Bowen and Simpson 2009).

\section{Groundwater}

The quality of groundwater resources in the Murray-Darling Basin varies naturally; in some areas it is fresh water, in others the salt load exceeds 
the salinity of sea water, as noted earlier (MDBA 2017). In general, their present-day condition as compared with their state before land clearing and development, shows that they have been severely compromised by overextraction. However, it is also affected by the increased aquifer recharge from local irrigation drainage and greater rainfall infiltration following land clearing.

\section{Users of the basin water resources}

The Basin's water resources are extensively used by agriculture, non-agricultural industry, urban and rural settlements and by recreational and cultural activities (Table 4.1). In the past, only after all these users were supplied was the task of maintaining freshwater ecosystems addressed. The Murray-Darling Plan was designed to offset this neglect. However, economic sector usage is concentrated, and in some locations, more is still taken than can be supplied (Cooper, Kato and Nakagami 2016; Guest 2017). In the agricultural sector, this is true of the resource used to grow extensive food, fiber and pasture crops, to provide water for livestock and in general farming operations. This is $40 \%$ of Australia's total production (ABS 2006), and realizes an annual return of $\$ 15$ billion to the region. This output consumes some $83 \%$ of the water that is extracted from Basin water resources, but also contributes to the further $13 \%$ that is lost or unaccounted for water (Waldron 2008) from irrigation water supply losses.

In recent times the agricultural sector has had to consider the impact of government measures such as The Living Murray program, which was designed to recover water for the environment (MDBA 2011b). As at 31 March 2012, 1,344 GL/year of environmental water had been recovered (MDBA 2012b) from over users, illegal users and the rectification of inadequate technologies in irrigation systems and other areas since 2009. Compared to this, the mining, other industries and domestic use sectors in fact use comparatively little water.

Nevertheless, water is used for domestic purposes across the Basin, and to supply the city of Adelaide and regional South Australia, the city of Lithgow and the Blue Mountains in NSW, the city of Canberra and the ACT, and settlements in southern Victoria outside of it. This extra-territorial requirement is a significant extra burden on the river and its tributaries. They are also used for recreational activities and as tourist attractions, and cultural use of the water resources by indigenous communities is also important - people, land and rivers are culturally connected (Arthur 2010). Thus, the environmental and cultural health of the Basin is important to many different users.

Finally, all communities in the Basin have now been registered under the National Water Initiative in relation to the statutory provision of water for the environment (MDBA 2017). Water entitlements of this type are held by governments on behalf of the environment, and used by communities to fulfil their specific environmental objectives. This process is typically informed by community advice (NWC 2011). 


\section{Malcolm Cooper}

Table 4.1 Murray-Darling Basin long-term annual inflow and water use.

\begin{tabular}{lrr}
\hline Surface-water & Gigaliters & $\%$ \\
\hline Inflows & & \\
Inflows to the Basin & 31,599 & 97.1 \\
Transfer into the Basin & 954 & 2.9 \\
Total & 32,553 & 100.0 \\
Water use & 10,903 & 33.5 \\
Watercourse diversions & 2,720 & 8.3 \\
Interceptions & 13,788 & 42.4 \\
Water used by the & & 15.8 \\
$\quad$ environment and losses & 5,142 & 100.0 \\
Outflows from the Basin & 32,553 & \\
Total &
\end{tabular}

Source: MDBA 2011c

\section{Governance, plans and reality}

This discussion has shown that there has been significant progress towards better water sharing and management in the Murray-Darling Basin in recent years; however, the fundamental issue of too much water being removed remains. The event known as the Millennium Drought, which occurred from the late 1990s to 2010 across much of the catchment, further exposed the weaknesses in Basin water management, and highlighted the need for continuing reform. In response, the Federal Government announced a $\$ 10$ billion plan to improve water efficiency and address the over-allocation of water in rural Australia, and passed the Water Act 2007. Under this legislation, the MDBA was required to formulate a Basin-wide plan. The 2007 Water Act was designed to:

(a) Allow the Australian Federal Government and the Basin States to manage area water resources in the national interest;

(b) Give effect to relevant international agreements such as RAMSAR;

(c) Regulate the use and management of the Basin water resources in a way that optimizes economic, social and environmental outcomes; and

(d) Without limiting (b) or (c), (i) ensure a return to environmentally sustainable levels of extraction for water resources that are over-allocated or over-used, and (ii) protect, restore and provide for the ecological values and ecosystem services of the Murray-Darling Basin (MDBA 2017).

Of course, any plan resulting from the provisions of the Act would have to be designed to maximize the net economic returns to the Australian community from the use and management of Basin water resources, improve water security, ensure that the management of water resources is cost-effective and consider the broader management of the natural resources in the Murray-Darling Basin. So, we are entitled to ask the following question. 


\section{A controversial water policy or an adaptive plan?}

A synopsis of the draft Basin Plan was released in 2010. Unfortunately, this was based on continuing the historically strong allegiance of the Australian governance system to State and individual "rights" to access water. This continuing rights-based approach made the proposed Basin Plan one of the most controversial pieces of public policy in recent times; as competing viewpoints from irrigators and environmentalists were at the forefront of the debate (MDBA 2017). In addition, South Australia insisted strongly on more environmental flows (to keep the Coorong open to the sea was one reason) and drinking water for Adelaide, while NSW and Victoria stressed that there should be more water for irrigation.

The Plan was put on public exhibition from November 2011 to May 2012. The MDBA consulted with all the stakeholders during this period. One of the key changes to the usual pattern of consultation was the hardwiring of local communities into the planning process, something not often done in major projects in Australia (Cooper and Flehr 2007). In all, over 11,000 submissions were made. After considering these, the MDBA incorporated more than 300 changes in the draft Plan (MDBA 2017).

Many of the proposed actions in the Basin Plan were thus reached through collaboration, so while the main protagonists considered it to be controversial initially, there is no doubt that the process adopted for its preparation contributed enormously to the reform of water management in the Basin, and provided the required platform on which to build integrated water management from the Basin community point of view, going forward. The draft Basin Plan was adopted on 22 November 2012, and, on 29 November 2012, was passed into law. Adaptation is required throughout the implementation of the Plan during the initial period 2012 to 2019; the MDBA continues to fine-tune its policies and requirements based on research, the experience gained from its progressive implementation and on feedback from stakeholders.

\section{Communities as stakeholders in the Basin}

The communities dependent on Basin water resources include the 1.3 million people living outside the catchment, as well as the more than 2 million people within it (ABS 2009). There are 400+ urban centers, towns and rural localities spread across the Basin, and $78 \%$ of the population live in these, with the rest living in rural areas (ABS 2009). The urban areas use water for domestic purposes, while local authorities use it to maintain recreational facilities. All the 60,000 agricultural businesses in the Basin are directly reliant on the available water resources: about 18,000 use it for irrigating their crops (ABS 2006), and the industries based on agriculture also use water. Mining and manufacturing companies also depend on access to Basin water resources. In addition, about 430,000 people make more than 5 million recreational fishing trips a year in or to the region, generating an estimated AUD1.35 billion (DPI 2011), while there are also large numbers of tourists moving through the Basin at any one 


\section{Malcolm Cooper}

time. Strangely, the overseers of water management in the Basin consider recreational and touristic use of water to be generally non-consumptive, with only minor impact on the ecological and resource health of the rivers and wetlands. So, while the water needs of the 16 RAMSAR-listed wetlands are taken care of in the allocation of this resource for environmental reasons, and because they are also significant tourist destinations, the consumption of water by temporary visitors to the communities along the river is not.

In agriculture, farmers have had to manage their water input costs to remain competitive, while at the same time increasing their productivity. For example, water usage by the dairy industry dropped by $64.4 \%$ between $2005-2006$ and 2007-2008 (drought years), but the value of production declined by just $26.5 \%$ (MDBA 2011a). Here, the development of real-time water trading markets has been important to the ability of irrigated agriculture to adjust to the seasonal variations in water availability (MDBA 2011a).

\section{Tourism, recreation and sustainability}

The close association between rivers and human settlements has often left a rich social and cultural heritage that in recent times has generated significant tourist interest in river valleys, while the rivers themselves act as a major tourist attraction (Erfurt-Cooper 2009; Prideaux and Lohman 2009). In its broadest sense, the attraction of a river includes both natural areas and a built element that has resulted in human cultural landscapes. Both the built and natural elements have been subject to tourism-induced redevelopment to enhance their ability to generate a net economic return. This growing interest in tourism has introduced a new element into the estimation of a river's economic and social worth.

While the consideration of cultural and social heritage resources as products for tourism consumption is relatively new in the literature (Ho and McKercher 2004), their adaptation in respect of river heritage at least in the Basin river context can be traced back to the 1960s, when the river port town of Swan Hill first opened a 'Folk and Pioneers Settlement' museum on the banks of the river in 1963 (Davidson and Spearritt 2000; Prideaux 2009). Because of this development, it is now easier to argue the case for the preservation of the natural and built elements of the Murray-Darling environment than was the case in the past (Prideaux and Timothy 2008).

\section{The Murray-Darling's heritage}

Both natural and built aspects of heritage occupy important positions in the Basin's heritage appeal. The earliest settlement of the area can be traced back to c. 50,000BP, when the forefathers of Australia's aboriginal people first settled in the region (Murray-Darling Commission 2008). While several of the 10,000 or so sites identified to date have been listed on the National Estate registrar of important sites, many have not, and the only knowledge of their whereabouts resides with traditional owners (Taylor and Biddle 2004). One of the most significant 
Aboriginal sites is Lake Mungo where evidence of occupation has been found dating back 40,000 -BP. Throughout the following 40,000 years until the time that the basin was settled by Europeans, the river dominated aboriginal life, yielding food as well as being central to their beliefs and culture.

European settlement occurred when the Basin's extensive rangelands were opened for cattle and sheep production in the early 1800s. Numerous towns were established to support these rural industries, and from the 1850s to support the gold mining industry. The associated development of the Murray-Darling as a major internal transport route made a significant contribution to the development of the region (though not to the ocean, as it does not empty into a harbor in South Australia). Later, the construction of irrigation systems resulted in a third wave of development based on irrigation agriculture. The changes to the landscape that occurred through the growth of pastoralism and other forms of agriculture, as well as mining, have created a rich mosaic of built heritage that has become an important riverine tourism resource in the 21 st century.

Aside from this built heritage, the basin contains a wide variety of natural heritage (Prideaux 2009). These areas, particularly the Alpine region have become popular recreational areas and support a number of national parks. In Victoria, Parks Victoria has established several parks near the Murray River organized into three designated Reserves: Mildura to Robinvale, Headwaters to Echuca and Echuca to Robinvale (Parks Victoria 2008). Such heritage sites have a commercial value and one of them, the inland Port of Echuca, highlights the issues associated with river heritage. While the value of these sites can be measured from several perspectives - as an attraction that provides employment, as an iconic experience that underpins the sustainability of local settlements, as an educational experience that connects present generations with the past, as an activity that has encouraged local participation and maximized local benefits (Swarbrooke 1999) and as a significant heritage site that preserves significant elements of the past - the heritage value of Echuca was not officially recognized for nearly 60 years after its on-river trade role effectively finished. The buildings that comprise the heritage precinct of the old Port survived because there was no other use for them or the land they were on, not as part of a conscious effort to preserve such heritage. After the decline of the use of the river as a transport medium, the relocation of the town's commercial center to the main highway spared this historic area from commercial redevelopment. However, recognition of its heritage value alone was not enough to preserve the site in its entirety; the sensitive refurbishment of the buildings in the precinct to suite their current use as tourism attractions was what enhanced their claim for preservation.

Another lesson that can be drawn from the Port of Echuca example for our discussion of the social importance of rivers is that heritage precincts can operate without major public subsidies for running and maintenance costs, provided that adaptive reuse of original buildings is allowed, and that the precinct is managed from the outset as an enterprise that is given the task of running on commercial lines within the parameters imposed on it by its heritage status. The purposeful creation of a tourism product managed in a way that it can be consumed by 
visitors may be criticized because authenticity is lost as commodification becomes the dominate driver; however, as Prideaux and Lohman (2009) note, the development of a cultural tourism product that offers a satisfactory tourism experience while retaining its cultural heritage value can be achieved. Without attractions such as a paddle steamer ride on the river and the opportunity to shop and eat at a variety of outlets, restored buildings, even with museum-standard interpretation and a claim of historical significance, are unlikely to excite a high level of visitor interest and support. From a wider perspective, the development of the Port of Echuca supports the case for the development of river heritage sites that offer celebration of the past in a contemporary context, rather than as heritage that offers interpretation but neglects to offer activity. It is through offering life and activity that community-supported heritage attractions are able to avoid the fate of heritage attractions that have failed.

\section{Conclusions}

The Murray-Darling Basin catchment covers five States and the Australian Capital Territory. These entities are responsible for managing the water resources of the catchment under the Australian Constitution. An initial attempt at joint basin governance was the River Murray Commission, established in 1917 (Pigram 2007). However, under the resulting River Murray Waters Agreement, which did not include Queensland even though this State contains 25\% of the catchment, the Commission was an advisory body only, and had no power to enforce any of the agreement's provisions. For most of its life this entity was concerned with the maintenance of water quantity, until quality in the form of raised levels of salinity became a problem and provoked reform of its responsibilities in 1982 (Pigram 2007). These minor reforms did however lead to further discussion on the need for an integrated management plan for the Basin.

A new Basin Agreement was adopted in 1985, but it was not until 1993 that it gained full legal status (Pigram 2007). Several new organizations and policies were created under the resulting Murray-Darling Basin Initiative. These included a Ministerial Council, the Murray-Darling Basin Commission and, ultimately, the plans discussed in this chapter. Entering into force in March 2013, the Plan is the official response to the problems faced by the MDBA, and is designed to secure the long-term ecological health of the Basin as distinct from trying to guarantee the absolute quantity of water as before. It is legally enforceable, and is based, for the first time, on reducing water allocations for agriculture, industry and households, and increasing environmental flows (Thomsen 2010), while improving water security in the future for all users (Guest 2017). It is also designed to minimize social and economic impacts while achieving its environmental outcomes.

The processes and outcomes described in this chapter provide a useful case study for the understanding of the difficulties often found when trying to understand the environmental and social uses of rivers. While the Basin Plan is a positive step towards implementing the types of measures needed to ensure the ecological sustainability of the Murray-Darling River, it unfortunately can do little about 
the drought risk (the River Murray has dried up twice since records began). The development of indicators for the health of the system found that the Basinwide Environmental Water Requirement benchmark requires that a reduction in user-allocations of some 7,600 GL per year be implemented, so that the river system will retain its ecological health. However, objectors cite the socio-economic impacts of major cutbacks to wide-scale farming (and in some areas vineyards) that will occur in the Basin if this requirement is implemented.

The conclusion must then be that no amount of careful planning and policymaking in a water catchment (even one as large and as important as the Murray-Darling Basin) can succeed without the ability for coercion (with incentives) when the time comes for implementation. The fallback position thus remains the same as it always has been; introduce more water into the system from other sources such as rivers in wetter parts of the country (McKenzie 2017) or desalination plants (to cover South Australia's needs), in lieu of achieving a better balance between available water and water demand within the catchment (Cooper 2017).

\section{References}

ABS. 2006. Census of Population and Housing 2006. Canberra: Australian Bureau of Statistics.

ABS. 2009. Experimental Estimates of the Gross Value of Irrigated Agriculture Production, 2000-01 to 2006-06. Canberra: Australian Bureau of Statistics.

Arthur, W. S. 2010. The Murray - Darling Basin Regional and Basin Plans: Indigenous Water and Land Data. Report to the Murray - Darling Basin Authority. Canberra: MDBA.

Boulton, A. 1999. "Why Variable Flows Are Needed for Invertebrates of Semi-Arid Rivers." In A Free-Flowing River: The Ecology of the Paroo River, edited by R. T. Kingsford, 113-128. Hurstville, NSW: NSW National Parks and Wildlife Service.

Bowen, S., and Simpson, S. 2009. Changes in Extent and Condition of the Vegetation Communities of the Macquarie Marshes Floodplain 1991-2008. Sydney: NSW Department of Environment, Climate Change and Water.

Cooper, M. 2017. River Tourism. Chapter 14 this volume.

Cooper, M., and Flehr, M. 2007. Government Intervention in Tourism Development: The Case of Japan and South Australia. Tourism and Land Development: A Special Issue of Current Issues in Tourism 9(1): 69-85.

Cooper, M., Kato, H., and Nakagami, K. 2016. Participatory Approaches to Environmental Management: Future Design for Water Resources Management. In Sustainable Water Management: New Perspectives, Design, and Practices, edited by K. Nakagami, J. Kubota, and B. I. Setiawan. Berlin: Springer.

Crabb, P. 1997. Murray - Darling Basin Resources. Canberra: Murray - Darling Basin Commission.

CSIRO. 2008. Water Availability in the Murray: A Report to the Australian Government From the CSIRO Murray - Darling Basin Sustainable Yields Project, Whole of Basin Report. Canberra: CSIRO.

CSIRO. 2010a. Climate Variability and Change in South-Eastern Australia: A Synthesis of Findings From Phase 1 of the South Eastern Australian Climate Initiative (SEACI). Canberra: CSIRO. 
CSIRO. 2010b. Dryland Diffuse Groundwater Recharge Modeling Across the Murray - Darling Basin. Canberra: CSIRO.

CSIRO. 2012. Assessment of the Ecological and Economic Benefits of Environmental Water in the Murray - Darling Basin. Canberra: CSIRO.

Davidson, J., and Spearritt, P. 2000. Holiday Business: Tourism in Australia Since 1870. Carlton, VIC: Miegunyal Press.

Davies, P. E., Harris, J. H., Hillman, T. J., and Walker, K. F. 2008. Sustainable Rivers Audit Report 1: A Report on the Ecological Health of Rivers in the Murray - Darling Basin, 2004-2007. Report prepared by the Independent Sustainable Rivers Audit Group for the Murray - Darling Basin Ministerial Council. Canberra: Murray - Darling Basin Commission.

DPI. 2011. Economic Contribution of Recreational Fishing in the Murray - Darling Basin. Report prepared by Ernst \& Young for the Department of Primary Industries. Melbourne: Ernst \& Young.

Erfurt-Cooper, P. 2009. "European Waterways as a Source of Leisure and Recreation." In River Tourism, edited by B. Prideaux and M. Cooper, 95-116. Wallingford, UK: CABI.

Guest, C. 2017. Sharing the Water - 100 Years of Politics. Canberra: MDBA.

Ho, P. S. Y., and McKercher, B. 2004. "Managing Heritage Resources as Tourism Products." Asia Pacific Journal of Tourism Research 9(3): 255-266.

Kingsford, R. T. 2000. "Ecological Impacts of Dams, Water Diversions, and River Management on Floodplain Wetlands in Australia." Australian Ecology 25: 109-127.

Kingsford, R. T., and Auld, K. 2005. "Waterbird Breeding and Environmental Flow Management in the Macquarie Marshes, Arid Australia." River Research and Applications 21: 187-200.

Kingsford, R. T., Curtin, A. L., and Porter, J. 1999. "Water Flows on Cooper Creek in Arid Australia Determine 'boom' and 'bust' Periods for Waterbirds." Biological Conservation 88: 231-248.

Kingsford, R. T., and Johnson, W. J. 1998. "Impact of Water Diversions on ColoniallyNesting Waterbirds in the Macquarie Marshes of Arid Australia." Colonial Waterbirds 21(2): 159-170.

Kingsford, R. T., and Thomas, R. F. 1995. "The Macquarie Marshes in Arid Australia and Their Waterbirds: A 50-Year History of Decline." Environmental Management 19(6): 867-878.

Kingsford, R. T., and Thomas, R. F. 2004. "Destruction of Wetlands and Waterbird Populations by Dams and Irrigation on the Murrumbidgee River in Arid Australia." Environmental Management 34(3): 383-396.

Lintermans, M. 2007. Fishes of the Murray - Darling Basin: An Introductory Guide. Canberra: Murray - Darling Basin Commission.

Mckenzie, R. 2017. "Rivers and Communities: Can We Drought Proof a Catchment and an Entire Country?" Chapter 3 this volume.

MDBA. 2010a. Guide to the Proposed Basin Plan, Overview, Appendix C. Canberra: MurrayDarling Basin Authority.

MDBA. 2010b. Guide to the Proposed Basin Plan, Technical Background. Canberra: Murray Darling Basin Authority.

MDBA. 2011a. Socioeconomic Analysis and the Draft Basin Plan, Part A - Overview and Analysis. Canberra: Murray - Darling Basin Authority.

MDBA. 2011b. The Living Murray Story - One of Australia's Largest River Restoration Projects. MDBA publication number: 157/11. Canberra: Murray - Darling Basin Authority. 
MDBA. 2011c. Water Resource Assessments for Without-Development and Baseline Conditions, Supporting Information for the Proposed Basin Plan. Murray - Darling Basin Authority Technical Report 2010/20 Version 2, November. Canberra: Murray - Darling Basin Authority.

MDBA. 2012a. The Proposed Groundwater Baseline and Sustainable Diversion Limits: Methods Report. MDBA publication no: 16/12. Canberra: Murray - Darling Basin Authority. MDBA. 2012b. Murray-Darling Basin Authority. www.mdba.gov.au/.

MDBA. 2017. Towards a Healthy, Working Murray-Darling Basin. Canberra: Murray - Darling Basin Authority.

MDC. 2008. Annual Report 2007-2008. Canberra: Murray-Darling Commission.

National Water Commission. 2011. The National Water Initiative - Securing Australia's Water Future: 2011 Assessment. Canberra: NWC.

Parks Victoria. 2008. Annual Report 2008-2009. Melbourne: Parks Victoria.

Pigram, J. J. 2007. Australia's Water Resources: From Use to Management. Collingwood, VIC: CSIRO.

Prideaux, B. 2009. "River Heritage: The Murray - Darling River." In River Tourism, edited by B. Prideaux and M. Cooper. Wallingford, UK: CAB International.

Prideaux, B., and Lohmann, G. 2009. "The Amazon: A River Tourism Frontier." In River Tourism, edited by B. Prideaux and M. Cooper, 147-164. Wallingford, UK: CAB International.

Prideaux, B., and Timothy, D. J. 2008. "Themes in Cultural and Heritage Tourism in the Asia Pacific Region." In Cultural and Heritage Tourism in Asia and the Pacific, edited by B. R. Prideaux, D. J. Timothy, and K. Chon, 1-14. London: Taylor \& Francis.

Roderick, M. L., and Farquhar, G. D. 2011. "A Simple Framework for Relating Variations in Runoff to Variations in Climatic Conditions and Catchment Properties." Water Resources Research 47: W00G07. DOI:10.1029/2010WR009826

Swarbrooke, J. 1999. Sustainable Tourism Management. Wallingford, UK: CAB International.

Taylor, J., and Biddle, N. 2004. Indigenous People in the Murray-Darling Basin: A Statistical Profile. Discussion Paper 264/2004. Canberra: ANU Centre for Aboriginal Economic Policy Research.

Thomsen, J. 2010. MDBA Chair Explains Water Allocation Cuts. ABC Goulburn-Murray, 12 October. Canberra: Australian Broadcasting Corporation.

Tomlinson, M. 2011. Ecological Water Requirements of Groundwater Systems: A Knowledge and Policy Review. Waterlines Report Series 68. Canberra: National Water Commission.

Waldron, T. 2008. "Expertise in Water Loss Control Applied to Extreme Problems of Water Distribution Management." Water Science and Technology: Water Supply 8(1): 107-112. DOI:10.2166/ws.2008.031 


\title{
5 Life, identity and work in an arid river basin
}

\author{
The case of the Zayandeh-Rud \\ (life-giving river) in central Iran
}

\author{
Kazem Vafadari Mehrizi
}

\section{Introduction}

The Zayandeh-Rud is the most important water body in Central Iran, providing water for around 4.5 million people (Figure 5.1). The river originates in Chaharmahal-va-Bakhtiari province in the Zagros Mountains, at an altitude of about 2,300 meters (Tabatabaei 2011). On its nearly $400 \mathrm{~km}$ course, the river flows through four provinces, across semi-arid and arid areas, and its catchment includes many different climatic and ecological conditions within a total area of only 42,000 $\mathrm{km}^{2}$ (Tabatabaei 2011). These micro environments directly influence not only water availability but also the forms of water use encountered. On its course, the river passes by the important city of Esfahan, whose historical buildings have been declared as world heritage by UNESCO, and finally flows into the Gavkhouni salt-lake, a marshland internationally acknowledged by the Ramsar Convention in 1975 as RAMSAR Site 53 (IUCN 1985), and an important way-point for bird migration.

Climate changes in the region, and with them longer extreme dry periods, have led to a considerable decrease in water availability during the last few years (IUCN 1985; Molle, Ghazi and Murray-Rust 2009). At the same time, water management in the catchment is characterized by conflicting interests that have been exacerbated by fast population growth and industrial development. Drinking water suppliers, large industrial settlements and the agricultural sector which depends on irrigation all have a high demand for water. A strategy for balanced and sustainable water management to react adequately and flexibly to the different needs and extreme climatic changes is however missing. Consequently, the yearly deficit between supply and demand is increasing rapidly, and too little water - which is, moreover, of bad quality - reaches the Gavkhouni area (Sahardi and Soltani 2013). In recent years, citizens of both Yazd and Esfahan have seen river beds dry out on several occasions, and even water allocation for irrigation purposes has had to be cut. The social, economic and ecological effects are already dramatic.

In the past, user communities have developed robust means of sharing what water there is through qanats (human-made underground galleries that drain those aquifers that exist at a distance), collecting intermittent stream flows and using the river flows. Yet, basin closure - a state where all resources are fully committed and where water only reaches the terminus of the basin in exceptional 


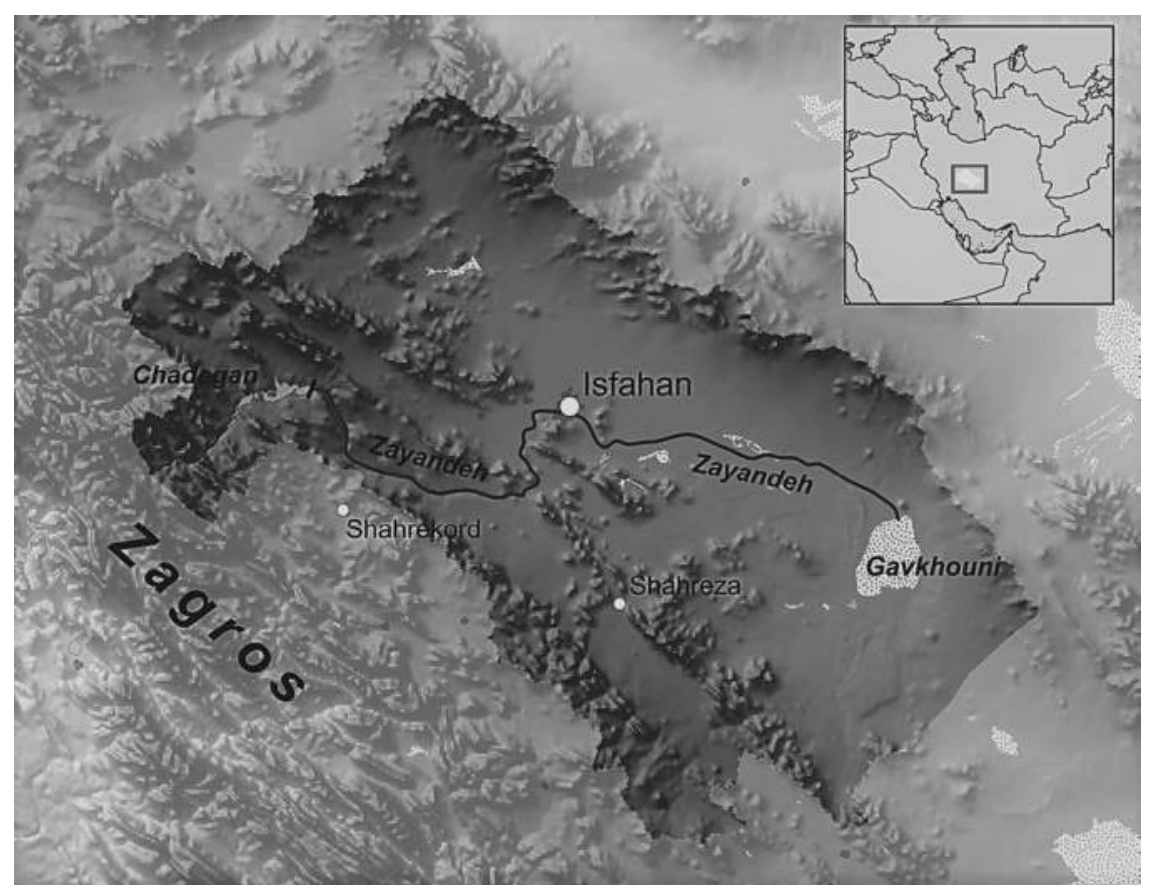

Figure 5.1 Map of the Zayandeh/Gavkhouni drainage basin.

Source: Zayandeh river map.png, K Musser 2013, CC BY-SA 3.0

years - coupled with the reshaping of waterscapes by large-scale state intervention, has made use of the river dependent on decisions taken at scales other than the local community (Molle, Ghazi and Murray-Rust 2009). Competition for resources and basin closure generate increased hydrological interconnectedness between users, but also potential conflict between community needs and water management regimes. This chapter describes the physical and human settings of the Zayandeh Rud, and then reflects on the hydrological, social and institutional consequences of overuse of the water resources of the river basin. The Zayandeh Rud basin provides a vivid account of an oasis buying respite by implementing successive water imports from neighboring basins. It also offers a textbook illustration of both the process of continuing river basin overbuilding and its consequences.

\section{The geophysical and climatic background}

\section{General geology}

The geology of the basin is very diverse; the oldest formations are metamorphosed sedimentary rocks that are widespread in the West and South West of 
the catchment (Precambrian-Cambrian; Aghanabati 2003), and include marbles and quartzite. The next major sequence is the Early Paleozoic-Paleozoic formations of limestone and dolomite found in the highlands of Meymeh East, Zaygvn Lalun and the central Alborz area. These also include shale and sandstone, and fossils from the Silurian and Carboniferous eras. Triassic and Jurassic formations are more widespread. Of these, the Shemshak Formation, widely used for building stone, consists of thick greenish gray shale and sandstone that contains marine fossils. Jurassic rocks in the West Highlands and North West of Najaf Abad have been altered by the intrusion of granite, and similar volcanic intrusions (andesite) are also seen in the later Cenozoic-Eocene period, with two outcrops of mixed volcanic and sedimentary deposits in the highlands of West and South West Najaf Abad. Sandy limestone and plaster outcrops (the Bakhtiari conglomerate), along with Eocene basalt occur in the South and West (Aghanabati 2003).

Quaternary sediments of sand are found in the Segzi Foothills, and northern Central Plains and West Plains, while the Gavkhouni wetland area is built on deposits of chalk and salt. Evaporite deposits of gypsum and salt are found in a broadband around this marshland, and old river bed sediments up to 200 meters deep are common in this area (Dardasht Segzi; Aghanabati 2003).

\section{Geological formations and their characteristics in terms of quantitative and qualitative effects on water in the river basin}

The oldest metamorphic rocks contribute little to groundwater, due to a lack of porosity and permeability in relation to aquifer recharge (Aghanabati 2003). The main charge into the river system in these areas is from snow and rain-fed runoff on the surface in the north and west of the basin; but where the Cretaceous limestone and alluvial formations that are found in the north and south of the basin exist, they have the potential to feed in groundwater (in the Najaf Abad, Lenjanat, and Dardasht areas; Figure 5.1). However, the existence of aquifers and other storages for water in these formations is complicated by the tectonic faults in the basin.

There are several faults in the area parallel to each other. This valley, like most of the Central Plains of Iran and the Alborz Mountains is affected by tectonic activities within a Horst and Graben regime, leading to the breakage of cretaceous limestone floors, and consequently disruptions to the extent and capacity of the aquifers within it. Thus, small springs feeding ephemeral watercourses and the Qanat system in the hills, and those found in some parts of the plain, are the primary sources of the groundwater that is available, though a full-scale analysis of storage and feeders has yet to be carried out (Aghanabati 2003).

\section{The regional climate}

The province of Chaharmahal Bakhtiari has a special geophysical and hydrological position in terms of the supply of water to the river basin, given its diversity of topography (Masih et al. 2011). The western Zagros Mountains create diverse 
climatic conditions where low-pressure systems originating from the Mediterranean, North Atlantic and Black Sea are the primary source of precipitation in the area, and are a key catchment area for rainfall in the river basin. A study of precipitation in the province shows that in the wettest part, the northwestern highlands, rainfall peaks of over 1,600 mm a year are experienced; much of this falling as snow. The second core area for rain, the Sabzkouh Highlands province to the north, receives about $1200 \mathrm{~mm}$ per year. In the remainder of the catchment though, there is very little rainfall. In the northeast part of the province the average amount of rainfall is between 250 and $300 \mathrm{~mm}$ (Tabatabaei 2011). Here, the wet season is in winter: about $52 \%$ of all precipitation falls during this time as snow. Precipitation in the region usually starts from October and continues until May. The total number of rainy and/or snowy days during the year is usually around 66. Snow fall occurs above 2500 to $3000 \mathrm{~m}$, and annually varies between 5 to 10 meters. A height of over 3,500 meters in the province generally has constant snow cover. Overall, about $40 \%$ of rainfall falls in the 2000- to 2500 -meter height band throughout the northwestern mountainous area.

Affecting the retention of this water are the temperature regimes. In terms of temperature, the highlands generally experience between $3-16^{\circ} \mathrm{C}$, while the central lowlands experience $32-45^{\circ} \mathrm{C}$ during the day across the year. The average annual relative humidity is about $47 \%$. This low humidity means that for some 7 months of the year rainfall exceeds potential evapotranspiration. However, for the remaining 5 months of the year there is an absolute water shortage. Studies analyzing the amount of annual evaporation show an amount of evaporation at high altitudes in the Northwest of about 1,000 mm, and 2,200 mm in the province of Chaharmahal Bakhtiari (Tabatabaei 2011). In general, there is a gradient from West to East and from North to South, where evaporation in the province increases.

In Chaharmahal Bakhtiari province, as in most parts of the north of Iran, the sky is cloudy in winter. This area of the river basin has a cold climate with warm and dry summers, while the rest of the basin has a semi-arid to arid climate, with hot summers and warm winters. This climatic regime also impacts on water resources in another way - Iran's major forestry reserves are found in this province (almost 1.4 million hectares), along with 307,000 ha of pasture land. Pasture land uses water intensively and has the potential to degrade landscapes once forest cover is removed, but the remaining forest cover does reduce this tendency, helping to collect water in the wetter parts of the basin.

\section{Water resources}

It follows from the above discussion that the main source of water in the Zayandeh Rud catchment is rainfall in the Northwest during fall and winter, which is a Mediterranean precipitation regime. Less than $7 \%$ of annual precipitation occurs in the dry season from mid-May to early October. In addition to this regular rainfall there can be some rain at a local level throughout the year. In terms of the volume of rainfall, the distribution of annual precipitation in the branches of 


\section{Kazem Vafadari Mehrizi}

Zayandeh Rud (West Zayandeh Rud and east Zayandeh Rud sub-basins), are thus very different. Sometimes there is up to $2,600 \mathrm{~mm}$ in the west, while there is less than $45 \mathrm{~mm}$ in parts of the east. On top of these annual and local regimes there is a drought cycle of 4 to 5 years, and a 6 -year wet period. The highest discharge is in May, and the lowest in the period from mid-January to mid-March. The decrease in the discharge in winter is due to the snow-rain regime of the river (i.e. snowmelt provides much of the river's water), and the Zayandeh Rud (Chadagan) Dam operation protocol. The dam is closed in winter to gather enough water for spring and summer (Tabatabaei 2011). In terms of the flows in the river, in the 1970s, the flow was estimated at 1.2 cubic kilometers $(0.29 \mathrm{cu} \mathrm{mi})$ per annum, or 38 cubic meters $(1,340 \mathrm{cu} \mathrm{ft})$ per second all year round, but now it often runs dry before reaching the city of Esfahan due to excessive water extraction. In the early 2010s, the lower reaches of the river dried out completely after several years of seasonal dry-outs (Assari and Assari 2012).

Despite the fracturing of the aquifers mentioned earlier, groundwater resources do form a major source of water supply in the river basin. These can make up almost $78 \%$ of the water resources for various sectors of activity and various locations, though they are increasingly compromised due to a lack of awareness of the need to cease over-exploitation, and control inappropriate and indiscriminate harvesting. In general, groundwater levels are dropping throughout the basin (1-2 meters in recent years); so much so that in the local plains (subsidiary river valleys) resources are often at such a critical level that further exploitation is now being prohibited (Assari and Assari 2012). In terms of total supply related to consumption, groundwater resources, including wells, canals and springs in the Esfahan area for example (Figure 5.1) include a total of about 7,603 wells, 2,104 qanats and 1,758 subterranean springs, out of a total of 15,700 wells, 2,776 qanats and 2,732 springs in the whole of the river basin (Esfahan Regional Water Board 2014a). These Esfahan-based sources produce about 231, 856 and 643 million cubic meters $\left(\mathrm{m}^{3}\right)$ of water per year respectively, and at the basin level such sources produce 824, 1,344 and 4,506 million cubic meters respectively (Esfahan Regional Water Board 2014b). These geological and climatic environments mean that the exploitable volume of surface water in the basin is equivalent to 1,500 million $\mathrm{m}^{3}$, or about $7 \%$ of the country's surface water, but this is mainly confined to the course of the Zayandeh Rud as the only perennial stream. Along with the groundwater sources just described, this gives a per capita water availability in Esfahan Province for example of only 1,450 $\mathrm{m}^{3}$ compared with 2,150 $\mathrm{m}^{3}$ on a world-wide basis (67\% of the global availability; Nasri and Modarres 2009).

\section{The Gavkhouni wetland}

This wetland is $140 \mathrm{~km}$ Southeast of Esfahan, and $30 \mathrm{~km}$ from Varzaneh City (the nearest town), at the end of the Zayandeh-Rud River but within its catchment (Figure 5.1). It lies $1,470 \mathrm{~m}$ above sea level; its maximum width is about $50 \mathrm{~km}$, and its maximum length is $25 \mathrm{~km}$. The water depth in most parts is about one meter, but this varies with water input throughout the year. Its area 
is about 47,000 ha, which also varies with water input to the wetland, so that its area increases in wet and humid seasons, but considerably decreases in summer due to lower inflow as well as a higher evaporation rate (Soltani and Sarhadi 2011). The mean day temperature of the wetland varies from 1.8 to $28.9^{\circ} \mathrm{C}$ throughout the year, and the minimum and maximum average temperature of the wetland is $-6.6^{\circ} \mathrm{C}$ and $37.4^{\circ} \mathrm{C}$, respectively. Its temperature in 5 months of the year is above $20^{\circ} \mathrm{C}$ and in another 5 months is below $10^{\circ} \mathrm{C}$. The average annual rainfall is about $83 \mathrm{~mm}$, whereas the annual evaporation rate in the area is estimated at 3,000 to $3,200 \mathrm{~mm}$; a situation that means that the river must provide the environmental flows crucial for the environmental sustainability of the wetlands.

Located in the arid region of central Iran, the Gavkhouni wetland is one of the most important aquatic ecosystems of this region, and was registered under the Ramsar Convention in 1975 as an important wetland (www.ramsar.org; Sahardi and Soltani 2013). It is one of 1,220 wetlands registered under this convention, of which 22 are found in Iran. The wetland is a salt marsh with a salinity of $315 \%$, and an average depth of about $1 \mathrm{~m}$. It can dry up in summer. To keep its ecological balance, the lake needs an estimated $70 \mathrm{~m}^{3}$ minimal inflow per hectare of its surface. Over recent years, however, less than half of this amount of water has been available. Moreover, the surface water quality in the catchment has been decreasing rapidly (Hekmatpanah, Nasri and Sardu 2012; Tabatabaei 2011).

Today, a major problem of many domestic wetlands in Iran is the significant increase in pollution that is mostly associated with agricultural and industrial activities. Agricultural and industrial wastewater is discharged into wetlands, which endangers the ecologic environment of the region, and reduces the biodiversity of the area. Majnunian (1998) stated that the Gavkhouni wetland, with its living species and the human communities living adjacent to it form an integrated system whose life and survival is dependent on the river, and is being destroyed by the pollution now sent into it (Esmaili Sari 2003). Hekmatpanah et al. (2012) argue that heavy metals are one of the most important pollutants that are either naturally present in the water or get into the water through municipal, industrial and agricultural waste discharge. Since the flow of water slows down in the wetland, heavy metals accumulate in the soil, plants and aquatic species, and eventually finding their way into the human food chain. This process ultimately endangers both human health and the environment and, in the long run, can reduce the population size and diversity of plans and animals.

The Gavkhouni wetland thus has an important role in the sustainable development of the catchment. From a conservation standpoint, it provides habitat for over 140 bird species and numerous other flora and fauna. Moreover, this ecosystem has had an effective role in water refinement and the stabilization of sand dunes located around the wetland. Unfortunately, recent population growth and inadequate water resources management in the rest of the catchment have resulted in a reduction in the quantity and quality of the wetland's incoming fresh water, and destruction of this ecosystem has begun (Hekmatpanah et al. 2012; Sahardi and Soltani 2013). The upstream diversions and other unreasonable 
in-basin transmission of water resources involved in population, agricultural and industrial growth, and the consequent reduced inflows downstream, have resulted in undesirable ecological effects on the wetland. Additionally, the influx of excessive partially treated industrial and domestic wastewater from Esfahan especially has influenced the wetland's water quality. All these problems have been intensified in recent years by the increasing frequency of drought occurrences arising from climate change (Modarres and da Silva 2007; Modarres and Sarhadi 2009; Assari and Assari 2012). These conditions have exerted adverse impacts on the wetland, and have changed the hydrologic regime of its ecosystem; so much so that parts of this natural ecosystem have been turned into a salt pan. No fauna and flora now exist in many parts of this wetland.

To restore this ecosystem and maintain it in a state of a good health is one of the most important tasks for the planning and development authorities in Iran at both National and Regional levels. To do this, the requirement inflow of the wetland must be calculated and then supplied. The problem with this realization is that because, except for some halophytes, no fauna and flora are found in those parts of the wetland now converted to salt pans, over much of the area there is no plan to redefine ecological water demand in terms of pre-existing biota water requirements (Sahardi and Soltani 2013). Nevertheless, this could be changed by using the existing historical hydro-meteorological dataset to estimate a threshold of inflow that could provide suitable wetness levels and healthy conditions for the ecosystem, and implementing measures to ensure that this happens.

\section{Water management}

In Esfahan Province, the location of the major settlements in the river catchment, the distribution of water followed the Tomar management system until the 1960s, a water distribution policy that dates from the 16th century (Beaumont 1974). The Tomar divided the flow of the Zayandeh River into 33 parts, which were then specifically allotted to the eight major districts within the region. At the district level the water flow was divided either on a time basis, or by variable weirs, so that the proportion could be maintained regardless of the height of the flow. At the settlement level, Esfahan City, now a metropolitan area containing some 2.4 million people, was a green oasis in the desert, noted for its surrounding fertile lands and prosperity supplied by the river. The main user of the available water resources is the agriculture sector. Until the 1960s, industrial and domestic demand for water was minimal, but with a growing population within the basin, and rising standards of living, particularly within the cities, the pressure on water resources steadily increased until the division of water using the Tomar was no longer feasible. The creation of large steel works and other new industries placed further demands on available water (Beaumont 1974; Zayandab Consulting Engineers 2008).

The Chadegan Reservoir dam project of 1972 was a major hydroelectric project designed to stabilize water flow and generate electricity. Since 1972, the Chadegan Reservoir has helped prevent seasonal flooding of the Zayandeh River, 
but has reduced environmental flows in the river. The result: water discharge from the reservoir is increased during the Persian New Year to allow the river to flow through Esfahan during that public holiday. Today, $80 \%$ of the Zayandeh Rud's extracted water is used for agriculture, $10 \%$ for human consumption (the drinking and domestic needs of a population of 4.5 million), 7\% for industry (like the Zobahan-e-Esfahan and Foolad Mobarekeh steel companies, and Esfahan's petrochemical refinery and power plants), and 3\% for other uses (Madani and Mariño 2009). To support these developments, tunnel projects (Koohrang) have been constructed to redirect water from the Karun river (Iran's largest river that also starts in the Zagros Mountains), to the Zayandeh Rud. These have helped provide water for the growing population and new industries in both Esfahan and Yazd provinces (Assari and Assari 2012).

In summary, while the recent drying-out of the lower reaches of the Zayandeh Rud has been attributed to drought, the main reasons are man-made. Poor planning and populist politics have led to years of mismanagement and overuse that have resulted in seasonal dry-outs and ultimately causing the river to dry out completely before reaching Esfahan (Assari and Assari 2012).

\section{Agriculture}

The greatest potential for a reduction of resource use (water and soil) in the Zayandeh Rud basin lies in agriculture. This sector uses around $83 \%$ of the water withdrawn for human use in the catchment, and the demand for agricultural land is still growing (Felmeden et al. 2014). Given its importance, the agricultural sector in the catchment particularly suffers from increasing drought periods, but massively over-uses the available water (Beaumont 1974; Felmeden et al. 2014). Within the Zayandeh Rud catchment there are three main types of farming: (1) agriculture, (2) livestock and (3) orchards, and different combinations of these types can be observed. Arable farming is the largest single farming type at about $19 \%$ of the total, and agriculture and orchards is the largest combination type at about $38 \%$ of all farms: $22 \%$ of all farms are located within the county of Esfahan.

The currently high demand for water from agriculture leads not only to problems for other water users, such as for drinking water or secondary industry, but also to a massive overuse of these resources. To place this in context, while the predicted growth in urban residential and commercial use is not expected to add greatly to the water resource problem; by 2025 a further increase of industrial activities, and with it a doubling of this sector's water demand, is likely (Assari and Assari 2012; Felmeden et al. 2014, 16). This will undoubtedly exacerbate conflicts over water in the basin.

To implement strategies for an economical and considerate exploitation of water resources in agriculture, the active participation of the affected farmers will be necessary. For this, research findings about the hydrological system need to be merged with agricultural transformation strategies to develop and evaluate practical measures for change. At the same time, however, the frequent dry periods in the catchment have led to resource scarcity. The decreasing water supply for 
irrigation has led to severe economic impacts as farmers have lost their crops several times in recent years, and this makes it difficult to finance any changes to less water-intensive products or to induce them to take further risks (Acreman et al. 2007). Thus, experts from different public authorities, universities, agricultural consultants and local communities have commented that overall reform of water use in the agricultural sector in the basin is necessary (Foltz 2002). This will need to involve the reduction, but also modernization, of agricultural production through the application of water-saving and more efficient irrigation technologies (Jamab Conductor Engineers 1978; Yang et al. 2009).

\section{Industry}

The conflicting interests of agriculture and industry have led to tension time and again in the river basin (Molle, Ghazi, and Murray-Rust 2009). While agriculture, a sector that has evolved over centuries, has often suffered from water shortages, the demand for water for industrial purposes has usually been met (Esfahan Regional Water Board 2014d). Some 30 large industrial companies account for approximately $75 \%$ of the total industrial water use in the basin of 200 million cubic meters, while the other 13,000 small and medium sized enterprises in industrial settlements are demanding a growing amount of water, and must therefore also be added to the ever-developing adverse water resource equation. It is estimated that industrial water demand in the catchment will increase from around 200 million $\mathrm{m}^{3}$ to between 350 and 450 million $\mathrm{m}^{3}$ within the next 20 years (Molle, Ghazi and Murray-Rust 2009). As with agriculture, to enable this level of development and to reduce the wider social tensions over water, more efficient use of the available water resources in industry is essential. Therefore, the assessment and analysis of adjusted planning approaches and methods for an efficient and environmental friendly development of industrial settlements is a central issue for the short to medium term future (Safavi, Golmohammadi, and Sandoval-Solis 2015).

The Zayandeh Rud River provides water to Iran's second largest industrial area: $50 \%$ of all steel produced in Iran stems from this region. Further industrial and commercial settlements are in the planning stage. This development, however, is jeopardized by the increasing water shortage. In terms of policy creation and implementation, Industrial Settlement Organizations (ISOs), subordinate entities of the Ministry of Energy, are, amongst others, responsible for reducing water consumption by industry at the national level. They lack, though, the conceptual base and experience for a coordinated, resource-efficient and environmentally friendly reorganization of the growing industrial settlements (Esfahan Regional Water Board 2014d). Specifically, the basin industrial settlement organization "Moorcheh khort," must be upgraded so that it can test and assess different options for reducing water consumption, and reusing wastewater. Research has shown that the best way to prepare a coordinated development plan for such organizations is to focus on water and wastewater following an "Eco-industrial Parks" concept (Safavi, Golmohammadi, and Sandoval-Solis 2015; Sayedipour, 
Ostad-Ali-Askari, and Shayannejad 2015). The bounded nature of such parks enables a water resource policy authority to build and control discrete area-based solutions; thus, for the production industries based in Moorcheh khort, fact sheets are being drawn up covering their water demand (quantity and quality) and waste water production. From these data, practical recommendations for the settlement of water resource efficient industries in the catchment may be derived.

\section{Urban use}

The Zayandeh Rud River provides support for the urban-based livelihoods of large areas of four central Iranian Provinces. For example, $80 \%$ of the drinking water for the city of Esfahan and its surrounding towns and villages are taken and purified in the higher reaches of the northwestern Zayandeh Rud. The city of Yazd (outside the Basin) also derives much of its water from the same sources. But, while sufficient water can presently be secured for urban use, the same cannot be said for environmental flows in the river basin, or for the safe treatment of the waste water from household and industrial uses. Household and industrial wastewater is treated in wastewater treatment plants of differing capacities and quality, and is flushed back into the river or used for irrigation (Sayedipour, Ostad-Ali-Askari, and Shayannejad 2015). In rural areas wastewater also ends up in the river, but in general it is only partly treated, and contributes to decreasing water quality.

Water consumption per day per person in towns in the Esfahan province has been estimated at 250 liters, and in rural areas it is only a little less (Esfahan Regional Water Board 2014b). Thus, against the backdrop of increasing water shortages and population growth, measures for reducing urban as well as agricultural water consumption are necessary. These should cover the efficiency and effectiveness of the existing physical collection and supply infrastructure, its renovation as and when necessary, the pricing of water, and the modernization of or construction of waste water treatment systems. In respect of the first of these, recent research based on the introduction of water meters showed that water losses in the reticulation system are around 30\%, quite low by international standards (generally between 25 and 40\%; Waldron 2004). Overall, a total water loss of $14 \%$ was identified, again not an unusual amount when compared to other countries (Waldron 2004). When the World Bank water system efficiency criteria, as expressed in the Infrastructure Leakage Index (ILI), are applied to the local distribution network in the river catchment, a value of 2.2 is obtained, which is also good (an ILI of 1.0 means a very good network). If the overall water stress in the Zayandeh Rud river basin is considered, these network conditions can be considered as "acceptable," according to the World Bank criteria, provided that remedial measures are taken to reduce water losses (Esfahan Regional Water Board 2014b).

Globally, urban household connections are generally the actual weak point in a river basin household water use context: despite a network length share of only $25 \%$ of the total in the Zayandeh Rud basin (industry and agricultural networks 
make up the rest), and made up of small pipes, the pipe break rate here is five to ten times higher than for larger supply pipes. The conclusion to be drawn from this is that most water losses occur in the last five meters of pipes in this system. Based on these results, short-, medium- and long-term measures to reduce water losses may be suggested. These measures should be applied to all urban areas, and would include pressure balancing, the installation of smart water meters and the replacement of suspect pipes (Waldron 2004).

\section{Water and wastewater pricing}

Water and wastewater prices have a direct impact on all economic activities, and should therefore be a key issue for both the future water management and economic situation of the Zayandeh Rud river basin. This crucial role is reflected in the recent introduction of "cost-effective prices" in the Iranian water industry. These new tariffs, however, only cover operational costs and not capital costs. To carry the introduction of real prices for water further, it is however possible to use this new tariff data to calculate shadow prices and conduct interviews with users. In this way, the impact of the new tariffs can support the determination of the willingness to pay of different water users, and allow the derivation of realistic demand curves for policy construction and implementation (Waldron 2004). A comparison of these derived demand curves with current tariffs will identify the expected impact on communities and their environments resulting from an improved pricing system.

Assessment of the willingness to pay is also able to point out the circumstances in which the introduction of new, water-efficient technologies would be economically reasonable. It is possible, for example, that at current prices a farmer would irrigate conventionally for financial reasons, while at cost-covering prices it would be rational to invest in water-efficient technologies. The resulting water savings could, for example, be used to produce additional products in other sectors of the economy that would generate higher added value from all activities, and provide water for environmental flows and the tourism based on these.

\section{Wastewater treatment}

The largest share of water in the Zayandeh Rud river basin is used for irrigating agricultural products. Due to increasing fresh water shortages, the reuse of treated wastewater for irrigation is becoming more and more important in Iran. This policy change, however, requires the appropriate treatment of wastewater to minimize health hazards for consumers and field hands. International experience has shown that the development of strategies for the introduction of non-hazardous agricultural wastewater reuse in the Zayandeh Rud catchment would go a long way in the short term to alleviate the water resource shortage (Acreman et al. 2007; Molle, Ghazi, and Murray-Rust 2009). However, aspects like the selection of appropriate irrigation methods and crops must be taken into consideration, as should the replacement of the currently illegal reuse of non-treated water by a 
reliable and safe process for treating that water and ensuring its quality at a reasonable price. While the technologies currently in place are not able to ensure sufficient quality standards, an additional and relatively low cost disinfection process such as UV radiation might be an adequate treatment level for agricultural users (Waldron 2004).

\section{The social and political environment - integrated water catchment management}

Throughout the world, the catchments of rivers, lakes and aquifers usually do not correspond with administrative borders: so it is not surprising that the Zayandeh Rud catchment itself stretches across four provinces as noted. Unfortunately, this has the effect that the necessary centralized organizational structures for river basin management at the Zayandeh Rud catchment level are missing. Neither vertical (national to local), nor horizontal (water using sectors) governance levels are endowed with the coordination or cooperation powers that would allow for decisions or actions to be made or implemented across the entire catchment (Esfahan Regional Water Board 2014b).

Capacity development is generally acknowledged as an important precondition for a successful integrated water management (IWRM) process (Zhang and Mitsch 2005). This includes continuing education and awareness-raising about IWRM and its basic principles (e.g. the necessity for there to be a comprehensive legal basis, as well as cross-sectoral cooperation, and greater cost effectiveness and efficiency in the measures taken or proposed), as well as technical competency and implementation methods and political approaches. Without the complementary capacity development measures that are offered and accepted under IWRM, optimization measures and instruments often remain misunderstood and unused by target groups (Esfahan Regional Water Board 2014b). Ideally, capacity development can support a close and long-term cooperation between the provinces involved.

Since an IWRM process in general and any new (e.g. irrigation) methods and technologies in the water sector cannot be implemented without accompanying awareness and educational training, it is necessary to analyze and understand the social standing of the technical and further education structure in Iran's water sector. Analyses have shown that, while technical education is very diverse, both structural and content-related challenges exist that reinforce each other (Esfahan Regional Water Board 2014b). This includes deficits in demand assessment, evaluation, in the practical relevance of the courses, and in available equipment like demonstration facilities, such that the value of technical education is underestimated by companies and authorities as well as by staff members (Assari and Assari 2012). Therefore, employees are not motivated by their employers to take part in training courses.

In Iran, widespread forms of public participation are uncharted territory for political institutions and for the public. A profound understanding of participation must therefore be established among local decision-makers and the public in 


\section{Kazem Vafadari Mehrizi}

a continuous and step-by-step process. For the development of socio-economic scenarios, a participatory approach should be conducted with representatives of the urban water, agricultural and business sectors. This would show that as part of an integrated water management approach, communication between the stakeholders involved needs to be improved. This holds true for communication between single sectors (farmers, for example, will emphasize their traditional right to water), and the water-related authorities/companies, and any other affected people. In addition, and based on the assumption that IWRM can only be realized when it reaches out to relevant decision-makers as well as the public, classical promotional and information brokerage measures adjusted to local and cultural conditions must be designed and implemented. In this way, the social environment as well as the technical and physical resource environments can be brought together for effective management of the Zayandeh Rud catchment (Beaumont 1974).

\section{Tourism}

Local recreation areas and large holiday resorts in the Zayandeh-Rud catchment are located upstream in the Chadegan region (see Figure 5.1) near the reservoir of the same name. A further expansion of tourist facilities in this area that will attract investors is currently being debated. However, this debate needs to acknowledge that persistent dry periods in the catchment have led to water stress in the agricultural and tourism sectors, and this had a heavy economic impact on the region (Modarres and Silva 2007). The flow of the river through Esfahan's ancient center and its bridges has been particularly affected, and this has impacted tourism flows to the region. The bridges over the river include some of the finest heritage architecture in Esfahan.

The oldest bridge is the Shahrestan bridge or "Pol-e Shahrestan," whose foundations were built in the Sassanid Empire (3rd-7th century CE), and were repaired during the Seljuk period. About 100 meters away from this bridge the river has recently been diverted towards the south, and an artificial lake established around the bridge to protect it from further damage. Further upstream are the "Pol-e Khaju" and "Siosepol" (Figure 5.2), built by Shah Abbas II in 1650 and 1632 respectively. The Pol-e Khaju is 133 meters long with 23 arches, and also serves as a sluice gate. To preserve these attractions in their riverine environment, any new activity in tourism or any other economic sector that affects the Zayandeh-Rud catchment's overall potential as a tourist destination must reduce its impact on water resources.

The realization of new tourism proposals is likely however to lead to a conversion of land, especially in rural agricultural areas, into areas used for tourism. This will lead to new dynamics in water use and wastewater production, and therefore will have direct impact on the potential for integrated water management of the river basin. While tourism currently plays a minor economic role in the region (though the cities of Esfahan and Yazd are major domestic and international tourism destinations), investment in previous years has concentrated mainly on 


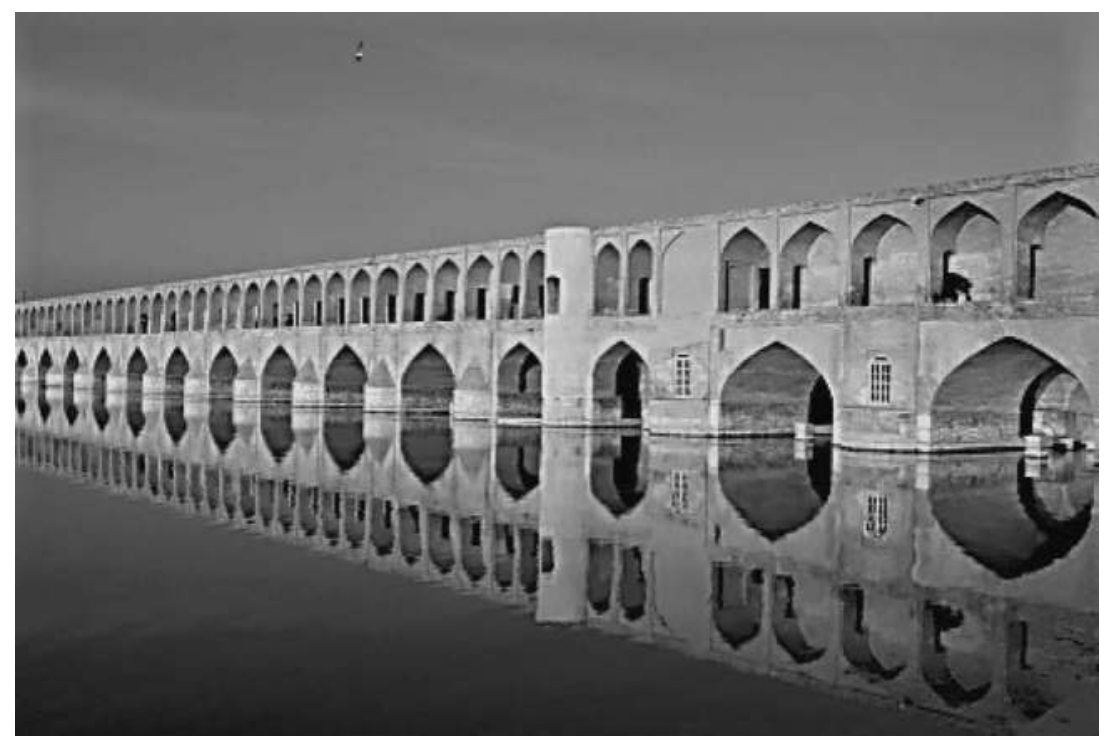

Figure 5.2 The Shahrestan Bridge, Esfahan.

Source: Photo courtesy of the Author

ecotourism (for domestic tourists). The drying up of the Zayandeh-Rud has thus had a negative effect on the number of tourists travelling to the region for the purposes of ecotourism (Foltz 2002). The region, however, is well positioned for a wide variety of other tourist offerings because of its climatic, environmental and structural conditions. Their impact on water resources and the Zayandeh Rud catchment will be much wider than just in Esfahan, but the promotion of eco-tourism and the implementation of Integrated Water Management in the river basin could be of mutual benefit if investments are made purposefully, and if professional water resources management can be established (Esfahan Regional Water Board 2014b).

\section{Conclusions}

This chapter has outlined the impact of the increasing population and industrial growth (including tourism) in a fragile river basin in the desert area of central Iran. The Zayandeh-Rud (literally, "life-giving river") is the largest river in this arid region: it begins in the Zagros Mountains in the west, flows for about $400 \mathrm{~km}$, and merges with the environmentally important Gavkhouni wetlands. It is not seasonal or ephemeral like the other rivers in the region, and the resulting population and industrial growth in the river basin to take advantage of this fact during the last few decades has put additional stress on this water resource. This has 


\section{Kazem Vafadari Mehrizi}

resulted in conflict between the rural and urban populations in Esfahan city in the southwest and in Yazd city in the center. The river is also very important in relation to tourism: for its historical bridges, famous parks, and diverse landscapes like the springs in the mountains (upstream) and the Ramsar Agreement protected swamp downstream, which is home to numerous animal and plant species. However, continuous drought during the last two decades, and the building of the Chadegan Reservoir in 1972, has reduced environmental flows and severely limited the tourism applications and ecosystem functions of the Zayandeh Rud. This has particularly affected the life of people in Yazd city (shortage of drinking water), and in Esfahan city (the river runs dry under its historical bridges), causing identity problems for local populations and tourists due to the drying out of the once famous waterway. Finally, these changes have eventually affected the wildlife and plants in the Gavkhouni wetlands.

The discussion has shown that, along with the continuing decline in the absolute volume of water delivered by the river, risk analyses of water quality in the region show disturbing trends. Given the industrial, agricultural and tourist areas surrounding the river, these changes should be considered more seriously. Regional water quality is very severely affected in times of drought, so more effective conservation policies are required, and urban and rural users should stop discharging their wastewater into the Zayandeh Rud river. The continuing minimum level environmental discharge rate in the river brings about a high concentration of heavy metals. This situation is causing unrecoverable damage to the ecosystem of the Gavkhouni wetland.

Thus, when the wetland inflow decreases (that is, river water discharge decreases), industrial factories and centers should discharge lower amounts of wastewater into the river, and agricultural use should be strictly controlled; and in wet years, more water should be directed toward the wetland. In this way, heavy metals concentration and other impacts in that globally important area can be decreased. To develop and implement this protection, a national wateruse strategy is required for this environmentally important river basin, just as it is in the other case studies outlined in this book (for example, the Murray-Darling river system in Australia).

\section{References}

Acreman, M. C., Fisher, J., Stratford, C. J., Mould, D. J., and Mountford, J. O. 2007. "Hydrological Science and Wetland Restoration: Some Case Studies From Europe." Hydrology Eु Earth System Sciences 11(1): 158-169.

Aghanabati, S. 2003. Geology of Iran. Tehran: The Geological and Explorations Survey of Iran.

Assari, A. and Assari, E. 2012. "Urban Spirit and Heritage Conservation Problems: Case Study of Esfahan City in Iran." Journal of American Science 8(1): 203-209.

Beaumont, P. 1974. "Water Resource Development in Iran." The Geographical Journal 140(3): 418-431.

Esfahan Regional Water Board. 2014a. Groundwater Report. Esfahan: Esfahan Regional Water Board. 
Esfahan Regional Water Board. 2014b. Integrated Water Resource Management in Esfahan, Zayandehrud River Catchment Reports. Esfahan: Esfahan Regional Water Board.

Esfahan Regional Water Board. 2014c. Agriculture Report. Esfahan: Esfahan Regional Water Board.

Esfahan Regional Water Board. 2014d. Industry Report. Esfahan: Esfahan Regional Water Board.

Esmaili Sari, A. 2003. Pollution, Health and Environmental Standards. Tehran: Naghshe Mehr, 767.

Felmeden, J., with support from Schramm, E., Sattary, E., and Davoudi, A. 2014. Agriculture in the Zayandeh Rud Catchment. Esfahan: Frankfurt: Institute for Social-Ecological Research.

Foltz, R. C. 2002. "Iran's Water Crisis: Cultural, Political, and Ethical Dimensions.” Journal of Agricultural and Environmental Ethics 15: 357. DOI:10.1023/A:1021268621490

Hekmatpanah, M., Nasri, M. and Sardu, F. S. 2012. "Effect of Industrial and Agricultural Pollutants on the Sustainability of Gavkhouni Lagoon Wetland Ecosystem." African Journal of Agricultural Research 7(20): 3049-3059.

IUCN. 1985. Wetlands of the Seistan Basin, South Caspian and Fars Areas, Islamic Republic of Iran. Ramsar Convention Monitoring Procedure, Report No. 6. Geneva: IUCN.

Jamab Conductor Engineers. 1978. Climate and Water Resources Condition in the Gavkhouni Watershed, Now and in the Future. Tehran: National Management Office (Water Affairs).

Madani, K., and Mariño, M. A. 2009. "System Dynamics Analysis for Managing Iran's Zayandeh-Rud River Basin.” Water Resources Management 11: 2163-2187.

Majnunian, H. 1998. Wetlands: Classifying and Protecting Wetlands. Tehran: Dayereye Sabz Publication Co.

Masih, I., Uhlenbrook, S., Maskey, S. and Smakhtin, V. 2011. "Streamflow Trends and Climate: Linkages in the Zagros Mountain, Iran." Climatic Change 104: 317-338.

Modarres, R. and da Silva, V. P. R. 2007. "Rainfall Trends in Arid and Semi-Arid Regions of Iran." Journal of Arid Environments 70(2): 344-355.

Modarres, R. and Sarhadi, A. 2009. "Rainfall Trends Analysis of Iran in the Last Half of the Twentieth Century." Journal of Geophysical Research 114. DOI:http://dx.doi. org/10.1029/2008JD010707

Molle, F., Ghazi, I., and Murray-Rust, H. 2009. "Buying Respite: Esfahan and the Zayandeh Rud River Basin, Iran." In River Basin Trajectories: Societies, Environments and Development, edited by F. Molle and P. Wester, 196-213. Wallingford: CABI.

Nasri, N. and Modarres, R. 2009. "Dry Spell Trend Analysis of Esfahan Province, Iran." International Journal of Climatology 29: 1430-1438.

Safavi, H. R., Golmohammadi, M. H. and Sandoval-Solis, S. 2015. "Expert Knowledge Based Modeling for Integrated Water Resources Planning and Management in the Zayandehrud River Basin." Journal of Hydrology 528: 773-789.

Sahardi, A., and Soltani, S. 2013. "Determination of Water Requirements of the Gavkhouni Wetland, Iran: A Hydrological Approach." Journal of Arid Environments 98: 27-40.

Sayedipour, M., Ostad-Ali-Askari, K., and Shayannejad, M. 2015. "Recovery of Run off From the Sewage Refinery, a Factor for Balancing the Esfahan-Borkhar Plain Water Table in the Drought Crisis Situation in Esfahan Province - Iran." American Journal of Environmental Engineering 5(2): 43-46. DOI:10.5923/j.ajee.20150502.02

Soltani, S., and Sarhadi, A. 2011. Determination of Water Requirements of the Gavkhouni Wetland. Esfahan: Department of Natural Resources, Esfahan University of Technology.

Tabatabaei, J. 2011. "Hydrogeology and Hydrogeochemistry of the Zayanderoud River and Its Effect on Heavy Metals (Iran).” In MNICEG-17, Recent Advances in Environment, 


\section{Kazem Vafadari Mehrizi}

Energy Systems and Naval Science, edited by the World Scientific and Engineering Academy, 106-111. Athens: WSEAS.

Waldron, T. 2004. "Water Demand Management and Associated Environmental Impacts." Paper presented to the RCAPS Annual Conference, November.

Yang, Z. F., Sun, T., Cui, B. S., Chen, B., and Chen, G. Q. 2009. "Environmental Flow Requirements for Integrated Water Resources Allocation in the Yellow River Basin, China." Communications in Nonlinear Science and Numerical Simulation 14(5): 2469-2481.

Zayandab Consulting Engineers Co. 2008. Study of Water Resources and Water Consumption in the Zayandeh Rud Basin. Isfahan: Zayandab Consulting Engineers.

Zhang, L., and Mitsch, W. J. 2005. "Modeling Hydrological Processes in Created Freshwater Wetlands: An Integrated System Approach." Environmental Modeling $\mathcal{E}$ Software 20: 935-946.

\section{Websites visited}

www.ramsar.org. 


\title{
6 Rivers and water security \\ Supply adaptation strategies in the city of Chennai, India
}

\author{
Sharanya Sethuram and Malcolm Cooper
}

\section{Introduction}

The shortage of potable water in many parts of the world is a cause for concern at the local level in human communities (UN Water 2006; Anand 2007; UNFAO 2007; Back and King 2009; Cook 2012). Urban and rural regions in many countries suffer shortages of potable and industrial/agricultural water due to their geographical location, growing populations, unmet supply expectations, poor policy management, and overexploitation of available supplies (Bates, Kundzewicz et al. 2008; Bakker and Allen 2012; European Commission 2013). Despite recent technological and funding enhancements though, many strategies to improve supply have not helped to create water security (IWA and WWC 2012). Successful water management requires supply enhancements, demands related conservation practices, and encourages environmental conservation in equal measure (Heiland 2009; Loftus 2011; Government of South Africa. 2013). This chapter assesses the impact of this situation on the contribution that the three rivers (and their associated water bodies) that flow through the metropolitan area of Chennai (formerly Madras), India, make to that city's water resources.

The chapter notes that the rivers in question, the Kotalaiyar, Coovum, and Adyar, are terminally degraded within the urban area, and consequently can have little bearing on the solutions to current or future Chennai water supply problems until they are rehabilitated. This situation requires the urban communities in the metropolitan area to seek alternative sources of supply, while imposing more effective waste and other pollution management practices in relation to those rivers. This case study is, therefore, a description and analysis of a failed river system in community water resources terms, a case that has some similarities with those described in Chapters 4, 5, 7, and 10 of this volume.

\section{The Chennai river system}

Chennai is both a City and a Metropolitan Area in the Southern Indian state of Tamil Nadu. The area, with a growing population of more than 8.6 million, faces daily supply and demand management related threats to its existing water resources, plus the already growing hydrological cycle-based water scarcity brought about by climate change. The population density of the district is about 
27,000 inhabitants per $\mathrm{km}^{2}$, and this concentration has been growing at about 7.8\% per year over the decade 2001-2011 (TNWRD 2011).

Metropolitan water demand is $900 \mathrm{ml} / \mathrm{d}$ for the urban domestic sector (households), while only 700 to $730 \mathrm{ml} / \mathrm{d}$ can be supplied (Lakshmi and Ramalingam 2012). Hence there is a supply gap. Thus, extra-supply initiatives have been the main policy focus in the past, but the resulting desalination plants, alternative river-based supply schemes (out of State), the Krishna and Veeranam supply schemes (described later), and most other remedial measures have failed to improve the water scarcity situation, essentially because the major perennial supply system, the three rivers of Chennai, is heavily polluted and barely usable, while its alternative, ground water, is rapidly moving in the same direction (Deccan Chronicles 2011). Also, although Chennai has 100\% pipe connections, water supply is intermittent, therefore what the metropolitan area requires is completely re-focused management initiatives designed to improve the quality, conservation, and use efficiency of its existing river system (Deccan Chronicles 2011).

Three main rivers traverse Chennai, the Kotalaiyar River (draining at Ennore shore in the north of the city), the Coovum River (Koovam) in the central region, and the Adyar River in the south. A fourth river, the Otteri, a Nullah or minor watercourse, runs through north Chennai and meets another but artificial water course, the Buckingham Canal, that travels parallel to the coast, linking the Adyar and Coovum rivers. All these watercourses are heavily polluted with effluent and trash from domestic and commercial sources within the urban area. However, only one, the Adyar, which is much less polluted than the Coovum or the Kotalaiyar, is de-silted and cleaned periodically by the State government. This action is due to the need to preserve its protected estuary that forms the natural habitat of several species of birds and animals (Ramanujam, Devi, and Indra 2014). Finally, there are several artificial lakes of varying size fed by the rivers that are located on the western fringes of the city: The Red Hills, Sholavaram, and Chembarambakkam lakes. These intercept part of the perennial river flows prior to the urban area, and supply Chennai with part of its potable water needs. Groundwater sources in the metropolitan area are mostly brackish, but are also used to supply the urban area.

Historically, Chennai has often faced the problem of water supply shortage, as its three rivers are not major watercourses, and there is a consequent reliance on the annual monsoon rains to replenish the artificial lakes and groundwater storages scattered around the metropolitan area. The city's ground water resources have also been depleted to very low levels in many areas, forcing many residents to buy their drinking water from suppliers whose source is further afield, while even the monsoon can fail. Thus, most Chennai districts are currently water starved (Chennai Metropolitan Water Supply and Sewage Board 2008) because of their inability to use the rivers as a source of potable water. The city of Chennai is itself part of the larger Chennai Metropolitan Area, which includes some urban areas and villages outside of the core city. In addition to Chennai city, the jurisdiction of the Chennai Metropolitan Water Supply and Sewage Board (CMWSSB) extends to urban outlying regions covering about $164.6 \mathrm{~km}^{2}$, and 
rural regions covering about $142 \mathrm{~km}^{2}$. The urban outlying areas are called Adjacent Urban Areas (AUA), and the rural regions are called Distant Urban Areas (DUA) (CMWSSB 2011).

The Chennai Metropolitan Development Authority (2007) noted that the current water supply-demand policies and management systems in Chennai need improvement, although little was being achieved. In this situation, droughts or floods can cause administrative and policy chaos through decreased demand satisfaction, further reduced water quality, and increases in the water-poor population within the city. To manage supply and demand in Chennai, and in any centre facing these problems, there is a need to develop effective conservation practices regarding the rivers and canals that traverse the Metropolitan Area, to bring them back to a situation where their potential to supply much of the metropolitan area's water requirements through proper planning and implementation of future drought-proofing projects (Chapter 3, this volume), matches their ability to do so (Sivakumar 2013). Planners must also pay attention to past project failures, and learn from these (Planning Commission 2007). The adaptation programs most often recommended are the simple ones of reduce demand, reuse and recycle, accurate inventories of water resources, and accurate household surveys of actual use (Waldron 2008). Therefore, the major policies for Chennai in the short to medium term include reworking and renovating the river water supply systems, ponds, and Kollams (traditional storage tanks), and improving distributed quality through effective treatment and monitoring stations (Srinivasan 2008; Government of India Ministry of Water Resources 2012). In addition, the strategy of using closed conduits for carrying water to households, and selective supply hours, would also improve conservation and water security in the city (CMWSSB 2008, 2011).

\section{Water resource management: important variables to consider in Chennai}

There are three sides to effective water resource management: 1 . appropriate policies and regulations for administering water supplies; 2 . modern water utility infrastructure managed using up-to-date methods; and 3. effective supply and demand side management (UNEP 2012). Administrative programs include upgrading customer advisories (for the user), improving utility productivity measures, providing effectual informatics, implementing practical approaches and goal setting for future management, enhancing education and creating awareness, improving local participation, and managing grievances and feedback (GWP 2011). River and ground water extraction controls, water pricing, the imposition of fines within an appropriate regulatory system, and a code of conduct for the public and for relevant administrative entities, should also be major policies within the administrative system for water utility management that require periodic attention (UNESCAP 2010).

Water resource management is like any other management system; it is often flawed and failing. Attempting to carry-through on the aforementioned 
approaches indicates that the water management systems in many countries require change and reinforcement. In this regard, India, China, and South Africa are introducing new technologies, administrative measures, and conservation techniques to improve their adaptability (Government of South Africa 2013; Rademeyer, van Rooyen, and McKenzie 1997). Administrators use strategies to create and implement policies to manage water to create security and adapt to stress factors. But, although there is need to understand the impact of demand on the available water, it is equally necessary to consider the overall situation - people, environment, economic conditions, and, nowadays, climate change. Consideration given to the impacts of climate on water security and on environmental sustainability is vital when planning for the required adaptation of management policies (UN Water 2006; GWP 2011). Thus, changes in overall supply-demand management systems are required to establish a firm foundation for adaptive societal responses to water supply crises.

Finally, the water supply system in any location is intricately linked to the effective functioning of the hydrological cycle, which is the balance of precipitation, temperatures, and evaporation levels (Iglesias et al. 2010). Water security is the availability, accessibility, affordability, and allocation of sufficient clean potable water for all people. In turn, this cycle is affected by climate change, which has the potential to cause acute imbalances in water resources (IPCC 1997, 2008). Climate change in this context is made up of the effects of rising temperatures, changes in wind circulation patterns, and changes in ocean currents, among other factors. The global increase in temperature (2000-2016) is 0.5 degrees higher than the average warming between the years 1960 and 1990 (EPA 2012). Temperature changes can impact rainfall and sea temperatures, leading to increases in droughts or floods. Temperature rise may also denote an increase in surface or soil water evaporation (i.e. reducing surface resources). This increases the demand for water to support food production for city populations, amongst other pressures. Thus, the water cycle is becoming increasingly distorted and uneven (IPCC 1997, 2008). This is now recognized as the climate-related water crisis (Huhne and Slingo 2009).

In consideration of all these variables, the aim of this chapter is to identify the context of river water resource management in Chennai, to assess the contribution of the metropolitan rivers to solving the existing supply problems (Butterworth 2007), to describe the community supply and demand initiatives that have arisen in response to these problems, and to analyse the core policies and adaptation strategies required to combat the supply reduction impact of looming climate change. From this analysis, it is possible to provide recommendations for change. The key problem in Chennai is that past supply restrictions and poor water quality management policies have led to the current water security and scarcity issues, and it appears that there are few possible solutions to this problem within the current framework of policy planning and demand-related conservation practices in relation to the three rivers of Chennai. 


\section{The water supply system in Chennai}

\section{Rivers and surface water bodies}

The Kotalaiyar River on the north side of the urban area is $136 \mathrm{~km}$ long and drains into the Bay of Bengal. Its northern tributary (the Nagari river) originates in Andhra Pradesh and joins the main river in the Poondi dam. From the Poondi reservoir, the river flows through rural areas, then enters the Chennai metropoli$\tan$ area, to join the sea at Ennore Creek. The river flows for $16 \mathrm{~km}$ within the Chennai city area. The total catchment area of the river is $3,757 \mathrm{~km}^{2}$, and the bed width ranges from 150 to 250 metres. The discharge capacity of the river basin is $110,000 \mathrm{~m}^{3}$ per second, and the anticipated flood discharge capacity is about 125,000 $\mathrm{m}^{3}$ per second (Kanthimathinathan 2015).

In 2011, the Chennai Water Resources Department (WRD) initiated a subproject under the national Irrigated Agriculture Modernisation and Waterbodies Restoration and Management (IAMWARM) project to rejuvenate nearly 200 lakes in this river basin (Lakshmi 2011), and to reduce the formation of sand bars near the mouth of the river. Finally, while the estuary of this river is heavily polluted with effluent released by the industries in the region, the upper reaches remain a source of water for agriculture and villages (Jagadeshan, Anandasabari, and Poornavel 2015).

The Coovum River in central Chennai is the shortest classified river draining into the Bay of Bengal. This river is about $72 \mathrm{~km}$ in length, flowing for $32 \mathrm{~km}$ in the urban area and for $40 \mathrm{~km}$ in the rural area. The river is highly polluted in the urban area (Chennai City). Along with the Adyar River running in parallel to the south, the river trifurcates the city and separates Northern Chennai from Central Chennai. Owing to the intensive use of surface water upstream for agriculture, indiscriminate pumping of groundwater leading to reduced base flow in the river, the formation of a sand bar at the mouth of the river, the discharge of untreated sewage and industrial effluents, and residential encroachment along the banks, the river, especially downstream, is highly polluted (Ramakrishnan 2009).

Once a fresh water source and a fishing river, it is today simply a drainage course inside the city of Chennai, collecting the surpluses of 75 small tanks in a minor basin. The total catchment area of the river is about 400 square kilometres, and the bed width ranges from 40 to 120 metres. The capacity of the river is $19,500 \mathrm{~m}^{3}$ per second, and the anticipated flood discharge is around $22,000 \mathrm{~m}^{3}$ per second (Lakshmi 2012). Of the three main rivers, it has borne the brunt of the city's unplanned urban growth. Upstream, the Kesavaram dam diverts the river into the Chembarambakkam Lake, which supplies drinking water to the city of Chennai. Thereafter, the flow of water in the river downstream is much reduced.

For centuries, the Coovum has been an integral part of the socio-economic and cultural life of Chennai. Until the early twentieth century CE, it was a clean river, and navigable. Earlier, it played a pivotal part in the far-flung maritime trade between the Roman Empire, South India, and Sri Lanka. Archaeologists have discovered ancient wine jars, and Roman and Chinese coins on the banks 
of the river. In the late eighteenth century, Pachaiyappa Mudaliar, the renowned philanthropist, bathed in this river before offering prayers at the Komaleeswarar Temple in Komaleeswaranpet (Suresh 2012). Currently, the urban part of the river is highly toxic and completely non-potable; upstream, however, the unpolluted part is still being used for the drinking water needs of many villages.

A study of the river was undertaken as part of a World Bank-funded project (TNSUDP 2015), and showed that it is $80 \%$ more polluted than treated sewage. Fish can survive in the water for only 3 to 5 hours, even after the river water they are exposed to has been diluted with fresh water. The Public Works Department sources contacted during the research for this chapter suggested that government agencies like Chennai Corporation and business units and retail outlets on the banks of the river were responsible for the pollution (Sethuram 2014). The water has almost no dissolved oxygen, and instead there are traces of heavy metals like copper, as well as sewage and sludge. Due to its narrow width and the approximately 3,500 illegal dwellings along its banks, it has not been recently desilted, which has closed it to river traffic. In 2003 about 9,000 families lived along the river, in addition to 450 shops and commercial buildings (Ramakrishnan 2009). There are 700-odd points along the river bank where sewage flows straight into the river; 127 of these are authorized sewage outfalls into the river ( 85 of these are currently in use). Nearly $30 \%$ of the estimated 55 million litres of untreated sewage being let into the waterways of Chennai daily, including that from facilities operated by the Chennai Metropolitan Water Supply and Sewerage Board, gets into the Coovum river, while $60 \%$ flows into the Buckingham Canal, and the Adyar River takes the rest.

On a more positive note, the Adyar River, $42.5 \mathrm{~km}$ long and on the south side of the urban area, contributes to the maintenance of the remaining estuarine ecosystem of Chennai (Periakali et al. 2009). Despite the high pollution levels, boating and fishing take place in this river. The river collects surplus water from about 200 tanks and lakes, small streams, and the rainwater drains in the city, and has a combined catchment area of $860 \mathrm{~km}^{2}$. It discharges between 190 and 940 million cubic metres of water annually to the Bay of Bengal. The discharge is seasonal with between 7 to 33 times more than the annual average occurring during the Northeast monsoon season between September to December. The river is also supplied by surplus water from about 40 ponds. The normal discharge of the river is $39,000 \mathrm{cuft} / \mathrm{s}$ whereas the anticipated flood discharge capacity is about $60,000 \mathrm{cuft} / \mathrm{s}$. During the floods of 2005, the river had a discharge of 55,000 cuft/s (Krishnaveni and Gowri 2008).

The Adyar Estuary has long been a haven for migratory and resident birds. The environmental conditions in the estuary provide low salinity, good shelters, and high plankton availability as a good nursery for fish (Ramanujam, Devi, and Indra 2014). The flow of tidal water in and out of the creek allows for the easy travel of boats, and once encouraged fishing. However, with the city's sewage and effluent from its various industries emptying into the river, the biological activities in the region have been affected. Recently, with the opening of the Adyar Estuary Nature Park (Adyar Poonga), painted storks, grey heron, large egret, and black 
winged stilt have returned: "Painted stork has not been seen in the Adyar Estuary for many years. Getting to see painted stork this year is very good news," said Mr. K. V. Sudhakar, President of the Madras Naturalists' Society, in 2011 (Lopez and Oppili 2016). Around 200 species of birds have been reported in the Adyar area in the past, he added, however many species had vanished from the vicinity because of rapid urbanization. According to officials, increased availability of fish in the waterbodies of the 58-acre area and improvement in habitats are some of the reasons for the migration of birds to the park. In a further contribution to the clean-up, in 2012, the state government allotted 3,000 million rupees towards the construction of 337 sewage cleaning systems in the waterways in the city, including 49 locations in the Adyar river, 105 in the Coovum river, and 183 in the Buckingham Canal (Dina Malar 2012).

The Buckingham Canal has an influence on drainage. This canal is a $796 \mathrm{~km}-$ long fresh water navigation canal, running parallel to the coast of South India, from Andhra Pradesh to Tamil Nadu. The canal was formed during drought relief work in 1806. It intercepts all the east-flowing drains during its $44 \mathrm{~km}$ path in Chennai connecting all three rivers in the City, however its main function was to join the natural backwaters along the coast to Chennai (Madras) port. It was constructed during colonial times, and was an important waterway during the late nineteenth and early twentieth centuries. The canal also acts as a barrier to sea water intrusion in the coastal aquifers. Now however, as with the rivers it connects, the canal is disrupted by solid waste and the severe anaerobic conditions arising from the sewage it carries. In addition, within the city limits of Chennai much of the canal has been used as the route of the elevated Chennai Mass Rapid Transit System (MRTS). MRTS stations have encroached on the canal, reducing its width to less than 50 metres in a few places. The Buckingham Canal is the most polluted of the four major waterways in the city, with nearly $60 \%$ of the estimated 55 million litres of untreated sewage from the city being placed into it daily (Ramakrishnan 2009).

The main alternative surface sources of freshwater are the Cholavaram, Poondi, and Redhills Lakes (Tanks). The lakes are three interconnected reservoirs are used to collect, store, and supply water to the Chennai region via the Kortalaiyar Nagari and Nandi rivers (outside the metropolitan area). The fourth lake is Chembarambakkam, which is also a reservoir used to supply water to the city, but only during drought years. The lakes supply a total of about 7,412 million $\mathrm{m}^{3}$ of water to the metropolitan area.

\section{Augmenting these sources}

Chennai has developed or considered alternative supply sources to the basic artificial lake and perennial river systems in the past to increase the supply of potable water (Figure 6.1). These are as follows:

(1) The Veeranam Project: The Veeranam Lake is located $230 \mathrm{~km}$ from Chennai. This lake draws water from the Cauvery River and provides drinking 


\section{Sharanya Sethuram and Malcolm Cooper}

water to Chennai. An earlier version of the Veeranam Lake project (19651967) was a failure, as it did not produce the necessary amount of water required. The current Veeranam Lake project (from 2004) has managed to reduce the level of interstate water purchase that is required to service Chennai. The total capacity is 1465 million $\mathrm{m}^{3}$ but the project currently only stores about 320 million $\mathrm{m}^{3}$ (180 MLD). The raw water is pumped $20 \mathrm{~km}$ and then treated before being transported $200 \mathrm{~km}$ to the city;

(2) The Krishna River Project: The Krishna River is in Andhra Pradesh State, north of Tamil Nadu. Under an agreement with neighbouring states, the Telugu Ganga Project on this river is to supply 1,100 million $\mathrm{m}^{3}$ per year to meet Chennai's agricultural, industrial and domestic needs. The water received under the Krishna Water Supply Scheme is in two stages, I and II, conveying 400 and 530 MLD to Chembarambakkam Tank (Lake), respectively;

(3) Ground Water Sources: The CMA, DUA, and AUA regions obtain groundwater from two main sources, the Araniyar-Koratalaiyar Basin (A-K Basin) and the South Coastal Aquifer (SCA); and

(4) Desalination: Desalination is fast becoming an option for urban cities in Tamil Nadu and other states; Chennai already has two plants supplying $100 \mathrm{ML} / \mathrm{D}$ each. With the recent increase in industrial demand, water supplies for the domestic sector have been further reduced in Chennai, and desalination plants have been designed to offset this problem. Chennai also has five other smallscale desalination plants with capacities of less than $15 \mathrm{ML} / \mathrm{D}$ each.

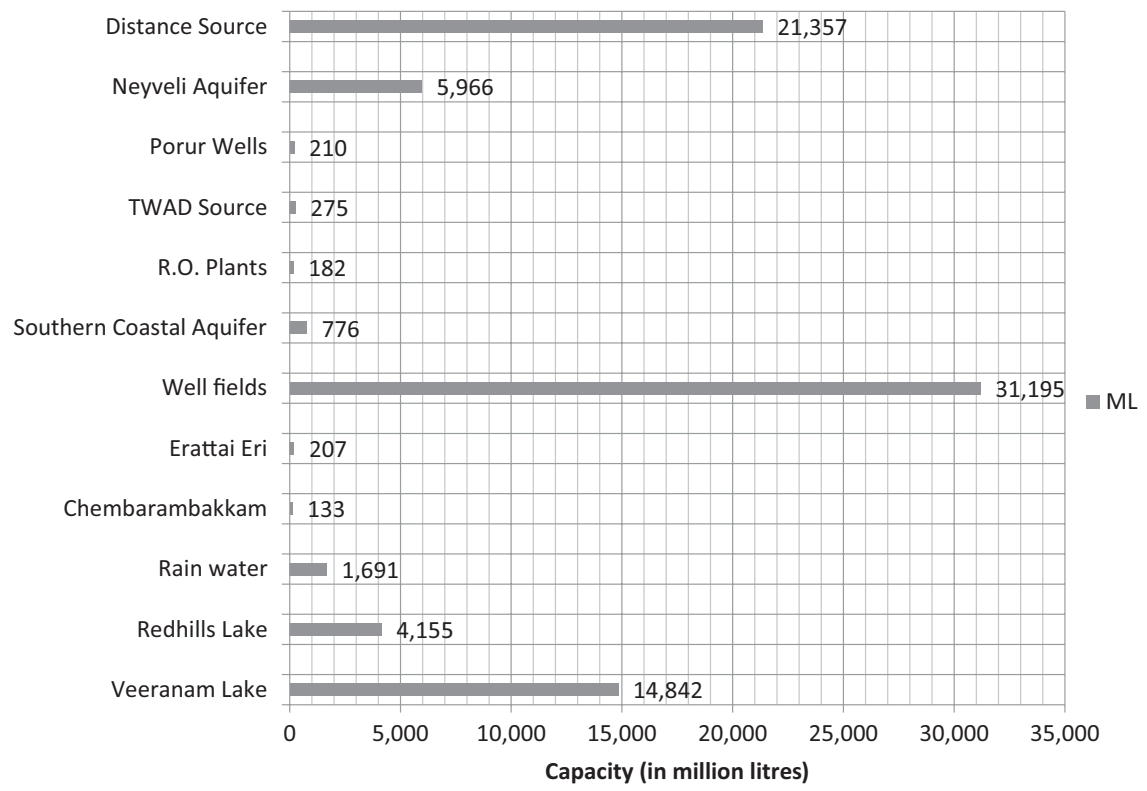

Figure 6.1 The water resources of Chennai.

Source: the Author 


\section{The rivers and Chennai's water supply status}

Local water authorities indicate that the total effective supply from all sources in the Chennai Metropolitan Area is approximately $730 \mathrm{ML} / \mathrm{D}$ (2012-2015), and the total required is about 900ML/D (Figure 6.2; Lakshmi and Ramalingam 2012). This chapter has shown that it has become obvious that the development of water supplies for Chennai has to be secured without any further use of the rivers within the City area at least in the short term, since they are so heavily polluted that they are, to all intents and purposes, irrelevant unless they can be cleaned up. The chief improvements being talked about then involve extraction from rivers and other sources outside the Metropolitan area, and even outside the State (Selvaraju 2004; Lakshmi and Ramalingam 2012). An additional perspective may be gained from a walk through the streets of Chennai. Various problems such as supply pipe leaks, sewer pipe leaks, tankers with people fighting over who gets water first, and even a few places using hand pumps to draw water from bore wells, are seen. Thus, the problem in Chennai is how to deal holistically with the faulty water supply system, degraded ecosystems, the rich and poor divide (not to mention political unwillingness or vested interests, corruption, and so on), which make the water management landscape in Chennai very complex (Figure 6.3).

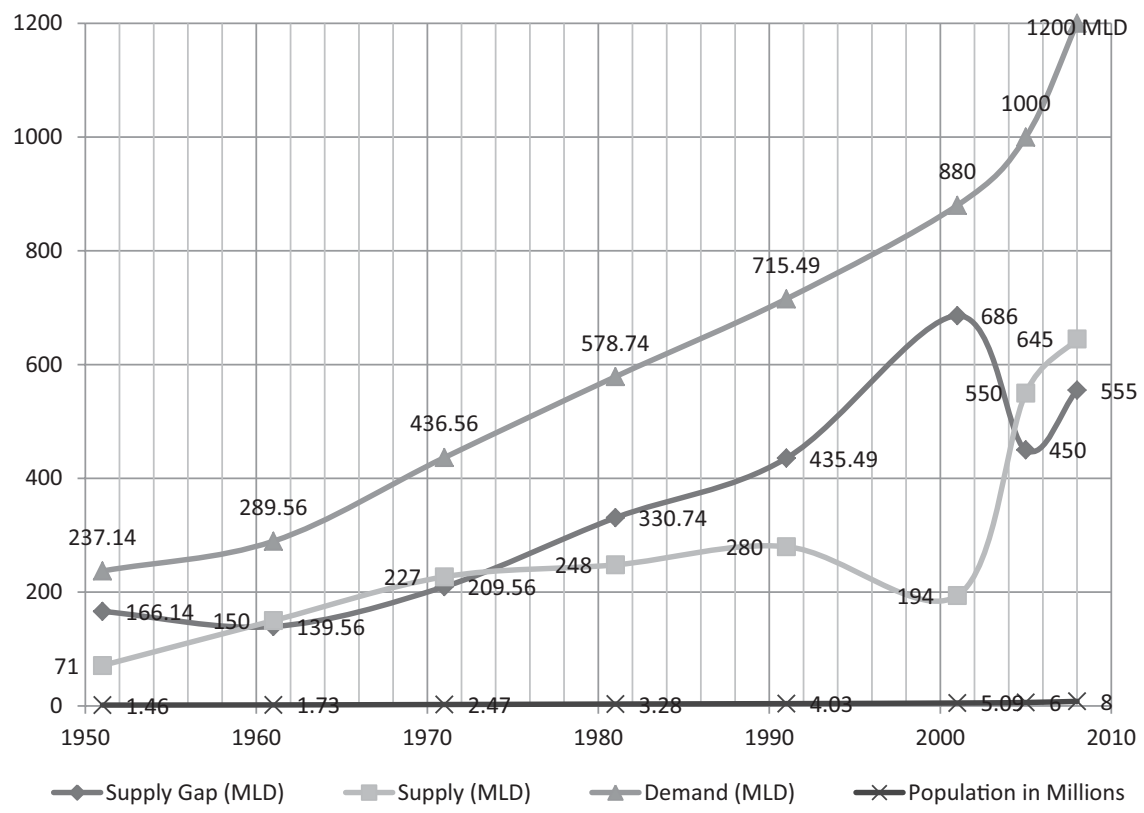

Figure 6.2 Chennai's population growth, water demand, and supply gaps.

Source: the Author 


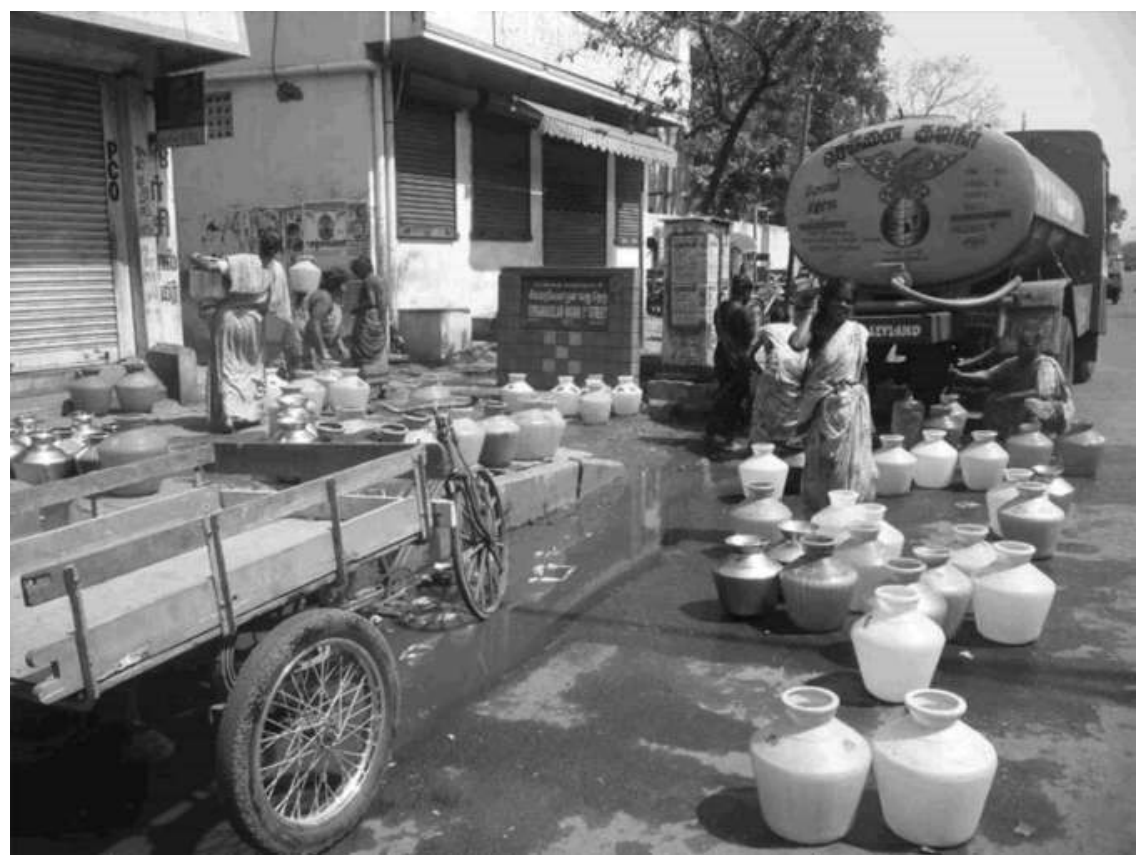

Figure 6.3 Chennai's water supply system for many people - storage of water for two or three days in jars.

Source: Photo Courtesy of the Author.

\section{Water quality}

While it is almost impossible to find absolute purity in available water resources across the globe (WHO 2006), especially in India (BIS - Indian Water Quality 2009), a recent study (Janardhanan 2011) indicates that both the quality and amount of water sources within Chennai are particularly bad. The surroundings of reservoirs are not kept clean, and domestic, industrial, construction, residential, commercial, and other activity wastes pollute lakes and rivers. As we have seen, the water in the Adayar and Coovum Rivers, for example, is highly contaminated, and is at present unsafe to use for all domestic purposes. The Coovum River is also saline, as there are sea inlets that allow saline intrusion. However, while this water could be desalinated, the smell of the river is so revolting that people must cover their noses before they reach it. This is partly due to regulatory non-compliance and the location of the slum regions close to that river, where people do not have toilets or clothes washing facilities at home.

The most common water-borne diseases resulting from this situation are Diarrhoea, Typhoid, Paratyphoid, Cholera, Dysentery, Protozoal, viral infections, and Helminthic worms. These diseases are pathogenic and contaminate water 
through sewerage or unsanitary toilets (Cariappa and Khanduri 2003; Sethuram 2014). This issue requires attention if there is to be better management of the quality of water sources in Chennai (Mariappan 2013).

\section{Awareness, information, and communication relating to the quality of water from the rivers}

Awareness of the actual quality of water is low in Chennai, even if the state of the rivers is obvious to all on visual inspection. This is because the government does not provide information and test results to local people. The information available currently only indicates the type of quality measures and the available standards, while most actual data from regional chemical, bacteriological, and physical test results are not available (Sethuram 2014).

Regarding the alternative source of supply to the polluted rivers; the groundwater aquifers, Chennai residents indicate that illegal groundwater extraction is high, and quality controls are very sporadic (Sethuram 2014). Janardhanan's (2011) study indicates that there is widespread illegal pumping and sales of freshwater from this source. The major well fields are thus highly exploited, and these well fields are also used for sectors other than domestic water supply. Besides keeping track of the number of wells, it is also very hard to maintain a record of how much well water is extracted, consumed or wasted in these cases. "Currently, 40 million litres of water is drawn from Metro Water's wells in Neyveli, Poondi, Thamaraipakkam and Minjur to augment the supply from reservoirs" (Mariappan 2013). Observation reveals that these wells were dug between 2003 to 2005 to support extra sources, when Chennai began to face droughts and started relying on well and tankers for supply. For this reason, illegal supply points are not going to be capped in the current situation of chronic water shortage.

\section{Discussion}

Based on this investigation, the following points can be made about water supply and demand management in relation to the rivers of Chennai: the total water supply is irregular, unreliable, polluted, and inadequate overall. This is due to both availability problems and accessibility problems. In addition, a noteworthy point is that the water resource database in Chennai is generally inaccurate and unreliable, even though data is collected by the administrative authorities in the region. Hence, accountability and reliability are also low. Also, when data is inaccurate this can lead to the assumption that the stock of water resources is adequate (although distribution problems exist), and the actual demand-supply gap is not considered to require resolution.

The research that this chapter is based on makes it clear that both water scarcity issues and security concerns exist in Chennai. While the evidence does suggest that the various Chennai Water Boards are trying their best to reduce the impact of these issues and improve water supplies from both the rivers and other sources, there are certain obstacles that affect this. These include policy 
weaknesses, physically inadequate collection and distribution systems, distribution equity issues, water quality issues, problems with information dissemination, and low overall awareness of these problems in the population.

This lack of awareness also extends to the reasons for the climate-change related water shortages that occur every four years due to regular lapses in the monsoon. And this means that the policy system cannot assist consumers to cope with the fact that this regular pattern has been changing recently due to the increased frequency of sudden extremes brought about by climate change (Michel, Pandya, and Mahanta 2009). For example, there are now frequent floods as well as droughts in Chennai and the coastal areas of Tamil Nadu. The increased flooding of the rivers of Chennai though has not aided the authorities in their clean-up; it has instead increased the penetration of saline water into fresh ground water sources. This creates further issues for the security of current and future water supplies. Managing floods requires more effective quality control of the river systems in the city (TNWB 2006).

Recently, Chennai has recorded an increase in its yearly maximum temperature to about 42 degrees centigrade, and this is one sign that should be a sufficient trigger for the Metropolitan Area to take better steps to prevent severe droughts. This, as in South Africa for example, will require going to the extent of transporting existing and available sources in closed conduits from water-rich areas to water-poor areas like Chennai. This will however pose further quality problems. There are several bacterial infections that make water unusable, and their existence creates more water waste and reduces water security. Nevertheless, TNWRD documents indicate that Chennai is prepared to tackle the water biosecurity issues that may rise in this situation (TNWRD 2011).

However, the supply and demand management investigation carried out on the rivers and storages presented here indicates otherwise. Respondent comments on the actual operation of the supply and demand management systems indicate that there are issues and concerns that could intensify with increasing climate change. While climate change may not currently look like a pressing issue in the Chennai rivers case, given the over-riding pollution problem, it is impossible to ignore the fact that droughts occur at least every 4 years, and floods approximately every other year (mild intensities). Thus, while "drought" in Chennai is presently mostly caused by inadequate and polluted flows in the supply chain (the rivers), and is demand rather than purely climate related, it is not possible to ignore the increasing signs of water scarcity and insecurity from the climate change source.

\section{Adaptation strategies}

The major causes of Chennai's discontent with its river and groundwater resources are not only related to the polluted and inadequate river flows; they also concern the connected pipe mains (distribution system), which does not supply water on a regular basis. Given these problems, policy changes are essential. Government can enforce policy, if this is made, but policies can be weakened due to corruption and low positive responses within communities (Srinivasan 2008; Michel, 
Pandya, and Mahanta 2009; Lakshmi and Ramalingam 2012). A favourable societal response is thus crucial in relation to cleaning up the rivers of Chennai. While the "polluter pays" policy is accepted in Chennai, and makes for effective reinforcement, in this case, of the clean-up strategies for the rivers and ground water supplies, without effective information, security of total supplies, and their effective distribution, this approach cannot be sustained (Sopac 2013).

\section{Conclusions}

This chapter suggests that an increase in water use efficiency in Chennai is much needed. The concerns about sporadic supply and low quality from the three rivers and the available groundwater resources are currently not situations that alternatives like desalination are able to totally rectify, but this does not seem not to galvanize local communities and authorities to clean up the rivers. This case study also concludes that Chennai has a greater potential water crisis than that which is produced by the ineffective demand and supply management strategies now in place in relation to its major sources of water, the river basins. This is because, at the same time as the quality and volume of water from its rivers and groundwater sources will continue to cause major policy problems, the metropolitan area will have to cope with an absolute shortage of water from the increasing periods of drought brought about by climate change in Southern India.

The three urban rivers of Chennai, together with the existing polluted and inadequate sources of groundwater, cannot maintain supplies of good quality water now, and this immediate problem is being compounded by poor policy construction and implementation concerning future supplies. Demand and supply management through effective clean-up and conservation, and serious attempts at increasing efficiency of treatment and distribution need to be enhanced by robust policy-making and effective legal frameworks to create room for additional drought-related requirements. There is also a need to enhance new project management capabilities, as there are many failures on record.

The obvious recommendations for policy change in Chennai in relation to the conservation and use of its water supplies (especially from the rivers) are to reduce demand and clean up existing sources, to improve the groundwater recharge system to lessen the threat from seawater intrusion, to provide better training of supply personnel, to obtain better inventories of resources, and to carry out continued surveys of actual use (to allow for effective management of reticulation and storage systems). The major infrastructure policies required include much greater efforts to rework and renovate the rivers, water tanks, ponds, and lakes; to improve quality through monitoring and effective treatment; and to ensure the implementation of simple measures for rainwater harvesting (RWH) and Artificial Recharge (AR) to local aquifers. In addition, creating a system for selective supply hours from existing sources on several days of the month will improve conservation of the river systems, and improve water security in Chennai (IWA and WWC 2012). In turn, the communities involved must develop a sense of ownership and responsibility for the state of their rivers and associated water supply networks (Sopac 2013). 


\section{References}

Anand, P. B. 2007. "Right to Water and Access to Water: An Assessment." Journal of International Development 19(4): 511-526.

Back, M., and King, J. 2009. The Atlas of Water: Mapping the World's Most Critical Resources. Los Angeles: University of California Press.

Bakker, K., and Allen, D. 2012. Water Security: Governance and Climate Change Challenges From a Canadian Perspective. Vancouver: Pacific Institute for Climate Solutions (PICS).

Bates, B., Kundzewicz, Z., Wu, S., and Palutikof, J. 2008. Climate Change and Water. Technical Paper IV. Geneva: Inter Governmental Panel on Climate Change (IPCC).

BIS - Indian Water Quality. 2009. Draft Indian Standards - Drinking Water Specifications (Second Revision). http://bis.org.in/sf/fad/FAD25(2047)C.pdf.

Butterworth, J. D. 2007. Peri-Urban Water Conflicts: Supporting Dialogue and Negotiation. Technical Paper Series; no 50. Delft, The Netherlands: IRC International Water and Sanitation Centre.

Cariappa, M. P., and Khanduri, P. 2003. "Health Emergencies in Large Populations: The Orissa Experience." Medical Journal of the Armed Forces of India 59(4): 286-289.

Chennai Metropolitan Development Authority. 2007. Draft Master Plan II for Chennai Metropolitan Area, 2026. Egmore, Chennai: CMDA.

Chennai Metropolitan Water Supply and Sewage Board. 2008. Development of Water Supply System to Chennai City in Chennai Metropolitan Water Supply and Sewage Board Online Database. www.chennaimetrowater.com/operatiomain_main.html.

Chennai Metropolitan Water Supply and Sewage Board. 2011. Improvement Works Taken Up for Water Supply Distribution in Chennai City Under JNNURM Funding. www. chennaimetrowater.tn.nic.in/con-wsy/JNNURM.htm.

Cook, C. B. 2012. "Water Security: Debating an Emerging Paradigm.” Global Environmental Change 22(1): 94-102.

Deccan Chronicles. 2011. The Decccan Chronicles: Chennai Worst in Saving Water. www. deccanchronicle.com/channels/cities/chennai/chennai-worst-saving-water-782.

Dina Malar. 2012. Rs300 Crore to Purify Water Routes: Possible to Swim in the River? July 26. Chennai: Dina Malar.

EPA. 2012. Water Resources Impacts and Adaptation: Climate Impacts and Adaptation. www. epa.gov/climatechange/impacts-adaptation/water.html.

Eric Ramanujam, M., Rema Devi, K., and Indra, T. J. 2014. "Ichthyofaunal Diversity of the Adyar Wetland Complex, Chennai, Tamil Nadu, Southern India." Journal of Threatened Taxa 6(4): 5613-5635.

European Comission. 2013. Climate Action Adaptation to Climate Change. http://ec.europa. eu/clima/policies/adaptation/what/index_en.htm.

Government of India Ministry of Water Resources. 2012. Ministry of Water Resources Programs and Schemes. http://wrmin.nic.in/index3.asp?subsublinkid=367\&langid=1\& sslid=362; http://wrmin.nic.in/index1.asp?linkid=144\&langid=1.

Government of South Africa. 2013. Water Conservation and Water Demand Management Strategy for the Water Services Sector. Government Communications (GCIS), South African Government Information. ZA: GCIS.

GWP. 2011. Water Security as a Catalyst for Achieving Food Security. Stockholm: Global Water Partnership.

Heiland, S. 2009. "Key Elements for Good Governance in Water Management." Rural Development News 1: 54-57. 
Huhne, C., and Slingo, J. 2009. Climate: Observations, Projections and Impacts. Department of Energy and Climate Change India, Met Office, Hadley Centre; University of Nottingham, UK; Walker Institute; Centre for Ecology and Hydrology; University of Leeds; Tyndall Centre for Climate Change. Nottingham: Met Office, UK.

Iglesias, A., Quiroga, S., and Schlickenrieder, J. 2010. "Climate Change and Agricultural Adaptation: Assessing Management Uncertainty for Four Crop Types in Spain.” Clim Res 44: 83-94.

IPCC. 1997. An Introduction to Simple Climate Models Used in the Second Assessment Report. Inter Governmental Pannel on Climate Change, UNEP and WMO, IPCC Working Paper Group. Geneva: Inter Governmental Pannel on Climate Change.

IPCC. 2008. Climate Change and Water. UK, Germany, China, Australia: IPCC Working Group II. Geneva: WMO and UNEP.

IWA and WWC. 2012. Radical Changes Needed to Quench the World's Thirst. International Water Association's (IWA) World Water Congress and Exhibition in Korea, 2012, Korea Press Centre, Korea Press Foundation. Busan: International Water Association.

Jagadeshan, G., Anandasabari, K., and Poornavel, S. 2015. "Groundwater Quality of Kosasthalaiyar River Basin, Thiruvallur District, Tamil Nadu, India." International Journal of Innovative Research in Science, Engineering and Technology 4(3): 1164-1170. DOI:10.15680/IJIRSET.2015.04030731164

Janardhanan, A. 2011. Overexploitation of Groundwater Affects Quality. The Times of India. http://articles.timesofindia.indiatimes.com/20 11-08-27/chennai/29935486_ 1_groundwaterwater-sources-water-levels.

Kanthimathinathan, T. T. 2015. "Waterways in Chennai." Presented to Session 3, River and Drainage Systems in the Chennai Metropolitan Area. Chennai Government Seminar on Waterways. www.cmdachennai.gov.in/pdfs/SeminarOnWaterways/5.pdf.

Krishnaveni, K., and Gowri, V. 2008. "Application of GIS in the Study of Mass Transport of Pollutants by Adyar and Cooum Rivers in Chennai (Madras), Tamilnadu." Environmental Monitoring and Assessment 138: 41-47. DOI:10.1007/s10661-007-9789-9

Lakshmi, K. 2011. Life Set to Flow Back to 200 Lakes. Chennai: The Hindu.

Lakshmi, K. 2012. Mogappair Residents Await Lifeline Over Cooum. The Hindu. Chennai: The Hindu.

Lakshmi, K., and Ramalingam, J. 2012. City Asks for More Krishna Water to Last Until Monsoon. Chennai, Tamil Nadu, India: The Hindu.

Loftus, A. C. 2011. Adapting Urban Water Systems to Climate Change: A Handbook for Decision Makers at Local Level. Germany: ICLEI European Secretariat Gmbh, Leopoldring.

Lopez, A. X., and Oppili, P. 2016. More Winged Visitors Flock to Adyar Poonga. July 30. Chennai: The Hindu.

Mariappan, J. 2013. Chennai's Key Water Sources Almost Dry. http://articles.timesofindia. indiatimes.com/2013-04-21/chennai/38709843_1_dead-storage-red-hills-water-storage.

Michel, D., Pandya, A., and Mahanta, C. 2009. Indian Climate Policy: Choices and Challenges: Climate Change Threats to India's Water Resources and Emerging Policy Responses. Stimson Centre Regional Voices. Washington, DC: The Henry L. Stimson Centre.

National River Conservation Directorate. n.d. Adyar River. New Delhi: Ministry of Environment and Forests. National River Conservation Directorate.

Periakali, T. V., Giridharan, L., Jayaprakash, M., and Periakali, P. 2009. "Environmental Impact Assessment and Seasonal Variation Study of the Groundwater in the Vicinity of the River Adyar, Chennai, India." Environmental Monitoring and Assessment 149(1-4): 81-97. DOI:10.1007/s10661-008-0185 


\section{Sharanya Sethuram and Malcolm Cooper}

Planning Commission. 2007. Rural Drinking Water and Water Sanitation in the Eleventh Plan Period. New Delhi: Government of India, 54th NDC Meeting.

Rademeyer, J. I., van Rooyen, P. G., and McKenzie, R. S. 1997. Water Demand and Demand Management. Proceedings of the South African Institute of Civil Engineers, September, $13-14$.

Ramakrishnan, T. 2009. Cooum Project Keeps Hopes Afloat. The Hindu. Chennai: The Hindu.

Selvaraju, R. A. 2004. Seasonal Rainfall Analysis (2000-2003). Coimbatore: Report submitted to TNAU, Coimbatore - 3 .

Sethuram, S. 2014. "Case Study: Water Management Issues in Chennai, India." Universal Journal of Environmental Research and Technology 4(6): 299-306.

Sivakumar, C. 2013. Metro Water Rolls Its Sleeves to Fight Summer, Quench Chennai's Thirst. http://newindianexpress.com/cities/chennai/Metro-Water-rolls-its-sleeves-to-fightsummer-quench-Chennai's-thirst/2013/04/20/article1552990.ece.

SOPAC. 2013. IWRM Programme. www.pacificwater.org/pages.cfm/water-governance/ integrated-water-resource-management/.

Srinivasan, V. 2008. An Integrated Framework for Analysis of Water Supply Strategies in a Developing City: Chennai, India. Stanford, CA: Stanford Thesis Publishing.

Suresh, S. 2012. A River for All Seasons. The Times of India. Chennai: The Times Group. Tamil Nadu Sustainable Urban Development Project (TNSUDP). 2015. Storm Water Drainage Project for the Selected Areas of Chennai Corporation. Final Environmental Assessment Report E4672V4REV. Chennai: Government of Tamil Nadu.

Tamil Nadu Water Board. 2006. A Note on the Major Calamities, Areas Affected, Total Assiatance Provided (Calamity Wise and Area Wise). Kind of Assistance, Source of Funding (Central, State and Other Assistance) $\mathcal{E}$ Details on System of Assessing the Damage Adopted by the State. Tamil Nadu Government. Topic no.18 pp 206-210: www.tn.gov.in/ budget/12thfincomm/topic_18.pdf.

Tamil Nadu Water Resources Department. 2011. Irrigation and Water Supply. Chennai: TNWRD.

UNEP. 2012. United Nations Status Report on The Application of Integrated Approaches to Water Resource Management. Rome: UNEP.

UNESCAP. 2010. Water Security - Good Governance and Sustainable Solutions. www. unescap.org/speeches/water-security-good-governance-and-sustainable-solutions.

UNFAO. 2007. Coping With Water Scarcity: Challenge of the Twenty-First Century. www. unwater.org/downloads/escarcity.pdf.

UN Water. 2006. UN Water. www.unwater.org/downloads/Water_facts_and_trends.pdf. Waldron, T. 2008. "Expertise in Water Loss Control Applied to Extreme Problems of Water Distribution Management." Water Science and Technology: Water Supply 8(1): 107-112. DOI:10.2166/ws.2008.031

WHO. 2006. Guidelines for Drinking-Water Quality. Geneva: World Health Organisation. 


\title{
7 The Velho Chico \\ Perceptions and conflicts
}

\author{
Lucigleide Nery Nascimento ${ }^{1}$
}

\section{Introduction}

The São Francisco River (SFR) originates in the state of Minas Gerais, in the southeastern region of Brazil, and undertakes a 2,700 km journey to empty into the Atlantic Ocean (CBHSF 2004; Figure 7.1). The river is sometimes referred to as the River of National Unity or Velho Chico.

The basin covers approximately $8 \%$ of Brazil's territory and has an area of the size of Spain, Portugal and Denmark combined (nearly 640,000 km²) (Figure 7.2). Despite comprising territories in 6 different states and in the Brazilian Federal District, nearly $48 \%$ of the watershed lies in the state of Bahia and nearly $37 \%$ of it falls within the Minas Gerais state (CBHSF, 2004).

The basin ecosystems are characterized by savannah and steppe biomes. Although in smaller proportion, the basin's zone by the Atlantic Ocean is categorized as being an Atlantic Rainforest biome (CBHSF, 2004). According to the São Francisco River's physical characteristics, such as the existence of rapids and falls, the basin forms four sub-regions: upper, middle, lower middle, and lower. The lower-SFR comprises the smallest zone (4\%) and the middle-SFR (63\%) the largest area of the basin (CBHSF, 2004) (Table 7.1).

Table 7.1 Geography and demographic characteristics

\begin{tabular}{lllll}
\hline Sub Regions & Total Area $\mathrm{km}^{2}$ & $\begin{array}{l}\text { Percentage of } \\
\text { the Sub-region in } \\
\text { Relation to the } \\
\text { Total Size of the } \\
\text { Basin }\end{array}$ & Total Inhabitants & $\begin{array}{l}\text { Percentage of the } \\
\text { Population to the } \\
\text { Total of the Basin }\end{array}$ \\
\hline Upper-SFR & 100,076 & $16 \%$ & $6,247,027$ & $48.8 \%$ \\
Middle-SFR & 402,531 & $63 \%$ & $3,232,189$ & $25.3 \%$ \\
Lower-middle- & 110,446 & $17 \%$ & $1,944,131$ & $15.2 \%$ \\
$\quad$ SFR & 25,523 & $4 \%$ & $1,372,735$ & $10.7 \%$ \\
Lower-SFR & $25,5 \%$ & &
\end{tabular}

Source: Created by the author using data from the CBHSF (2004) 


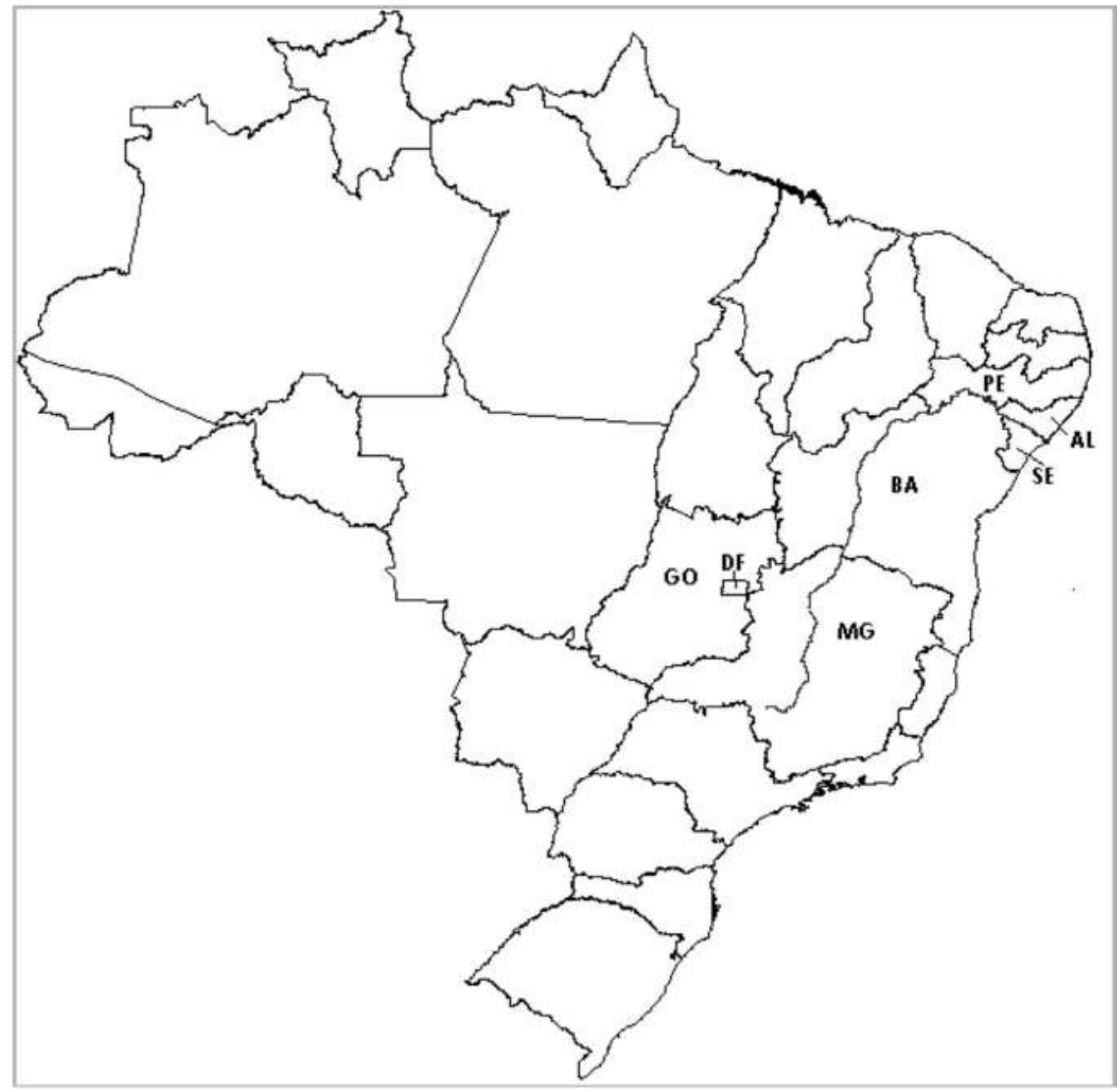

Figure 7.1 Sao Francisco River, Brazil.

Note: Areas from six states (Minas Gerais $=\mathrm{MG}$, Goiás=GO, Bahia=BA, Pernambuco=PE, Alagoas $=\mathrm{AL}$ and Sergipe $=\mathrm{SE}$ ) and the Brazilian Federal District (Distrito Federal) constitute the São Francisco River Basin.

Source: Figure 7.1 and Figure 7.2 are derived from georeferenced data available from http://siscom. ibama.gov.br/shapes visited on October 10, 2009 (IBAMA, 2009). Created by the author.

Rocha (1983) asserted that, during colonial times (1500-1815), the São Francisco served two major purposes for the nation: (1) its resources allowed population settlement in the basin, and (2) the river and its tributaries linked inland regions. Indigenous people, white Europeans, as well as African slaves and escapees comprised the early inhabitants of the valley (CODEVASF, 1978). Today, the basin is home for almost $8 \%$ of Brazil's population, the majority of which $(75 \%)$ lives in urban areas (CBHSF, 2004). The highest population density is located in the upper-SFR where the climate is tropical humid as well as in the tropical semi-humid lower-SFR (CBHSF, 2004). The birth of the SFR in the upper-SFR is situated further from the equator than the other parts of the river. That fact, 


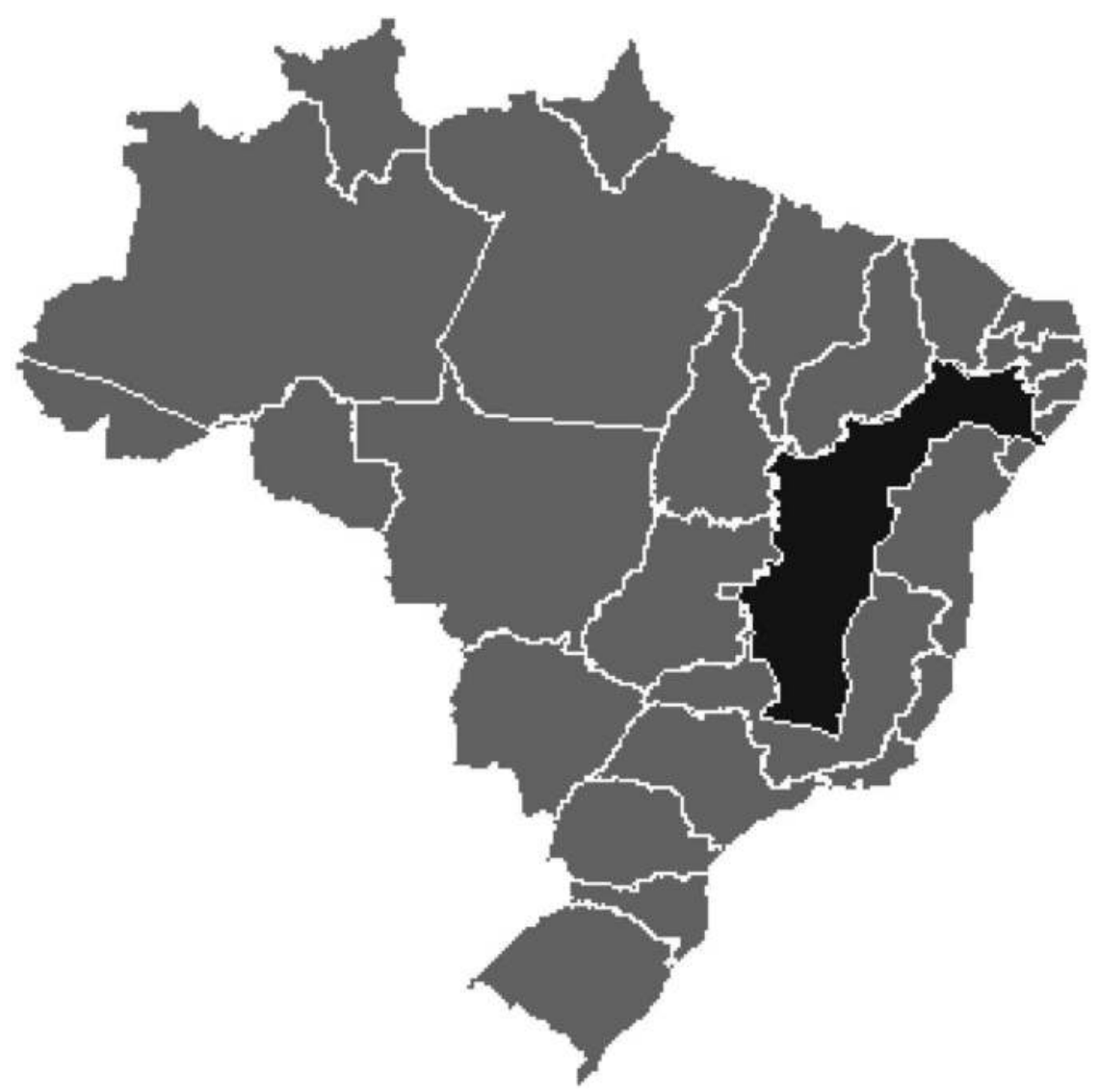

Figure 7.2 The Sao Francisco River Watershed.

associated with the high elevation contributes to lower air temperatures (CBHSF, 2004). A third climate condition prevails (SRH-MMA, 1998); nearly $57 \%$ percent of the basin is located in a semi-arid zone ${ }^{2}$ (CBHSF, 2004) and is naturally drought-prone. Ab'Sáber (1999) noted that in the northeast of Brazil droughts are recurrent climatic events.

In the upper-SFR and in the semi-arid region of the middle and lower-middleSFR, the winter, referred to as the irregular and short rainy period, is the wet season. It centers in the South American summer in the months of November to January. In the lower-SFR, it rains from May to June and August to September. The valley is susceptible to high evaporation rates. In the semi-arid zone, that number can be in average 79 inches annually (CBHSF, 2004). Consequently, rain-free seasons occur every year. However, the longer lasting droughts, which occur during consecutive years in the absence of rain, are the ones that reveal the face of human tragedy.

The duration and the intensity of droughts and the extent of the area affected determine the consequences. The effects on populations and local environment 


\section{Lucigleide Nery Nascimento}

of the Northeast are well documented (Sampaio, 1987; Cavalcanti, 1988; Cerqueira, 1988; José, 1988; Ab’Sáber, 1999; Kenny, 2002): hunger, death and loss of plants and animals. Migration is an escape valve for local inhabitants (Nascimento, 2010). Studies have linked drought in the Northeast of Brazil to the topography of the region, the soil's capacity to reflect solar radiation, the temporal and spatial inter-annual variability of rainfall and the El Niño (Serebrenick, 1953; Davis, 2001; SBPC, 2005; Nascimento, 2010). The place exemplifies the disparity between the regional reality and the view that Brazil is a water rich environment (Gleick, 2009).

\section{The users and uses}

The river has long been a source of spiritual, cultural, ecological and material sustenance. Local Brazilians sing and pray for the São Francisco; the river formed a backdrop for novels, movies, soap operas and religious events. The waterway supplied fish to the basin communities and the riverbanks supported riparian agriculture (Nascimento, 2010). Navigation was essential throughout the SFR valley (Pierson, 1972a,b,c; Neves, 1998). In the late 1940s to early 1950s, the economy of the municipalities of the valley was based upon herding, agriculture, gathering and, on a much smaller scale, manufacturing (Pierson, 1972abc). Fishing was an important subsistence activity in cultural and economic terms (Nascimento, 2010).

In Brazil, from 1930s to early 1990s, the state invested in the provision of basic inputs and infrastructure. Frieden (1981) asserted that the pro-growth state developed areas were areas that the private sector did not want or could not use. Some sectors were exclusively state business. For example, according to the 1934 Brazilian Constitution (Article 118 and Article 119) and the 1934 Water Code (Article 43, Article 63 and Article 139), the state was supposed to undertake or oversee the industrial use of the waters, such as for hydropower (1934 Brazilian Constitution; 1934 Water Code). Hydropower had all the incentives to become the major use of Brazilian rivers, as subsequent events show.

By the 1950s, electricity shortages and a growing demand for energy caused by urbanization cum industrialization challenged Brazilian development (Brewer 1954), and the government planned to change that. Indeed, in the São Francisco Basin, the first station producing electricity on a large-scale, Paulo Afonso I, went on-line in 1954. Through power lines, electricity started to flow outward from the valley in the same year (CHESF, 1998). A new notion of the São Francisco River emerged. In the post-1950 era, the geographical distance between the river and the users of its resources increased. It fostered a connection and dependence between human beings and a remote river environment that supplied the hydropower (Nascimento, 2010). 
Previously, in 1913, the first hydroelectric station, a product of private entrepreneurship, Usina Hidrelétrica Angiquinho or Delmiro Gouveia, started working near Paulo Afonso Waterfall (Figure 7.3). Due to the nature of this activity, a small-scale operation, the river kept following its major course and maintaining its natural level. However, after the 1940s, the construction of larger dams and electricity generation plants prompted vast environmental and socio-economic changes (CVSF, 1959; Hall, 1994; Collins and Krippner, 1999; CBHSF, 2004). Hydropower infrastructure made possible the existence of larger-scale irrigation systems such as canals and pumping stations (Collins, 1993) (Figure 7.4). The basin produces services ${ }^{3}$ such as the provision of electricity and also agricultural goods, not only for the valley's inhabitants, but for people in other parts of Brazil, and even international consumers (in the United States, the Netherlands and China) (Selwyn, 2007; Nascimento and Becker, 2008; Sampaio and Claudino, 2013). Consequently, two major perceptions of this river have come to dominate basin management discourse: those of the river as a power generator and as an irrigation water-provider. Irrigation now accounts for nearly $69 \%$ of the water withdrawal in the basin (CBHSF, 2004).

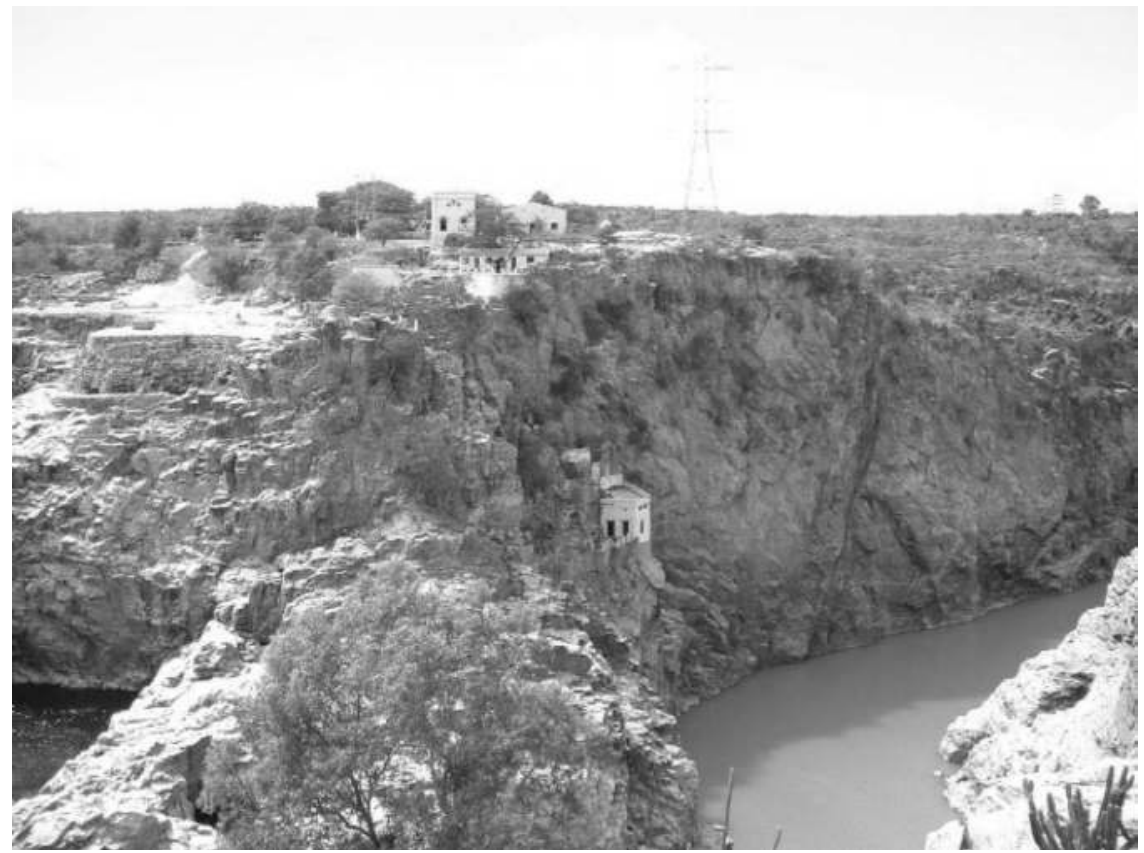

Figure 7.3 Hydropower stations: past.

Source: Photo Courtesy of the Author 


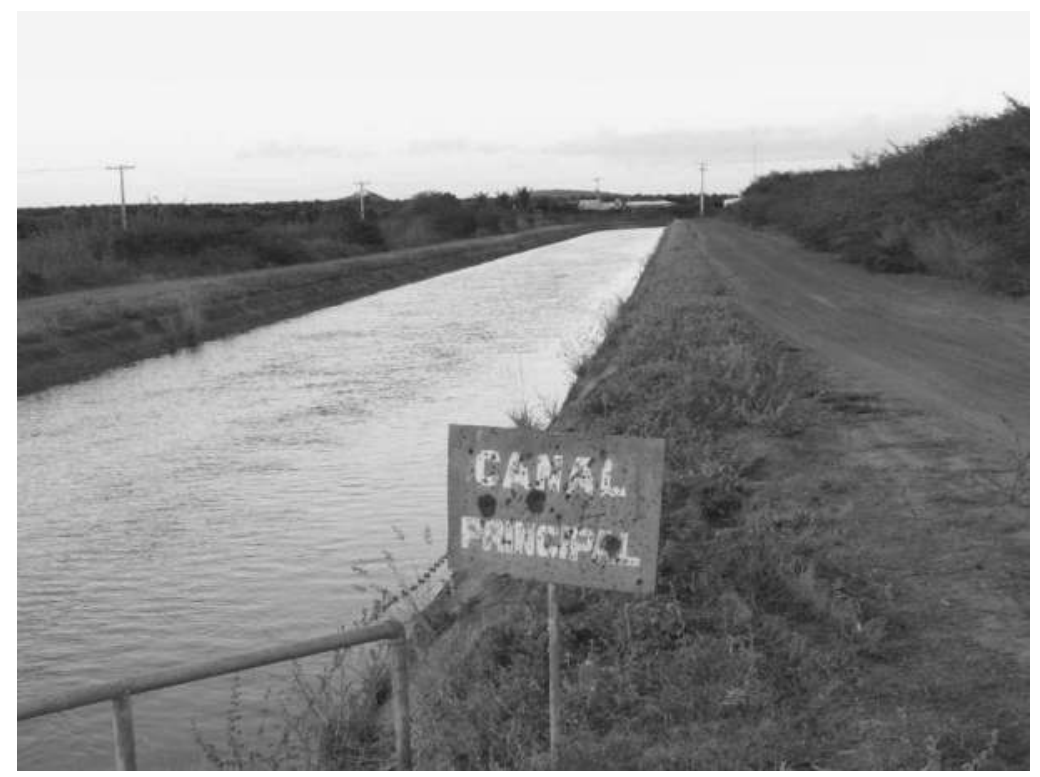

Figure 7.4 Infrastructure for irrigation.

Source: Photo Courtesy of the Author

\section{Stakeholders of management discourses at Velho Chico}

Governmental and private choices regarding the river are shaped by internal and external political and economic priorities (Carvalho and Silva, 2008). The World Bank financed the construction of dams, hydropower stations and irrigation schemes. The national government implemented structural adjustment programs that were overseen by the International Monetary Fund in exchange for loans (Carvalho and Silva, 2005). Adopting conventional development approaches, the government included energy and irrigation in national and north-eastern development programs, such as Plano Nacional de Desenvolvimento - PND (Santana, 1990).

Araújo (2004) concluded that, since the 1970s, the area devoted to growing traditional products (e.g., manioc) decreased in the Northeast. High market prices propelled the production of non-traditional crops, such as tomatoes, mangoes, grapes, sugar cane and soybeans (Collins, 1995, 2000; Silva et al, 2000; Araújo, 2004; Topik, 2006). Based on the commodity chain analysis, Collins (2000) noted that First World consumers influence products that grow in the valley. ${ }^{4}$ The selection of products is oriented by an export market and not local people's needs (Nascimento, 2010).

By 1960, in the São Francisco River Basin, 10,800 hectares were irrigated (CODEVASF, 2006). The National Water Agency predicted that about 400,000 hectares would be irrigated in the watershed by 2007 (ANA Resolution\# 145 of 
2002). Irrigation influenced changes from subsistence to large-scale agriculture. Nonetheless, intensive planting has many costs: major use of water and fertilizers, soil depletion and pollution (Nascimento, 2010).

In the Northeast and in the valley, studies have revealed the disparity among modern corporate agriculture and traditional communities (Caviedes and Muller, 1994; Marsden, 1997; Araújo, 2004). Critics assert that projects do not meet their goals regarding poverty alleviation, especially during the occurrence of droughts (Caviedes and Muller, 1994). Besides, continuing land ownership concentration supports the traditional power structure in the Northeast (rural oligarchies) (Hirschman, 1963; Hoge, 1983; Araújo, 2004).

\section{Who controls the river's flow?}

In addition to the diverse national constitutions (1934, 1937, 1946, 1967 and 1988) of the 20th century, the 1934 Water Code, under the responsibilities of the Agriculture Ministry, was the major law concerning water resources management for many years. It was an advanced piece of legislation for its time and included the concepts of the Polluter Pays Principle, User Pays Principle and a Water Use Right or Permit System (Pompeu 2006). In spite of these foresights, the Water Code failed to bear actual results (Pompeu 2006).

Article 143 of the 1934 Water Code stated that hydropower development had to meet various conditions: riparian communities would be guaranteed their basic survival needs met (food, water, shelter), navigation and irrigation would be facilitated, floods would be controlled and fish would be able to circulate and would be protected. However, a careful analysis of the 1934 Water Code reveals the existence of contradictory aims, such as flood control and fish circulation. In the case of the São Francisco, some prerequisites were not met. For example, dams were an obstacle to fish migration, the river was not managed for navigation as shown by the ever-shrinking portions open to navigation and people living close to the river had no access to public water supply (Nascimento, 2010).

The electric supply sector positioned itself as a planner and regulator of the hydro resources of the basin. Nine dams dictate the flow of the São Francisco (Table 7.2). Minas Gerais Energy Corporation (Companhia Energética de Minas Gerais - CEMIG) manages one and the São Francisco Hydropower Corporation (Companhia Hidro Elétrica do São Francisco - CHESF) controls eight of them. The natural average discharge in the lower part of the river is $2,850 \mathrm{~m}^{3} / \mathrm{s}$ (for the period of 1931-2001) (CBHSF 2004). Nevertheless, CHESF maintains an average flow level of $1,815 \mathrm{~m}^{3} / \mathrm{s}$ under normal circumstances, which creates an anomaly between observed natural discharge levels and planned normal discharge levels and robs the river of a part of its essential flow. The 10-year management plan for the basin established a minimal daily average flow discharge volume of $1,300 \mathrm{~m}^{3} / \mathrm{s}$ as the ecological discharge at the river's mouth. This is the level that allows the maintenance of aquatic life and ecosystem functions, though at times flow rates above this need to occur (CBHSF 2004; ANA Resolution\#412 of September 22, 2005). 
Table 7.2 Hydropower Stations

Operator - Unity - Reach of the River

Date went on-line

CHESF - Paulo Afonso I

1954

Lower-middle-SFR

CHESF - Paulo Afonso II

1961

Lower-middle-SFR

CEMIG - Três Marias

1962

Upper-SFR

CHESF - Paulo Afonso III

Lower-middle-SFR

CHESF - Apolonio Sales

Lower-middle-SFR

CHESF - Sobradinho

Lower-middle-SFR

CHESF - Paulo Afonso IV

Lower-middle-SFR

CHESF - Luiz Gonzaga

Lower-middle-SFR

CHESF - Xingó

Lower-SFR

Source: Created by the author using data from the CEMIG (2002) and CHESF (n.d.)

The 1997 Water Policy was supposed to change the predominance of the electric sector in the use of water. The policy introduced a new model: a holistic approach with decentralized decision-making. It sought to secure water availability in adequate quality for present and future generations and for multiple purposes. It aimed for rational and integrated use of water resources, including for transportation. It sought to prevent and to protect against natural and anthropogenic events caused by inadequate use of water resources, such biological and chemical pollution (Nascimento, 2010). In addition, the 1997 National Water Policy established that water use grants are subject to suspensions in special cases, such as an unexpected climatic event, to allow the water body to meet primary uses (e.g., drinking water supply) during these situations (Article 15). Direct human and animal supply constitute priority for the use under scarcity conditions. According to this policy, water is a public resource, and it is a finite resource with recognized economic value.

The legislation created new institutions and invested them with several tasks. For example, the National Water Agency - ANA (Agência Nacional de Águas) is in charge of issuing water use rights for any river that crosses more than one state (ANA 2015a). The National Water Resources Council - CNRH (Conselho Nacional de Recursos Hidricos) acts as a supreme arbiter, but despite the diversity of its members, representatives of entities from various levels of government occupy most of the positions on the CNRH. Watershed committees are a governmental entity, made up of representatives of water resource users groups, governmental 
managers and the civil society. Nonetheless, these have no enforcement or penalty power. The federal and state institutions are the ones that monitor and assure compliance with the law. A watershed committee is in charge of planning the use of the water resources of the watershed. In 2001, the former-president of Brazil, Fernando Henrique Cardoso, created the São Francisco River Basin Committee (CBHSF) (Nascimento, 2010) and introduced watershed-based management to an area of nearly $640,000 \mathrm{~km}^{2}$.

In practice, and in the São Francisco case, the new model, defined by the 1997 Water Policy, is not as participatory and decentralized as commentators suggest. The National Water Agency - ANA and the National Electric System Operator - ONS (Operador Nacional do Sistema Elétrico) are in charge of establishing criteria for the utilization of water resources and overseeing the use of water in reservoirs (Law n ${ }^{\circ} 9.984$ of July 17, 2000, Article 4). Consequently, regarding the meanings of the Velho Chico, power generation dominates. According to the World Resources Institute (2003), the São Francisco River is "strongly affected" by river fragmentation and flow regulation (WRI, 2003).

\section{The effects of extreme temporal and climatic events on the management of the river: the 2012-2015 drought}

Droughts lower the water flow and reduce the resources available in reservoirs. This affects water supply, agricultural production, hydropower generation and all the economic activities and people that depend on them. Studies by the National Water Agency (Agência Nacional de Águas - ANA, 2013, 2015b) showed an abnormal precipitation cycle and severity of droughts for the 2012-2014 period in both the Northeast and Southeast regions of Brazil. The ANA does not admit the phenomenon is direct consequence of climate change, but recognizes the low level of rainfall for those years as an anomaly (ANA 2013, 2015b), in accordance with other scientists (Escobar 2015).

Getirana (2015) investigated the drought in Eastern Brazil for the 2012-2015 period. The event depleted surface water storage, ground water and soil moisture (Getirana 2015). Referring to the findings of another study (Nazareno and Laurance, 2015), Getirana (2015) linked the extreme event to climate change and deforestation in the Amazon. According to Marengo (2009), extreme events do not conform to the average climatic state and present themselves as temporal (short-term) or climatic (long span). The abnormal occurrence still presented itself in 2015, especially in the Northeast, and influenced the low levels of water in reservoirs for multiple uses. In fact, the drought in that region of Brazil was worse than the one that happened in 2001, a period where power shortage measures had to be imposed (Figure 7.5).

According to Gleick (2016), water use and energy production have solid links, and "when less water is available in rivers or stored in reservoirs, less hydroelectricity is generated" (Gleick 2016, 5). The dependence on hydropower generation increased the level of susceptibility of the valley even more. Hydropower 
infrastructures and their management have led to changes in the landscape, and in both water and sediment flows (Lima et al, 2005; Alves et al, 2007; Nascimento, 2010). The alterations affected the provisions of other ecosystem services too, disturbing fish, fishery, fishermen and traditional riparian agriculture (Godinho and Godinho, 2003; Gutberlet et al, 2007; Nascimento, 2010).

Sobradinho Dam retains three-fourths of the sediment flow. The amount discharged into the sea is very small (Lima et al, 2005). At the river's mouth, as the load of sediments is reduced, sea waves accelerate beach erosion (Kondolf, 1997; Bittencourt et al, 2007). Because of the decrease in water and sediment flows at the mouth of the Velho Chico, the sea has completely washed out the waterfront village of Cabeço (Alves et al 2007; Bittencourt et al, 2007). "Damming directly affects the fish communities, because its changes on the river's flow regimes cause a higher frequency of extended periods without flooding" (Pompeu and Godinho 2006, 428). Studies show negatives consequences of dams on fish populations of the SFR (Godinho and Godinho, 2003; Gutberlet and Seixas, 2003; Alvim and Peret, 2004; Pompeu and Godinho, 2006; Alves et al, 2007; Gutberlet et al, 2007; Nascimento, 2010). Dams prevent the flooding of riparian lagoons (fish growth sites) and the inundation of floodplains (Alvim and Peret, 2004; Alves et al, 2007). The lack of periodic floods inhibits the ability of fish to enter and exit existing riparian inundated areas (Gutberlet and Seixas, 2003) and impedes the transport of fish eggs and youngsters from the

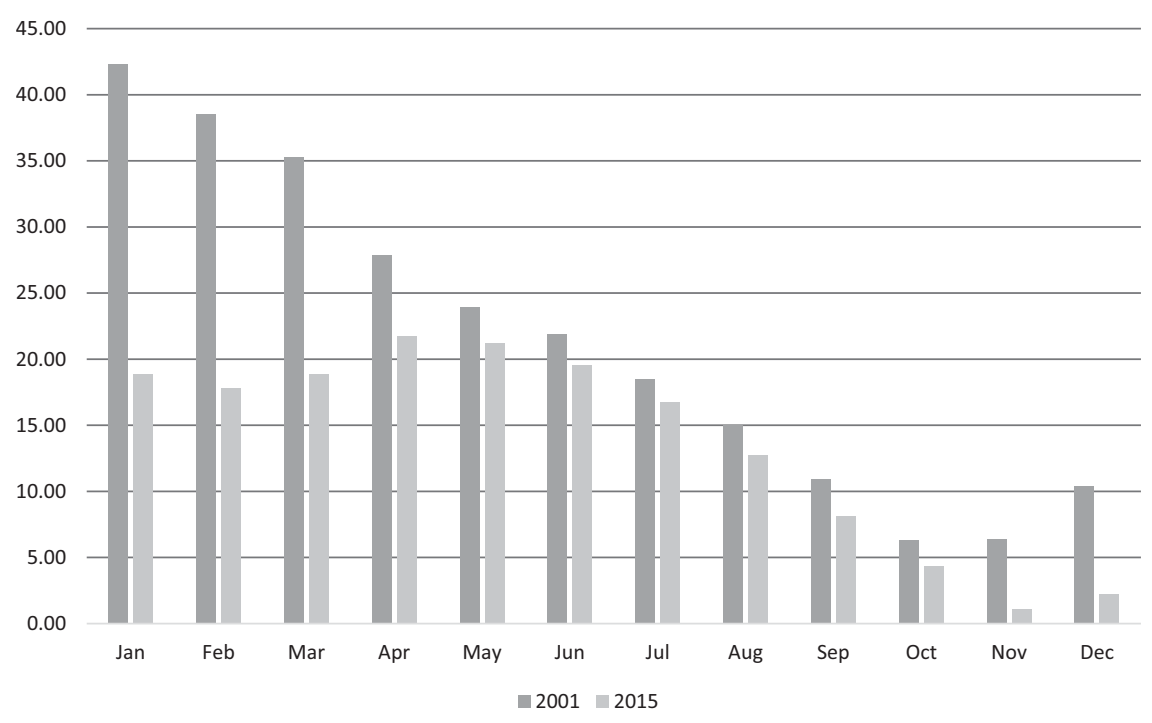

Figure 7.5 Percentage of water volume available (volume útil) in Sobradinho reservoir during two years of extreme droughts: 2001 and 2015.

Source: Created by the author with data from the National Electric System Operator (Operador Nacional do Sistema Elétrico - ONS, 2016). 
river's channel to the lagoons where mature fish spawn (Godinho and Godinho, 2003; Gutberlet et al, 2007). The lack of overflowing isolates these lagoons from the river's main channel and adult migratory fish cannot return to spawn (Pompeu and Godinho, 2006).

In the São Francisco, dams impair migration of species such as Dourado (Salminus spp.), Surubim (Pseudoplatystoma spp.), Matrinxã (Brycon melanopterus), Pirá (Conorhynchus conirostris) and Curimatã (Prochilodus spp) (Gutberlet and Seixas 2003). Migratory species seek their spawning grounds during the phase of reproduction and cannot return due to the barriers (Gutberlet and Seixas, 2003). LASA and TECNOSOLO report (1962) concluded that fish ladders would be inefficient in the case of Três Marias and Sobradinho Dams because they are over 6 meters. But navigation locks could be employed during reproductive seasons to allow migration (LASA and TECNOSOLO, 1962). Posteriori studies asserted that the height of the ladder is one among many important variables influencing the success of migration. The outcome is also associated with the design of the ladder, and the species, size and age of the fish (Orsborn, 1982-1984; Fernandez et al, 2004). Velho Chico's fish stock has continuously declined and the diversity of fish species has deteriorated (Sato and Godinho, 2003; IBGE, 2005; Nascimento, 2010). Dams have affected fish, fishing and fishermen; imposing socioeconomic impacts on traditional communities (Godinho and Godinho, 2003; Gutberlet et al, 2007; Nascimento, 2010).

Irrigated agriculture reshaped and created vulnerability in the valley (Marsden, 1997). In economic terms, the dependence on international markets has made the basin susceptible to worldwide crisis and fluctuations in the level of demand and price. It has exposed the system to global market forces and product requirements (Duarte, 1971). In environmental terms, the valley's economy is highly reliant on a scarce natural resource, water.

The discharge below its ecological level contributes to the river's ecosystems collapse due to changes in water characteristics, destruction of habitat and disturbance of species' reproductive cycles (Nascimento, 2010). During the 2012 to 2015 period of extreme drought, based on the National Electric System Operator's (Operador Nacional do Sistema Elétrico - ONS) demands, the National Water Agency (ANA) reduced the discharge from Sobradinho and Xingó reservoirs to assure power generation and, according to ANA, the multiple uses of the water resources of the São Francisco Basin (Table 7.3).

The important point is however that the temporary resolutions have allowed a discharge as low as $800 \mathrm{~m}^{3} / \mathrm{s}$. It implies a reduction of nearly $38 \%$ of the ecological flow, which means a decline in the discharge necessary to allow the sustainability of natural processes. For example, it increases the pressure over migratory species already under stress. The resolutions open temporary exceptions to the return of discharge to $1,300 \mathrm{~m}^{3} / \mathrm{s}$ for momentary boat navigation from Sobradinho to Juazeiro and require that the electricity company, CHESF, keeps the watershed users and Watershed Basin Committee informed during the period of reduced discharge. 
Table 7.3 Changing River Flows

\begin{tabular}{|c|c|c|c|}
\hline ANA Resolution/Year & Date of resolution & $\begin{array}{l}\text { Reduced discharge, in } \\
\text { Sobradinho and Xingó } \\
\text { reservoirs }\end{array}$ & Timeframe \\
\hline $442 / 2013$ & Apr 08, 2013 & $\begin{array}{l}\text { From } 1,300 \mathrm{~m}^{3} / \mathrm{s} \text { to } \\
1,100 \mathrm{~m}^{3} / \mathrm{s}\end{array}$ & Until Nov 30, 2013 \\
\hline $1406 / 2013$ & Dec 04, 2013 & $\begin{array}{l}\text { From } 1,300 \mathrm{~m}^{3} / \mathrm{s} \text { to } \\
1,100 \mathrm{~m}^{3} / \mathrm{s}\end{array}$ & Until Dec 31, 2013 \\
\hline $1589 / 2013$ & Dec 30, 2013 & $\begin{array}{l}\text { From } 1,300 \mathrm{~m}^{3} / \mathrm{s} \text { to } \\
\qquad 1,100 \mathrm{~m}^{3} / \mathrm{s}\end{array}$ & Until Jan 31, 2014 \\
\hline $102 / 2014$ & Jan 30, 2014 & $\begin{array}{l}\text { From } 1,300 \mathrm{~m}^{3} / \mathrm{s} \text { to } \\
\qquad 1,100 \mathrm{~m}^{3} / \mathrm{s}\end{array}$ & Until Feb 28, 2014 \\
\hline $333 / 2014$ & Feb 25, 2014 & $\begin{array}{l}\text { From } 1,300 \mathrm{~m}^{3} / \mathrm{s} \text { to } \\
\qquad 1,100 \mathrm{~m}^{3} / \mathrm{s}\end{array}$ & Until Mar 31, 2014 \\
\hline $416 / 2014$ & Mar 26, 2014 & $\begin{array}{l}\text { From } 1,300 \mathrm{~m}^{3} / \mathrm{s} \text { to } \\
1,100 \mathrm{~m}^{3} / \mathrm{s}\end{array}$ & Until Apr 30, 2014 \\
\hline $680 / 2014$ & Apr 30, 2014 & $\begin{array}{l}\text { From } 1,300 \mathrm{~m}^{3} / \mathrm{s} \text { to } \\
\qquad 1,100 \mathrm{~m}^{3} / \mathrm{s}\end{array}$ & Until Jul 31, 2014 \\
\hline $1046 / 2014$ & Jul 28, 2014 & $\begin{array}{l}\text { From } 1,300 \mathrm{~m}^{3} / \mathrm{s} \text { to } \\
\qquad 1,100 \mathrm{~m}^{3} / \mathrm{s}\end{array}$ & Until Ago 31, 2014 \\
\hline $1258 / 2014$ & Ago 25, 2014 & $\begin{array}{l}\text { From } 1,300 \mathrm{~m}^{3} / \mathrm{s} \text { to } \\
\qquad 1,100 \mathrm{~m}^{3} / \mathrm{s}\end{array}$ & Until Sep 30, 2014 \\
\hline $1514 / 2014$ & Sep 29, 2014 & $\begin{array}{l}\text { From } 1,300 \mathrm{~m}^{3} / \mathrm{s} \text { to } \\
\qquad 1,100 \mathrm{~m}^{3} / \mathrm{s}\end{array}$ & Until Oct 31, 2014 \\
\hline $1604 / 2014$ & Oct 30, 2014 & $\begin{array}{l}\text { From } 1,300 \mathrm{~m}^{3} / \mathrm{s} \text { to } \\
\qquad 1,100 \mathrm{~m}^{3} / \mathrm{s}\end{array}$ & Until Nov 30, 2014 \\
\hline $1778 / 2014$ & Nov 26, 2014 & $\begin{array}{l}\text { From } 1,300 \mathrm{~m}^{3} / \mathrm{s} \text { to } \\
1,100 \mathrm{~m}^{3} / \mathrm{s}\end{array}$ & Until Dec 31, 2014 \\
\hline $2050 / 2014$ & Dec 19, 2014 & $\begin{array}{l}\text { From } 1,300 \mathrm{~m}^{3} / \mathrm{s} \text { to } \\
\qquad 1,100 \mathrm{~m}^{3} / \mathrm{s}\end{array}$ & Until Jan 31, 2015 \\
\hline $85 / 2015$ & Jan 29, 2015 & $\begin{array}{l}\text { From } 1,300 \mathrm{~m}^{3} / \mathrm{s} \text { to } \\
\qquad 1,100 \mathrm{~m}^{3} / \mathrm{s}\end{array}$ & Until Feb 28, 2015 \\
\hline $132 / 2015$ & Feb 23, 2015 & $\begin{array}{l}\text { From } 1,300 \mathrm{~m}^{3} / \mathrm{s} \text { to } \\
\qquad 1,100 \mathrm{~m}^{3} / \mathrm{s}\end{array}$ & Until Mar 31, 2015 \\
\hline $206 / 2015$ & Mar 23, 2015 & $\begin{array}{l}\text { From } 1,300 \mathrm{~m}^{3} / \mathrm{s} \text { to } \\
1,100 \mathrm{~m}^{3} / \mathrm{s} \text { (and } \\
1,000 \mathrm{~m}^{3} \text { under low } \\
\text { charge) }\end{array}$ & Until Apr 30, 2015 \\
\hline $499 / 2015$ & Apr 30, 2015 & $\begin{array}{l}\text { From } 1,300 \mathrm{~m}^{3} / \mathrm{s} \text { to } \\
1,100 \mathrm{~m}^{3} / \mathrm{s} \text { (and } \\
1,000 \mathrm{~m}^{3} \text { under low } \\
\text { charge) }\end{array}$ & Until May 31, 2015 \\
\hline $602 / 2015$ & May 26, 2015 & $\begin{array}{l}\text { From } 1,300 \mathrm{~m}^{3} / \mathrm{s} \text { to } \\
1,100 \mathrm{~m}^{3} / \mathrm{s} \text { (and } \\
1,000 \mathrm{~m}^{3} \text { under low } \\
\text { charge) }\end{array}$ & Until Jun 30, 2015 \\
\hline $713 / 2015$ & Jun 29, 2015 & $\begin{array}{l}\text { From } 1,300 \mathrm{~m}^{3} / \mathrm{s} \text { to } \\
\quad 900 \mathrm{~m}^{3} / \mathrm{s}\end{array}$ & Until Jul 31 of 2015 \\
\hline $852 / 2015$ & Jul 27, 2015 & $\begin{array}{l}\text { From } 1,300 \mathrm{~m}^{3} / \mathrm{s} \text { to } \\
\quad 900 \mathrm{~m}^{3} / \mathrm{s}\end{array}$ & Until Oct 31, 2015 \\
\hline $1208 / 2015$ & Out 27, 2015 & $\begin{array}{l}\text { From } 1,300 \mathrm{~m}^{3} / \mathrm{s} \text { to } \\
\quad 900 \mathrm{~m}^{3} / \mathrm{s}\end{array}$ & Until Nov 30, 2015 \\
\hline
\end{tabular}




\begin{tabular}{llll}
\hline ANA Resolution/Year & Date of resolution & $\begin{array}{l}\text { Reduced discharge, in } \\
\text { Sobradinho and Xingó } \\
\text { reservoirs }\end{array}$ & Timeframe \\
\hline $1307 / 2015$ & Nov 30,2015 & $\begin{array}{c}\text { From } 1,300 \mathrm{~m}^{3} / \mathrm{s} \text { to } \\
900 \mathrm{~m}^{3} / \mathrm{s}\end{array}$ & Until Dec 20, 2015 \\
$1492 / 2015$ & Dec 18, 2015 & From 1,300 m³ to & Until Jan 31, 2016 \\
& Jan 28, 2016 & From $1,300 \mathrm{~m}^{3} / \mathrm{s}$ to & Until Mar 31, 2016 \\
$66 / 2016$ & & $800 \mathrm{~m}^{3} / \mathrm{s}$ & \\
\hline
\end{tabular}

Source: Created by the author based upon the National Water Agency - ANA's regulations

Extreme events in the Southeast and the Northeast resulted in economic costs for the larger society: higher energy bills. Under unfavorable climatic conditions (droughts), Brazil replaced hydropower by thermal power, a more expensive form of electricity generation. The fuel sources applied are natural gas, biomass and petroleum products (Nascimento, 2015).

Droughts increase the need for federal and state support. Cities in the basin have received from the Bahia State government financial aid and equipment to allow water pumping in a reservoir with a lower level (G1 GLOBO BAHIA 2015). The government of Alagoas State has announced an emergency plan to adjust the water withdrawal system to the new river conditions (CBHSF 2015). The Pernambucan Sanitation Agency (Companhia Pernambucana de SaneamentoCompesa) has also expressed the need to adapt its water supply system (CBHSF 2016), while the federal government has supplied resources to municipalities during drought-related emergencies.

\section{Assessing public participation}

Using the three dimensions (problem orientation, the social process and the decision process) of the Policy Sciences Analytic Framework (Lasswell, 1971, Clark, 2002) to assess the case of the São Francisco for the 1940s to 2008, Nascimento (2010) found several points. The interviewees perceived that: (1) the dams are the major inducer of socio-environmental alteration; (2) environmental changes affected local's support systems; (3) river restoration is necessary; (4) federal and governmental programs imposed on local people threatened their traditional way of life; and (5) access to water was still an issue of concern. Nascimento (2010) study's methods included those of qualitative field-based empirical research, such as critical assessment of secondary literature, field observations and interviews (fisherman, boat worker, small farmer, public employees-managers, cloth washer, rural worker, environmental organizations leaders, etc.).

The new form of management of the Velho Chico altered the structure of how the decisions are taken and how the organizations involved in the process interact. "Structural changes may take the form of shifts in the degree of participation in 
power-shaping and power-sharing; or in the allocation of power among decisionmaking organizations" (Lasswell 1965, 289). In theory, in the case of the SFR, it is possible to notice all those. In practice, the framework of governance shared the power of decision and management of the uses of the resources with new entities (e.g., National Water Agency). Nevertheless, it is still under the control of the executive branch of Brazilian government.

Local stakeholders approach has shifted from a past characterized mostly by reactive alternatives to a present that attempts to adopt preventive measures, such as the creation of a management plan for the basin (Nascimento, 2010). Alternatives should not only attempt to address a moment of crisis (Lasswell, 1971). Still, giving geographic (size of the basin, population density) and other limitations, such as financial resources, it is difficult to mobilize all interested groups in the valley.

\section{The traditional form of participation: citizen initiated}

Historically, political and socio-economic variables inhibited public participation in the valley (Nascimento, 2010). The possession of vast herds and large estates (latifúndio) determined the socio-political and economic status of Colonels (coronéis) (Chilcote, 1990). The influential figures also used guns to enforce their rule in a nation where power has ties to land (Chilcote, 1990). They benefited the most from anti-drought governmental support distributed based on political criteria. The colonel-client relationship meant the exchange of client's vote for favors or only promises (clientalism) (Forman, 1971; Pierson, 1972c). Older and newer colonels and their family members still exercise influences in the Brazil of the 21st century (Araújo, 2004).

From 1930 to 1945, Brazil had in power a strong populist and nationalist head of state, President Vargas. He applied a civil ruling approach to govern the country and emphasized decision-making at the national level, from 1937 to 1945. He attempted to reduce Colonel's influences (Chilcote, 1990; McCann, 2009; Nascimento, 2010). During his regime, regions such as the Northeast and the São Francisco Valley received national capital to foment policy to mitigate the effects of droughts and, later on, to trigger development (e.g., hydropower projects) (1934 Constitution; Nascimento, 2010). The 1964-1985 military dictatorship limited public participation from elections to associations. The government constrained, suppressed and even dictated how conflicts should be handled (Forman, 1971; Chilcote, 1990; Favareto, 2006).

Despite the restrictions, public engagement in the Northeast and in the valley occurred and changed in different ways. Water was one among many contested issues: agrarian reform, labour and workers' rights, assistance for the poor, threats to local identity and livelihood (Camara, 1971; Forman, 1971; Madden, 1991; Johnson, 2005; Lopes, 2007; McCann, 2009). Dams triggered a new form of participation of those affected by the perceived threat. The attention moved to the river and to discussions beyond social issues to include environmental magnitudes (Nascimento, 2010). 
In the late 1970s, the construction of a large hydropower infrastructure and its consequences instigated local protests, initially unorganized but later on included associations, cooperatives and unions, leaders of the Catholic Church and international non-governmental organizations (Favero and Santos, 2002; Goulet, 2005; Nascimento, 2010). The structured movement organized street demonstrations, halted construction vehicles, occupied working sites, stopped construction and then negotiated conditionality for relocation. Goulet (2005) asserted that the engagement of people affected by dams, over decades, was vital to the creation of the mandated participatory approach of the management of river systems in Brazil.

In the beginning of the 2000s, an inter-basin water transfer project (Transposição), still under construction, attracted attention and analysis regarding public participation. According to the National Integration Ministry (Ministério da Integração Nacional - MIN, 2004), the project (Projeto de Integração do Rio São Francisco com Bacias Hidrográficas do Nordeste Setentrional) will remove $3.5 \%$ of the SFR's available discharge at Sobradinho Reservoir $\left(63.5 \mathrm{~m}^{3} / \mathrm{s}\right)$. The water will leave the Velho Chico by two passages. The project will involve largescale infrastructure traversing part of the basin and other regions of the Northeast; a total of $720 \mathrm{~km}$ of aqueducts, 26 reservoirs and 2 small-scale hydropower plants and pumping stations (IBAMA Previous License\# 200 of 2005; IBAMA Notice\# 31 of 2005).

The Transposição will reduce CHESF's hydropower production by an estimated $2.4 \%$ (MIN, 2004). It will introduce changes into the water-receiver ecosystems too: "Water carries with it the imprint of its place of origin, including various types of microbial life and dissolved solids, temperature, corrosiveness, and taste" (Blatter et al, 2001, 46). It also carries the consequences of "the human processes to which it has been subjected" (Blatter et al, 2001, 46). The water will bring new aquatic species to the receiver region, including vectors of waterborne diseases. In addition, change in the fluvial regime of the São Francisco River is a possible risk (MIN, 2004). The project will include resettlement schemes (MIN, 2004). It has interfered with indigenous populations.

Conflicting goals and interests exist regarding the Transposição. According to MIN (2004), the project seeks to increase the access to water in the semi-arid region and to reduce uneven water availability among populations and basins of the Northeast. Nevertheless, the project does not guarantee water delivery to vulnerable individuals, the ones who need it the most: dispersed small-scale farmers in and outside the valley (Nascimento, 2010).

In 2005 and 2007, a Catholic Church Bishop, Luiz Flávio Cappio with the support of social organizations, such as Pastoral Land Commission, fishermen, small farmers, landless workers and many others, undertook hunger strikes to stop the inter-basin water transfer project and its socio-environmental costs. However, their efforts were unable to permanently stop the construction (Cappio, 2006; Laura, 2007; Nascimento, 2007). Other protests took place in and outside the valley (Figure 7.6). 


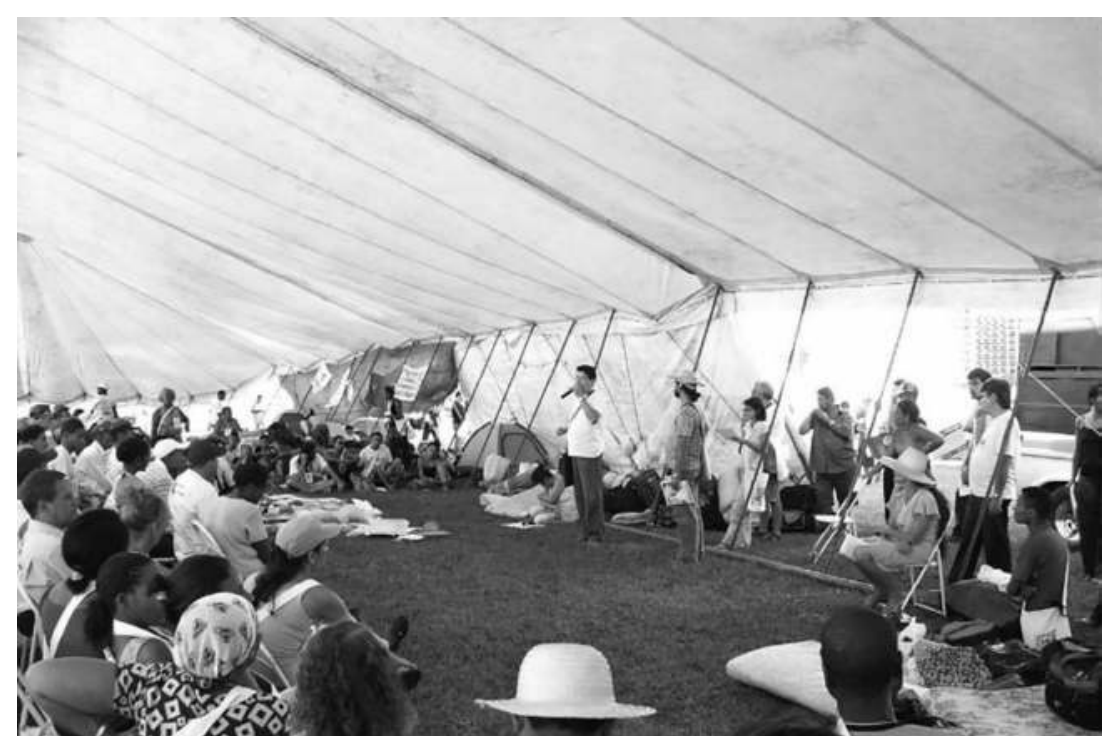

Figure 7.6 The civil society against the Inter-basin water transfer project: protests in Brasília.

Source: Lucigleide Nascimento, 2007

Something has not changed in the history of public participation in the Northeast: the presence of strong religious leaders, usually members of the Catholic Church. Padre Cicero, Dom Helder Câmara and Luiz Flávio Cappio are classical illustrations of public/citizen leadership intended to improve the life of the poor. In these cases, the ones in need were planned to be the beneficiaries of the actions; the religious figures fought in favor of the poor north-eastern populations. The support did not always come from their institution, the Catholic Church, but from its followers. The religious leaders and the organizations that they were able to involve held the belief that the condition of the lives of the deprived ones had to change.

Cicero Romão Batista, a Catholic priest, born in Crato, Ceará, engaged in politics (Della Cava 1968, Sanchis, 2007). From 1872 to 1934, in Juazeiro do Norte, Ceará, he led religious and political crusades against the governmental system and in favor of the poor. Besides being a priest, Padre Cicero was mayor, federal representative and vice-governor. He became the most popular religious figure of the region, a saint in believers' views (Della Cava, 1968). Padre Cicero or Batista was controversial. His actions, such as the recognition of what he and his followers, including priests, alleged to be miracles, did not make everyone happy, especially the hierarchy of his church (Della Cava, 1968; Sanchis, 2007). 
The Catholic Church expelled him in 1917 for breaking hierarchical rules. Due to the priest's popularity and ability to attract crowds of about two million pilgrims per year to Ceará, the church decided to review his case (Sanchis 2007).

From the 1930s to retirement in 1985, Dom Helder Câmara, the archbishop of Recife-Olinda, worked to improve the life conditions of the poor, people and nations, and was the image of Liberationist Catholicism. He reached a broad range of supporters from students to politicians, religious and lay individuals and had enemies as well; namely the officers of the military regime (Serbin, 1999). He confronted social, economic and spiritual issues (Camara, 1971).

Beginning in the 1950s, the Catholic Church's religious leaders engaged in a more participatory approach, seeking solutions to the socio-economic problems of the Northeast, such as the agrarian ones. For example, the National Conference of Brazilian Bishops - CNBB, which existed since 1952, had Dom Helder as its general secretary for over a decade (Serbin, 1999). Leading church figures got involved with the rural workers associations' movement and created and implemented assistance programs (Souza, 1979). Members of the church created ecclesiastical-based communities and later on pastoral commissions, such as the Pastoral Land Commission - CPT, which has been an important group involved in the citizen-initiated fight against dams and the inter-basin water transfer project.

Catholic religious leaders tried to do what they thought the government was not doing for the Northeast. They brought attention to the problems of the region, held meetings with members of governmental entities and were influential in the creation of a development agency: The Development Superintendence of the Northeast - SUDENE (Superintendência de Desenvolvimento do Nordeste) (Furtado 1989; Souza, 1979). Brazilian President Juscelino Kubitschek invited Dom Helder Câmara and representatives of various interest groups to a brainstorm session in Petrópolis in January of 1959. Dom Helder did not attend that meeting but he and the president met in a conference of Northeastern bishops held in Natal in May of that same year (Furtado, 1989).

\section{The new model}

Endorsed by the 1997 Water Policy, the new approach to water resources governance differs from, but coexists with, the old form of participation. Engagement is now legally mandated. The São Francisco River Basin Committee (CBHSF) exists since 2001. CBHSF, as any other watershed committee, is in charge of, among other things, conflict resolution at the first level of decision-making process on the matters of water resources of the basin and approval of the management plan (CNRH Resolution\# 5 of 2000, Article 7). It sets rules, decides on matters and acts as a consulting entity. It increased the debate on issues related to the basin and policy implementation and plans for the watershed. The natural boundaries of the river basin delineate the new governance system of the water resources of the valley, employing a more holistic alternative (Nascimento, 2010). 
Spokespersons of governmental entities (municipalities: states and federal, $32 \%)$, civil society $(26 \%)$, indigenous people $(3 \%)$ and water users $(39 \%)$ form the 62-member committee for the São Francisco watershed (Nascimento, 2010). The list of members includes associations and groups from different sectors: public water suppliers, industry and mining, agriculture and irrigation, boat owners, fishing and tourism, hydropower generators, environmental organizations, universities and other research associations and traditional communities, local/ state/federal government. The plenary session meets twice a year and decisions take place by consensus or by two-thirds of the members present at the plenary (CBHSF Bylaw of 2007). This process incorporates the input from the different stakeholder groups, representatives from various spheres of society, diverse backgrounds and social class. Participation for citizens occurs as representative of an organized group. The CBHSF is a place for debate.

During the 2012-2015 drought cycle, members of the civil society voiced their concern regarding the river. People gathered to protest against the condition of the Velho Chico. In addition, the president of the São Francisco River Basin Committee expressed the group's criticisms over the reduction of the river's discharge (CBHSF, 2015, 2016; ATarde, 2016). The low discharge is especially worrisome during the migratory fish reproductive cycle season (CBHSF, 2015). Nevertheless, in practice, time has shown that the CBHSF's influence is limited. For example, ANA has the decision power over the volume discharged by rivers with water reservoirs. Despite the diversity of members present during the discussions regarding the management of the SFR (such as the CBHSF, ANA, ONS, CHESF, mayors and irrigated farmers), ANA is the one in charge of the decision.

\section{Final remarks}

Located at a drought-prone environment, the São Francisco River is highly vulnerable to temporal and climate events. Despite of the climatic condition of the basin, a new notion of the São Francisco River crystalized in the post-1950 era and two major intensive applications of the Velho Chico's water dominated discourse and practice: hydropower and irrigation. For hydropower generation, nine dams are located on the São Francisco and such infrastructure has made possible the existence of larger-scale irrigation systems. Agriculture is an intensive activity that accounts for nearly $69 \%$ of the use of the water resources of the basin.

Internal and external political and economic priorities shaped government and private choices regarding the river. The geographical distance between the river and the users of its resources has increased because hydropower was destined for the northeast region, and commodities export came to surpass the impaired local uses for navigation, riparian agriculture and fishing.

The existence of the water reservoirs for hydropower generation places the Velho Chico's water resources under the management of the National Water Agency and thus, in practice, away from the decentralized model of management endorsed by the 1997 Water Policy. The new approach to water resources governance differs from, but coexists with, the older forms of participation in the basin. 
The new process mandates participation and is supposed by law to incorporate the input from the different stakeholder groups. Nevertheless, in practice, time has shown that the public's influence is limited, especially in rivers with water reservoirs.

In the case of the São Francisco, the river management robs the river of a part of its essential flow. The discharge is below its ecological level and contributes to the ecosystem's collapse, while impairing the provision of ecosystem services for both local and distant users. Recent extreme droughts have increased the pressure over and the conflict for the use of the scarce water resource of the Velho Chico. Locally, environmental and social costs have risen as development increased. Thus, the 1997 Water Policy has not yet reversed the negative ecological trends in this river system.

\section{Notes}

1 Lucigleide Nery Nascimento holds a BS in Economics, a MS in Natural Resources Environmental Conservation and a PhD in Natural Resources and Environmental Studies. She is an Specialist in Production of Economic, Social and Geoenvironmental information at the Superintendence of Economic and Social Studies of Bahia (Especialista em Produção de Informações Econômicas, Sociais e Geoambientais at Superintendência de Estudos Econômicos e Sociais da Bahia) - SEI, Salvador, Bahia, Brazil. The views and opinions expressed in this article are those of the author and do not necessarily reflect the official policy or position of any agency of the Bahian government.

2 A semiarid region has average annual precipitations equal or less than 800 millimeters (SUDENE, 2015).

3 "Ecosystem services are the benefits people obtain from ecosystems" (Millennium Ecosystem Assessment, 2005, sec.1, xiv). Other species and aspects depend on these assistances for existence. The assistance comprises four categories: provisioning, regulating, cultural and supporting.

4 For more on commodity chain analysis see Topik, S. et al (Eds.). From Silver to Cocaine: Latin American Commodity Chains and the Building of the World Economy, 1500-2000 (Durham, NC: Duke University Press), 2006.

5 Tests were undertaken to reduce the discharge (Special Authorization 001-2013 of April 1, 2013; Special Authorization 004-2014 of December 2, 2014; and Special Authorization 005-2015 of April 17, 2015).

\section{References}

Ab’Sáber, A. N. (1999) “Sertões E Sertanejos: Uma Geografia Humana Sofrida.” Estudos Avançados: Dossiê Nordeste Seco 13(36): 7-59.

Alves, N. M. S., Fontes, A. L., Silva, D. B. and Almeida, J. A. P. (2007) "Dinâmica Geoambiental, Processos Morfodinâmicos E Usos Das Terras Em Brejo Grande, Baixo São Francisco - Sergipe." Revista Brasileira de Geomorfologia 8(2):11-21.

Alvim, M. C. C. and Peret, A. C. (2004) "Food Resources Sustaining the Fish Fauna in a Section of the Upper São Francisco River in Três Marias, MG, Brazil.” Brazilian Journal of Biology 64(2):195-202.

ANA, Agência Nacional de Águas (2013). Conjuntura dos Recursos Hídricos no Brasil: 2013, ANA, Brasília, D. F., http://conjuntura.ana.gov.br/docs/conj2013_rel.pdf, accessed 13 August 2015. 


\section{Lucigleide Nery Nascimento}

ANA, Agência Nacional de Águas (2015) Conjuntura dos Recursos Hídricos no Brasil - informe 2014: encarte especial sobre a crise hídrica, ANA, Brasília, D. F., http:// conjuntura.ana.gov.br/docs/crisehidrica.pdf.

Araújo, T. B. (2004) "Northeast, Northeasts: What Northeast?" Latin American Perspectives, 31-2(135):16-41.

ATarde (2016) "Reunião debaterá a crise hídrica na Bahia." ATarde Online, http://atarde. uol.com.br/static/intertitial?id=1739743-reuniao-debatera-a-crise-hidrica-na-bahia

Beyer, R. C. (1968) 'The Search for Identity: Two Very Different Approaches', Journal of Inter-American Studies 10(3): 345-349.

Bittencourt, A. C. S. P., Dominguez, J. M. L., Fontes, L. C. S., Sousa, D. L., Silva, I. R. and Silva, GF. R. S. (2007) "Wave Refraction, River Damming, and Episodes of Severe Shoreline Erosion: The São Francisco River Mouth, Northeastern Brazil.” Journal of Coastal Research 23(4): 930-938.

Blatter, J., Ingram, H. and Levesque, S. L. (2001) "Expanding Perspectives on Transboundary Water." In Reflections on Water: New Approaches to Transboundary Conflicts and Cooperation, edited by J. Blatter and H. Ingram. London: MIT Press.

Brewer, S. P. (1954) "Power Shortage Eased in Brazil." The New York Times, 20 November, 8.

Camara, H. (1971) Spiral of Violence. London: Sheed and Ward.

Cappio, D. L. F. (2006) "Carta Ao Presidente Da República De Dom Luiz Flávio Cappio Bispo Diocesano De Barra, BA. Brasília, 15 De Dezembro De 2005.” Estudos Avançados 20(56): 284-285.

Carvalho, M. A. and Silva, C. R. L (2005) "Vulnerabilidade do Comércio Agrícola Brasileiro." Revista Econômica do Nordeste 43(1): 9-28.

Carvalho, M. A. and Silva, C. R. L (2008) "Mudanças Na Pauta Das Exportações Agrícolas Brasileiras." Revista Econômica do Nordeste 46(1): 53-73.

Cavalcanti, C. (1988) "A Seca Do Nordeste Brasileiro: Uma Visão De Estudos E Pesquisas Elaborados Em Um Século De Produção De Conhecimento.” Revista Econômica do Nordeste 19(1): 97-127.

Caviedes, C. N., and Muller, K. D. (1994) "Fruticulture and Uneven Development in Northeast Brazil." Geographical Review 84(4): 380-393.

CBHSF, Comitê da Bacia Hidrográfica do Rio São Francisco (2004) Plano De Recursos Hídricos Da Bacia Hidrográfica Do Rio São Francisco, 337. Salvador: CBHSF.

CBHSF, Comitê da Bacia Hidrográfica do Rio São Francisco (2015) "Agonia do Velho Chico aumenta com vazão ainda menor." http://cbhsaofrancisco.org.br/ agonia-do-velho-chico-aumenta-com-vazao-ainda-menor/.

CBHSF, Comitê da Bacia Hidrográfica do Rio São Francisco (2016) "ONS admite o uso do volume morto de Sobradinho." http://cbhsaofrancisco.org.br/ons-admite-o-uso-dovolume-morto-de-sobradinho/.

Cemig, Companhia Energética de Minas Gerais (2002) 'Usina - Três Marias', www.cemig.com.br.

Cerqueira, P. C. L. (1988) “A Seca No Contexto Social Do Nordeste.” Cadernos do Centro de Estudos e Ação Social 115: 13-33.

CHESF, Companhia Hidro Elétrica do São Francisco (1998) 50 Anos Chesf: Companhia Hidro Elétrica Do São Francisco - 1948-1998. Recife: CHESF.

CHESF, Companhia Hidro Elétrica do São Francisco (n.d.) "Parque de Geração." www. chesf.gov.br.

Chilcote, R. H. (1990) Power and the Ruling Classes in Northeast Brazil: Juazeiro and Petrolina in Transition. Cambridge: Cambridge University Press.

Clark, T. W. (2002) The Policy Process. New Haven, CT: Yale University Press.

CODEVASF, Companhia de Desenvolvimento do Vale do São Francisco. 1978. São Francisco O Rio Da Unidade. Brasília: Mercedes-Benz do Brasil S.A. 
CODEVASF - Companhia de Desenvolvimento dos Vales do São Francisco e do Parnaíba (2006) "Irrigação: Histórico E Vantagens." www.codevasf.gov.br/ menu/os_vales/ historico.

Collins, J. L. (1993) "Gender, Contracts and Wage Work: Agricultural Restructuring in Brazil's São Francisco Valley." Development and Change 24: 53-82.

Collins, J. L. (1995) "Farm Size and Non-Traditional Exports: Determinants of Participation in World Markets." World Development 23(7): 1103-1114.

Collins, J. L. (2000) "Tracing Social Relations in Commodity Chains: The Case of Grapes in Brazil." In Commodities and Globalization: Anthropological Perspectives, edited by A. Haugerud, M. Priscilla Stone, and P. D. Little, 97-109. New York: Rowman \& Littlefield.

Collins, J. L., and Krippner, G. R. (1999) "Permanent Labor Contracts in Agriculture: Flexibility and Subordination in a New Export Crop." Comparative Studies in Society and History 41(3): 510-534.

CVSF, Comissão do Vale do São Francisco (1959) Comissão Do Vale Do São Francisco: 10 Anos De Realizações - Volume X. Rio de Janeiro: CVSF por Indústrias Gráficas Brasiluso.

Davis, M. (2001) Late Victorian Holocausts: El Niño Famines and the Making of the Third World. London: Verso.

Della Cava, R. (1968) "Brazilian Messianism and National Institutions: A Reappraisal of Canudos and Joaseiro.” The Hispanic American Historical Review 48(3): 402-420.

Duarte, P. de Queiroz (1971) O Nordeste Na II Guerra Mundial: Antecedentes E Ocupação. Rio de Janeiro: Record.

Escobar, H. (2015)"Drought Triggers Alarms in Brazil's Biggest Metropolis: Water Shortages Blamed on Climate Anomaly, Tardy Response.” Science 347(6224): 812.

Favareto, A. (2006) "Agricultores, Trabalhadores: Os Trinta Anos Do Novo Sindicalismo Rural No Brasil." Revista Brasileira de Ciências Sociais 21(62): 27-44.

Favero, C. A., and Rodrigues dos Santos, S. (2002) Semi-Árido: Fome, Esperança, Vida Digna. Salvador: UNEB.

Fernandez, D. R., Agostinho, A. A. and Bini, L. M. (2004) "Selection of an Experimental Fish Ladder Located at the Dam of the Itaipu Binacional, Paraná River, Brazil.” Brazilian Arquives of Biology and Technology 47(4): 579-586.

Forman, S. (1971) "Disunity and Discontent: A Study of Peasant Political Movements in Brazil." Journal of Latin American Studies 3(1): 3-24.

Frieden, J. (1981) "Third World Indebted Industrialization: International Finance and State Capitalism in Mexico, Brazil, Algeria, and South Korea." International Organization 35(3): 407-431.

Furtado, C. (1989) A Fantasia Desfeita. Rio de Janeiro: Paz e Terra,.

G1 Globo Bahia (2015) "SIHS autoriza uso de R\$ 4,5 mi para conter efeitos da seca em Sobradinho." G1 Globo Bahia Online. http://g1.globo.com/bahia/noticia/2015/11/ sihs-autoriza-uso-de-r-45-mi-para-conter-efeitos-da-seca-em-sobradinho.html.

Getirana, A. (2015) "Extreme Water Deficit in Brazil Detected From Space." Journal of Hydrometeorology 17: 591-599. DOI:10.1175/JHM-D-15-0096.1

Gleick, P. (2009) The World's Water 2008-2009: The Biennial Report on Freshwater Resources. Washington: Island Press.

Gleick, P. (2016) Impacts of California's Ongoing Drought: Hydroelectricity Generation 2015 Update. Oakland, CA: Pacific Institute.

Godinho, H. P. and Godinho, A. L. (Org.) (2003) Águas, Peixes e Pescadores do São Francisco das Minas Gerais. Belo Horizonte: Pontifícia Universidade Católica de Minas Gerais.

Goulet, D. (2005) "Global Governance, Dam Conflicts, and Participation." Human Rights Quarterly 27: 881-907. 


\section{Lucigleide Nery Nascimento}

Gutberlet, J. and Seixas, C. S. (2003) “Avaliação De Campo: A Situação Sócio-Econômica De Comunidades De Pesca No Alto, Médio E Baixo Rio São Francisco - Uma Avaliação Rápida E Independente."

Gutberlet, J., Seixas, C. S., Thé, A. P. G. and Carolsfeld, J. (2007) "Resource Conflicts: Challenges to Fisheries Management at the São Francisco River, Brazil." Human Ecology 35: 623-638.

Hall, A. (1994) "Grassroots Action for Resettlement Planning: Brazil and Beyond." World Development 22(12): 1793-1809.

Hirschman, A. O. (1963) "Brazil's Northeast." In Journeys Towards Progress, edited by A. O. Hirschman. London: Twentieth Century Fund.

Hoge, W. (1983) "Rural 'Colonels' of Brazil: Their Power Never Dies.” The New York Times, 25 January, www.nytimes.com/1983/01/25/world/rural-colonels-of-brazil-theirpower-never-dies.html

IBGE, Instituto Brasileiro de Geografia e Estatística (2005) Pesquisa De Informações Básicas Municipais - Perfil Dos Municípios Brasileiros: Meio Ambiente 2002. Rio de Janeiro: IBGE. Johnson, A. M. C. (2005) "Subalternizing Canudos." Hispanic Issue: 355-382

José, E. (1988) "Tucano: O Sertão E a Luta Pela Água, Terra, Vida." Cadernos do Centro de Estudos e Ação Social, 114: 23-39.

Kenny, M. L. (2002) "Drought, Clientalism, Fatalism and Fear in Northeast Brazil." Ethics, Place and Environment, 5(2): 123-34.

Kondolf, M. (1997) "Hungry Water: Effects of Dams and Gravel Mining on River Channels." Environmental Management 21(4): 533-51.

LASA, Levantamentos Aerofotogramétricos S.A., and Engenharia e Tecnologia de Solos e Materiais S.A. TECNOSOLO (1962) Barragem De Sobradinho: Aproveitamento Múltiplo - Rio São Francisco. Rio de Janiero: Comissão do Vale do São Francisco - CVSF.

Lasswell, H. D. (1965) "The Policy Sciences of Development." World Politics 17(2): 286-309.

Lasswell, H. D. (1971) A Pre-View of Policy Sciences. New York: Elsevier.

Laura, C. (2007) "Ato Público Reúne Quase Cinco Mil Pessoas Em Solidariedade a Dom Luiz Cappio." ATarde Online, www.atarde.com.br

Lima, J. E. F. W., Lopes, W. T. A. Carvalho, N. O. C., Vieira, M. R. and Silva, E. M. (2005) "Suspended Sediment Fluxes in the Large River Basins of Brazil." Paper presented at the Symposium S1 - Seventh IAHS Scientific Assembly, Foz do Iguaçu, Brazil, April 2005

Lopes, E. S. A. (2007) “Um Balanço Da Luta Pela Terra Em Sergipe.” Scientia Plena 3(1): 6-17.

Madden, L. (1991) "Evolution in the Interpretations of the Canudos Movement: An Evaluation of the Social Sciences." Luso-Brazilian Review 28(1): 59-75.

Marengo, J. A. (2009) "Impactos de extremos relacionados com o tempo e o clima impactos sociais e econômicos." Boletim do Grupo de pesquisa em mudanças Climáticas, Cachoeira paulista, SP 8, 01-05. http://mudancasclimaticas.cptec.inpe.br/ rmclima/ pdfs/newsletters/boletim_no8_port.pdf

Marsden, T. K. (1997) "Reshaping Environments: Agriculture and Water Interactions and the Creation of Vulnerability." Transactions of the Institute of British Geographers, New Series 22(3): 321-37.

McCann, F. D. (2009) Soldados da Pátria: História do Exército Brasileiro, 1889-1937, translated by Laura Teixeira Motta. São Paulo: Companhia das Letras.

Millennium Ecosystem Assessment (2005) Ecosystems and Human Well-Being: Synthesis. Washington, DC: Island Press.

MIN, Ministério da Integração (2004) Projeto De Integração Do Rio São Francisco Com Bacias Hidrográficas Do Nordeste Setentrional - Relatório De Impacto Ambiental - Rima. Brasília: Ministério da Integração Nacional. 
Nascimento, L. N. (2007) "Brazilian Bishop on Hunger Strike to Protect River." World Rivers Review 22(4).

Nascimento, L. N. (2010) The Long Journey to Become the River of National Unity: The São Francisco River Basin From 1940s to 2008 and the Interactions of Environment, Government and Citizens. Durham: University of New Hampshire.

Nascimento, L. N. (2015) Custos socioeconômicos e ambientais decorrentes de eventos extremos de tempo elou clima para o estado da Bahia: o caso do setor elétrico. Salvador, BA: Superintendência de Estudos Econômicos e Sociais da Bahia - SEI, Textos Para Discussão 10. www.sei.ba.gov.br/index.php?option $=$ com_content $\&$ view $=$ article\&id $=803 \&$ Itemid $=110$

Nascimento, L. N. and Becker, M. L. (2008) "The Implications of the Virtual Water Trade and Virtual Environmental Degradation Trade for the São Francisco River Basin in Brazil." Revista Ciências Administrativas 14(2): 175-190.

Nazareno, A. G. and Laurance, W. F. (2015) "Brazil's drought: Beware deforestation." Science 347(6229):1427-1427

Neves, Z. (1998) Navegantes Da Integração: Os Remeiros Do Rio São Francisco. Belo Horizonte: Editora UFMG.

Neves, Z. (2006) Na Carreira Do Rio São Francisco: Trabalho E Sociabilidade Dos Vapozeiros. Belo Horizonte: Editora Itatiaia.

ONS, Operador Nacional do Sistema Elétrico (2015) Volume útil dos principais reservatórios. www.ons.org.br/historico/percentual_volume_util_out.aspx\# Accessed 3 March.

Orsborn, J. (1982-1984) "New Concepts in Fish Ladder Design, Volume I of IV; Summary." Bonneville Power Administration - BPA Report DOE/BP - 36523-2, Portland, OR: Bonneville Power Administration.

Pierson, D. (1972a) O Homem No Vale Do São Francisco, 1, Superintendência do Vale do São Francisco - SUVALE, Rio de Janeiro: SUVALE.

Pierson, D. (1972b) O Homem No Vale Do São Francisco, 2, Superintendência do Vale do São Francisco - SUVALE. Rio de Janeiro: SUVALE.

Pierson, D. (1972c) O Homem No Vale Do São Francisco, 3, Superintendência do Vale do São Francisco - SUVALE. Rio de Janeiro: SUVALE.

Pompeu, C. T. (2006) Direito De Águas No Brasil. São Paulo: Editora Revista dos Tribunais. Pompeu, P. S. and Godinho, H. P. (2006) "Effects of Extended Absence of Flooding on the Fish Assemblages of Three Floodplain Lagoons in the Middle Sao Francisco River, Brazil." Neotropical ichthyology: official journal of the Sociedade Brasileira de Ictiologia 4(4): 427-433.

Rocha, G. (1983) O Rio São Francisco: Fator Precípuo Da Existência Do Brasil. 3rd ed. São Paulo: Companhia Editora Nacional.

Sampaio, J. and Claudino, A. (2013) "Vale do São Francisco: Investimento Rende Frutos." www.sdec.pe.gov.br/clipping/vale-do-sao-francisco-investimento-rende-frutos/

Sampaio, Y. (1987) "O Setor Público E as Secas: Uma Reflexão Sobre a Ação Governmental Em Relação Às Secas Nos Últimos 25 Anos.” Revista Econômica do Nordeste 18(1): 27-48.

Sanchis, P. (2007) "Desponta Novo Ator No Campo Religioso Brasileiro? O Padre Cícero Romão Batista." Religião Eु Sociedade 27(2): 11-29.

Santana, J. F. De. ed. (1990) Modernização Regional Em Curso - 30 Anos De Sudene. Recife: Impressão Gráfica SUDENE.

Santos, H. A., Pompeu, P. S., Kenji, D. O. L. (2012) 'Changes in the flood regime of São Francisco River (Brazil) from 1940 to 2006', Reg. Environ. Change, 12: 123-132.

Sato, Y. and H. P. Godinho (2003) "Migratory Fishes of the São Francisco River" in Migratory Fishes of South America, edited by J. Carolsfeld, B. Harvey, C. Ross and A. Baer. Ottawa: The World Bank. 


\section{Lucigleide Nery Nascimento}

SBPC, Sociedade Brasileira Para o Progresso da Ciência (2005) "As Incertezas Do Projeto De Transposição." Ciência Hoje - Revista de Divulgação Científica da SBPC: O Rumo do Velho Chico: Benefícios e Incertezas da Transposição das Águas do Rio São Francisco, Julho, 48-52.

Selwyn, B. (2007) "Labour Process and Workers' Bargaining Power in Export Grape Production, North East Brazil." Journal of Agrarian Change 7(4): 526-553.

Serbin, K. P. (1999) 'Obituary: Dom Helder Camara.' NACLA Report on the Americas 33(3): 51-53.

Serebrenick, S. (1953) Condições Climáticas Do Vale Do São Francisco: Clima - Enchentes E Estiagens - Reflorestamento, 136. Rio de Janeiro: Comissão do Vale do São Francisco CVSF - Departamento de Imprensa Nacional.

Silva, J. M. A., Rezende, A. M. and Silva, C. A. B. (2000) "Condicionantes Do Desenvolvimento Do Pólo Agroindustrial De Petrolina/Juazeiro." Revista Econômica do Nordeste 31(1): 48-64.

Souza, J. G. (1979) O Nordeste Brasileiro: Uma Experiência De Desenvolvimento Regional. Fortaleza: Banco do Nordeste do Brasil.

SRH-MMA, Secretaria de Recursos Hídricos do Ministério do Meio Ambiente (1998) Atlas Hidrológico Do Brasil - Versão 1.0, http://ana.gov.br/Bacias/SFrancisco/ BacSaoFrancisco.htm

SUDENE, Superintendência de Desenvolvimento do Nordeste (2015) Semiárido. www. sudene.gov.br/acesso-a-informacao/institucional/area-de-atuacao-da-sudene/semiarido.

Topik, S. (ed) (2006) From Silver to Cocaine: Latin American Commodity Chains and the Building of the World Economy, 1500-2000. Durham, NC: Duke University Press.

WRI, World Resources Institute (2003) "Watersheds of the World - CD [Online]." http:// water.wri.org/pubs_pdf.cfm?PubID=3818.

\section{Legislation}

Agência Nacional de Águas Resolutions: 145/2002, 412/2005, 442/2013, 602/2013, $1406 / 2013,1589 / 2013,102 / 2014,333 / 2014,416 / 2014,680 / 2014,1046 / 2014,1258 / 2014$, 1514/2014, 1604/2014, 1778/2014, 2050/2014, 85/2015, 132/2015, 206/2015, 499/2015, 602/2015, 713/2015, 852/2015, 1208/2015, 1307/2015, 1492/2015 e 66/2016

Agência Nacional de Águas Special Authorization 001-2013 of April 1st, 2013

Agência Nacional de Águas Special Authorization 004-2014 of December 02, 2014

Agência Nacional de Águas Special Authorization 005-2015 of April 17, 2015

Comitê da Bacia Hidrográfica do São Francisco Bylaw 2007

Conselho Nacional de Recursos Hídricos Resolution no 5 of 2000

Brazilian Constitutions: Constituição da República Federativa do Brasil 1934, Constituição da República Federativa do Brasil 1937, Constituição da República Federativa do Brasil 1946, Constituição da República Federativa do Brasil 1967 and Constituição da República Federativa do Brasil 1988

Federal Law Código de Águas - the Water Code no 24, 643 of 1934

Federal Law Lei das Águas - the National Water Policy no 9.433 of 1997

Federal Law Criação da Agência Nacional de Águas - Creation of the National Water Agency no 9.984 of 2000

Instituto Brasileiro do Meio Ambiente e dos Recursos Naturais Renovaveis Notice 31 of 2005

Instituto Brasileiro do Meio Ambiente e dos Recursos Naturais Renováveis Previous License 200 of 2005 


\title{
8 Rivers as vernacular landscapes
}

\author{
Place and experience in making \\ the Clutha River, New Zealand
}

\author{
Andrea Farminer
}

\section{Rivers, landscape and place}

Rivers are embodied with multiple meanings and values, geographic, economic, political and socio-cultural, that have been shaped, claimed and frequently contested into the present. The freshwater values that rivers represent have strongly influenced how people-river relationships are understood and valued. For example, many western countries such as the US and the UK have employed utilitarian economic frameworks to capture and express these values, which abstract and simplify rivers into unitary values. At the same time, rivers have often been ring-fenced within human thought by their association with the commonly held concept of landscape as an external, fixed entity, divorced from the activities of everyday life. In doing so, these approaches overlook the complexities and richness that people-river relationships offer when framed and explored through the concept of place relationships, and, at a deeper level, rivers as multiple places constructed through everyday experience over time. This chapter seeks to explore these concepts and relationships, firstly, through briefly exploring the conceptual framings of landscape, place and rivers, followed by selected examples from a recent study focused on exploring and understanding the place relationships and expressions of vernacular landscape of a group of participants with the Clutha River, Otago, New Zealand. Finally, the chapter discusses the tensions in framing rivers such as the Clutha as vernacular landscapes and how place-meanings sit in relating to the concept of the Clutha River as a vernacular landscape.

\section{The idea of landscape and its cultural geographical bearings}

'Landscape' is a troublesome word. Many esteemed volumes of writing and thought line the shelves of libraries across the world, devoted to defining, exploring and redesigning the landscape. For some scholars, landscape is an ideal to return to, for others, one to reclaim and mould to some current cultural ideal or desire, or a location of conflict and tension (Cronon 1996; Macnaghten and Urry 1998). For many people, 'landscape' is a given, a taken-for-granted word that needs no explanation: it is around us (of course), outside, we go into the landscape and we look at landscape and appreciate its beauty (or not). But our experience of 
landscape is a binary one; we experience it primarily through our visual senses and mobility and are always in the landscape, but at the same time we are apart, separate from landscape, which remains external to us (Ingold 2000).

The noted American landscape writer, John Brinckerhoff Jackson, discussed the many interpretations of the meaning of landscape, and concluded that a new definition was needed, although he was reluctant to propose one directly (Jackson 1984, 8). However, Jackson did suggest a re-definition that centred on 'a composition of man-made or man-modified spaces to serve as infrastructure or background for our collective existence'. Although he acknowledged that the word 'background' appeared rather modest, he also noted it meant 'that which underscores not only our identity and presence, but also our history'.

From a different scholarly perspective, John Bradley suggested the following interpretation of the meaning of landscape (Bradley 2011, 47):

the notion of landscape has been constructed in diverse ways over the last century, each according to the dominant ideas, theories and paradigms of the time. As such, landscape has always been a Western epistemological view of the world. [Barbara] Bender describes it as 'the western gaze': a historically defined way of viewing the world that creates a separation between nature (the object) and culture (the people).

Despite these definitional issues, most scholars agree, landscape is a product or construction between nature and humans (Malpas 2011). Both nature and construction are thorny words in themselves and their discourses, complex (Cronon 1996). Construction in everyday language tends to refer to the physicality of making things or acts of physical creation, which are clearly pertinent to the ordinary idea of landscape as a physical reality. However, in academic circles construction can also mean the very way we conceive and live in our world(s), and therefore how we experience and express it through language simultaneously (Pouliot 2004). Because these creative acts of conception are inevitably shaped through an individual's social and cultural environment and experiences from birth, so each person's world is socially, as well as physically, constructed (Alvesson and Sköldberg 2009; Pouliot 2004). By default, each person's world is also unique to herself/himself, but, importantly, that word is shaped by some shared commonalities or frames of reference produced by membership of certain social, cultural and political groups at different scales (for example, religious, racial, national and familial groups).

Through this combination of social, cultural and physical influences, landscape emerges not just as an external 'reality' we view, visit or travel through, but one which is intrinsically part of our human-scale, experienced, meaning-laden and lived-in world. This plurality was summarised aptly by James Raffan $(1992,6)$ when he suggested:

although land exists, the scape is a projection of the human consciousness. . . land - the thing you can walk on, measure, map, paint, buy, sell and 
assay - is transformed in the human mind into landscape, a much broader, far reaching, and illusive entity.

The predominant cultural geographical perspective on landscape, at its simplest form, seeks to 'explore the intersections of culture and context. It asks why cultural activities happen in particular ways in particular contexts. . . It operationalises this interest through identifying that the product of the intersection between context and culture is place' (Anderson 2010, 3). Thus, place has been central to cultural geography research for some time and within its broad frame of inquiry, landscape has featured as a significant participant (Malpas 1999, 2011; Relph 1976; Stokols and Shumaker 1981; Tuan 1974). Place and landscape have been discussed in terms of both reciprocal and dichotomic relationships, with landscape often distinguished in terms of its spatial qualities, and place in terms of its relational ones. However, as Jeff Malpas noted in his introduction to Place and Landscape (2011, ix):

There is a widespread tendency for discussions of landscape to privilege both space and vision ... in terms of the place of landscape, the emphasis is also on the opening up of the possibility that the place at issue here is one that encompasses more than the visual alone, one that combines the spatial and the temporal and constitutes a mode of engagement with, rather than merely separation from.

Finally, Edward Casey $(2002,271)$ summed up this conceptualisation with his comment that 'Landscapes are, in the final analysis, placescapes; they are congeries of places in the fullest experiential and represented sense. No landscape without place; this much we may take to be certainly true'.

The significance of 'vernacular landscapes' as a cultural geography expression of the ordinary, everyday places inhabited by people, has gained credence and momentum through research of the many types, scales and creation practices of people and their places. The scope of the vernacular landscape, as originally envisaged by John Brinckerhoff Jackson during the 1950s and 1960s, encompassed many kinds and scales of landscape - expansive and intimate, mountain valleys and shopping malls - all connected through their influence and shaping by human cultures. It is this relationship between the physical landscape and human culture, generated, as Jackson saw it (Jackson 1984), through ordinary, everyday cultural practices (or living) in places, that has produced 'landscape' (or placescapes to use Casey's term). Jackson also described the vernacular landscape (Franklin 1999, 233):

As opposed to the highly-engineered scenery produced by designers such as Frederick Law Olmsted, most of the landscape of a country or region is produced by the way relatively free ordinary agents act in the world according to their own innate sense or shared cultural templates. 
To Jackson, this production of culture in place was visible in every landscape produced. Applying this to a specific landscape type such as a river immediately raises questions of scale, locality and the validity of place itself due in part to the wide variability and broad spatial extent of most river systems and, significantly, the people dwelling within them.

\section{Rivers as vernacular landscapes}

The concept of riverscape, which has been developed largely in the field of freshwater ecology, advocates for a whole-system approach to researching and understanding river systems, interpreted as: 'The entire spatially heterogeneous scene of the river environment, the riverscape, unfolding through time' (Fausch et al. 2002, 483). Haslam $(2008,1)$ defined it as follows:

The riverscape and, to a considerable extent all that grows on it or is put on it, depends on the river, since the river (or the ice-river of a precursor glacier) first formed the riverscape. The two are interdependent, both are modified by human impact . . . and both are natural capital, hence natural resources for people.

Thus, rivers are not just their water. The margins, banks, terraces and gorges that rivers frequently cut through are also often conceptualised as 'the river' and have been subject to heated disputes of power and domination as referred to by Swyngedouw $(2004,134-5)$ :

Water embodies, simultaneously and inseparably, bio-chemical and physical properties, socio-economic and political characteristics, and cultural and symbolic meanings. These multiple metabolisms of water are structured and organized through relations of power, that is relations of domination and subordination, of access and exclusion, of emancipation and repression.

In physical geography and cultural geography, rivers are dominantly discussed in spatial, physical and political terms, the latter expanding progressively into cultural and indigenous understandings and meanings of rivers and their often-disputed discourses (see Steenstra 2009; Strang 2004; Swyngedouw 2004). Within these cultural and indigenous discourses, rivers have been represented as both dividing and bordering 'land', holding multiple cultural meanings simultaneously, and as places of meeting and meaningful engagement (Buttimer 1985; Sadoff and Grey 2002; Toussaint 2008). An increasing emphasis on the complex meanings of rivers produced through both situated and social place relationships has emerged in recent research (for example, Goodall 2002; Farminer 2013). Perry $(2009,17)$, for example, noted in relation to the conflicting meanings of the Ganges is that:

These are clearly very different socio-cultural constructions of the same river. . . Consequently, these socially constructed meanings of the Ganges say more about how people identify themselves with others and the natural 
world than they do about the bio-physical attributes of objects and spaces. However, all of these river 'realities,' despite their contrasting meanings, are valid, at least to the groups that hold them.

Toussaint's work with the people of the Kimberly region in northern Western Australia examined their attachments to the Fitzroy River developed through the various local conflicts and disputes over water (Toussaint 2008). She framed people's attachment to water as being 'constantly created and re-created by people's social and political engagement with that place' $(2008,48)$, and observed that for both the indigenous (Aboriginal) and non-indigenous groups living in the Fitzroy Valley, the river had become 'a site of meaningful engagement' $(2008,57)$. Toussaint concluded that through such political, ecological and social engagement, both in terms of group friction and attachment to place, place-based cultures developed meaning and acquired new forms of river symbolism that reflected the past, current and ongoing relationships of these different cultural groups of people with their shared river places. Therefore, by framing rivers as being comprised of multiple places of social and cultural meaning produced through human activity and experience, whilst simultaneously embodying ideas of landscape, the conceptualising of rivers as vernacular landscapes begins to emerge.

\section{Vernacular landscapes in time}

There is an additional element to consider briefly in constructing rivers as vernacular landscapes: their spatiotemporal perspective. Overlapping with Jackson's framing of landscape as the result of everyday living, Tim Ingold (1993, 2000) merged ideas of place with the concept of dwelling, a philosophical concept originally developed by Martin Heidegger that was further developed by both geographers and philosophers from the 1990s onwards (Cloke and Jones 2000). The concept of dwelling used in this context described the continuing formation of landscape (or places) through human interaction/activities (or 'tasks') over time, which leave their traces both on and in the world. This landscape or 'taskscape' was in fact one, which could be distinguished by its temporality or 'time-depth' (Ingold 1993). By connecting Heidegger's human being-in-the-world with the embodied practices that this entailed (e.g. everyday living), the human world was created (and continues to be created) and made visible through the forms (natural and built) that together engender landscape (Ingold 1993, 2000). Ingold $(1993,155)$ explained this further, noting that:

a place in the landscape is not 'cut out' from the whole. . . Rather, each place embodies the whole at a particular nexus within it.... A place owes its character to the experiences it affords to those who spend time there. . . It is from this relational context of people's engagement with the world, in the business of dwelling, that each place draws its unique significance.

Similarly, New Zealand geographer Janet Stephenson concluded in her study of landscape cultural values in the South Island of New Zealand (Stephenson 


\section{2}

2008, 136), that 'localised values create a distinct identity that comprises the relationships between people and the landscape'. Another way of looking at this is that landscape and place are the result of ongoing human living (dwelling) in the world and the accumulation of human experience embedded in, and expressed as, the world. When one perceives a landscape or place, he/she is seeing/experiencing not just the physical survival of material forms, but traces of human be-in $(\mathrm{g})$ and therefore culture in those very same forms. As Stephenson $(2008,130)$ also noted, this 'engagement with the land and its human and nonhuman components continuously generates both cultural knowledge and bodily substance'. Through such 'world-making', Ingold (1993, 152) attempted to dissolve the naturalistic and culturalistic binary of a 'natural' landscape external to human activity placed in opposition to a 'cultural' landscape existing only as a cognitive or symbolic ordering of space.

Cloke and Jones $(2000,664)$ took Ingold's static conception of dwelling a step further by questioning the rather idyllic and romanticised thread running through his theorising, which they viewed as being at odds with the 'multiembodied, multipractised business of moving' that being-in-the-world involved. Instead, they emphasised a greater sense of movement, unfixedness and constantly changing perspectives/viewpoints in their concept of dwelling and place, of 'being in the landscape' - not just gazing at it from a fixed position $(2000,663)$ :

Being in, and moving through, landscape is different from gazing upon it from a point which always seemingly puts you at the edge of it, or even outside it ... dwelling is an embodied and an imaginative embeddedness in landscape.

This recognition of the relentless movement of people and things through the everyday practices of living (in places) can be applied on multiple scales and perspectives - each working simultaneously and interconnectedly. In conclusion, Cloke and Jones $(2000,664)$ forwarded a position which favoured:

the complex interpenetration of places with other places . . the flows of ideas, people, and materials which co-constitute and co-construct those places; and dynamic ... ways of understanding embodied engagements with landscapes.

Drawing these different standpoints together provides a tangible lens through which to explore how rivers are created as vernacular landscapes. Rivers are just one of many complex productions of a creative and continuously emerging relationship of landscape, place and people that are simultaneously created, perhaps symbiotically, and ultimately produced by natural/human cultural activities over different, but interrelated, spatio-temporal scales. We will now explore some examples of this creative relationship in relation to the Clutha River/Mata-au on the South Island of New Zealand. 


\section{The Clutha River study - a vernacular landscape in practice}

Rivers and their basins are made up of multiple places, created by multiple processes and practices and therefore hold many place meanings simultaneously, all the while retaining a conceptual identity of their own. Add to this the element of temporality - or time depth - which extends and multiplies the place meanings of rivers, and the complexity and challengers of framing rivers as vernacular landscapes begins to emerge. Using an interpretive hermeneutic methodology, the researcher interviewed a group of thirteen participants regarding their lifelong experiences with, and meanings for, the Clutha River (Farminer 2013). The hermeneutic approach interprets human meaning and experience through 'texts' of speech and action in a reiterative process that continuously acknowledges the multiple perspectives of subjectivity and the ever-present pre-understanding of the researcher. The interviews, framed through the lens of place and place-meanings, provided fresh insights into how the participants constructed, expressed and, at the same time, frequently contradicted, the meaning of their Clutha River broader life place-experiences. Finally, the interviews were analysed using a modified thematic networks approach to create a transparent, descriptive and detailed interpretation of both the empirical (transcribed interview) information and its many significant and interrelated Clutha River themes and discourses, at both semantic and latent levels.

And so, to the river. The Clutha River/Mata-au, to acknowledge its dual European and Māori name, is commonly referred to as 'the big river' in New Zealand (McKinnon 2016), a discourse that reflects many aspects of its character, not just its morphological extent as the country's largest river by volume and flow, and its second longest (Figure 8.1). Its average discharge rate is estimated at 614 cubic metres per second and its length is $338 \mathrm{~km}$ (ORC 2012). The Clutha also has the largest catchment area of any river in New Zealand at nearly $20,580 \mathrm{~km}^{2}$ (over 13\% of the South Island); its main tributaries are the Hawea, Cardrona,

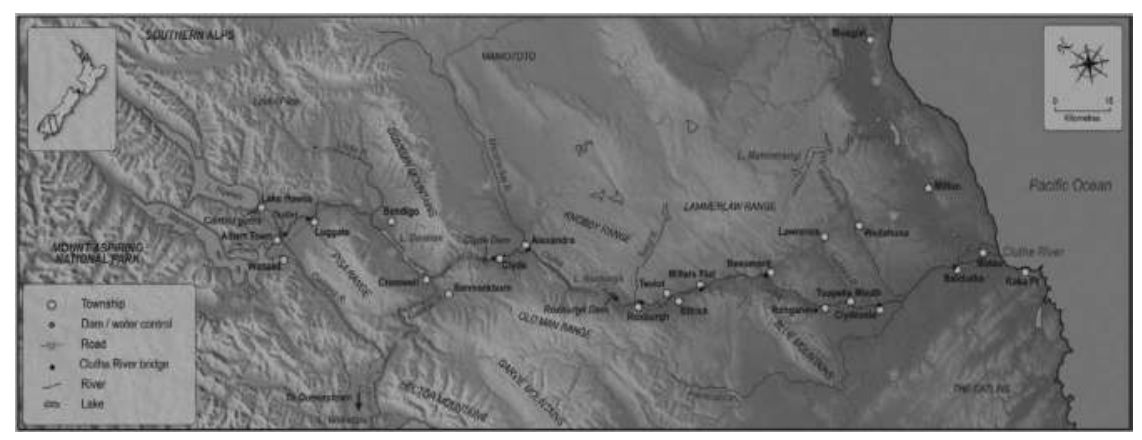

Figure 8.1 The Clutha River system, Otago, New Zealand.

Source: the Author 


\section{Andrea Farminer}

Kawarau, Lindis, Manuherikia, Tuapeka, Waitahuna and Pomahaka rivers (ORC 2012). The Clutha flows in a south-easterly direction from the outlet of Lake Wanaka in the Southern Alps of the South Island, across the Otago Region to a dual outlet southeast of Balclutha (forming a delta), before discharging into the Pacific Ocean at Molyneux Bay. Along its length are various small towns and settlements including Wanaka, Cromwell, Clyde, Alexandra, Roxburgh, Beaumont, Clydevale, Balclutha and Kaitangata.

Māori discourses for the Clutha River can be centred on its name - the Mataau - which in common English translation means a current or eddy in an expanse of water (Reed 1975). To illustrate the importance of the river to the dominant iwi (tribe) of Otago, Ngāi Tahu, the following extract from the Käi Tahu Ki Otago Natural Resource Management Plan (KTKO 2005, 192) explains their relationship (past and present) with the Mata-au:

The Mata-au river takes its name from a Ngāi Tahu whakapapa [ancestry] that traces the genealogy of water. On that basis, the Mata-au is seen as a descendant of the creation traditions. For Ngāi Tahu, traditions such as this represent the links between the cosmological world of the gods and present generations, these histories reinforce tribal identity and solidarity, and continuity between generations, and document the events which shaped the environment of Te Wai Pounamu [South Island] and Ngāi Tahu as an iwi.

The Clutha River/Mata-au formed part of a network of routes that linked the coastal areas of the South Island with the inland valleys, plains and mountains, that allowed iwi access to many kinds of food sources and other resources such as pounamu (greenstone, jade) which was traded amongst iwi and later, with European settlers (KTKO 2005). The headwaters of the river and its catchment 'were the traditional focus of seasonal migrations for many of the hapū [sub-tribes] and whānau [extended family]' living in the Araiteuru and Murihiku areas (roughly Canterbury and Southland/Otago respectively; KTKO 2005, 127). The knowledge of these traditional routes and places along the Clutha River/Mata-au is a taonga or 'treasure' by current hapū, as not only are some of the traditional mahinga kai (traditional food gathering places) locations still used, but stories of their tūpuna (ancestors) and locations of their urupā (burial places) are maintained through retracing the trails on hikōi (journeys) and the re-telling of their stories to whānau (KTKO 2005).

The dominant historical discourse of the Clutha River is The Golden River, not just a metaphorical reference, but a literal discourse of the gold first discovered at Gabriels Gully (modern Lawrence) in 1861, then along the Clutha River between Roxburgh and Cromwell in 1862 and the subsequent 'gold rush' (Murray and Murray 1977; SPAR 2010). The development of the Central Otago goldfields, focused on either side of the river, was not only significant in itself, but is credited for the establishment and settlement of Otago through the people, 
wealth and technology it attracted (Connell 1998). Towns such as Cromwell, Clyde and Alexandra grew and flourished as supply towns to the goldfields and the miners who came and went; the goldfields eventually waning by the 1890 s with the growth in river dredging for gold. The golden river discourse of the Clutha River has continued into the present - as a heritage and tourism destination where the goldfield history and archaeology of the nineteenth and twentieth centuries is blended with the internationally famed Central Otago wineries and vineyards. Many of these lie along the Clutha valley and take their name and brand from the various goldfields and mining iconography (e.g. Three Miners, Quartz Reef and Kawarau Estate; Carpenter 2012). As Carpenter (2012) notes, this combination of gold mining history, nostalgia and wine-branding provides a romantic and unproblematic image or discourse of the goldfields - 'the past without pain' - which fuses place and nostalgia to market wines and reinvent history.

Of the many discourses, which the Clutha has shaped, flooding has been an issue since the Otago region was settled by migrants from the 1840s onwards with two major floods in 1878 and 1978, which did substantial damage to settlements particularly in the lower catchment of the river. Due to its enormous volume of water and velocity, the Clutha was an obvious choice for the development of hydro-electric power, one that was realised first by the construction of the Roxburgh dam and hydro-electric power station in the 1950s, and followed by the Clyde Dam power station in 1980s.

As a substantial 'influence' in the lives of so many people over time, including the participants in this study, the Clutha River took on a role as a 'partner' in the research, which was two-fold. It situated the research beyond the obvious; being more than just a 'place' to undertake the fieldwork; the river and its environs (landscape and human) became a subject of the research itself alongside the participants. It was thus the participants' relationships with the Clutha - recreational and beyond - that I asked about; the situation that had provided them with a broad array of diverse and sometimes contradictory experience/meanings. Through exploring these participant-Clutha River relationships (which gained increasing emphasis as my interviews and observations progressed during the year of field research), the river moved beyond a mere setting for the research and became the very heart of the research itself with its own influence and affects. The recognition of the importance of the 'place' of research in research methodology has increased in recent years, (Anderson et al. 2010) and it has been argued that "by situating place, time and author centrally in the process, the research "consumer" is given the capacity to acknowledge the existence of the politics of location within its production' (Anderson et al. 2010, 600). In this way, Anderson et al. $(2010,599)$ argued that the inclusion of 'place', vis-à-vis the Clutha River, creates a new kind of research dialogue - a polylogue - that recognises and 'alludes to a non-modern perspective that grants agency to non-human actors in constructive and discourse acts'. As a result, the Clutha became a nexus through its agency that grounded both the place of research and the research of place, simultaneously, in the study. 


\section{The language of a vernacular riverine landscape}

Extending this idea of the human/socio-cultural and landscape environment of the Clutha River, a key theme identified within the study was the language of how meanings relating to participants' place experiences and the Clutha River as a place, was constructed. The language encompassed both spatial/ place-based terms (so geographic, aesthetic and located) and in meaning/ experience terms, whether from direct or indirect experiences associated with river. Woven through these language expressions was the degree of familiarity a participant had with the river/places that influenced the strength and to a lesser extent, the character of such meanings. For example, some participants expressed the Clutha in the follow ways when asked how they thought of the Clutha River:

a lot of people refer to The Clutha or Clutha as the Lower Clutha ... it still really confuses me because when they say The Clutha... I think of the Upper Clutha and I think of the whole river going into and out of the whole system.

I just don't know it that well to be honest; it's in my backyard but I don't really know it that well.

Yeah, I think of it as different places, yeah. There's the Upper Clutha which is Wanaka and Hawea I guess, and then there's this area - Alex, Cromwell, Clyde I guess - . . . then Roxburgh's another spot, and then you get down, Beaumont's another spot, Tuapeka Mouth and Balclutha.

Even in this limited range of extracts, the diversity and degree in how people expressed their concept of the Clutha River as a place is evident. Whether as a single place, multiple places traversing the length of the whole river, to the river as a system, the Clutha was thought of at many scales, some seemingly simultaneously. Of these, the second extract is interesting for the apparent paradox shown between spatial proximity and yet a lack of familiarity when the participant stated that they didn't know the Clutha that well yet it was in his/her 'backyard'. This comment challenges the common assumption that proximity to places, or being in places, generates familiarity and knowledge for residents and visitors alike (Kyle et al. 2004).

In another theme, life experiences associated with the Clutha comprised a diverse mixture of experiences generated through engagements with work, leisure/recreation, family and indigenous cultural contexts amongst others. These 
partly framed how participants 'saw' or conceived the river, and how they were able to express their 'knowing' of the river.

but look, I see the Clutha in sections and whether the sections are a result of the [wildlife] work that I've undertaken or the [survey] work that I still presently do.... But all these different stages have got different qualities.

[T5.44/45]

Well, I work for a small vineyard down on Wanaka Road which is up on the terraces above Queensberry and so for the past few summers I have been able to look down from there and see the Clutha and it just never ceases to amaze me that view. ... I'll come out and I'll look up, and it takes my breath away every time.

the whole river basically except for the last part from about Tuapeka ferry down, is just quite an experience ... there's preferred areas - from the bottom of Roxburgh down .... through the Millennium Track is probably the best part of the river you can do.... I mean I take everybody that visits me [boating] down there.

Running through these extracts is a dual sense of the participants engaging with the Clutha through viewing and experiencing the river simultaneously whilst experiencing this engagement repeatedly. In doing so, it raises the question as to if, and how, they were also introducing culture to their Clutha places/landscapes and through what mechanisms? To respond to this literally, the focus of their responses has to be turned away from the Clutha and directed back to the location of the participants in these extracts, where their respective locales would be flying above the river in a light plane (T5), on a vineyard on the Queensberry river terrace overlooking river (T4), and jet boating down the river along the Beaumont Gorge. Of these three, perhaps only the second example - the river terrace vineyard - would sit comfortably within a simple vernacular landscape framework whereby the act of creating the vineyard had altered the physical landscape of the river terrace through every day acts of tending and viticulture. However, if the focus is returned to the Clutha itself, an expanded, more dynamic and riverine interpretation of the vernacular landscape is required.

\section{Vernacular practices making river places}

Every day practices of the study participants, and from general river observations, associated with the river included regular driving along the main highways either side of the river; walking, cycling and exercising along the many river tracks; family picnics and fishing, boating and kayaking on the river. Intermixed with these 
activity-focused practices were those who lived adjacent to the river on its banks and terraces and whose everyday practices comprised living on and with the river. Likewise, the many small tourism businesses focused on the river, vineyard businesses and farms adjacent to the river, and the large, hydro-electric power stations who harness the Clutha's river flow, all involved every day practices by their inhabitants of varying degrees and nature. All of these varied human practices have had a cultural influence on the Clutha's physical landscape whether through the construction of individual houses, small sub-divisions and towns; roads, bridges, tracks and pathways and, at a much larger scale, dams that have literally reshaped the Clutha River's morphology and flow characteristics. For example, the opening of the Clyde Dam in 1992 created a lake (Lake Dunstan) $26 \mathrm{~m}^{2}$ in area and inundated the Cromwell Gorge, which contained some of the best natural rapids and kayaking experiences in the South Island (Farminer 2013; Figure 8.2). Add in the catchment-scale practices (and effects) of farming, irrigation, fish-stocks and other ecological-impacting practices, and making sense of the Clutha River as a place and vernacular landscape becomes mired.

If the temporal perspective is added to this Clutha River cultural landscape, then, to use Ingold's (2000) term, it gains time-depth. As a result, the landscape acquires layers of geological and geomorphological meaning alongside the layers of Māori and nineteenth-century European activity meaning, which all merge, to some degree, into the present. Janet Stephenson's work on a cultural values model of landscape similarly focused on places in the South Island of New Zealand (Stephenson 2005, 2008). In developing her model, three basic components were identified:

- Forms - physical, tangible and measurable aspects of landscape, place or space;

- Relationships - people-people relationships, people-landscape/place relationships and ecological relationships; and

- Practices - human practices and human/natural processes.

These are seen as 'inseparably interwoven as the dynamic landscape' and the model proposed 'that these dynamic interactions help generate cultural values, and are also generated by them' $(2008,135)$. Stephenson added a temporal quality to her model by suggesting the dynamic interplay of these three components over time, in the sense that (ibid; my emphasis):

It expresses the concept that landscape is created from the dynamic interaction of forms, practices and relationships, occurring over time, and that landscape values are contingent on elements from both the past and present. Landscape is thus always changing.

Bringing us back to the Clutha River study, this idea of a temporally driven, dynamic cultural interaction with landscape forming participants' river places was interpreted through some of their responses. For example, in terms of the 
actual water flow of the Clutha as a tangible and temporal riverine landscape, one participant commented in relation to the pre-Clyde Dam river at Cromwell:

The other place that I still remember so vividly is the 'meeting of the waters', and just the line in the water where the two rivers came in and I can still see that.

Another participant described the changes he had observed in his river places since his arrival in the area:

When I first shifted through to Wanaka in 1985 . . . I spent quite a bit of time on the river fishing ... in those days there wasn't a walking track down the edge of the river, [the] Wildlife Service actually started that track . . . [I helped] personally built [it] by hand. with my superiors at the time.

[T5.5a/6]

Continuing this thread, the same participant expressed his thoughts on the changes the development of the walking tracks had brought to the Outlet section of the river [T5.9]:

And so yeah, it wasn't as populated as it is now, it was quiet, I could go and fish the river ... and you could have the section of river to yourself. It was peaceful, it was passive, and it was sort of also a bit more wild in those days. ... I mean there's a lot of development that's gone on around the boundaries and that sort of thing, so it was a bit more secluded probably to what it is now. In all honesty, the river hasn't changed much - there's no change to the river - just the surroundings and probably just the depth in which the track has been upgraded and allowing more recreation, in terms of there's more use for walkers.

This fusion of memories of his early recreational experiences with the river in certain places, reflections on the changing character of those places and the recognition of his own participation in building some of the earliest access tracks along the river bank, is one example of the many types of relationships and practices that created a very personal and vernacular landscape or placescape on the Clutha River. Another significant point in this extract is the last sentence, which highlights the separation by the participant of the river's landscape into its riverine element and dry marginal landscape, that in turn reflects a broader fluidity in meaning found in the study, regarding the Clutha River as a whole. The Clutha is not a static or fixed 'place' as such in these expressions, but one of fluid meanings and temporalities subject to constant change through changing personal and social discourses combining the experiences of the river and the participants. This framing also echoes Anderson's (2010) concept of 'place-traces' - the personal/social meanings constructed by participants embodied as place-traces that are reflected in the material/tangible places/landscapes of the Clutha River. This could also be phrased as the vernacular placescape (s) of the river (Figure 8.2). 


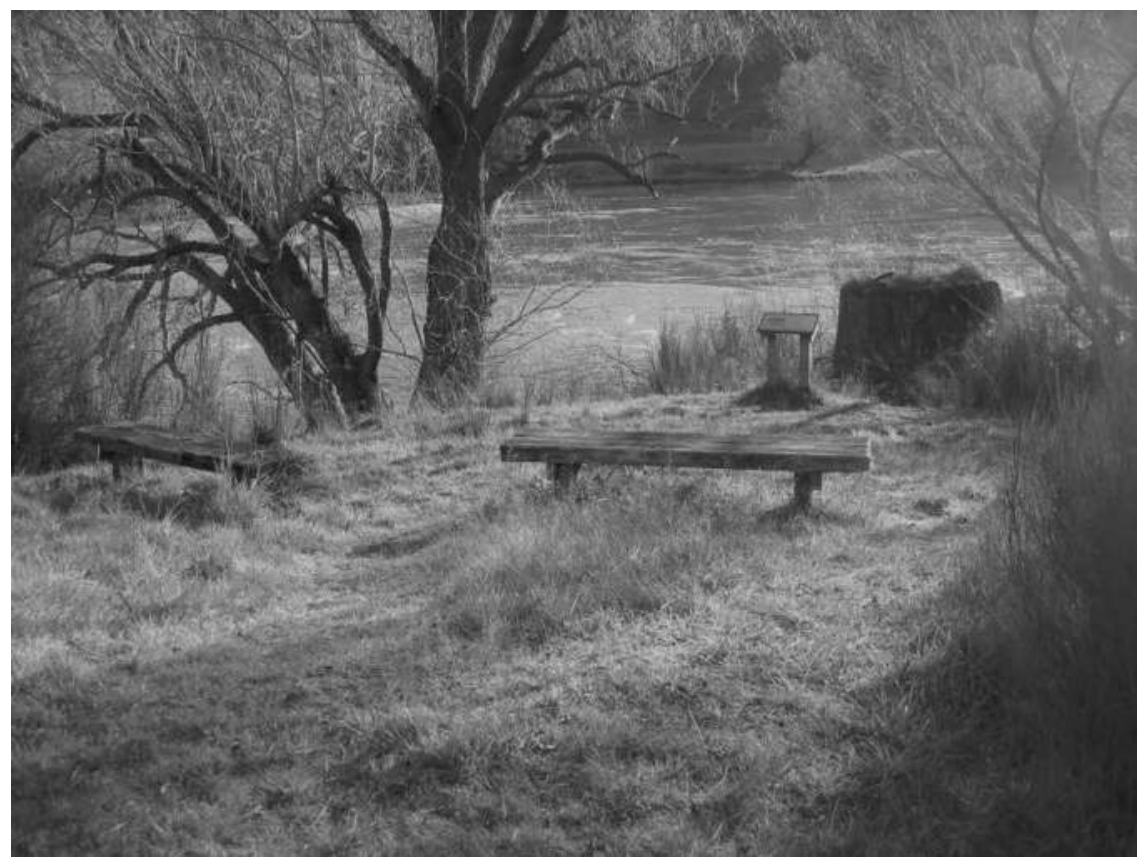

Figure 8.2 Personal placescapes layering the Clutha River vernacular landscape - a wellworn picnic bench, heritage board and old bridge abutment overlooking the Clutha River in the Beaumont Gorge.

Source: Photo courtesy of the Author

\section{Reflecting on people, place and rivers - a fluid and cultural relationship}

In some ways, the idea of a river such as the Clutha River being a 'vernacular landscape' in the general concept first proposed by Jackson seems at first contrary in terms of its wide geographic and political scales. However, if 'the river' is realised as being and comprised by multiple personal, socio-cultural and spatiotemporal places/landscapes simultaneously, this begins to allow a different and more intimate scale of understanding to be engaged with. At this scale, 'the river' can be considered as being manifested through and within people's everyday cultural practices with, and on, the river. These practices in turn have formed sometimes complex - sometimes simple, people-river relationships, and have changed and adapted over time as societal and individual people's cultural, aspirational and particularly resource-driven needs have changed. In the case of the Clutha River, these cultural practices have encompassed food gathering, navigation, transportation, gold mining, farming, recreation, habitation and power generation, to name but a few. 
One result of these diverse and fluid relationships of cultural practices in place is the creation and gradual (and occasionally rapid in the case of the dams) change of the riverine and terrestrial landscapes of the Clutha River. This change of the river's landscapes has occurred on a broad range of scales: geological, human, spatial and temporal. Within these different scales, it has been the human-place relationships that have further formed and modified the meanings and experiences of the Clutha, producing a rich, complex and meaning-filled river landscape that continues to change with new practices, people and increasingly competing demands. Indeed, the current discourse for many rivers worldwide is one as a highly valued, but often taken-for-granted resource - to be controlled, sold and fully exploited (Postel and Richter 2003). This strongly utilitarian discourse is expressed in equally utilitariandriven languages, whether that of science, resource management or economics. The interpretive study of the Clutha River and its many diverse people-place relationships demonstrated that this language is often at odds with the personal, cultural, meaningful and vernacular language of those who actually work, live, recreate and culturally relate with the river (Farminer 2013, 7). Likewise, the scale of much of the resource-driven discourse is at the macro level; the value of relating with rivers at a vernacular scale, therefore, is in providing alternative ways to engage with and understand people-place river relationships and their effects at both macro and micro levels. This accords with the conceptual need for engaging with rivers as both simultaneously single and multiple place entities - vis-à-vis riverscapes. This perspective is fundamental to the present and future health, management and realistic sustainability of our river systems.

\section{Conclusions}

This chapter discussed a broad range of mainly cultural and human geography perspectives relating to the positioning of rivers as vernacular landscapes that reflect individual and collective human-scale influences on the on-going creation of both river meanings and their landscapes. Concepts of dwelling, time-depth and the inter-weaving of human and geomorphological activities were explored to try to understand the different scales (temporal and spatial) and inter-relationships that have produced our riverscapes in the present. Whilst recognising the underlying importance of natural processes in river formation, it is the human, socio-cultural practices as expressed through place-meanings that were focused on, to understand the different relationships and language of people-river relationships. Examples, such as those highlighted from the Clutha River research study in New Zealand, demonstrate that vernacular landscapes do not just result in physical entities created through diverse cultural practices, but that such landscapes are created and held through human experience and meaning simultaneously. It also illustrated the challenges of applying a riverscape or whole-system approach when trying to understand human-scale conceptions of river place-relationships and, specifically, the everyday practices that help form rivers as vernacular landscapes. However, such challenges are there to be engaged with and developed, to provide the very interconnectedness that managing and respecting our rivers demands. 


\section{References}

Alvesson, M., and Sköldberg, K. 2009. Reflexive Methodology: New Vistas for Qualitative Research. London: Sage Publications.

Anderson, J. 2010. Understanding Cultural Geography: Places and Traces. Oxford: Routledge. Anderson, J., Adey, P., and Bevan, P. 2010. "Positioning Place: Polylogic Approaches to Research Methodology.” Qualitative Research 10(5): 589-604.

Bradley, J. B. 2011. "White Fellas Have to Learn About Country, It Is Not Just Land: How Landscape Becomes Country and Not an 'Imagined' Place." In The Place of Landscape: Contexts, Concepts, Studies, edited by J. Malpas. Cambridge, MA: MIT Press.

Buttimer, A. 1985. "Nature, Water Symbols, and the Human Quest for Wholeness." In Dwelling, Place and Environment: Towards a Phenomenology of Person and World, edited by D. Seamon and R. Mugerauer. Dordrecht: Martinus Nijhoff Publishers.

Carpenter, L. 2012. "Nostalgia and Wine Labelling." Presented at 150 Years of Riches: The Central Otago Gold Rush, 1862-2012, Cromwell, New Zealand, August.

Casey, E. 2002. Re-Presenting Place: Landscape Painting and Maps. Minneapolis: University of Minnesota Press.

Cloke, P., and Jones, O. 2000. "Dwelling, Place, and Landscape: An Orchard in Somerset." Environment and Planning A 33: 649-666.

Connell, J. 1998. Otago Conservation Management Strategy. Dunedin: Department of Conservation/Te Papa Atawhai.

Cronon, W. ed. 1996. Uncommon Ground: Rethinking the Human Place in Nature. New York: Norton \& Company.

Farminer, A. 2013. "People, Rivers and Recreation: Fluid Relationships of Place and Experience on the Clutha River, Otago, New Zealand." Unpublished PhD thesis, University of Otago. Dunedin: University of Otago.

Fausch, K., Torgersen, C., Baxter, C., and Li, H. 2002. "Landscapes to Riverscapes: Bridging the Gap Between Research and Conservation of Stream Fish.” Bioscience 52(6): 483-498.

Franklin, W. 1999. Landscape in Sight: Looking at America (Review). http://ir.uiowa.edu/ annals-of-iowa/vol58/iss2/24.

Goodall, H. 2002. "The River Runs Backward." In Words for Country - Landscape and Language in Australia, edited by T. Bonyhandy, and T. Griffiths. Sydney: University of New South Wales Press.

Haslam, S. M. 2008. The Riverscape and the River. Cambridge: Cambridge University Press. Ingold, T. 1993. "The Temporality of the Landscape." World Archaeology 25(2): 152-174.

Ingold, T. 2000. The Perception of the Environment: Essays on Livelihood, Dwelling and Skill. London: Routledge.

Jackson, J. B. 1984. Discovering Vernacular Landscapes. New Haven and London: Yale University Press.

KTKO. 2005. Kāi Tahu Ki Otago Natural Resource Management Plan. Dunedin, New Zealand: KTKO.

Kyle, G., Graefe, A., Manning, R., and Bacon, J. 2004. "Effects of place attachment on users' perceptions of social and environmental conditions in a natural setting." Journal of Environmental Psychology 24: 213-225.

Macnaghten, P., and Urry, J. 1998. Contested Natures. London: Sage Publications.

Malpas, J. E. 1999. Place and Experience: A Philosophical Topography. Cambridge: Cambridge University Press.

Malpas, J. E. ed. 2011. The Place of Landscape: Contexts, Concepts, Studies. Cambridge, MA: MIT Press. 
McKinnon, M. 2016. "Otago Places - Clutha River/Mata-Au.” Te Ara - the Encyclopaedia of New Zealand. www.TeAra.govt.nz/en/map/22184/clutha-rivermata-au.

Murray, J. S., and Murray, R. W. 1977. Costly Gold: Clutha Riches and Their Human Toll. Wellington, New Zealand: A.H. and A.W. Reed.

ORC. 2012. "Clutha River Catchment Report Card.” www.orc.govt.nz/Publicationsand-Reports/Research-and - Technical-Reports/Surface-Water-Quality/Annual-waterquality-and-bio-monitoring-summaries/201112/Clutha-River-Catchment/.

Perry, S. L. 2009. "More Than One River: Local, Place-Based Knowledge and the Political Ecology of Restoration and Remediation Along the Lower Neponset River, Massachusetts." PhD thesis, University of Massachusetts. Amherst: University of Massachusetts.

Postel, S., and Richter, B. 2003. Rivers for Life: Managing Water for People and Nature. Washington, DC: Island Press.

Pouliot, V. 2004. "The Essence of Constructivism." Journal of International Relations and Development 7(3): 319-336.

Raffan, J. 1992. "Frontier, Homeland and Sacred Space: A Collaborative Investigation Into Cross-Cultural Perceptions of Place in the Thelon Game Sanctuary, Northwest Territories." Unpublished PhD thesis, Queen's University. Kingston, Ontario: Queen's University.

Reed, A. W. 1975. Place Names of New Zealand. Wellington, New Zealand: A.H. and A.W. Reed.

Relph, E. 1976. Place and Placelessness. London: Pion.

Sadoff, C., and Grey, D. 2002. "Beyond the River: The Benefits of Cooperation on International Rivers.” Water Policy 4: 389-403.

SPAR. 2010. Archaeological Baseline Survey and Management Plan of the Clutha Mata-au River. A report prepared for The New Zealand Historic Places Trust by Southern Pacific Archaeological Research. Dunedin, New Zealand: University of Otago.

Steenstra, A. 2009. "Accommodating Indigenous Cultural Values in Water Resource Management: The Waikato River, New Zealand; The Murray-Darling Basin, Australia; and the Colorado River, USA." Presented to the Australian Agricultural and Economic Society's Annual Conference, Cairns, 11-13 February.

Stephenson, J. 2005. "Values in Space and Times: A Framework for Understanding and Linking Multiple Cultural Values in Landscapes." Unpublished $\mathrm{PhD}$ thesis, University of Otago. Dunedin, New Zealand: University of Otago.

Stephenson, J. 2008. "The Cultural Values Model: An Integrated Approach to Values in Landscapes." Landscape and Urban Planning 84: 127-139.

Stokols, D., and Shumaker, S. 1981. "People in Places: A Transactional View of Settings." In Cognition, Social Behaviour, and the Environment, edited by J. Harvey. Hillsdale, NJ: Lawrence Erlbaum Associates.

Strang, V. 2004. The Meaning of Water. Oxford: Berg.

Swyngedouw, E. 2004. "Scaled Geographies: Nature, Place, and the Politics of Scale." In Scale and Geographic Inquiry: Nature, Society, and Method, edited by E. Sheppard and R. B. McMaster. Malden, MA: Blackwell Publishing.

Toussaint, S. 2008. "Kimberley Friction: Complex Attachments to Water-Places in Northern Australia." Oceania 78(1): 46-61.

Tuan, Y. F. 1974. Topophilia: A Study of Environmental Perception, Attitudes, and Values. Upper Saddle River, NJ: Prentice-Hall. 


\title{
9 Keep it flowing
}

\author{
The restoration ecology of \\ indigenous culture and language \\ along the Missouri River
}

\section{Dean P. Good Eagle Fox and Alesia Maltz}

\section{Introduction}

The Missouri River is "big, unique, and temperamental" (Billingston et al. 2005, 236). It flows over $3,800 \mathrm{~km}$ (2,300 miles), through seven semi-arid agricultural states, from the Continental Divide of the Rocky Mountains to the city of St. Louis, where it joins up with Mississippi River. From the headwaters of the Missouri to the mouth of the Mississippi in the Gulf of Mexico, the two rivers make up the fourth longest river system in the world (Billingston et al. 2005, 253).

The Big Muddy - which refers to both the Missouri and the Mississippi - is "too thick to drink and a mite too thin to plow" (Lawson 1982, 4; Morris 2012). In its natural state, the river carries 250 million tons of sediment a year by the time it reaches the confluence with the Mississippi River (USACE 2006). It has a reputation for its propensity to jump its banks. As the writer, George Fitch, commented in 1907 (Lawson 1982, 3):

There is only one river with a personality, habits, dissipations, a sense of humor, and a woman's caprice; a river that goes travelling sidewise, that interferes in politics, rearranges geography, and dabbles in real estate; a river that plays hide and seek with you today and tomorrow follows you around like a pet dog with a dynamite cracker tied to its tail.

The Missouri River was located in the United States at last report. . . Its perpetual dissatisfaction with its bed is the greatest peculiarity of the Missouri. Time after time it has gotten out of its bed in the middle of the night with no apparent provocation, and has hunted a new bed, all littered with forest, cornfields, brick houses, railroad ties, and telegraph poles. . . It makes farming as fascinating as gambling. You never know whether you are going to harvest corn or catfish.

Once Congress passed the Flood Control Act of 1944, the US Army Corps of Engineers transformed the free-flowing Big Muddy. The lower river basin was tamed by a set of artificial channels to produce steady stream flow and flood protection. The Corps coerced the tribal governments in the upper river basin to relinquish millions of acres of reservation land to create a chain of six immense reservoirs. Ranking among the largest reservoir systems in the world, 
the reservoirs store up to three years of the river's flow as measured below the lowest dam (US Army Corps of Engineers 2006). The dams and channels disrupted patterns of sedimentation, disrupted the annual flooding patterns, and altered the River's ecology. They also radically altered the cultures of indigenous people living along the River. One tribal chairman commented, "Every time the Corps of Engineers thinks of something, they create another problem for us Indians" (Capossela 2015, 144).

Rooted in the literature on Traditional Ecological Knowledge (Nadasdy 2005; Berkes 2008), this chapter draws on literature from the histories of the Missouri dams (Lawson 1982; Carrels 1999; Schneiders 1999; Van Develder 2004), indigenous studies (Hoxie 1984; Hyde 1998; LaDuke 2016), and research on endangered language revitalization (Nettle and Romaine 2000; Harrison 2007; Kroskrity and Field 2009), as well as on the traditional cultural knowledge of the Mandan, Hidatsa and Arikara people of the reservation of Fort Berthold, North Dakota, just north of Standing Rock (Crows Brest and Grinnell 2007; Murray et al. 2011). The story of the water protectors of Standing Rock cannot be told without the story of Fort Berthold because of the contested interplay of oil and water on indigenous lands along the Missouri River (LaDuke 2016).

\section{The history of the Fort Berthold reservation}

Unlike George Fitch, who saw the Missouri as a capricious woman, the indigenous people see the River as sacred. Everything in nature has a life force given by the Creator. The elders taught the Mandan, Hidatsa, and Arikara people to believe they were expected to keep the sacred relationship with one another and with all of Creation. Through seeking, making, sharing and celebrating these relationships, the Mandan, Hidatsa and Arikara people come to perceive themselves as living among a sea of relatives. The cultural, spiritual, and economic life of the people was predicated on the Missouri River. Water is key to survival and an integral part of who the Mandan, Hidatsa, and Arikara are. Most people understand the science surrounding the relationship our bodies have to water, but not that water is itself a living being. The lakes, rivers, and aquifers all have stories, which describe their import and value to the people. For example, the Missouri River is thought to be the Grandfather. There are specific ceremonies to be conducted prior to using the River's water, and traditional practices of offering and giving thanks.

The Mandan, Hidatsa, and Arikara people have made the Missouri River home for thousands of years. They were able to recover from germ warfare and from the taking of 90 percent of their treaty lands, but after World War II they were displaced as part of a major dam-building project, in which they lost another half million acres of their reservation. In the subsequent diaspora from the riverbed to the surrounding uplands, the Mandan, Hidatsa, and Arikara people became environmental refugees, suffering tremendous spiritual, cultural, health, economic, social, and psychological loss. The recent oil extraction along the Missouri River (USGS 2013) is just the latest violation. 


\section{Life in traditional villages}

The Mandan developed a unique cultural and economic place in Native American society. As accomplished farmers, they relied on the renewal of fertile riverine soils, which maintained soil moisture throughout the growing season, and supplemented their corn-based diet with meat from an annual upland excursion to hunt for buffalo. For centuries before the arrival of Europeans, the Mandan villages were a regional and continental center for trade, and many tribal members could speak four or five languages. Living in fortified villages next to the River, the people cultivated trade opportunities by cultivating the fertile river bottom, and placing themselves in a prime location for trade. However, as trading centers, the Mandan villages were particularly vulnerable to germ warfare. Within a few weeks of the time that smallpox-infested blankets arrived in 1837, the Hidatsa and Arikara had lost 50 percent of their people, while the Mandan had lost 90 percent.

The Mandan are remembered in the history of the early US republic for sheltering the members of the Lewis and Clark expedition their first winter, and the Hidatsa are remembered for Sakakawea, the young Hidatsa woman who guided Lewis and Clark in their exploration of the Louisiana Purchase. Through broken treaties, executive orders, Congressional Acts, the Allotment Act of 1887, and the Indian Reorganization Act of 1934, their land base was reduced from 12 million acres at the time of the Treaty of Fort Laramie in 1851 to less than a million today (Mander 1992). The people survived these land takings by consolidating their community strongholds in villages along the bottomlands of the Missouri River, but soon the Garrison Dam would tear the social fabric that bound the people to the river.

\section{The Garrison Dam and the taming of the Missouri River}

Although an extensive report by the Army Corps of Engineers in 1934 emphasized that flood control along the Missouri River would be a waste of taxpayer money and goodwill, the 1935 flood prompted Congress to ignore that report. The government pressed for flood control systems and took land by eminent domain and condemnation (Van Develder 2004). The flood of 1943 brought together two mid-level federal bureaucrats who were dreaming of engineering mega-projects for the upper and lower Missouri River. The Bureau of Reclamation engineer, Glenn Sloan, and Colonel Lewis Pick of the Army Corps of Engineers (Van Develder 2004), aided by planners and sometimes by residents of the river valley, formulated extensive river control schemes. At the center of Pick's $\$ 660 \mathrm{M}$ proposal was the Garrison Dam. Located in the heart of the Fort Berthold Reservation, the Garrison Dam was built between 1947 and 1953 to control floods, produce hydroelectric power, and provide water for irrigation. Garrison, the fifth largest earthen dam in the world, rises 210 feet above the riverbed to hold back a 178-mile long, and six-mile wide, man-made Lake Sakakawea. The project, initially projected at $\$ 660$ million, ended up costing $\$ 20$ billion (Van Develder 2004). 
In 1943 the Three Affiliated Tribes were threatened with having their reservation confiscated under eminent domain, and termination of the tribe's relationship with the federal government. While Congress was in process of debating the legality of taking land that was guaranteed by Treaty, construction for the Pick-Sloan Plan had already begun (Van Develder 2004). The Missouri River States Committee (MRSC) advanced its agenda at the expense of the tribes and in support of the white farmers who requested that the dam be sited downriver on reservation lands (Schneiders 1999). In the heady post-war political environment of 1947, human rights, civil rights, and treaty rights were swept to the side. In the legal mop-up that followed the passage of the Pick-Sloan Plan, the Three Affiliated Tribes lost their usufruct rights to hunt, fish, and gather food around Lake Sakakawea (Robinson 1999). They could not use the meager settlement money to bring claims against the government, and tribes or tribal members were prohibited from hiring their own lawyers.

\section{Exiled in place}

The indigenous peoples of this hemisphere believe that human beings are the least significant of all within the World of Beings. The lives of many beings were destroyed in the process of creating the Garrison Dam. Twelve of the nation's finest wildlife sanctuaries, all established in the 1920s, were obliterated. "The dam flooded some of the best riparian waterfowl habitat in the world" (Capossela 2015,154$)$. The dam construction destroyed the cottonwoods and medicinal plants, killed three fourths of the fish, dissolved the riverbanks, and drowned 155,000 acres of fertile farmland, forest, and towns (Carrols 1999). In addition, over 80,000 acres of wetlands and 40,000 acres of native grassland were lost (Carrels 1999).

The Garrison Dam destroyed the cultural cohesion that bound people to their human and non-human relatives, as well as the social fabric (Maltz and Fox 1999). When dam construction began, 80 percent of the tribal membership, consisting of 325 displaced families (1,700 people), were haphazardly and unexpectedly resettled in the middle of winter (Van Develder 2004). People were forced out of their homes, sometimes in the middle of dinner. The dam waters flowed into their villages before new homes were built and, because people were living in cars, shacks, animal sheds and coal bins in the middle of a severe winter, some froze to death. The remains of ancestors were uprooted and scattered across 400,000 acres of prairie upland. With the community likewise dispersed, and few roads to transport provisions in winter, starvation was a constant threat. "In a few short years, the Mandan, Hidatsa and Arikara people went from being the only self-sufficient tribal enclave in the United States to being one that was almost wholly dependent on outside help for day-to-day survival" (Van Develder 2004, 183).

Suicide rates, alcohol rates, and infant mortality rates skyrocketed. Unemployment reached 85 percent. The tribes lost 94 to 98 percent of their fertile agricultural lands and one fifth of their total lands, entire towns, all the extant 
tribal educational and medical facilities, 80 percent of the roads, 90 percent of the timber resources, fasting places, sacred sites, and grave sites (Lawson 1982). The North Dakota Supreme Court Chief Justice, Gerald VandeWalle, said that although he wanted to give everyone the benefit of the doubt, the Pick-Sloan plan had been, "all one huge scam, an economic and environmental disaster, from beginning to end" (Van Develder 2004, 242).

The relocation process created environmental refugees. Phyllis Old Dog Crow, commented: "Our identity derived from our villages. Those were destroyed. We were born into very dynamic and complex social networks that connected those identities across forty generations. Those went when the villages went" (Van Develder 2004, 32). Bucky Cross commented that more than the land was taken away: "What the Allotment Era started in the 1880s, the Garrison Dam finished. Now it's up to us, to this generation, to start dancing again" (Van Develder 2004, 244). Similar stories of tragedy and resilience are being retold by indigenous people in riverine communities around the world. In these situations, how do people maintain culture, clan, community, and connection with their River?

\section{The restoration ecology of culture}

This section offers a novel interpretation that focuses on the role of language, story, and ceremony in the restoration of relationship with the River. Cultural revitalization is crucial to restore the peoples' attachments to the River and the bottomlands, and suggests approaches to language restoration through media and ceremony.

\section{The restoration of language and story}

For many ethnic minorities, the thinking that happens in your mother tongue is different than the thinking that happens in the dominant national language. Language is alive when culture is alive, and needs to be woven into the fabric of lived experience to flourish. Before the dam, everyone spoke their language fluently because they knew their place in society and nature. "With language came a thought process, with the thought process comes respect, and culture. We were all speaking the language. ... Back then everything was about our language and it all fit together. ... You knew how to be, where to be, what to be; you knew how to address people and be respectful" (Five Rivers 2012, 7). The Missouri River dams threatened language and culture through landscape destruction, geographic displacement, and policies to promote acculturation. Christian boarding schools did considerable cultural damage by punishing any youth who spoke his/her indigenous language (Prucha 1979). Parents did not speak their native language to their children because they wanted to protect them from ridicule and beatings at school. Within one generation, indigenous languages had become endangered. Among the MHA Nation, encompassing 11,000 members today, less than 100 speak any of the three languages fluently (MHA Language Project 2016). 
Language is essential to place-making and cultural continuity. It expresses a form of life, eliciting meaning in the context of livelihood, ceremony, ritual, and prayer. For example, when homes were built on the bottomlands, there were prayers for the use of earth, wood, and willows. Once the dam was built, nature was so altered that it altered language itself, forcing people to speak English. The MHA Language Project identifies language as essential to cultural survival, and the health of the community. "At MHA Nation we believe that our language conveys our traditions, our ways of being, and our stories" (MHA Language Project 2016). Language can be a homeopathic remedy, bringing up the internal reserves of culture.

As with the restoration of an endangered species, the restoration of endangered language requires the concurrent restoration of a linguistic habitat that allows language to flourish. When a language is spoken in its native geographical locale, it creates the true resonance between human language and nature. Language loss is symptomatic of detachment from nature. Speaking a universal language like English in the home of your ancestors is unsound spiritual geography. The poetic sounds of an outside language like English do not resonate with place. The restoration ecology of these prairie languages requires the following: 1) a population of speakers, 2) the motivational trick to get non-fluent speakers to engage, 3) the revitalization of story, and 4) a system of local education involving the mass media.

\section{Speakers}

Indigenous languages are one of the strongest tools against colonialism because they are the key to intergenerational communication and communication with the natural world. The Mandan, Hidatsa, and Arikara oral traditions hold that ancestors talk to the people through dreams and ceremony. Some spirits sing their speech, which suggests that certain spirits prefer to communicate through song and dance, and the people communicate back to them through the same songs and dances that make up the rituals. Fluent speakers today are held in reverence. When language is not integrated into everyday life, the circle of speakers grows smaller and increasingly more precious. Elders now tend to speak their native language only to other elders. Many fluent speakers struggle and disagree on the use of terms, which further restricts the spoken word. Fluent speakers are encouraged to speak the language during social gatherings, ceremony, ritual, and prayer. This situation leaves non-fluent speakers mute through their respectful participation in public prayers.

As the circle of indigenous language becomes increasingly more restricted to prayer and ritual, it becomes even more difficult for people to express themselves spontaneously. When language becomes too precious, people need to get outside the rules. The restoration process requires raising the population of fluent speakers, but equally important, it requires raising the comfort and enjoyment level of non-fluent speakers. Participation frees people from the silencing caused 
by seeing the language as precious. A grasp of the language, however imperfect, contributes to the broad pool of language users.

Story

Clarissa Pinkola Estes describes traditional myths and stories as medicine. She says that "remedies for repair or reclamation" are contained within the stories, which are "embedded with instructions which guide us about the complexities of life" and which enable us to "raise a submerged archetype" (Pinkola Estes 1992, 15-16). What myth are you living, asks Joseph Campbell (1988); what is the moral code embedded in your myth?

Indigenous people deserve to hear a story told in their own language. Stories serve as medicine in multiple ways. They free the imagination to face and address overwhelming challenges. They go under the skin and directly to the heart. When placed in the context of an ever-changing present, stories become compasses to the direction of human intention. Stories maintain spiritual ecology, inviting the imagination to solve problems that seem insurmountable. "Stories map the geography of the human soul" (Cajete 1994, 137). They develop long-term relationships with people. The story and the listeners weave each other and become each other. The old stories, says Barry Lopez (1990), take care of people and are taken care of by them. Story that enters into peoples' lives through native languages can inform action in the way that a translated story cannot. Stories engage us in the act of remembering, or putting ourselves and our communities back together again. In many indigenous traditions, everything has a story, a ritual and a song. Sacred story is the narrative counterpoint to ritual, the basis of entry into ritual traditions (Gunn Allen 1990). Sacred stories are the road map of the spiritual tradition.

Indigenous stories come in many forms - creation stories, prophecies, and trickster stories are among the most important. Creation stories should not be written down and are able to be told at certain times of year and by certain people in the community. Prophecies are told as warnings, to provide people with opportunities to act differently. The ancient Black Snake prophecy of the Lakota foretells that a black snake will slither across the land, poisoning the water. Many Standing Rock water protectors interpret the DAPL pipeline as the black snake, and are intent to stop it before it goes underground and devastates the Earth. In some indigenous cultural contexts, laughter is considered the best pathway out of tragedy, and trickster stories as a path to liberation. Comedy and trickery can permit people to reclaim and revitalize their heritage through a living process that allows people to remember who they are.

The genre of trickster stories plays a special role in Indigenous traditions. In the Hidatsa story tradition, Trickster created the River, land on either side of the River, and the people who inhabited the bottomlands. Coyote stories teach about living in harmony with nature while developing the ability to survive and meet one's own needs and appetites. As trickster and teacher, Coyote identifies a creative path to liberation by getting around a situation. Paul Radin, as quoted by Lewis Hyde $(1998,10)$, says: "Trickster is at one and the same time 
creator and destroyer, giver and negator, he who dupes others and who is always duped himself. ... He knows neither good nor evil, yet he is responsible for both. He possesses no values, moral or social, yet through his actions all values come into being." Trickster, who made language and made the world through language, would motivate a people to speak their indigenous language again. His careless, anarchistic energy provides an antidote to the silence that can arise when language becomes precious. Trickster can jump-start the reclamation of culture through language. That shameless double-dealer can get outside the rules to set tongues wagging again.

Coyote's antics can make the mute laugh, can resurrect a dying language, and encourage speech that has been dammed up to flow freely again. With the help of Trickster, a precious language can become as spontaneous as waves, as freely moving as the vibrations of sound. Trickster can transform or reverse the current situation through fluidity. This generation can learn about the river by creating a free-flowing river of fluency, and learn how to respond to Trickster.

\section{Language restoration through media}

Restoration of indigenous languages requires a more playful public education; informal and creative approaches are required to restore language. Because the best approach to revitalize indigenous education requires that language be spoken both at home and in school, informal education must reach adults as well as children. People enjoying their language can be open to new experiences through mispronunciation, awkward translation, verbal spills of humor and play. By speaking an inverted language, people can rely on Trickster's humor and wit to jump the trap of trauma associated with the Garrison Dam and the current fracking boom and bust. Hyde $(1998,280)$ comments: "When human culture turns against human beings themselves, the trickster appears as a kind of human savior. When we have forgotten that we participate in the shaping of this world and become enslaved to shapings left us by the dead, then a cunning artus-worker may appear ... in short, when the shape of culture itself becomes a trap, the spirit of the trickster will lead us into deep shape-shifting."

The Missouri River, the longest river in North America, is a living being with the most spontaneous of characteristics: jumping its bank to carve new channels and pathways. With the help of stories and language, may the peoples of the River do the same.

\section{The restoration of healing rituals and ceremonies}

Language is a powerful medicine to restores the peoples' connection to their River. Ceremonies need to be practiced in indigenous languages, which include the words, grammar, and meaning as well as the pitches, vocables, rhythm, intonations inflections, and volume of song - in short, the poetry of the language. Language is the medicine that not only binds the community together, uniting the generations; it also unites each generation with the natural world. 
The oral traditions suggest that the Mandan, Hidatsa, and Arikara languages have sacred power in connection with nature. Indigenous languages are integral to maintaining communications with plants and animals, serving as the messenger between human beings and other beings. Initially, the plants and rocks gave language to the people. The oral tradition suggests that storytellers have the ability to vocalize with all beings, including plants, animals, and rocks. Vocables create a perfect pitch that resonates throughout the earth and the universe. Many languages are no longer spoken - including the languages of water, land, wind, fire, earth, plants, animals, and rocks - because the indigenous languages that complement them are not spoken or understood. Those who experience the mystery of nature and renewal of life through rituals and ceremony understand nature's wholeness in metaphorical, symbolic, respectful, and mystical ways.

Long before the Garrison Dam, the MHA Nation, like all indigenous nations, experienced severe restrictions on its religious freedom. US land claims constrained access to sacred geographical sites, which housed the sacred stories as well as the spirit guides who protected people living within those locales. The US government paid Christian missionaries to further restrict or obstruct spiritual practices (Prucha 1979). Sacred artifacts were confiscated. Starting in 1883, religious freedom for indigenous people was severely curtailed through the Rules Governing the Court of Indian Offenses, Congressional Indian Religious Criminal Code, Supreme Court rulings, and policies of the Bureau of Indian Afairs (USDI 1883). This period of religious oppression ended with the passage of the American Indian Religious Freedom Act in 1978. After people regained their religious freedom, many struggled to rekindle traditional rituals and ceremonies that had been banned for multiple generations. The Mandan Okipa Ceremony, the ceremony to bring back the buffalo, was reintroduced in 1983, and soon after the Hidatsa and Arikara brought back the Sundance Ceremony (Wallwork 2002).

Unlike the buffalo, the River's sacredness remains hidden under a man-made lake. People continue to reference sacred places in ceremony, offer cornballs to the lake, engage in ceremonial bathing, and "visit" cherished places by driving along the shore closest to sacred places (Crows Breast and Grinnel 2007). The water itself is still sacred. It has power to heal and is used in the Sundance, Okipa ceremonies, and in the Native American church. Many sacred sites and sacred bundles were left intact under water when the River was flooded. People recognize that sacred places have not gone away; they have become inundated and physically unavailable. Although "not visible, the [sacred] places are still there" because the lake has been transformed into "a repository of inaccessible heritage rather than an agent of erasure" (Murray et al. 2011, 477). By honoring what's sacred about the lake, "the community continuously creates and reifies cultural identity, meaning and memory" (Murray et al. 2011, 469). People maintain kinship with the River and the creatures in the River. Because the lake is seen as a "modern incarnation" of the River (Murray et al. 2011, 477), people have found ways to hold, "multiple, simultaneous and conflicting themes of loss and survival, death and renewal, and erasure and permanence" (Murray et al. 2011, 480). 
By holding this paradox, the people are creating possibilities of cultural continuity for future generations. "Our spiritual benefactors are waiting for this generation and future generations to seek their help. ... It may be that in the future other generations will want additional dreams. Then they, too, may get additional holy songs from us" (Crows Breast and Grinnell 2007, 33). The laws of the universe and Earth Mother are tied to the cosmologies and these laws do have consequences if not followed. As long as the people do not lose sight of their original instructions, they will continue in the long run to exist in a healthy manner.

\section{Water and oil}

Since 2008, there has been a significant increase in oil and gas production through hydraulic fracturing, or "fracking," in the Williston Basin of western North Dakota and eastern Montana. The Bakkan Oil field has become a world epicenter of hydraulic fracturing. Fort Berthold Reservation, which has less than $1 / 45$ th of the state's landmass, produces almost one third of the million barrels of oil extracted daily in the state of North Dakota. The Tribe's three-time chairman, Tex Fox, employed the slogan, "Today's Modern Day Gold Rush: The Dream Starts Here," to urge the tribe to achieve "sovereignty by the barrel" (McDonald 2014; Sontag 2014). Soon thereafter, the Water Protectors gathered at Standing Rock, the reservation just south of Fort Berthold, to stop the Dakota Access Pipeline (DAPL) that would transport the fracked oil.

\section{The fracking boom at Fort Berthold}

After being flooded out with water, the people are now facing a torrent of oil, brine, and cash. In the midst of prosperity from the oil boom, people continue to suffer from what development specialists refer to as the resource curse (Robinson et al. 2006). To abuse or destroy any part of nature is to do the same to our inner nature and our loved ones. The scale of infrastructure, environmental degradation, health risks, displacement, corruption, and unholy alliances has led to child abuse, drug addiction, and high-risk lifestyles. The New York Times produces a series of special reports on the corruption at Fort Berthold (Sontag 2014; Sontag and McDonald 2014; Sontag and Gebloff 2014; Aisch 2014). "Now," says tribal elder Marilyn Hudson, "you have murder, a hit man, and a five-time convicted felon.... It's like our reservation got hijacked by the plot of a bad movie" (Sontag and McDonald 2014). Tribal members expressed concern that, "While everything changed from the flood as a result of the Garrison Dam project, the new oil revenue coming in is, in essence, another type of flood" (Five Rivers 2012, 5).

The fracking infrastructure, production, and effluent have overwhelmed Fort Berthold. The oil and gas extraction technique of hydraulic fracturing, or "fracking" is water intensive in the construction and operation of oil wells. The New York Times produced an extraordinary map illustrating what the 40,000 miles of well bores already drilled near the River would look like if they were positioned above the River (Aisch 2014). One oil and gas pipeline had already been laid 
under Lake Sakakawea, and proposals exist to drill for oil under Lake Sakakawea. The Dakota Access Pipeline now crosses under the Missouri to transport 500,000 barrels of crude a day.

The reservation has suffered through several pipeline spills. The largest spill released over a million gallons of brine into Lake Sakakawea. A substance 10 to 30 times saltier than ocean water, "brine" can be laced with a cocktail of unidentified chemicals, heavy metals, methane, radioactive substances, diesel fuel and volatile organic compounds (VOCs) such as xylene, tolunene, benzene and acetone. Eighteen million gallons of oil and toxic waste were spilt, leaked or misted in North Dakota from 2006 to October 2014 (Sontag and Gebloff 2014). For every gallon of oil extracted, 1.4 gallons of brine is injected into a well. There has been little regulatory oversight of the development or cleanup. Because of purported cover-ups and monitoring restrictions, even the MHA Environmental Director does not have access to data about spills on the reservation, and the full extent of the spills and flares is unknown (Sontag 2014; LaDuke 2016).

At the national level, the "Halliburton Amendment" restricted oversight for fracking or flaring. Nationally, two billion gallons of fluid are injected into oil wells each day (GAO 2014). Companies are protected from disclosure by claiming trade secrets, and can choose from over 600 possible chemicals to create their fracking cocktail. The Federal Environmental Protection Agency has approved states to regulate fracking, yet it does not evaluate the states on an annual basis and does not have accurate data (GAO 2014). The EPA approved the 1,172 mile Dakota Access Pipeline (DAPL) without requiring an Environmental Impact Assessment (Sammon 2016).

\section{The water protectors at Standing Rock}

For years, a community watchdog group, "This is Mandaree," has been using Facebook in an innovative way as a publicly available video archive to carefully document flairs, spills, social impacts, and public hearings associated with the fracking boom at Fort Berthold (This is Mandaree Facebook page 2015). In May of 2016 one of the group's leaders, LaDonna Brave Bull Allard, put out a call for people to come to her land when she heard that the DAPL was scheduled to be installed near her son's burial ground. She expected a few people might come to the Sacred Stone Camp, yet tens of thousands of people showed up, representing over 350 indigenous nations in the United States as well as Canada, Mexico, Peru, Europe and New Zealand (LeBlanc 2017). Social media attracted people to the camps. The gathering gained significant international media attention and sparked a UN investigation on human rights abuses after peaceful protest and prayer on the DAPL was met with government violence (Wong and Levin 2016). Winona LaDuke calls North Dakota "The Deep North" comparing it to "The Deep South," where Martin Luther King's non-violent Civil Rights Movement developed (LaDuke, 2016). That violence ended when 3,000 US Veterans came out to take the front lines of protection, and the Army Corps of Engineers called a temporary halt to pipeline construction. 
Hightower $(2016,1)$ calls the face-off between the pipeline developers ETF and the water protectors at Standing Rock:

the panoramic story of America itself. It's a real reality show - a cultural, political, and moral drama featuring raw greed, grassroots courage, truly colorful characters, class war, ancient rites, human rights, Wall Street bankers, defenders of the common good, the most nefarious Texas oilman since J. R. Ewing, a historical gathering of Native tribes, echoes of Little Big Horn and Wounded Knee, and a Bull-Connor-style sheriff - all on location near a North Dakota town named Cannon Ball.

The strategy of Kelcy Warren, the CEO of ETF, was to string together a series of smaller "utility" pipelines to create the 2,000 km pipeline and then apply for a federal permit to go under the Missouri River (Hightower 2016). "Not since Custer has an Anglo been as surprised as Kelcy Warren by a powerful force of Indians thwarting his ambition" (Hightower 2016, 4). The Army Corp temporarily stopped the pipeline from being constructed under the Missouri River, but one of President Trump's first Executive Orders was to approve the ETF's proposal.

Despite the surge in oil fracking, we are simultaneously witnessing the emergence of a new era. Efforts to protect the Missouri River had become a catalyst for cultural revitalization and oil and water-related activism throughout the US and beyond (Woodard 2017). Traditional stories were told in the encampments, including the prophecy of how the black snake will destroy the Lakota if it is not stopped. At the camps, people of diverse ethnicities were invited to participate in prayerful ceremony and song. Many indigenous peoples have water ceremonies (pers comm. Cloud 2015; Gunn Allen 1990; Norman 2015), but before Standing Rock, they were not widely known or shared. As people from many indigenous nations came together at the Sacred Stone Camp and other camps nearby, they learned sacred songs and prayer in each other's languages, shared ceremony and story, and learned the lessons that the sacred waters teach. Most people returned home with a deeper cultural understanding of how to fight and pray for water and revitalize ceremony in their traditional homelands.

\section{Conclusion}

A thread of cultural resilience, as wide, muddy, sinuous, and unpredictable as the Missouri River, has persisted through the smallpox epidemics, the land theft, the dam construction period, and now the fracking boom. Indigenous people have drawn from their sacred stories to understand how creation emerged from the River, how the River renews life, and what to do when there's a flood. The gathering at Standing Rock may be just the thing to invigorate a new era of cultural resilience and cultural renewal.

Many policy and enforcement strategies experienced by the water protectors at Standing Rock were familiar to people who suffered from the Pick-Sloan dam development: lack of appropriate consultation; rerouting development away from 
white settler communities to Indigenous reservations; dehumanization; reduction of water quality; eminent domain threats; federal attention to the needs of people of the lower Missouri rather than the upriver Indigenous communities; no attempts at co-management; disregard for law, unfair treaties, regulations, and Supreme Court decisions; disregard for tribal claims to reserved water rights; eviction threats; and the ultimate threat of the termination of reservations.

At times during the Standing Rock gathering, especially when Energy Transfer Partners dug up graves and sacred sites, it seemed that the backhoe had crushed the legal system. Young people in the camps were learning that remaining in a prayerful and peaceful state proves more powerful than bullets (LeBlanc 2017). The Oahe Dam at Standing Rock, which was built just after Garrison Dam, "destroyed more Indian land than any other public works project in America" (Lawson 1982, 50). But Standing Rock may be remembered not for what was lost through Pick Sloan, but what was created there: an intertribal coalition for cultural revitalization that uses political training and prayer to protect water and social media to get tongues wagging.

There is no going back to an authentic state before the moment of colonization. The people can never go home again because the restoration of an ideal past is impossible. Yet the modern highway obscures multiple hidden pathways of cultural continuity. An indigenous heritage, however broken, provides the birthright to wander out and back on your own road seeking the company of the ancestor helpers. Walking the ancestors' road requires the courage to go to the depths of self. Only then can the people carry forward what has been lost or neglected by past generations.

For tens of thousands of people, the ancestors' road was rediscovered at Standing Rock. The largest intertribal gathering in over a century was a pivotal moment in environmental activism, indigenous activism, and river restoration. Driven by faith, prayer, and cultural traditions, this activism revitalized indigenous cultures, while innovative use of mass media developed allies across racial and international boundaries. While traditional myths were revived, a new story was being created. This gathering planted many seeds in the seventh generation that had been planted and harvested by previous generations of fluent and non-fluent indigenous language speakers through healing rituals, stories, and ceremony.

\section{References}

Aisch, G. 2014. "What North Dakota Would Look Like If Its Oil Drilling Lines Were Aboveground," New York Times, 24 November. www.nytimes.com/interactive/ 2014/11/24/upshot/nd-oil-well-illustration.html?_r=0.

Berkes, F. 2008. Sacred Ecology: Traditional Ecological Knowledge and Resource Management. Philadelphia, PA: Taylor and Francis.

Billingston, D., Jackson, D., and Melosi, M. 2005. The History of Large Federal Dams: Planning, Design and Construction in the Era of Big Dams. Denver, CO: Department of the Interior and Bureau of Reclamation. https://www.usbr.gov/history/HistoryofLargeDams/ LargeFederalDams.pdf. 
Cajete, G. 1994. Look to the Mountains: The Ecology of Indigenous Education. Skyland, NC: Kivaki Press.

Campbell, J. 1988. The Power of Myth. New York: Doubleday.

Capossela, P. 2015. "Impacts of the Army Corps of Engineers' Pick-Sloan Program on the Indian Tribes of the Missouri River Basin." Journal of Environmental Law and Litigation 30:143-217.

Carrels, P. 1999. Uphill Against Water. Lincoln, NE: University of Nebraska Press.

Cloud, Sylvia, 2015. Personal communication.

Crows Breast, E., and Grinnell, C. 2007. Traditional Cultural Property Study, Lake Sakakawea, North Dakota. Draft Report submitted to the US Army Corps of Engineers. New Town, North Dakota: Three Affiliated Tribes Cultural Preservation Office.

Five Rivers Consulting. 2012. Sustainable Prosperity: Building a Bridge to a Brighter Tomorrow www.visionwestnd.com/documents/MHANationSustainableProsperityReportFinalVersion-2.pdf.

Gruley, B. 2016. "Pipeline Billionaire Kelsy Warren Is Having Fun in the Oil Bust: The Founder of Energy Transfer Partners Has Built His \$7.3 Billion Personal Fortune by Making Smart Moves During the Industry's “dark times." Bloomberg, 19 May 2015. www.bloomberg.com/news/features/2015-05-19/pipeline-billionaire-kelcywarren-is-having-fun-in-the-oil-bust.

Gunn Allen, P. 1990. The Sacred Hoop: Recovering the Feminine in American Indian Tradition. Boston: Beacon Press.

Harrison, D. 2007. When Languages Die: The Extinction of the World's Languages and the Erosion of Human Knowledge. New York: Oxford University Press.

Hightower, J. 2016. 'Don't Miss 'The battle of two pipes,' an Epic Story From the American Heartland." The Hightower Lowdown Newsletter 18(10) 1-4, October. https://docs. google.com/document/d/1e3MrpfdH6AsrGT6910ErXSsJbJVvIRqO3G5TLBY6mnQ/ edit.

Hoxie, F. E. 1984. A Final Promise: The Campaign to Assimilate the Indians 1880-1920. Lincoln, NE: University of Nebraska Press.

Hyde, L. 1998. Trickster Makes This World. New York: North Point Press.

Kroskrity, P., and Field, M. eds. 2009. Native American Language Ideologies: Beliefs, Practices and Struggles in Indian Country. Tucson, AZ: University of Arizona Press.

LaDuke, W. 2016. The Winona LaDuke Chronicles. Ponsford, MN: Spotted Horse Press.

Lawson, M. 1982. Dammed Indians: The Pick Sloan Plan and the Missouri River Sioux 19441980. Norman: University of Oklahoma Press.

LeBlanc, J. 2017. "Standing Rock Is Everywhere." Circle of Blue Podcast, 4 January. www. circleofblue.org/2017/north-america/standing-rock-everywhere-interview-judithleblanc-native-organizers-alliance-podcast/.

Lopez, B. 1990. Crow and Weasel. New York: North Point Press.

Maltz, A., and Fox, D. P. 1999. "To Set Tongues Wagging Again: Endangered Languages of the Hidatsa, Mandan, and Arikara." In Endangered Languages and Education: Proceedings of the 3rd Foundation of Endangered Languages FEL Conference, edited by N. Ostler, 23-30. http://www.ogmios.org/conferences/1999/proceed1999.htm.

Mander, J. 1992. In the Absence of the Sacred. San Francisco: Sierra Club Books.

McDonald, B. 2014. "On Tribal Lands, Oil and Trouble." New York Times Documentaries, 29 December. www.nytimes.com/video/us/100000003419586/on-tribal-lands-oil-andtrouble.html.

MHA Language Project. 2016. www.mandanlanguage.org/; hidatsa.org/; and http:// arikara.org/index/about-arikara/. 
Morris, C. 2012. The Big Muddy: An Environmental History of the Mississippi and Its Peoples From Hernando de Soto to Hurricane Katrina. Oxford: Oxford University Press.

Murray, W. F., Zedeno, M. N., Hollenback, K. L., Grinell, C., and Crows Breast, E. 2011. "The Remaking of Lake Sakakawea: Locating Cultural Viability in Negative Heritage on the Missouri River." American Ethnologist 38(3): 468-483.

Nadasdy, P. 2005. "The Anti-Politics of TEK: The Institutionalization of Co-Management Discourse and Practice." Anthropologica 47: 215-232.

Nettle, D., and Romaine, S. 2000. Vanishing Voices: The Extinction of the World's Languages. Oxford: Oxford University Press.

Norman, E. S. 2015. Governing Transboundary Waters: Canada, the United States and Indigenous Communities. New York: Routledge, Taylor and Francis Group.

Pinkola Estes, C. 1992. Women Who Run With Wolves. New York: Ballentine Books.

Prucha, F. P. 1979. The Churches and the Indian Schools 1880-1912. Lincoln, NE: University of Nebraska Press.

Robinson, J. A., Torvik, R., and Verdier, T. 2006. "Political Foundations of the Resource Curse." Journal of Development Economics 79(2): 447-468.

Robinson, S. C. ed. 1999. The Story of Garrison Dam: Taming the Big Muddy. Garrison, North Dakota: BHG Inc.

Sammon, A. 2016. "The Government Quietly Just Approved This Enormous Oil Pipeline." Mother Jones, 12 August. www.motherjones.com/environment/2016/08/ new-american-mega-pipeline-youve-never-heard-dakota-access-bakken.

Schneiders, R. 1999. Unruly River: Two Centuries of Change Along the Missouri. Lawrence, KS: University Press of Kansas.

Sontag, D. 2014. "Where Oil and Politics Mix." New York Times, 23 November. www. nytimes.com/interactive/2014/11/24/us/north-dakota-oil-boom-politics.html.

Sontag, D., and Gebloff, R. 2014. "The Downside of the Boom: North Dakota Took on the Oversight of a Multibillion-Dollar Oil Industry With a Regulatory System Built on Trust, Warnings and Second Chances." The New York Times, 22 November. www. nytimes.com/interactive/2014/11/23/us/north-dakota-oil-boom-downside.html.

Sontag, D., and McDonald, B. 2014. "In North Dakota, a Tale of Oil, Corruption and Death." New York Times, 29 December. www.nytimes.com/2014/12/29/us/in-northdakota-where-oil-corruption-and-bodies-surface.html?_r=0.

This Is Mandareee. 2015. This Is Mandareee Facebook Page. www.facebook.com/ ThisisMandaree/timeline?ref=page_internal.

US Army Corp of Engineers. 2006. Missouri River Mainstem Reservoir System Master Water ControlManual: Missouri River Basin. www.nwd-mr.usace.army.mil/rcc/reports/mmanual/ MasterManual.pdf.

US Department of the Interior. 1883. "Rules Governing the Court of Indian Offenses." https://rclinton.files.wordpress.com/2007/11/code-of-indian-offenses.pdf.

US Geological Survey. 2013. Assessment of Undiscovered Oil Resources in the Bakken and Three Forks Formation, Williston Basin Province, Montana, North Dakota, and South Dakota. http://pubs.usgs.gov/fs/2013/3013/fs2013-3013.pdf.

US Government Accounting Office. 2014 "EPA Program to Protect Underground Sources From Injection of Fluids Associated With Oil and Gas Production Needs Improvement." GAO-14-555: 27 June. Washington, DC: USGAO.

Van Develder, P. 2004. Coyote Warrior: One Man, Three Tribes, and the Trial That Forged a Nation. Lincoln, NE: University of Nebraska Press. 
Wallwork, D. Director. 2002. Sacred Buffalo People. DVD First Nations Films, Vancouver, BC and Prairie Public Television, Fargo North Dakota. www.redeyevideo.org/SBP.html. Wong, J. C., and Levin, S. 2016. "Standing Rock Protesters Hold Out Against Extraordinary Police Violence.” The Guardian. www.theguardian.com/us-news/2016/nov/29/ standing-rock-protest-north-dakota-shutdown-evacuation.

Woodard, S. 2017. "The Spirit of Standing Rock on the Move." Yes Special Report. http://reports.yesmagazine.org/spirit-of-standing-rock/?utm_source=YTW\&utm_ medium=Email\&utm_campaign=20170127. 


\title{
10 The end of the Los Angeles River
}

\author{
A paradox
}

T.S. McMillin

\section{Introduction}

When is a river not a river? When it is less than a river, its bed dustier than it is wet? When it is more than a river, in flood, vast and catastrophic? When it has "been paved into irrelevancy" (Morrison and Lamonica 2001, 34)? When officials deem it a Flood Control Channel? When it is removed to the darker recesses of human consciousness? This chapter is part of an experiment to determine the nature of the Los Angeles River. Twofold in its approach, the experiment combines fieldwork on the current conditions of an urban waterway with interpretive study of textual representations of rivers. The primary goal of the experiment is to investigate the ways in which humanistic inquiry might serve as a means of conceptually "daylighting" a river. "Daylighting" most commonly refers to the process of opening or redirecting the channel of a stream that has been covered or obstructed by human structures, a physical return to the light of day.

Inspired by the term's metaphorical potential, I have adopted it as a key component in an area of study I am calling "textual potamology": an exploration of the cultural history of the river to imagine new ways of understanding a river's nature. Textual potamology pursues the possibility of bringing to light not only the river but our thought processes, our social practices and cultural biases regarding waterways. In what follows, I weave together a study of select fictional representations of the Los Angeles River with photographs, discursive description, and reflections on the lower portion of the river, from its mouth in Long Beach to Chinatown. Other parts of the experiment concern the relationship between non-fiction and the middle section of the river, centered on its confluence with the Arroyo Seco, and the relationship between poetry and the upper reaches of the river.

While it is a commonplace concept that fiction can enrich history through its manipulation of narrative, image, setting, character, etc., one of fiction's chief assets is its facility for revealing paradoxes in our ways of thinking. By considering fictional treatments of the conceptual end of the river (that is, when it ceases to be considered "a real river"), and connecting this with a field study of the physical end of the river (where it enters the ocean), I hope to daylight the L.A. River. 


\section{The Los Angeles River}

You can follow Interstate 710, the Long Beach Freeway, to the present end of the Los Angeles River (Figure 10.1). The 710, as locals call it, winds along a good portion of the lower river course, from Bell to Long Beach, heavy traffic flowing in ten or more lanes, concrete barriers separating one run from the other. Power cables form yet another kind of course and current for a long stretch, a suspended set of lines streaming above the river and road. At its mouth, the Los Angeles River disappears into San Pedro Bay beneath a low bluff of trade and recreation: a pier, a park, an aquarium, and "Shoreline Village," an artificial amusement municipality laid out like a broken leg near the Long Beach Marina. Fake Victorian signs top the fronts of an array of shops and eateries lining the olde tyme Boardwalk, an odd ensemble of the quaint and quirky designed to amuse tourists and relieve them of their lucre. It includes a carousel, "The All-American Melodrama Theater and Music Hall," Village Hat Shop, Pirates Cove ("Booty Is arrr business"), and a cigar store. Huge cranes in the distance mark the port and naval complex. Near the rock-pile banks of the river's last lengths, an RV "resort" stands; many of the residents have laid a square yard or two of Astroturf under their Winnebago awnings. Finally, just upriver a mile or so, under the Ocean Boulevard Bridge, a sign prohibits boating on (and most other kinds of direct contact with) what it names "The Los Angeles County Flood Control Channel."

The water through much of this lower section of the river is weedy and green, windblown and slightly tidal, ebbing and flowing slowly in a strangely straight bed about 150 meters wide. Petroleum pipelines cross it, as do the bridges of Shoreline Drive, Anaheim Street, Pacific Coast Highway, and Willow Street. Squatters' camps under the bridges and in sections of the river where trees grow on the edge of the bed can have twenty to thirty sites, with sleeping bags, blankets, tarp-tents,

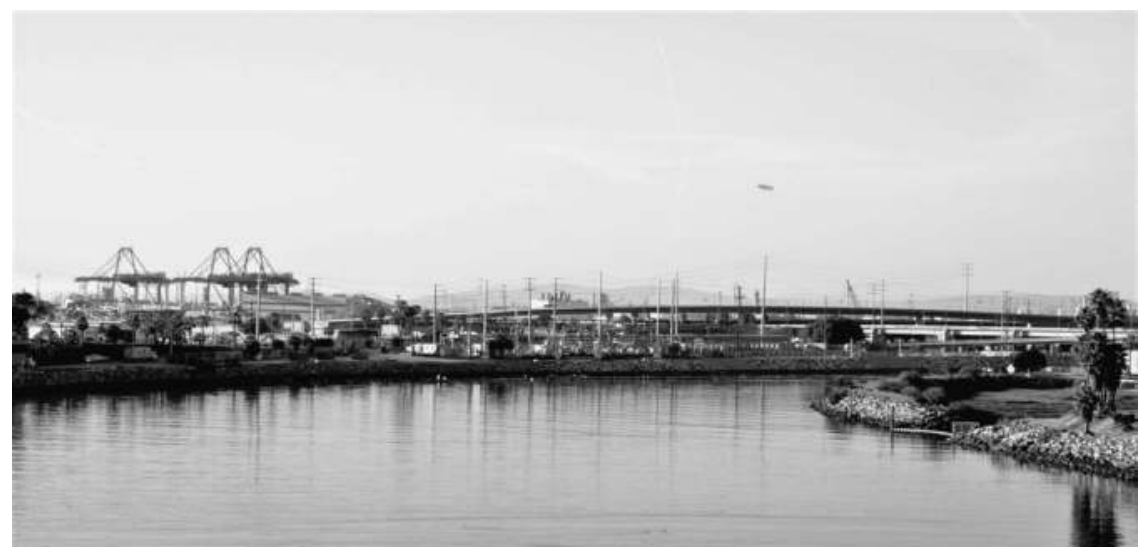

Figure 10.1 The Mouth of the Los Angeles River.

Source: Photo courtesy of the Author 


\section{T.S. McMillin}

laundry, and some toys scattered around. Bird life (Great Blue Heron, ducks, Killdeer, and Black-necked Stilts) pokes around the soft, murky bottom and the riprap or concrete banks in the estuarial stretch below Willow Street, and in parts of this section thick bushes and trees have taken root in the river's sandy margins, creating an almost pastoral setting for what looks almost like a river. Above Willow Street, though, the bed is concrete from bank to bank. Barbed- and razor-wire barriers separate the river from neighborhoods that sit well below the paved path atop the levee, and the river seems nothing if not sequestered, aislado.

Painted-over graffiti look like scabs on the concrete; more recent tags represent some of the river's occasional visitors: "Bubbles," "Rascal." Foam drifts slowly on the viscous surface of the six-meter wide, precisely engineered, low-flow channel that runs in the middle of the concrete bed. One commentator, Joe Linton, writes that it isn't easy to see this portion of the river "as a 'real' river"; residents are more likely to refer to it as "the sewer" or "aguas negras" (Linton 2005). Just as the surrounding cityscape varies considerably in the lower portion of the Los Angeles River - fenced-off trailer-park, restored wetlands, golf course, ramshackle horse-stables, houses tucked under flowering jacaranda and power-cable towers - so do the contents of the channel: sometimes a few centimeters of warm water in the wider bed, and up to one's shins in the low-flow notch, sometimes that notch hardly discernible amid an expansive dark flow. Below the Imperial Highway Bridge, bright-green water with a flotilla of foam pods idles down the cut, the rest of the bed is bone-dry.

Of all the ways of paradoxes, perhaps the quaintest is their capacity on occasion to turn out to be so very much less frivolous than they look.

W.V. Quine (1976, 18), "The Ways of Paradox"

Running fifty-one miles (eighty-two $\mathrm{km}$ ) from its concrete headwaters through the heart of the most populous county in the United States and emptying into the Pacific at its engineered mouth, the L.A. River is a study in paradox. Perhaps better than any other stream in the United States, it makes plain that an obtuse question worthy of Heraclitus - When is a river not a river? - is more than a philosophical conundrum. For the ancient Greek thinker, flowing water was an opportunity to consider a fundamental paradox of reality: things constantly change, including human beings, even though forms seem to stay the same. "We step and do not step into the same rivers; we are and are not" (Heraclitus 1987, 35). Paradox - etymologically, thinking in a manner that moves one beyond convention or orthodoxy - entails an unbelievable or even absurd contradiction that nonetheless enables us a glimpse of something true. The Los Angeles River, by both being a river and by not being a river, poses a host of questions about our understanding of natural phenomena: questions about being and meaning, about what we call "the environment," political and societal questions, and questions about the ecological and economic future of cities.

Before it was called "river," even before it was called "río," the stream and its watershed attracted the attention of various lifeforms, including humans. 
Hokan-speaking peoples lived near the waters 10,000 years ago until they were absorbed into or displaced by the Tongva or Kizh (the name is disputed by current descendants) around 1300-1400 years ago. These peoples were renamed the Gabrielenos (or Gabrielinos), which meant "people belonging to the Mission at San Gabriel," by the Spanish in honor of the religious outpost they established on Tongva land in 1771. The Tongva are considered to have been relatively well off among native peoples of the greater southwestern region, thanks in no small part to the life and livelihood provided by the river (though they were better known for their skill at navigating the ocean in long canoe-like boats; McCawley 1996). They settled close to the banks, but not too close, preferring high ground, which early Europeans didn't quite understand, at first. As other Southern Californian streams, the principal waterway of the Los Angeles basin has always had two primary manifestations: "a small gentle stream flowing through a small sandy bed most of the year and a large turbulent, unpredictable river for a few days every winter," as Blake Gumprecht described it in his detailed history. The Tongva knew the river when its delta occupied what is now called the Ballona Wetlands (west of downtown L.A. near Santa Monica); before the river was altered by human engineering, its mouth "was in a nearly constant state of flux," depending on flow and deposits (Gumprecht 1999, 12, 17, 19; Figure 10.2).

Among other conditions, the aridity of the climate prevented the river from establishing a stable channel. There was a river at the Ballona Wetlands and

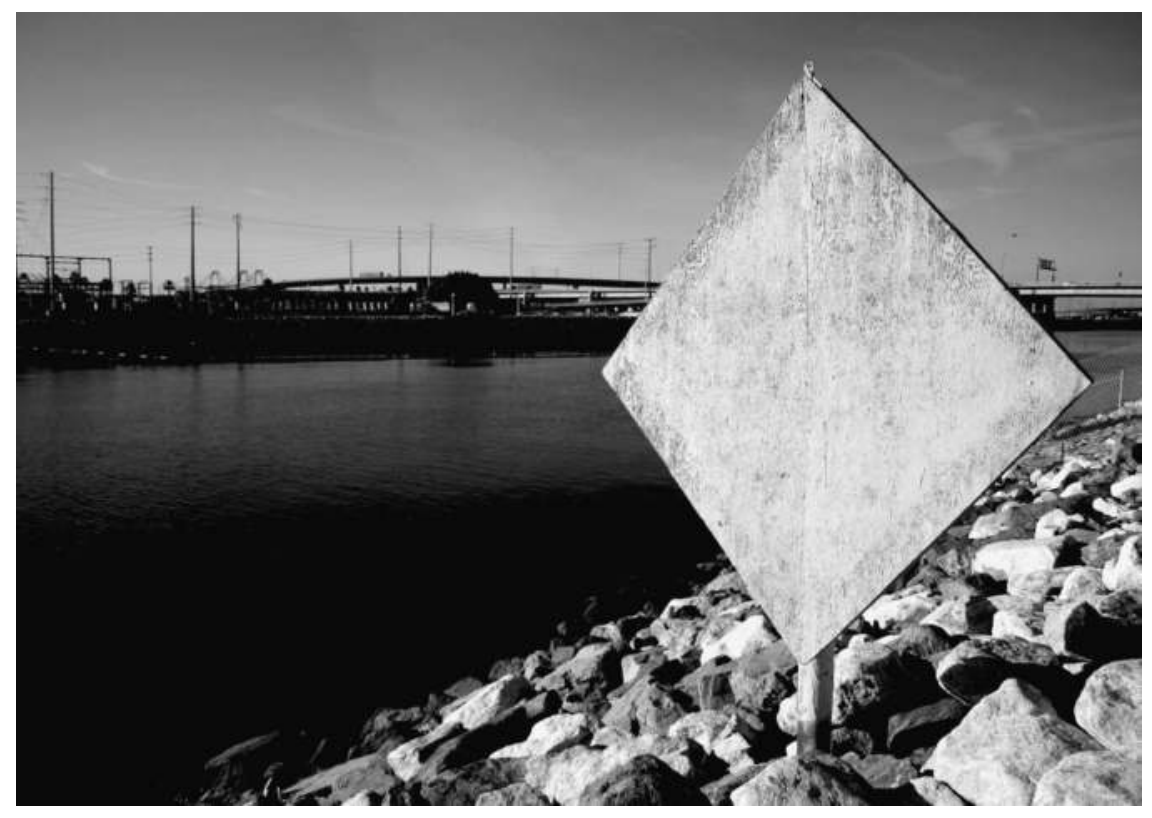

Figure 10.2 Sign at the end of the Los Angeles River.

Source: Photo courtesy of the Author 


\section{T.S. McMillin}

then there wasn't. The L.A. River steered clear of Long Beach and then it didn't. There was a river running through the Tovangar, "the culture and world of the Tongva," but then those "Ancestral Lands" were no longer "theirs." The Spanish named the principal waters of the basin El Río de Nuestra Señora de Los Angeles de la Porciúncula on August 2, 1769 - "Porciúncula" meaning "Little Portion" in honor of the minute chapel in Italy where Francis of Assisi had been visited by divine revelations (Gumprecht 1999).

As a dependable water-source in a semi-arid region, the Porciúncula, under which designation the river ran for a long time, "largely determined the location of Los Angeles" (Gumprecht 1999, 2). In its history of watering the region, The City of Los Angeles Department of Water and Power writes, "When Gaspar de Portola discovered and named the Rio Porciuncula on his mission of exploration from San Diego to Monterey in 1769, he recognized the site as ideal for settlement because of the ample water supply in the river" (City of Los Angeles 2015, n.p.). As Gumprecht concludes simply, "The river made settlement possible in the semi-arid country" $(1999,81)$. The Porciúncula was the principal water source for the pueblo of Los Angeles, enabling inhabitants of the region to cultivate a wide variety of crops, from grains to grapes to oranges, until the discovery of gold in Sacramento led to a population explosion in California. In the southern region of what would became the 31st state in 1850, that explosion was fueled by the river: Gumprecht asserts that "the significance of the river surpassed even its usefulness as a water source" $(1999,81)$. Booster-hyped imagery of the region as a newfound paradise drew hundreds of thousands west, suggesting that the river's meaning, its potential, was in some ways even greater than the water it supplied, that fanciful images of the edenic land it watered were more distinct than its fluctuating channel. As the soft-bottomed physical river continued to shift and vary, the firmer became the notion that its course must be fixed and its flow controlled. These two versions of the river, the physical and the conceptual, came increasingly into conflict, and something had to give.

Eventually, despite periodic busts, the enormous booms of population growth and development of lands in and around the city of Los Angeles through the 19th and well into the 20th century led to the diversion of the river's flow, widespread clearing of the flood plain, proliferating surface-paving, and the eventual depletion of underground sources (Gumprecht 1999). The seasonably on-again, off-again Little Portion of heaven dwindled until it could no longer serve as a reliable supply of water. In 1913, the Los Angeles Aqueduct was completed, bringing water to the basin from the Owens River (The City of Los Angeles Department of Water and Power 2015). Supplementing L.A. water with Owens River water contributed to the un-rivering of the Porciúncula. No longer a sufficient source of water, the stature of the intermittent stream diminished. Having lost a clear purpose in the eyes of the humans surrounding it - that is, by no longer performing one of the customary functions of a river - the Los Angeles River no longer meant life-giving freshwater, no longer meant "river." It had come instead to mean absence, gutter, dump. A Los Angeles Times banner headline from July 29, 1905 announced the progress of the aqueduct: "Titanic 
Project to Give City a River." (This project is cited in many sources, including "The Story of the Los Angeles Aqueduct" [Department of Water and Power] and Gumprecht [1999, 105]). A few weeks earlier, The Los Angeles Times quoted William Mulholland, the legendary head of Water and Power and a major force in the Owens Valley project, on the inverse trajectories of river and people in L.A.: "Our population climbed to the top and the bottom appeared to drop out of the river" (Gumprecht 1999, 95). Overuse, lack of conservation measures, and drought in the 1890s contributed to water scarcity. A new river, a real river, would finally replace the washed up Little Portion of the past. This headline suggests that a river is defined by what it does for people. When a river ceases to do what rivers usually do, when it no longer does right by the people surrounding it, it ceases to be a river.

\section{Controlling the "River"}

The sky hangs heavy over the city. A thin, remotely blue line below the clouds and above the distant trees hints that it's sunny somewhere in Southern California. The concrete bed of the river bears the burden of tottered obelisks, long blocks deployed to restrict flow, and is covered by a film of scum and run-off, an oily sheen reflecting suspended clouds. Black-necked Stilts seem to be stuck to the bottom: six or so stand still, tip forward, tip back, stand still. Two shopping carts form riffles in the undead stream. What would be water slides by me, on the bank, downriver from downtown, watching its smudge and rust, rot and sludge, damage and disrepair - the Los Angeles oozes at its mouth.

Not only did the river fail to do right in the eyes of the more recent human inhabitants of the Los Angeles basin; at the same time, it increasingly did wrong. Calamitous floods in 1886, 1914, 1934, and 1938 resulted in the "sentencing of the river to a life imprisoned in concrete" (Morrison and Lamonica 2001, 62). Although several mountain ranges give shape to the basin, the highest of these (the San Gabriels, to the north) traps moisture from winter storms coming in off the Pacific Ocean, sending the runoff from rain and snow, along with tons of "unstable hill-slope rock debris," down steep canyons, overwhelming the channel-capacity of the basin's rivers and their tributaries (USGS 2006). An epic deluge in 1825 , for example, redirected the course of the river almost ninety degrees, from a westerly to a southerly course. Dry spells of the late 1870s and early 1880 s coincided with a flood of newcomers to the region, along with a ceaselessly rising tide of ill-conceived construction projects. Homes and businesses were built in the floodplain (and sometimes in the bed of former channels) of the river, railroad trestle-style bridges obstructed the free flow of runoff, and artificial embankments constricted the river. Although occasional floods had enhanced the fertility of the land by providing much needed moisture and fresh layers of silt (and by removing accumulated salts), the population booms, rapid development, and construction practices stemming from "the amnesia Angelenos had about the river," meant that that erstwhile blessing known as the Porciúncula had come to be seen as "a treacherous stream" that "cannot be trusted," 
an irregular and destructive force requiring desperate measures of restraint (Gumprecht 1999, 156-171).

From 1938 to1959, the US Army Corps of Engineers built a concrete channel for most of the river and its major tributaries, as well as concrete storm drains to move rainfall into the main conduit - all parts of the Los Angeles Flood Control District, established in 1915 by decree of the California state legislature. The river itself became increasingly referred to as the "Los Angeles Flood Control Channel" in the media (Morrison and Lamonica 2001), another step in the process of un-rivering the river. The history of human interaction with the L.A. River at least from the 19th century on is thus a story of overuse, neglect, fear, and control, and it belongs to a larger story, a way of thinking about the relations between culture and nature in which those two categories are opposed to one another. In that way of thinking, nature exists as an inferior set of elements, circumstances, and conditions that are subordinated to the needs of a given culture. Once a river (nature) is no longer a boon to humans (culture), it becomes little more than a bane to be banished. No longer seen as nurturing humans, nature is driven out by culture with a pitchfork (Tom Waits, "Misery is the River of the World," 2002).

However, the river's more recent history includes human efforts to let nature back in. The Friends of the Los Angeles River was founded by poet Lewis MacAdams in 1986, and has sponsored an annual clean-up of the river for over twenty years. Six years later, the Los Angeles County government established an advisory committee to develop a "master plan" for the river. City Councilman Ed Reyes led efforts to create an Ad Hoc Committee on the Los Angeles River in 2002, which resulted in the Los Angeles River Revitalization Master Plan. In 2010, the US Environmental Protection Agency declared the river's waters officially navigable, overturning prior declarations to the contrary by the US Army Corps of Engineers and other governmental entities, thereby granting the river and its tributaries protection under the Clean Water Act. Two years after that, Governor Jerry Brown signed SB 1201, granting increased public access to the waterway and reclassifying it. What had become a "flood control channel" was now once again to be considered a river. The language of such measures - befriending the river, bringing it back to life, restoring it (returning to a previous state), gubernatorially declaring it a bona fide river - suggests that the river indeed had been un-rivered; that human deeds had undone its nature, but also that human activity can undo the undoing. Both aspects of the river's modern history make me wonder about the nature of our culture's thinking about nature. Does nature really go away when we arm ourselves with pitchforks? Can a river really cease to be a river if it still flows, albeit in a concrete channel? What makes a river a river, and what can render it a river no longer? Does a culture ordain - have the last word on - when a river is not a river?

Above the entrance of Compton Creek and below that of the Rio Hondo, the paved riverbed has dried into a semblance of a road. Cars and trucks hum and whine over the Century Freeway bridgeworks. I descend the slant bank passing over dull painted patches - blotches covering up graffiti, markers memorializing 
what had once been writing. Here the Little Portion seems more building than river. Far from a chapel, it is a testament to cement. The bed is desolate, level and blank, and the detritus of the last storm has been baked into a light dusty crust on the hard skin of the channel's precisely engineered course. In the exact center of the bed, a deeper low-flow channel carries what's left of the stream in the form of a frothy green liquid. The line is notched and angled to avoid the bridgework footings, the stream arranged, arraigned, estranged; for in such stretches the broad, calibrated bed is scoured and lifeless except for God knows what bacteria. Standing here, peering up the course, I am dizzied: the Century Freeway Bridge casts shadows, heavy horizontals, in the foreground. In the background, the sere surface diminishes into infinite iterations; the center-cut contents veer away into the vaguely shimmering, sun-beaten reach beyond Imperial Highway. The river disappears upstream, a calculus of line, lane, block, and buttress.

\section{A brief conceptual timeline of "The Los Angeles River": from presence to absence}

First, [the river is]. The brackets indicate a pre-human history in which "the river" is un-worded, unnamed, not known as a river. In this state, its being is not dependent upon or involved in meaning; it likely comes and goes, contingent on shifting conditions. Eventually, the river became whatever it was called by the Hokan people - a word I have been thus far unable to find - and it was this for millennia. The Tongva or Kizh later renamed and made the river mean - and thus, to them, be - yet something else. Eventually, it was the Porciúncula, then the Los Angeles River, then the L.A. Flood Control Channel, and by that point, for many, it no longer accorded with the meanings attached to the word "river." The river is not.

By the end of the 20th century, whatever it had been no longer mattered; to the authorities, and to most citizens of the county, the river wasn't a river. Beginning at that point and continuing today, numerous groups of people are working hard to restore the river, to make it present again or bring out its presence and latent meanings, so that it is or will be the L.A. River again. But isn't the river always, in some form, what it was when it was only in brackets? Or do our rivermeanings undo its river-being? If a river is a river even when it doesn't meet customary meanings of "river," does that disconnection between meaning and being suggest the insufficiency of the conceptual category of "River" to capture the existence of the phenomena comprising the category? Or does it suggest the insufficiency of being to unfold itself fully in meaning? Perhaps the river always [is], even when we think or say it isn't. In that case, some of the trouble surrounding the river's recent history stems from the difficulty we have in acknowledging and attending to paradox.

To return to the paradoxical end of the line, the mouth of the Los Angeles River has shifted considerably from one location to another. In the last couple hundred years alone, it moved from a scenic spot on Santa Monica Bay to a busy situation in San Pedro Bay, and even then it continued in a state of flux until heavy machinery and concrete fixed it permanently (for lack of a better word). 


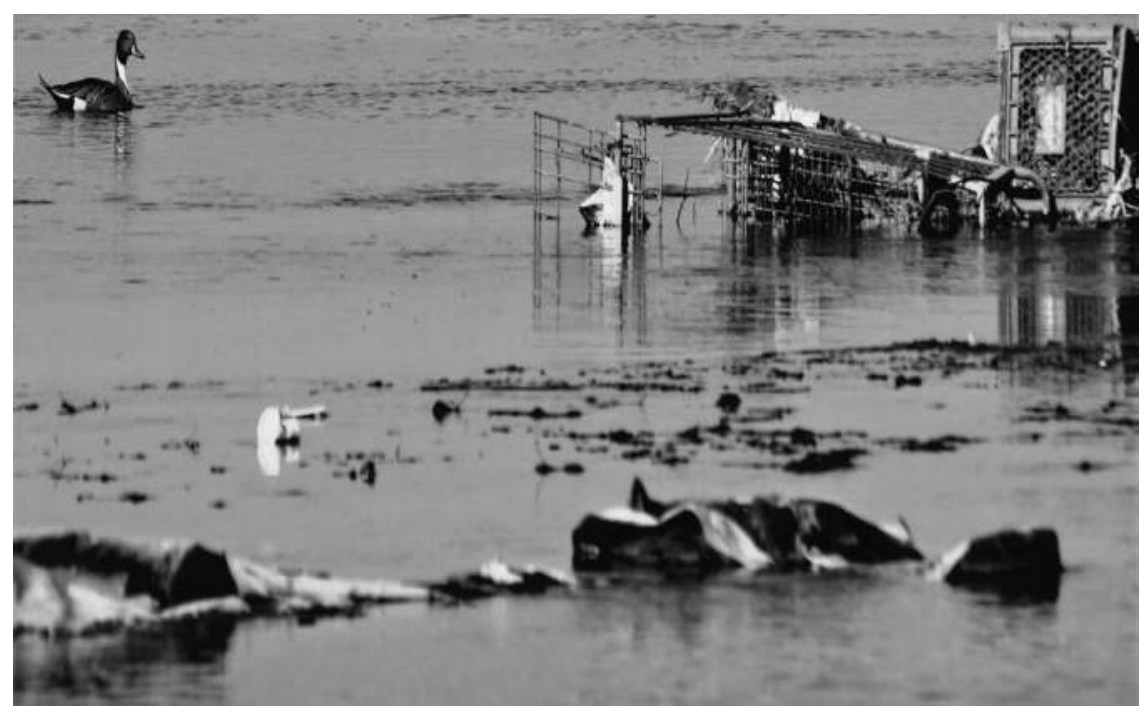

Figure 10.3 Lower Los Angeles River near Willow Street.

Source: Photo courtesy of the Author

But there was still a river and still a mouth, even when the mouth wasn't where it was said to be. The history of the mouth reveals aspects of the river's nature that are often elided: it's always present, even when it's absent; it's ever alive, even when it looks dead. The mouth of any river is the lowest elevation of the stream, as well as its destination, termination, resolution. When its destination changes, the nature of the river changes too, such that resolution is less resolved, more open to fluctuation. When the mouth is fixed - by tons of concrete, say - its resolution is more resolute. The mouth could come unfixed, of course, through earthquake or terrorism or some other happenstance, but we can also imagine the mouth in a way that opens it to more fluid meaning again. Thinking more deeply about its paradoxical qualities, thinking more broadly about its history and identities, we can regard the mouth as something other than the end of the river - not a beginning, perhaps, but an unending (Figure 10.3).

\section{The absent dragon}

Fiction about Los Angeles offers a way into further consideration of endings and beginnings, of the river and of paradox. Fictional treatments of the city tend to mirror the river's historical oscillation of presence and absence. To be sure, the river surfaces infrequently in novels and stories of the city. When it does appear, it is customarily as something glimpsed through the window of a car: an iconic urban phenomenon demarcating a separation of one section of L.A. from another 
or representing cultural progress. Caught in the right light, however, the river can be visually stunning, and has served numerous films and television shows as a set, a stage for culture to play its games in the absence of nature. In most appearances, it is cast as a passive conduit for (or alternatively an obstacle to) the movement of humans and our vehicles, especially chase scenes and other races. Exceptions to these fleeting set pieces, while rare, do raise possibilities for reconsidering its meaning. Rupert Hughes's novel City of Angels (1941), for example, portrays the L.A. River as a force of reckoning. The implausible rags-to-riches tale that plays out in early 20th-century Los Angeles features a handsome lifeguard whose heroics bring him unwonted and unwanted notice from hot-blooded married women, from real estate moguls, and from Hollywood hit-makers. Warren Thorburn, his head turned by a cavalcade of stock characters and random spotlights, mostly desires to be left alone so he can seriously pursue his studies at Cal Tech. Our hero is but one of the many Angelenos who set about taming wild nature in the L.A. basin. When discussing planned operations with a leading civil engineer, Thorburn gushes, "When you mention the flood-control works, I glow all over" (Hughes 1941, 294).

Hughes introduces the river early as a breed of sleeping beast to be awakened at untold peril. Appearing as a "waterless" scratch between the municipalities of Pasadena and Los Angeles, the river elicits the derisive laughter of visitors from the Midwest, for whom it does not sufficiently fit the category of "river." At this point, the author, who wrote more than 60 books (including a three-volume biography of Washington), and earned credits for forty-plus films, both silent and sound (Kemm 1985), cannot resist a bit of heavy-handed foreshadowing: his omniscient narrator remarks, "The strangers were laughing at the Los Angeles River, laughing in their ignorance, at the empty lair of an absent dragon" (Hughes 1941, 23).

Although Hughes counters the strangers' benighted view with a brief history of the river (as told by a professorial windbag), he does so not to celebrate the seemingly itinerant body of water itself - which is absurdly labeled a lucus a non lucendo by the windbag's windbaggy wife - but to extol civic projects that supplement and control it. Another prominent character, "Ranleigh the Realtor," boasts that "Not long ago, [Los Angeles] was dying of thirst. Long drouths broken by ruinous floods. Then Dad and I and some others went way up into Owens Valley and stole a river." His braggadocio continues with an account of "taming" and "caging" the Colorado River, adding it to their collection in order "to keep this place a Paradise" (Hughes 1941, 23-27 and 61-62). Ranleigh the Realtor's account of the cultural conquest of nature is tempered somewhat by a wise-use approach espoused by Gaunt, a civil engineer. Gaunt explains that, while God meant for the desert country "to support only a few people," humans are capable of rearranging nature and amending God's plan by controlling the ample mountain runoff into the L.A. basin. "We've got to bring in a steady supply of water and we've got to get rid of the deluges. That's why we're building some of the biggest engineering works in human history" (Hughes 1941, 119). Both Ranleigh's theft of the Owens River and Gaunt's flood-control projects resemble the 
operations of Fred Eaton, J.B. Lippincott, William Mulholland, and others in the first half of the 20th century. Even though dated, Hughes's fictional account can help us revisit the well-known history of water and power in L.A. and rethink the nature of the river (Reisner 1986, 58-100).

After a cascade of unlikely escapades that tumbled Warren Thorburn along from lifeguard to movie star to civil engineer (with stints as a failure, a drunkard, a cuckolder, and a poser), the novel concludes with a flood worthy of Cecil B. DeMille, one not unlike that which drowned the basin in 1938. "The ceaseless zeal of water" to undermine and undo sends it down canyon and gorge, streaming, swirling, "ripping away cottages and houses as if they were dead leaves. The highway might have been piecrust the way it broke off," until "the rivers themselves were lost to view beneath the lakes that spread above them, lakes in width but torrents in motion" (Hughes 1941, 321-323). Hughes's story does not imply that the deluge results from the Hand of God washing away the sins of the city. As human foibles and frailties unfold, the awesome power of water quietly builds... until the absent dragon returns! The suggestion seems to be rather that the river is always a river, and that even an apparent joke of a river possesses ever-present potential for destruction. Hughes draws readers' attention to the limits of certain stories and methods of telling them, trivializing the Hollywood machine as artificial and empty of meaning.

The power of water is the real story, nature's force and the need for culture to engineer its way to supremacy over that force. Whereas the film industry produces formulaic narratives that are detached from reality, mere tinsel, City of Angels lauds the digging down and building up of civic engineering. The deluge finally stops, and the "army of engineers" begin "doing the things that had to be done to save what could be saved and make ready for the next storm." These "real-life" heroes must "recapture the rivers and rebuild their channels," while shallow Hollywood busies itself with preparations for "a big picture, a nepic [sic] . . a natural" - a natural box office hit, that is, a successful artifice. Offered the lead in the next "nepic," the hero Thorburn turns away, explaining, "I'm going back to what I started out to be, an engineer" (Hughes 1941, 345-347). Against Hollywood's artificial construction of reality, Hughes places the scientific rearrangement of elemental nature, telling a fundamental story of water and power. In that story, the L.A. River may be a strange vagrant, but it is nonetheless a presence to be reckoned. The dragon must be corralled.

It is a stream of unction; little wonder that the Little Portion greatly concerns some of the people who live near it. A recent scheme to place screens and booms at various places is designed to "keep 840,000 pounds of debris - the equivalent of about 450 Volkswagen Beetles - from reaching the ocean each year" (Los Angeles Times 1 Nov. 2011). Tons and tons of garbage enter San Pedro Bay at the mouth of the river through its channel, trash from a million passers-by and passers-over, flotsam flushed by storms down drains and other tributaries, filth from the wreckage of continuous consumption, the effervescent effluents of production and transportation. Where flow is restricted, the waste and the want-not accumulate: bags, bottles, sediments, grasses, wrapping, boxes, blankets, clumps, sticks. Shopping carts, the most apt of river flora here, rust on their sides, not so much abandoned as 
collapsed from exhaustion, still sporting patriotic blues and reds in undying plastic. Gulls flock in the mid-stream dump, sorting through sewage. A Black-Necked Stilt, on what look like backward-bent red legs, steps with care through the watery muck and rubble, its head sometimes sweeping the surface like a metal detector, to and fro, the sensitive beak searching for life. At the confluence with the Rio Hondo, which is also baked dry as far up as one can see, I come across a pair of clean, white sandals, their straps still tracing the shape of the woman's feet that filled them.

\section{A river that is and is not}

The orthodox view of the Los Angeles River as expressed in most 20th-century accounts, be they fiction or non-fiction, is straight forward: What river? Rupert Hughes tries to tell a different story but, encountering the river's paradoxical nature, he resorts to orthodoxy: in City of Angels the L.A. River is present, even if it seems absent due to its peculiar nature, and because the river is an unpredictable force of nature, it requires man's exertion of power in a contest for control. Several decades later, in the film Chinatown (1974), writer Robert Towne and director Roman Polanski uncovered the paradox of a river that both is and is not; in their story, the play of presence and absence reveals sinister meanings in the vexed relations of Water and Power. Whereas City of Angels depicts a recalcitrant nature with which humans must wrestle, our technological muscles bulging in the Southern California sun, Chinatown takes us into the darkness in search of the nature that culture has sequestered.

The story twists together two main threads, one that is external or visible and the other internal or concealed, and the plot rolls toward the discovery of their entanglement. The concealed thread entails a perverse tale of father-daughter incest, while issues of water control constitute the external thread, as we are reminded by shots of the L.A. Department of Water and Power that emphasize signs bearing the name. The first few scenes of the film underscore the significance of the department and the relation to which its name refers: the action opens in the office of private investigator Jake Gittes, where we learn from the wife of Hollis Mulwray, chief engineer of Water and Power, that her husband is cheating on her. As the plot unfolds, we discover that Mulwray was not cheating on his wife and, in fact, it was not his wife who accused him but an impostor hired to help undermine his authority at Water and Power.

In another early scene at a public meeting at City Hall regarding a proposed dam project, witnesses testify to the fact that L.A. is in danger of being reclaimed by the desert from which it sprung - Culture is under threat from Nature (Figure 10.4). Desperate for water due to an extended drought, L.A. citizens clamor for measures that will slake the city's thirst. But chief engineer Mulwray, deeming the project unfeasible and even dangerous, refuses to build the dam, and we will later come to know that he bases his refusal in part on having already built a similar structure against his better judgment. The Van der Lip Dam disaster, we learn, drowned 500 people. (The incident, which is mentioned briefly on several occasions in the film, bears some resemblance to the collapse of the Saint Francis dam 


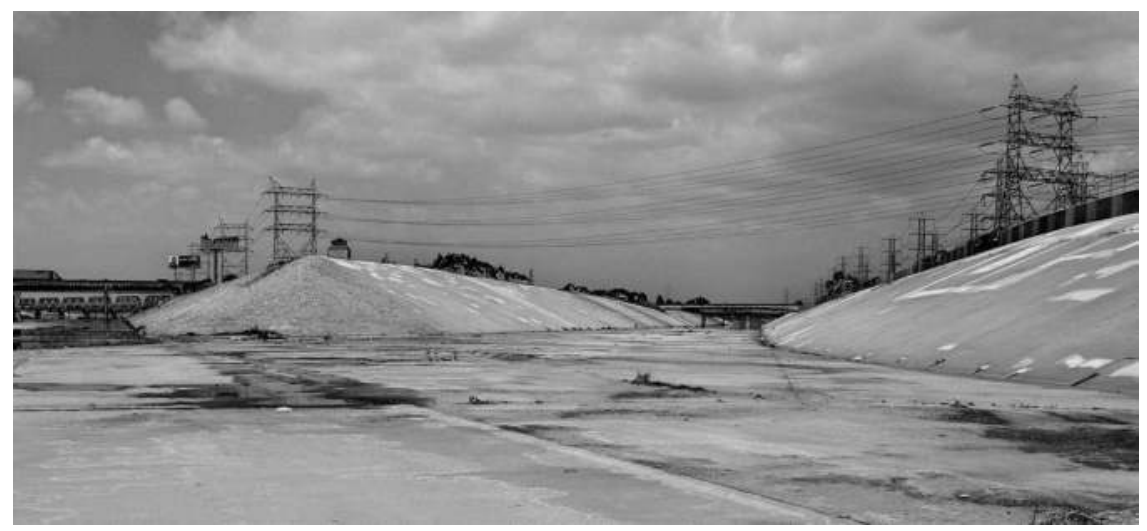

Figure 10.4 Confluence with the Rio Hondo.

Source: Photo courtesy of the Author

in 1928. For accounts of that historical catastrophe, see Reisner [1986, 96-99]; Davis [1993, 171-242]; Mulholland [2000, 319-28].

The ensuing scene takes place on a section of the rainless L.A. River bed. The detective watches from afar as the chief engineer carefully examines the bone-dry bottom. Towne's script makes clear what viewers of the film should see in the river: "It's virtually empty. Sun blazes off its ugly concrete banks. Where the banks are earthen, they are parched and choked with weeds." To drive home the point of a so-called river comprised primarily of grit and cement, the camera (and detective) follow the Water and Power chief engineer as he makes his way down to the center of the riverbed. "There Mulwray stops, turns slowly, appears to be looking at the bottom of the riverbed, or - at nothing at all" (Towne 1988, 12). Here the story explicitly signals its interest in the Poriciúncula Paradox: the absence of the river is quite present, and the emptiness of the scene - desiccated land lined with concrete and bleached by desert sun - functions both to remind viewers of the life-giving power of water and to prefigure the power of those who can control or manage the water. Mulwray is later found dead, and the circumstances of his death again feature the paradoxical play of the absence and presence of water. In the coroner's office, we hear: "Isn't this something? Middle of a drought and a water commissioner drowns. Only in L.A." (Polanski 1974). The coroner also informs Gittes that a drunk has been found drowned in the drought-ridden L.A. River - death by paradox. The detective eventually discovers that water appears and disappears in different sections of the river each night the river sometimes is and sometimes is not - and that discovery leads him to the power that controls the water, which power is intimately implicated with the internal, incest thread of the tale. 
At the center of the water and power story sits Noah Cross, capitalist captain of culture and tamer of wild nature. "Either you bring the water to L. A. - or you bring L.A. to the water," Cross explains, though he accomplishes both (Polanski 1974; Towne 1998, 140). We learn from Gittes's investigation that Cross owned the city's water supply, that he forced Mulwray to build the doomed Van der Lip Dam, that he is the main proponent for the new dam project, that he murdered Mulwray for opposing the dam project, and that he is buying up lands in the parched San Fernando Valley by nefarious means. Cross truly represents perversion. He perverts the name of "Noah" - he who in Genesis "walked with God," preserving life on earth from The Flood by following God's commandment. Cross, "this modern American Noah" (Stewart 1974-1975, 31), artificially aggravates drought conditions, restricting water to make a killing in land speculation. By variously diverting the waters of L.A., Cross exacerbates the river's paradoxical nature. And he also perverts the name of "father": the concealed storyline involves the strange affair of Noah Cross and Evelyn Cross Mulwray. It requires a painful process for Gittes to elicit paradoxes that he can't quite seem to understand: Evelyn is Noah Cross's daughter and his wife; her daughter Catherine is a "double-Cross," at once Noah Cross's daughter, and his granddaughter.

Chinatown lies on the west side of the river, an area of "many layers of history," as Joe Linton noted. Long a home for "waves of immigrants from Mexico, Croatia, and Italy," the place took its name in 1938, when construction of Union Station caused the relocation of several Chinese communities (Linton 2005, 112). Even before the relocation, Chinatown had earned a reputation: since the 19th century, "Anglo officials" had allowed sundry "vice industries" to flourish there "as a way to keep them out of 'respectable' areas" (Wild 2005, 16). Adjacent to the upper section of the lower Los Angeles River, present-day Chinatown comprises narrow alleys, sporadically busy walkways, ornate restaurants, scores of gift shops. The "many layers of history" in L.A. almost invariably entail strata of structure and transport, water and power. "Historic Route 66" runs through here, as well as the Metro Gold Line, and, in the Los Angeles State Historic Park, traces of the Zanja Madre emerge from the past: the "mother ditch" of the elaborate system that carried water from the Porciúncula to the pueblo. The Metro now runs the Zanja course, both past and present lines heading south into Downtown. Looking north I can almost make out where the waterwheel would have been, lifting the river into the Zanja. In the park, next to some of the ruins of the ditch, official writing labels the red brick infrastructure "circa 1781." Near the history lesson I read a message from the present: "Free the Prisoners • Fight the Power $\bullet$ Fuck the Police." Heading out of the park, closer to the river but cut off from direct access, I cross the bridges that span the stream, the Porciúncula flowing somewhere down below. Chinatown is the beginning of the end of the river (Figure 10.5).

Noah Cross's abominable perversion of the role of the father through incestuous acts stands for a more general perversion of nature, "a demonic parody of the original Noah's role in repopulating the earth after the Flood" (Stewart 


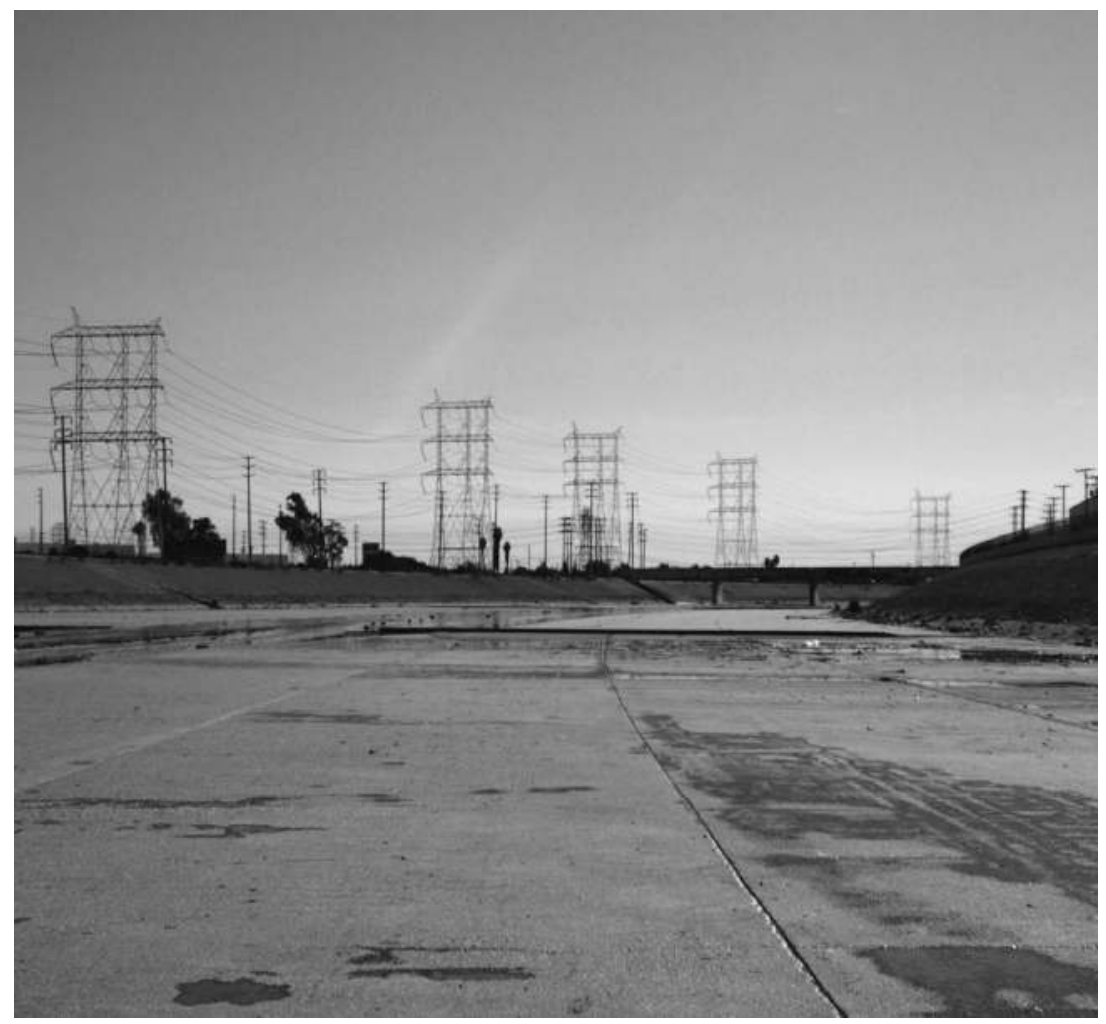

Figure 10.5 The beginning of the end.

Source: Photo courtesy of the Author

1974-1975, 31). Where the marriage of Water and Power begets more power and huge profits, the "marital consummation" between Noah Cross and his daughter yields a family collapsing in on itself. Although the historical basis for part of the plot of Chinatown is sordid enough, the tangling of the external and internal threads in the fictional approach of Towne (1998) and Polanski (1974) presents a stark view of a perverted landscape. Vernon Shetley writes of the film and L.A. history that:

no one disputes the fact that a group of the city's wealthiest men, privy to inside information about the plans of the Department of Water and Power, bought up land cheaply in the San Fernando Valley, and realized enormous profits on their purchases when the Owens Valley Aqueduct, completed in 1913, made water available to irrigate that land.

(Shetley 1999, 1094. See also Davis 1993, 21-32; Gumprecht 1999, 104-07) 
By revisiting this "fact" and imaginatively weaving it together with myth and moral inquiry, Chinatoun creates a compelling drama about nature and culture, water and power, life and death in the L.A. Basin, at the heart of which lies the river.

Paradoxically, the river's absence is what's most present in Chinatown. The river is absent due largely to the unnatural acts of abominable men. The solution to the story's mystery, for John Belton, "lies in the realm of the unnatural," beyond the reach of the detective hero (Belton 1991, 941). Belton sees in Chinatown the "central paradox" of the detective genre: "through the acquisition of knowledge the limitations of knowledge are discovered." The detective "is led step by step to an acknowledgment of the essential irrationality that governs human existence" (Belton 1991, 937). The film, however, gives viewers a glimpse of another sort of knowledge beyond the limits of reason, a truth revealed by the narrative's fundamental paradox. Noah Cross's smug snub of Gittes reminds the detective of the insufficiency of his thinking and knowing: "You may think you know what you're dealing with - but believe me, you don't" (Polanski 1974). The detective later explains to Cross's wife/daughter that he'd heard the same words before, while working in Chinatown. The trouble with that particular beat, Gittes says, is that "You can't always tell what's going on there" (Polanski 1974). Since Chinatown serves as both the titular concept of the film and as the scene of the story's conclusion, its obscure meaning is central to interpreting the story.

Through most of the film, no action takes place in Chinatown; it is absent, the marker for a dark, uncertain past. The place only emerges into the present in the film's finale - here again, absence is full of meaning. That which is not visibly present nonetheless presents problems for the characters of the story. Representative of what lies beyond the limits of reason, Chinatown stands for the paradoxical presence of absence. Gittes, the detective, the empirical thinker and viewers' on-screen surrogate, has proven himself incapable of perceiving the truth conveyed by this paradox, and thus fails to prevent Noah Cross from carrying out his perverse machinations. The last words of the film are a consolation uttered to Gittes by his associate: "Forget about it, Jake; it's Chinatown" (Polanski 1974). Chinatown is emblematic of the inevitable result of Cross's struggle for power over water, land, and bloodline. His drive to monopolize the nature of L.A. empties the place of meaning. Chinatown stands for a foregone conclusion: there's nothing to be done.

Such, anyway, is the conclusion within the framework of the story; viewers of the film, however, can see the traces of another conclusion forming outside of that frame. Garrett Stewart writes that "throughout the film the specter of Chinatown is vigorously signaled as the plot's inexorable destination” (Stewart 1974-1975, 28), the end of the line. John Belton adds that "Chinatown is a place where corruption, the unnatural, and the irrational reign, where reason has no force." The story thus concludes "with a sense of bewilderment, alienation, and despair" (Belton 1991, 947-948). This may be so, but by closing with the ineffective Gittes being ineffectually consoled by reference to Chinatown's durable obscurity, the film's paradoxes invite a more imaginative interpretation. Perhaps the paramount paradox of Chinatown is that hope both is and is not the absence of despair. 
In his thoughtful study of the film's double-plot, Vernon Shetley observes that, although the film "confines us" to Gittes's point of view, "it constantly reminds us of the limitations of that viewpoint." Shetley holds that because Gittes "never quite gets it," we are encouraged to go beyond his "limited imagination" (Shetley 1999, 1101-1103). To do so may enable us to view more clearly not only the L.A. past illuminated by Chinatown but also the seemingly denatured and unseemly future that Noah Cross engineers. Works of art, Shetley proposes, "may have other forms of political impact than that of providing positive role models of political struggle," explaining that "Chinatown" became "a rallying cry for water battles throughout California" in the 1970s and 80s (Shetley 1999, 1104). Thus, the end of the film is not necessarily the end of the story. That the name would be invoked by those challenging "the operations of Los Angeles's Department of Water and Power" suggests that "Chinatown" stands for more than absence or despair. It represents, rather, the possibility of people rethinking the monstrous acts of a culture hellbent on dominating nature for its own ends. A self-serving culture that drives out nature renders itself null in the resulting void. Or perhaps it represents the impossibility of the ultimate success of such a monstrous project: nature cannot be denatured, a river cannot really be un-rivered, for the result would be utter nothingness.

\section{Conclusions}

History's contradictions can be resolved like puzzles or mysteries by the logical detective; fiction's paradoxes present us with another story. In a recent issue of Human Ecology Review, Thomas Heyd wrote that "cultural frameworks are fundamental factors in human responses to natural changes insofar as they mediate the understanding of, and adaptation to, such processes" (Heyd 2010, 90). The history of the L.A. River describes a cultural framework based on the logic of separation from nature, in which culture obtains apparent control over nature and then manages those "resources." At the end of this chronology - that is, in the present - and, guided by critical histories and political remediation, we increasingly question the logic of this separation. But insofar as those efforts belong to the same cultural framework as that which produced the present moment, the questioning and the remediation can only go so far. It is exceedingly difficult to examine our cultural framework from within it. That framework shapes our thinking and informs our view; we are part of its logic. Art, and especially fiction, by combining imagination with unaccustomed associations, is particularly adept at revealing fault-lines in the stories by which we live, and in some instances these fault-lines take the form of paradox. While it is a commonplace that fiction can enrich history and fact with meaning through its manipulation of narrative, image, setting, character, and so on, fiction's chief asset, as we come to terms with the consequences of cultural estrangement from nature, may prove to be the potency of its paradoxes.

With paradox comes potential: the eminent philosopher W.V. Quine asserted in 1876 that "More than once in history the discovery of paradox has been the 
occasion for major reconstruction at the foundations of thought" (Quine 1976, 1). Paradox, an absurdity, a contradiction that disrupts reason, might offer a glimpse of the truth, might point to breaks in the logic that can then help us question it, rethink the frame, or at least discover its form and influences. At the very least, paradox might open us to humility by exposing a problem in the logic of hubris. But paradox itself is only part of a process, not an end in itself. Perhaps paradox, properly considered, brings us back down to earth, back down to the river, where we might renew our efforts to obtain some clarity regarding our nature, some vitality in our inhabiting, some fluidity in our thinking in relation to that river. Paradox (paradoxically) is a way of re-establishing contact with the river by introducing a moment of intellectual distancing or displacement, a detachment from what we think we know, and from our usual ways of making sense of things. Paradox is the mouth of the river, an ending and an opening.

\section{References}

Belton, J. 1991. "Language, Oedipus, and Chinatown.” MLN 106(5): 933-950.

City of Los Angeles Department of Water and Power. 2015. The Story of the Los Angeles Aqueduct. http://wsoweb.ladwp.com/Aqueduct/historyoflaa/index.htm.

Davis, M. L. 1993. Rivers in the Desert: William Mulholland and the Inventing of Los Angeles. New York: HarperCollins.

Gumprecht, B. 1999. The Los Angeles River: Its Life, Death, and Possible Rebirth. Baltimore: Johns Hopkins University Press.

Heraclitus. 1987. Fragments. Translated by T. M. Robinson. Toronto: University of Toronto Press, Toronto.

Heyd, T. 2010. "Climate Change, Individual Responsibilities and Cultural Frameworks." Human Ecology Review 17(2): 86-95.

Hughes, R. 1941. City of Angels. New York: Scribner's.

Kemm, J. O. 1985. "The Literary Legacy of Rupert Hughes." Books at Iowa 42: 1-46.

Linton, J. 2005. Down by the Los Angeles River: Friends of the Los Angeles River's Official Guide. Berkeley: Wilderness Press.

Los Angeles Times. 1905. "Titanic Project to Give City a River." Los Angeles Times, 29 July.

Los Angeles Times. 2011. "Tons of L.A. River Trash Will Be Captured Before It Hits the Sea." Los Angeles Times, 1 November.

McCawley, W. 1996. The First Angelinos: The Gabrielino Indians of Los Angeles. Banning, CA: Malki Museum Press.

Morrison, P., and Lamonica, M. 2001. Río L.A.: Tales From the Los Angeles River. Santa Monica: Angel City Press.

Mulholland, C. 2000. William Mulholland and the Rise of Los Angeles. Berkeley: University of California Press.

Polanski, R. 1974. Chinatown (film).

Quine, W. V. 1976. The Ways of Paradox $\mathcal{E}$ Other Essays. Cambridge, MA: Harvard University Press.

Reisner, M. 1986. Cadillac Desert: The American West and Its Disappearing Water. New York: Penguin.

Shetley, V. 1999. "Incest and Capital in Chinatown." MLN 114(5): 1092-1109.

Stewart, G. 1974-75. “The Long Goodbye From Chinatown.” Film Quarterly 28(2): 25-32. 


\section{T.S. McMillin}

Towne, R. 1998. Chinatown. London: Faber and Faber.

United States Geological Service. 2006. Geology of the San Gabriel Mountains, Transverse Ranges Province. http://geomaps.wr.usgs.gov/archive/socal/geology/transverse_ranges/ san_gabriel_mtns/index.html.

Wild, M. H. 2005. Street Meeting: Multiethnic Neighborhoods in Early Twentieth Century Los Angeles. Berkeley: University of California Press. 


\title{
11 The river's embrace The Rhine-Meuse delta (re)imagined
}

\author{
Eveline R. de Smalen
}

\section{Introduction}

Maarten 't Hart's 1986 novel De Jacobsladder (Jacob's Ladder) opens with the word "Weertij" (11; the translations are my own), an archaic Dutch word for ebb, and continues: "the ferryboat lay moored at the lowest landing stage" (Hart 1986, 11). ${ }^{1}$ Its narrator, Adriaan Vroklage, is about to cross the Nieuwe Waterweg (New Waterway), the artificial mouth of the river Rhine in the Netherlands, on that very ferryboat, but is delaying his boarding, enjoying the sights, sounds and smells produced by the river and the activity taking place. Standing near the rear of a frigate that lies moored in the harbour, he muses "It smelled so wonderful there, it was a smell like no other, a smell of decay and lubricating oil and ropes and, strangely enough, also of manure" (Hart 1986, 11). When he boards the ferry, he narrates: "On that broad gangway I ascended to heaven" (Hart 1986, 12). As much as he is intrigued by the frigate, the moment his ferry leaves for Rozenburg, at this point in time still an island in the Waterweg, he walks to the front of the ship to observe the river, already anticipating fresh joys:

It was always so lovely to look at approaching Rozenburg, to smell the briny water, and to feel the sea wind. Moreover, the ferry almost invariably had to give way to some coaster or tanker, so that you could see these ships from very close up as well. Common sandpipers or black terns or oystercatchers flew over the water in closed ranks.

(Hart 1986, 12)

This first scene and its evocative rendering of the many details that Adriaan registers are indicative for the rest of the story, in which the river plays a central role. The story mostly takes place near the mouth of the Rhine-Meuse delta, in the strictly Calvinist town of Maassluis, where since its founding, the river has dictated life, as it does for Adriaan. In this chapter, I will first discuss the role of the river and its surrounding ecology in De Jacobsladder, paying particular attention to the ways religion and materiality play into this. I will then move on to a discussion of non-literary texts that describe the development of Rozenburg, comparing the language of the novel to the language used by different parties 
involved in the development of the Rotterdam harbour, such as government officials and conservationists. I will finally show how shared themes of embraces, power and love work through all texts, moving towards the development of the river as a more artificial, but still ecologically significant area, and a green harbour that can, despite the destruction that lies at its base, become a place of new hope and beauty.

Rivers have always had great imaginary power in western culture. Simon Schama (1995) writes about the intimate connection between rivers and human life and imagination:

Were [rivers] not figured as bodies of water because, since antiquity, their flow was likened to the blood circulating through the body? . . . to see a river was to be swept up in a great current of myths and memories that was strong enough to carry us back to the first watery element of our existence in the womb. And along that stream were borne some of the most intense of our social and animal passions: the mysterious transmutations of blood and water; the vitality and mortality of heroes, empires, nations, and gods.

(Schama 1995, 247)

T.S. McMillin (2011) also notes the abundance of imaginative writing on rivers and argues that rivers are intrinsically linked to our process of meaning making because they share a similar system. He writes: "Literature presents a special set of conditions in which we can study meaning, and literature involving rivers offers a rich resource for understanding meaning's fluidity" (xiv). There is thus no doubt that rivers have a great bearing on our imagination, and Chad Wriglesworth $(2012,98)$ argues that the converse may also be true. He writes: "literary criticism can excavate 'the swirl of forces' that transformed specific watersheds; but more importantly, the arts can undermine and contest environmental injustices in ways that call for the reconstruction of human relationships with place." While I will not go so far as to say that De Jacobsladder has shaped the physical appearance of the Waterweg, I will show that ideas explored in the novel eventually also emerge in ecological development policy, indicating that the relation between literature and the material world is a reciprocal one.

When Adriaan arrives on the opposite side of the river, he says: "Rozenburg. The tide had turned" (13), which is true in more ways than he can yet fathom. When he looks back at the Maassluis bank, he sees the confusion surrounding an event that will mark the rest of his childhood and adolescence, although he does not realise this yet. He is slightly upset that he misses the spectacle, but as soon as the scene vanishes from view, his mind wanders again. Below the dyke:

I suddenly smelled the imperious, peaceful, deep smell of rapeseed, of a whole field full of rapeseed. I almost forgot what lay behind me. Also, poppies and snapdragons grew on the sloping dyke. In between them, rare blues and coppers and yellow small whites. They chased each other, crossed the road, disappeared in the rapeseed, reappeared in larger numbers. Yet it was more quiet 
than in an empty church. And it was warm, very warm. It was as if the silence and the warmth intensified each other. "It is warm-silent," I whispered, "it is silent-warm."

Adriaan is very perceptive to the life that grows, flutters and blossoms all around him. To him, the whole world is active and alive: "It was as if that whole field was in conversation, with the wind and the sky and the dunnocks sauntering about and sometimes flying over it" (Hart 1986, 15); he shows an acute awareness that "the world's material phenomena are knots in a vast network of agencies, which can be 'read' and interpreted as forming narratives, stories" (Iovino and Opperman 2014, 1).

The landscape becomes increasingly dreamlike and surreal: as Adriaan walks on:

It seemed as if the path went down and as if that buzzing, loud hawthorn hedge protected all that lay behind. It was as if it was on fire. . . I came to a gravel path that circled around a lawn. Two gigantic plane trees rose in the middle of the circle. A clothesline, on which sheets hung to dry, stretched between these two trees. The lawn was blue from bird's eye.

(Hart 1986, 16)

Then, from this mysterious place, shielded from the busy world he knows by bushes, dykes and the Waterweg, a girl appears:

Motionless I stood watching the blue lawn. It seemed even warmer there than elsewhere. It was incredibly summery, incredibly peaceful. Then, from the house beyond, a dark girl my age emerged. She was not startled when she saw me. She walked over the blue field. It seemed a coincidence that, as she did so, she came my way.

(Hart 1986, 16)

Adriaan's narration in all its celebratory dreaminess can be read as sensuous poesis, which Scott Knickerbocker (2012) describes as "[performing] the complexity, mystery, and beauty of nature rather than merely represent[ing] it" (Hart 1986, 159). In showing how alive the world around him is, how everything buzzes and flutters and grows, his perception also displays a "sense of strange and incomplete commonality with the out-side" that Jane Bennett (2010,17-18) advocates "to treat nonhumansanimals, plants, earth, even artifacts and commodities - more carefully, more strategically, more ecologically." This sentiment shines through clearly in Adriaan's narrative as he pays particular attention to all the different creatures, their behaviours and surroundings and all their wondrous particulars. Every detail of the material world merits specific attention, whereby Adriaan shows how important it is. In Adriaan's view, the world around him is a promise of a more interconnected, caring future for the relation between humans and non-humans. 


\section{Eveline R. de Smalen}

Adriaan spends the rest of the afternoon on Rozenburg with the girl Klaske, whom he decides to get married to when they both grow up, although Adriaan expressly states the precondition that he will only marry her if her house will still be there by that time, and will not have been swallowed by the Rotterdam harbour, the expansion of which threatens the island. He is very much impressed by the house and its surroundings. Again, in his description, the impressions of the senses are made incredibly vivid, so much as to be personified:

it was just as if there, yes, it sounds so silly, but still it was true, it was just as if summer lives there. I mean: somewhere else it is also summer, but he lives with you, there is his house and his garden, you understand, yes, I wouldn't want to live anywhere else more than there.

(Hart 1986, 23)

In ecocriticism, anthropomorphism is a much-contested literary device, as some believe it shows a harmful anthropocentrism (Knickerbocker 2012, 5), but Adriaan uses it to represent summer as a co-inhabitant, and to show how he and his surroundings exist entirely on equal footing. This sentiment resonates with Adriaan's earlier descriptions of the river and the ecology of the opposite bank, in which his attention for the vibrancy of the material world indicates a great respect for local riverine ecology.

Summer is hardly an obvious object for anthropomorphism. It is a concept that shines through in various materialities - the plants that are approaching the peak of their abundance; the animals that show behaviour particular to the season but it is not itself a tangible entity that agency can easily be ascribed to. Adriaan, however, sees a network of different material manifestations of the season that all connect and culminate in a symphony of summer. The fact that Adriaan ascribes agency to this assembly of ecological particulars, and brings them together in an extensive network of creatures shows how far his understanding of and respect for the natural world goes.

When Adriaan returns from his waking dream, he is confronted with the aftermath of the events he got a glimpse from after he got off the ferry earlier that day: a boy fell in the water, was caught by the frigate's propeller and died, his clothes torn and smeared with oil, his body maimed beyond recognition. Since people passing by saw Adriaan on the quay near the ship and the boy's knee showed a scar similar to one Adriaan has, he has been reported dead. When he returns home, he finds his parents grieving. This case of mistaken identity gravely impacts Adriaan. It results in a feeling of guilt that will haunt him for years and constitutes the main theme of the novel: he feels that the boy, Jan Ruygveen, died in his place and he himself should not be alive. No longer able to live a carefree life, he befriends Anton Ruygveen, Jan's younger brother, in an attempt to atone for what happened, but the rest of his childhood and adolescence will be marked by further tragedies, often but not always deaths, for which Adriaan feels a sense of responsibility even if he is not to blame. 
Adriaan, then, loses his innocence in the river which, having taken Jan's life, has become the site of Adriaan's guilt and shame. The tide also turns for his dream-island Rozenburg, which is increasingly being transformed until it is completely swallowed up, sacrificed to the Rotterdam harbour. Although Adriaan never returns, distant echoes of the island's transformation can be heard throughout the novel, and he keeps revisiting the day he spent there in his mind.

As he listens to the destruction of the idyllic landscape of the rural island from the opposite bank, Adriaan mourns the loss of nature deeply. At the beginning of the novel, Adriaan was equally excited about the river's ecology and its industry and appreciated their working together, but the balance has now tipped. Industry has become too powerful and ecology in the human world is receding further and further. There is no longer an equal relation but rather an overpowering of one force by the other. The bangs and hisses of industrialisation indicate to him that something is irretrievably lost; not only the beauty of nature, but its surprises and excitement.

To Adriaan's grandfather, religion is intertwined with local ecology. When he and his grandson attend the Ruygveen patriarch's public announcement of the establishment of a new church, they connect his occasional Bible reading directly to the loss of nature, although Ruygveen clearly does not have ecology on his mind. Adriaan's grandfather describes Ruygveen as "a truly magnificent bloke ... he is still one of those real old-fashioned followers of Ledeboer, ${ }^{2}$ one who ferrets through the Bible to dig out the very blackest" (Hart 1986, 32).

Indeed, Ruygveen starts the meeting by proposing to read the complete, not particularly cheerful, Book of Zephaniah, in which the eponymous prophet speaks of the Last Judgement. Both Adriaan and his grandfather are most captivated by Zephaniah 2:14:

And flocks shall lie down in the midst of her, all the beasts of the nations: both the bittern and the night owl shall lodge in the upper lintels of it; their voice shall sing in the windows; desolation shall be in the thresholds: for he shall uncover the cedar work.

$(\text { King James })^{3}$

Adriaan's grandfather comments: "How wonderful, this Book of Zephaniah. What language! I almost died when he read: 'Woe unto the inhabitants of the sea coast, I will even destroy thee, that there shall be no inhabitant.' As if he was reading about Rozenburg" (Hart 1986, 78, original omission in Bible quotation).

Adriaan's grandfather takes this comparison of the state of the land in Zephaniah and in his own region quite serious. Schama (1995) writes about the mythologising of rivers and the connections presumed to exist between Biblical and local rivers, creating a basis for a religious and cultural connectivity (Schama 1995, 266, 301). Barbara R. Rossing $(2000,205)$ also mentions the adaptability of river mythology in this respect. Schama (1987) argues that, to Calvinists in the seventeenth century, "The Bible became a source book of analogies for their own contemporary history, as well as an inspirational talisman on the field 


\section{Eveline R. de Smalen}

of battle. Its swarming detail, moreover, allowed for a high degree of specificity to suit all sorts of contingency" (Schama 1995, 95). The Dutch, in particular, "regard[ed] themselves as ordained and blessed survivors of the deluge." Even in the twentieth-century society that De Jacobsladder portrays, this way of reading the Bible is still in practice. By relating Biblical narratives to everyday situations, the characters show how acutely relevant the Bible is to them, and how important it is to their conception of the world they inhabit.

The initial point of connection that Adrian's grandfather identifies is the coast, but his focus soon shifts back inland to his native riverscape as he muses on the presence - or rather absence - of bitterns there: "If now you know there to be one somewhere, you'd lie in the reed bed in a rowing boat for three weeks just to see it, if you had to, and if you see it, you won't forget it as long as you live.... Could it be true? Could the bittern and the night owl live on Rozenburg?" (Hart 1986, 78). Although the landscapes Zephaniah and Adriaan's grandfather are confronted with are both infected by human degradation, they are also opposites. Zephaniah predicts a civilisation destroyed, its inhabitants exterminated and its ruins taken back by nature. The resulting image is exactly that which Adriaan's grandfather sees when he looks admiringly at the Rozenburg of old. In his view, this landscape is Edenic and civilisation, with its concrete and asphalt, is its ruin.

Elizabeth A. Johnson suggests that both the Old and New Testament "teach that the creating and redeeming God loves and takes delight in the natural world, which correspondingly enjoys an integrity that is not dependent on human decision" $(2000,6)$. Johnson suggests that in the scriptures of the Jewish tradition, from which Christianity took its early orientation, the natural world is pervasively and comfortably present. Not only is it depicted as God's good creation and covenant partner, but it shares in the blessings of the human covenant as well as in judgment when that covenant is broken (Johnson, 2000, 5)

This idea is very much related to Adriaan's grandfather's vision of Rozenburg. He sees the construction of the harbour as moral as well as ecological degradation, and finds the idea of God's punishment in the form of the destruction of civilisation unabashedly appealing. He would very much like the earth to share in God's judgement as it did in the Old Testament days. This ecological reading of Zephaniah is one that does not interest Ruygveen. The citizens of Maassluis are mostly concerned with spiritual matters, occupying themselves with a dematerialised Calvinist faith. Few people seem to concern themselves very much with matters of the material world. Johnson (2000) argues that the Reformation to a great extent meant a turn towards anthropocentrism in religion, which resulted in the non-human world being left behind in appreciation. Similarly, Manuel A. Vásquez (2011) argues that the move away from the Catholic Church meant a revolt against its appreciation of material wealth, and by extension materiality in general.

Adriaan and his grandfather form an antithesis to this tradition. When they talk about religion, they are very much preoccupied with its alignment with the material world. Like the presence of industry and ecology, the spiritual and material world must exist together. It is of great concern to him that when Biblical 
motives are applied to the real world, they do not conflict. Although he is deeply sceptical of religious institutions, he finds that religion must be treated with utmost attention and respect, and attentiveness to the material world is an integral part of that.

The earth and its ecology, to him, are the main source of meaningful comfort. When Adriaan expresses his concern regarding the future as they are fishing, a fish falls off his grandfather's hook, and he comments:

Look ... that's what I mean, you're always being tricked, but it doesn't matter, because now it's summer and the sun is shining, and if you smell very carefully you can feel the autumn coming. Soon, the migratory birds will come over, and it will be winter and you will have the most beautiful sunsets of the year, and maybe you can go skating. And then spring will come again. (Hart 1986, 108)

It is in this scene, perhaps, that his feelings for the landscape turn most directly and explicitly to ecological concern, as he mentions the impending destruction of nature reserve De Beer, the existence of which was threatened, and later indeed obliterated, by the development of the Rotterdam harbour.

Adriaan and his grandfather, then, do not at all share the classic Christian view that Crockett and Robbins $(2012,19)$ describe as "the religious denial or rejection of all things human, which is shown most clearly by the Christian despising of the world." They love the world and want to embrace it with both hands, as is shown in Adriaan's grandfather's love of women, and Adriaan's habit of embracing people to provide help and comfort. He is a strong person with the ability to use his muscular power not for dominance but for consolation.

In the hospital where Adriaan starts to work towards the end of the novel, he runs into Ruygveen again, and he provides Adriaan's deliverance from his perceived guilt. Ruygveen has lost all his children either to suicide, emigration, or marriage to a Catholic, or, as he puts it, a "whoremaster of Babylon" (Hart 1986, 200), and finally has also lost his sanity. During this meeting, Ruygveen mentions that Jan's death was not an accident, but a suicide. This insight changes the way Adriaan has made sense of his life, and the way he will be able to make sense of it in the future:

Yes, it did matter very much, it changed everything, I was not guilty in that case, or maybe I was, but there was no question about any mistake. This could not have happened to me just as well. I could have lived differently the last ten years, I could have been happy, I could have made other friends, could have put my arm around Klaske on the Zegwaartse weg.

(Hart 1986, 202)

It is Ruygveen, too, who encourages him to look towards the future and embrace it, as he, surprisingly for such a strict protestant, orders Adriaan to "Come on, put your arm around [Klaske]" (Hart 1986, 204). Ruygveen, in spite of his misery, also 
looks towards the future, but his is a dematerialised one: the future that comes after life.

Adriaan's future, conversely, is one that will take place very much on the blooming earth. As his grandfather, years before, had asserted, spring has come again and, as in the beginning of the book, Adriaan again comments on the vegetation around him: "[Ruygveen] stood still on the gravel path. It was spring. Close to his feet, the yellow celandine blossomed" (Hart 1986, 206). What finally unites Ruygveen and Adriaan, as well as the material and spiritual worlds, is a verse from Isaiah that Ruygveen cites at the very end of the novel:

The sun came through again, shone on his face. And he said, with the same voice as which he had said "I will also leave in the midst of thee an afflicted and poor people, and they shall trust in the name of the LORD," that weak, yet far-reaching voice of the Fenacoliusplein: "He hath lovingly embraced my soul." ${ }^{4}$

(Hart 1986, 206)

The rhetoric of love, embraces and equal relations that is present in De Jacobsladder is also pertinent to the relation of nature and industry in the harbour. Throughout the novel, Adriaan and his grandfather expressed a need for a dialectic between opposing sides, giving a voice to both ecology and industrial development, the spiritual and the natural world. Rather than one side overpowering the other, they speak for an embrace. When the Rotterdam harbour saw its first major expansion after the Second World War, many people involved in its development used the rhetoric of power to discuss what they saw as good or bad developments, depending on what institution they represented. From the last decade of the twentieth century onwards, however, we can see that the language that is employed, even if it invokes power, does so to move towards a concept of nature that can embrace seeming opposites. Industry and ecology can come together in this narrative, as spirituality and materialism had done before for Adriaan and Ruygveen.

As the Rotterdam harbour expanded, those with an interest in nature could only watch as government planned to "tarnish" (Van der Goes van Naters and De Wit 1959, 1.5n 1) or "sacrifice" (Van der Goes van Naters and De Wit 1959, 1.5 n 5) ever more parts of it. In 1959, the president and secretary of the ContactCommissie voor Natuur en Landschapsbescherming (Contact Commission for Nature- and Landscape Protection), M. Van der Goes van Naters and R. J. de Wit, petitioned against a new land use plan for the Den Briel Meuse, the branch of the Meuse flowing to the south of Rozenburg, which proposed far more extensive changes to the landscape than initially planned. They mentioned they were "deeply concerned about the consequences of the stormy development of the harbour and industrial area along the Nieuwe Waterweg for the preservation of natural areas located in this part of your province [of South Holland]," and that they "fiercely opposed" these plans (Van der Goes van Naters and De Wit 1959, $1.5 \mathrm{n} 1$ ). Subsequently they adopted a more resigned tone. They wrote that they 
would support parts of the plan: "if the execution of an important part of the plan-Europoort has to be accepted as reality" (Van der Goes van Naters and De Wit 1959, 1.5n 4). Van der Goes van Naters and De Wit pointed out that they only agreed because they knew their concerns about the area would not be taken into consideration by those who had the final say in the area's future. They saw this specific petition only as a way "to make the best of it" (Van der Goes van Naters and De Wit 1959, 1.5n 4, italics indicate original English).

Europoort is the part of the Rotterdam harbour that was built on Rozenburg and De Beer. De Beer was originally a dune landscape that owed much of its appearance in the 1950s to human activity, particularly to the construction of the Nieuwe Waterweg in 1872. This new canal separated De Beer from the main land that it was previously connected to, and instead connected it to Rozenburg. The location was now much more isolated, which facilitated the relatively undisturbed development of a rich ecology with a prosperous bird population (Buijsman, 2009). During the construction of the canal, nutrient-rich clay that was dug out of the Nieuwe Waterweg was dumped in parts of De Beer. This altered the course of the river, resulting in a decreasing flow rate and water level along the surface of De Beer, reducing the river's erosion potential and increasing siltation. The Second World War saw major disturbance on De Beer due to the construction of the Atlantikwall, but soon after the end of the war, the local ecology recovered and flourished again, albeit in an altered state (Buijsman 2009). In their letter, Van der Goes van Naters and De Wit employ a language of violence and power when they write about the government's plans for De Beer. They personify the area as Adriaan did earlier, but rather than showing nature as equal, their writing presents nature as a victim of human actions: "we see this alternative land use possibility as a gun to the heart of nature reserve De Beer" (Van der Goes van Naters and De Wit 1959, 1.5n 4-5). Similarly, the mayor and secretary of Heenvliet, a small town on the other side of the Den Briel Meuse, J. H. Vijgeboom and J. van Herpen (1959) described the revised plan in another petition as a "fatal intervention" (p. 1.5t 3) to the existence of the reserve. Henrik Stevens (1999), on the other hand, personifies the city of Rotterdam, by showing it as violent and dangerous monster: "the De Beer nature conservation area, would have to be cleared to satisfy Rotterdam's hunger for land" (Stevens 1999, 88). The same literary device of personification, then, is employed in different ways and in different texts, fictional and non-fictional. It serves to present river and riverine ecology as entities that are emphatically alive and have agency and particular interests that have to be taken into account.

The newfound glory of De Beer, however, did not last long. That Van der Goes van Naters and De Wit are truly in despair over this came through very clearly in their letter, in which they wrote: "We ask with emphasis: does the industrial expansion have limits nowhere anymore?" (Van der Goes van Naters and De Wit 1959, 1.5n 5). Van der Goes van Naters and De Wit already realised that the days of De Beer were most likely numbered in 1958. In a letter to H.J. Hofstra, Minister of Finance, they anticipated "that the object of trusteeship of the actual nature reserve De Beer, because of the execution of the Rotterdam Europoort 
plans, will be diminished in the near future, and in a farther future possibly will be lost completely" (Van der Goes van Naters and De Wit 1958, 2).

Indeed, the Provinciale stedebouwkundige dienst in Zuid-Holland (Provincial Urban Development Service in South Holland) had expressed little concern for the protection of native species in their 1950 Rapport over de toekomstige landschappelijke ontwikkeling van de oeverlanden langs de Brielsche Maas (Report on the Future Landscape Development of the Banklands along the Den Briel Meuse) (Provinciale stedenbouwkundige dienst 1950). The report showed no awareness that the river is a living entity that needs to be taken care of. Nature was rather seen as a canvas to be painted on at humankind's leisure. The Rapport is mostly concerned with industrial and recreational developments, and with related infrastructure. As far as nature is concerned, the stedenbouwkundige dienst considered the harbour plans as an opportunity to improve its aesthetics to its own taste. Rather than engaging with the workings of local ecology, it took a very anthropocentric view, stating that local ecology had a "stiff, somewhat inhospitable character" (Provinciale stedenbouwkundige dienst 1950, 3), but also that, "despite its hardly hospitable character still has a special charm, all its own" (Provinciale stedenbouwkundige dienst 1950, 4). It continued that "salt marshes, mud flats and reed lands do not only appear inhospitable, they indeed are" (Provinciale stedenbouwkundige dienst 1950,4), and because this made them unsuitable for recreation, they needed to be improved.

The stedenbouwkundige dienst's characterisation of the region as inhospitable is a value judgement; presumably the land is not inhospitable to the life that flourishes there. The stance that is expressed here is typical for its time. In the post-war years, many conservationists, even within the Contact-Commissie, emphasised the value of "recreation, aesthetics and newly developed knowledge on landscape types. To the new practices of landscape care and landscaping plans, too, the nature and shape of the area, the so-called cultural-historical value, and the attractiveness of the surroundings of citizens and visitors were central" (Van der Windt 1995, 129). Thus, at the time, in conservation efforts much depended on the aesthetic appeal of a certain area to humans.

In the face of this objective, local ecology sometimes had to suffer. Although the stedenbouwkundige dienst expressed a desire to keep the influences of industry and tourism far from the most ecologically rich areas, it drily remarked that in other places "the bird population shall have to try to find its nourishment elsewhere" (Provinciale stedenbouwkundige dienst 1950, 5). It also applauded the damming of the Den Briel Meuse, which would turn its salt water into fresh and provide for plant life:

Fortunately, the closure also provides quite new possibilities. The turning fresh of the Den Briel Meuse basin of course enables tree plantations as a new element to the river. Assuming the existing, valuable givens, such as a.o. the surprising run of the Meuse, it is now possible to build a whole new landscape, that is appropriate for the development of an intensive recreation area.

(Provinciale stedenbouwkundige dienst in Zuid-Holland. 1950, 4) 
At the end of the report, the stedenbouwkundige dienst did not dwell much on the lost ecology of the area, instead, as far as nature is concerned, they are very optimistic about the future of De Beer as a newly beautified place: "The landscape to be created will be counted amongst the most beautiful ones in this region" (Van der Goes van Naters and De Wit 1959, 16).

Nature conservation in this document thus echoes contemporary Dutch ideas of conservation as to a large extent concerned with the management and development of beautiful landscapes. It should also be noted that conservation in the Netherlands is necessarily a practice that involves a high degree of human influence. Since prehistory, humans have actively shaped the appearance of the low-lying, fragile delta region, constructing dykes and drainage systems to keep them dry even before Roman times (Nienhuis 2008, 17). This has impacted the ecology to a very large extent. The cultivation of land even contributed to the establishment of a rich biodiversity that is unique in Europe (Schaminée et al. 2010, 11). As I have mentioned, this is very true of De Beer. Biologist V. Westhoff argued in 1945 that "In principle, . . nature must live according to its own laws, but in the Netherlands this is impossible" (as cited in Van der Windt 1995, 84).

The enthusiasm regarding the development of new nature in the harbour has not lost any of its power since then, although of late there is more attention for restoration of original ecology than for landscapes that are primarily beautiful to human eyes. In 1994, the Groenakkoord (Green Agreement) decided that, in the Rotterdam harbour, 1750 ha of additional land should be dedicated to nature. Of these 1750 ha, 50 ha were to be located on the Landtong Rozenburg (Spit Rozenburg). On the Landtong, Rijkswaterstaat, ${ }^{5}$ Havenbedrijf Rotterdam (Port of Rotterdam Authority), the municipality of Rotterdam and the WWF work together to create what they call a "green stage in the harbour" (Landtong Rozenburg n.d). This phrase also appears on informative signs placed on the Landtong. It echoes the language of the Rapport, in which repeated mention was made of a "wingseffect" that should be created in the landscape, referring to the wings of a theatre stage. This effect would be employed so that "plantation that is located farther away will also be given enough visual closure, retaining a large sense of visual depth." As I mentioned before, nature then primarily existed for human pleasure, and this is made very clear in this passage. While aesthetic considerations have changed since then, the artificial dimension of nature is still celebrated in a similar way.

In the report Van steenoever tot leefoever in Rotterdam (From Stone Bank to Living Bank in Rotterdam), representatives of all four parties involved in the project wrote that the project is a way for companies to "show the world their green business card" (Hiddema, Van Leeuwen, Van Zonneveld, and Zwakhals 2014, 14). This sounds insincere, a cheap attempt at greenwashing. A large part of the Rotterdam harbour is taken up by the petro-industry, which today is regarded almost as the antithesis of anything green. However, it may be conversely argued that though they are not on equal footing yet, industry and ecology do try to come 
together here. The parties propose to build dams to protect the Landtong ecology by warding off strong waves created by ships, which:

should not consist of new material, but of debris. And preferably debris that is released nearby ... so that few transportation kilometres are needed. Because the lesser transportation, the lesser disturbance for the environment. And the lesser emission of carbon dioxide, the more sustainable the solution.

(Hiddema, Van Leeuwen, Van Zonneveld, and Zwakhals 2014, 13)

Whether this proposal is the most ecologically beneficial solution for this area can be contested. However, it indicates that there is a shift taking place in society's ecological consciousness that can think nature in unexpected places. Emma Marris (2011) argues that small strips of green space such as:

organic farms, industrial green space, and rambunctious home gardens, . . provide one particular value better than anyplace else. These living slivers connect people to nature, and once people learn to love nature, they will be much more likely to support conservation efforts. They'll also be healthier and happier.

(Marris 2011, 150)

Indeed, for reasons of popular awareness of nature conservation, places like the Landtong are crucial because:

When conservationists focus on "pristine wilderness" only, they give people the impression that that's all that nature is. And so urban, suburban, and rural citizens believe that there is no nature where they live; that it is far away and not their concern. They can lose the ability to have spiritual and aesthetic experiences in more humble natural settings.

(Marris 2011, 150)

The language of power that I drew attention to before is still present in the report Van steenoever tot leefoever. The word fierce, however, which was used earlier to describe opposition to proposed actions, is now used to indicate improvement to De Beer. The Rapport of the stedenbouwkundige dienst had already noted that its plans for the area would mean that "The position of the municipality of Rozenburg will . . be fiercely improved" (Provinciale stedenbouwkundige dienst 1950, 17). In a report for the project Herinrichting Landtong Rozenburg about natural growth of forests on the Landtong, the word is used again as its author asserts that "the grazing area on the Landtong has shown a fierce forest development in the last 15 years" (Linnartz 2014, 7). What we see here, as we did in Adriaan's engagement with people in distress, is power being used not to establish hierarchy, but rather as an embrace, a sign of love and an attempt to comfort. In this case, it is a double embrace: the harbour embraces nature, and nature, or its advocates, embraces, even celebrates, artificiality. 
This is a sentiment that increasingly emerges in contemporary ecological debate, which is marked by a growing awareness that nature conservation has to see a major shift in the era that is referred to as the Anthropocene by many geologists. On her part, Marris continues her vindication of small-scale urban or rural ecology with a great sense of urgency:

If we fight to preserve only things that look like pristine wilderness, such as those places currently enclosed in national parks and similar refuges, our best efforts can only retard their destruction and delay the day we lose. If we fight to preserve and enhance nature as we have newly defined it, as the living background to human lives, we may be able to win. We may be able to grow nature larger than it currently is. This will not only require a change in our values but a change in our very aesthetics, as we learn to accept both nature that looks a little more lived-in than we are used to and working spaces that look a little more wild than we are used to.

Gaia Vince (2014), who also recognises that there is no going back to the methods of old, and that a major shift in conservation thought is necessary, similarly argues:

Nostalgia for the untamed rivers of the Holocene is a pointless sentiment that cannot and should not preserve them in the Anthropocene. Instead, we need to look dispassionately at the planet's great water courses and understand their interactions with ecosystems, chemical and physical cycles, and with the human populations living on their banks. Only then can decisions be made, by everyone concerned, about how we use our rivers - and how to supplement their capacity to meet our needs.

(Vince 2014, 105)

Something very interesting is happening here, as we can see literary ideas finding resonance in policy. Knickerbocker (2012) writes:

Instead of being merely a "device of the poetic imagination and the rhetorical flourish - a matter of extraordinary rather than ordinary language," metaphor shapes our "ordinary conceptual system," and thus "the way we think, what we experience, and what we do every day is very much a matter of metaphor."

(Knickerbocker 2012, 4-5)

In this chapter I have shown that the language and motifs used in the novel De Jacobsladder return in the language used by today's policy makers. Our language does shape our world, and parallels can be drawn between the ways we write about our rivers imaginatively and the ways in which we engage with them practically; how we develop river banks to serve us economically, and how we try in 
return, as we move increasingly consciously into the era called the Anthropocene, to serve them ecologically. On this note, I would like to return to the wise words of Adriaan's grandfather that I cited before:

Look ... that's what I mean, you're always being tricked, but it doesn't matter, because now it's summer and the sun is shining, and if you smell very carefully you can feel the autumn coming. Soon, the migratory birds will come over, and it will be winter and you will have the most beautiful sunsets of the year, and maybe you can go skating. And then spring will come again.

(Hart 1986, 108)

\section{Notes}

1 The translations of De Jacobsladder and other Dutch texts are my own.

2 Lambertus Gerardus Cornelis Ledeboer (1808-1863) was a preacher whose career was marked by many conflicts in different Protestant Churches. His ideas were highly conservative; he opposed singing in church and any kind of governmental influence on church affairs.

3 In my translations of Bible verses, I have referred to the King James Bible. This version gives the names of the birds as "the cormorant and the bittern" which is in discord with the Statenvertaling, the Dutch translation used by protestant congregations in the Netherlands and 't Hart in this novel. I have changed the species in my citation to reflect the Dutch translation, as this is relevant to the reflections of Adriaan's grandfather.

4 For all quotations from the Bible in Jacob's Ladder, I have referred to the King James Bible for my translations. This last verse, however, I have translated myself from the Dutch. The King James translation of this verse, "thou hast in love to my soul delivered it from the pit of corruption" (Isaiah 38:17), is very different from the Dutch translation and does not fit the context of the novel well.

5 Rijkswaterstaat is the executive arm of the Dutch Ministry of Infrastructure and the Environment which is concerned with water management.

\section{References}

Bennett, J. 2010. Vibrant Matter: A Political Ecology of Things. Durham and London: Duke University Press.

Buijsman, E. 2009. De geschiedenis van De Beer, 1870-1940. www.natuurmonumentdebeer. $\mathrm{nl} /$ geschiedenis/geschiedenis_1.html.

Crockett, C., and Robbins, J. W. 2012. Religion, Politics, and the Earth: The New Materialism. New York: Palgrave Macmillan.

't Hart, M. 1986. De Jacobsladder. Amsterdam: De Arbeiderspers.

Hiddema, P., van Leeuwen, J., van Zonneveld, G., and Zwakhals, W. 2014. "Van steenoever tot leefoever." Land+Water No. 10. www.rotterdam.nl/Clusters/Stadsontwikkeling/ Document\%202014/Groene\%20Poort-artikel\%2020141015.pdf.

Iovino, S., and Opperman, S. 2014. "Introduction: Stories Come to Matter." In Material Ecocriticism, edited by S. Iovino and S. Opperman, 1-17. Bloomington, IN: Indiana University Press. 
Johnson, E. A. 2000. "Losing and Finding Creation in the Christian Tradition." In Christianity and Ecology: Seeking the Well-Being of Earth and Humans, edited by D. T. Hessel and R. Radford Ruether, 3-28. Cambridge, MA: Harvard University Press.

Knickerbocker, S. 2012. Ecopoetics: The Language of Nature, the Nature of Language. Amherst, MA and Boston, MA: University of Masachusetts Press.

Marris, E. 2011. Rambunctious Garden. New York: Bloomsbury.

McMillin, T. S. 2011. The Meaning of Rivers. Iowa City: University of Iowa Press.

Nienhuis, P. H. 2008. Environmental History of the Rhine-Meuse Delta. Dordrecht: Springer.

Provinciale stedenbouwkundige dienst in Zuid-Holland. 1950. [Rapport over de toekomstige landschappelijke ontwikkeling van de oeverlanden langs de Brielsche Maas.] Vereniging tot behoud natuurmonumenten (Archive number 999, Inventory number 2634), Stadsarchief Amsterdam.

Rossing, B. R. 2000. "River of Life in God's New Jerusalem: An Eschatological Vision for Earth's Future." In Christianity and Ecology: Seeking the Well-Being of Earth and Humans, edited by D. T. Hessel and R. Radford Ruether, 205-224. Cambridge, MA: Harvard University Press.

Schama, S. 1987. The Embarrassment of Riches. New York: Random House.

Schama, S. 1995. Landscape and Memory. London: HarperCollins.

Schaminée, J., Dirkx, J., and Janssen, J. 2010. Grenzeloze natuur. Zeist: KNNV Uitgeverij.

Stevens, H. 1999. The Institutional Position of Seaports: An International Comparison. Translated by K. Owen. Dordrecht: Kluwer Academic Publishers.

Van der Goes van Naters, M., and de Wit, R.J. (1958). [Letter to H.J. Hofstra, Minister of Finance]. Vereniging tot behoud natuurmonumenten (Archive number 999, Inventory number 2626), Stadsarchief Amsterdam

Van der Goes van Naters, M., and de Wit, R.J. (1959) [Bezwaarschrift No. 5n.]. Buitengewone zitting 1960: Herziening streekplan Brielse Maas, Vereniging tot behoud natuurmonumenten (Archive number 999, Inventory number 2634), Stadsarchief Amsterdam.

Vásquez, M. A. 2011. More Than Belief: A Materialist Theory of Religion. Oxford: Oxford University Press.

Vijgeboom, J. H., and van Herpen, J. 1959. [Bezwaarschrift No. 5t.]. Buitengewone zitting 1960: Herziening streekplan Brielse Maas, Vereniging tot behoud natuurmonumenten (Archive number 999, Inventory number 2634), Stadsarchief Amsterdam.

Vince, G. 2014. Adventures in the Anthropocene. London: Random House.

Windt, H. van der. 1995. En dan: wat is natuur nog in dit land? Natuurbescherming in Nederland 1880-1990. Amsterdam: Boom.

Wriglesworth, C. 2012. "The Poetics of Water: Currents of Reclamation in the Columbia River Basin." In The Bioregional Imagination: Literature, Ecology, and Place, edited by T. Lynch, C. Glotfelty, and K. Armbruster, 86-99. Athens: The University of Georgia Press. 


\title{
12 Art custodians of our rivers \\ Basia Irland, Daniel McCormick and Mary O'Brien
}

\author{
Valerie Behiery
}

\begin{abstract}
So, what is one to do when a beloved river that once rushed past mighty cities now trickles from one diesel irrigation pump to another? Or when the glacier at the head of a river slowly retreats into its mountain cirque and sinks away, and a riverbank that once was a cottonwood swale sweet with birdsong is now only a cliff of broken concrete along a darkly muttering river?
\end{abstract}

Kathleen Dean Moore $(2010,54)$

\section{Introduction}

The idea that nature can become art in a literal sense precedes the 21 st century. It dates to the Land Art and Earthworks movements of the late 1960s that saw artists move out of the studio and museum and away from traditional media and the commercialization of art. Land Art artists adopted the earth as both canvas and medium for often monumental site-specific projects. If these were produced in natural settings, they were not always ecological. As Beth Carruthers observes: "Far from embodying sensitivity to, or awareness of, bioregional complexity, much Land Art of the 1960s and 70s involved what we now recognize as tremendous imposition on local eco-systems" (Carruthers 2006, 6). For example, if the most famous and stunning earthwork sculpture, Robert Smithson's "Spiral Jetty" (1970) in Great Salt Lake in Utah, was meant, in part, to garner attention to environmental damage in the lake's northern section, the process of moving 6,650 tons of earth and rock to create the $4.6 \mathrm{~m}$-by- $460 \mathrm{~m}$ sculpture obviously constituted a massive manipulation of the terrain. Thus, much land art effectively still operates within the modernist paradigm of human domination over nature, despite often seeking to re-establish a harmonious relationship between humans and the natural world.

Art that specifically addresses environmental issues is called ecological art or EcoArt and, somewhat confusingly for those outside of the art world, is not generally called environmental art. Ecological art possesses a plural mandate, helping to explain the diversity of art practices the category encompasses. It seeks to highlight, protect, and, sometimes, restore vulnerable or damaged ecosystems, while simultaneously advocating a new or renewed, more equitable modus 
vivendi between humans and the rest of nature. It is this ethical philosophical aspect underwriting EcoArt that ties it to numerous other environmental movements like ecofeminism or deep ecology, and to contemporary philosophers such as Heidegger, who equally call for a shift away from anthropocentrism and the concomitant technological mastery of nature (Callicott 2004; Hartford 2009). Repositioning the world as a set of interconnected living systems of which we humans are not masters, but simply a part, elucidates why rivers, one of the most visible of the Earth's complex and vital natural systems, form not only sites for environmental analysis and remediation, but also serve as a key metaphor for an environmental epistemology.

Water is central to the EcoArt movement for the simple reasons that, as writer and curator Jennifer Heath neatly sums up, "Water is the world's most crucial and precious resource, the basis for all earthly life. Its preservation and protection is our greatest environmental challenge" (Heath 2014, 6). Even before discussions of climate change emerged, environmentalists were preoccupied with water problems caused by industrialization such as pollution and overuse. Artists too addressed water issues early on, for example, Joseph Beuys's performance-action to clean up the Elbe River in Hamburg back in the early 1960s, or Helen and Newton Harrison's projects on watersheds in the 1970s that already integrated a bio-remedial or restorative dimension (Ingram 2013).

The many realities of climate change: from increased droughts and storms, rising sea levels and melting ice caps, to the drying up of water sources caused by raising temperatures, or to the plausible spectre of war over water rearing its ugly head, have clearly imprinted the dire future consequences of inaction on human consciousness; but not enough, unfortunately, to sufficiently rouse political, corporate, and individual will to action. Economic interests, the quest for easy living, and the rampant consumerism of which we are all guilty prevail over stewardship of the earth whose very resources enable our excess.

Ecoartists have therefore to produce work, which, in addition to being ecological, must incorporate a pedagogical and political dimension. They have been quite successful to date in that governments, activist groups, and local, national, or international environmental organizations are increasingly recognizing the positive impact that art and artists can have on environmental policies and practices. Numerous organizations have now been established to bring scientists and artists to work together for the sake of climate change and other environmental issues; amongst them are Cape Farewell (UK), Common Ground (UK), ArtsCatalyst (UK), Ars Bioarctica (Finland) Symbiotic A: Center for Excellence in the Biological Arts (Australia), EcoArts Australis, the Australia Network for Art and Technology, and the National Science Foundation Antarctic Artists and Writers Program (USA).

However, if the crisis of water and ecology more generally needs art as many scholars now claim (McKibben 2005), both scientists and artists understand that meeting contemporary environmental challenges requires a multi-pronged approach and, more importantly, concrete action, new regulatory systems, and a profound change in human thought and practices. To introduce and assess the 
diverse ways in which ecoartists are addressing the endangered ecologies of rivers, and their effects on those communities dependent upon them, this chapter examines a set of specific river art projects: Basia Irland's "Receding/Reseeding" (2009) and "Gathering of Waters" (1995-2000) on the Río Grande and Watershed Sculpture team Daniel McCormick and Mary O'Brien's "The Nature of Art" (2015) on the Truckee and Carson rivers in Nevada. Please note that, while I have specifically chosen these artists to highlight the rich spectrum of ecological art, limitations of length alone have prevented me from including other artists who have done vital work on rivers, their surrounding wetlands, or on other waterways; such as Betsy Damon, David Haley, Dominique Mazeaud, Aviva Rahmani, Lillian Ball, Ichi Ikeda, Tim Collins, and Reiko Goto, to list only a few.

Rivers possess metaphorical resonance across cultures. A subject of art, poetry and literature, and a site of ritual, relaxation, and religion, the flowing waters of the Earth's rivers provide the clearest mirror of human life and experience. Echoing the fluid systems of our own bodies, rivers have often symbolized life and life cycles, manifesting simultaneously our connection to and oneness with the world, and our inability to ever really see the whole picture. Awareness of the unique symbolic and cultural capital of rivers and water, more largely, informs the work of the artists treated here, particularly that of Irland, emphasizing that this evocative dimension of rivers must be considered in answering the larger theoretical questions underwriting the study, namely whether art is indeed capable of changing the world by changing us, or of articulating the interdependence at the heart of life and life systems obscured by present forms of knowledge, and of helping to open up a way through the water crises plaguing the planet in the 21 st century.

\section{Basia Irland: remembering and remediating the Río Grande}

Basia Irland, who grew up along Colorado's Boulder Creek, is an Albuquerquebased multidisciplinary artist and Professor Emerita of Art at the University of New Mexico, where she founded the Art and Ecology Program. Like Watershed Sculpture, Irland has dedicated her life and art to water. Focusing on rivers, her art addresses myriad water issues from water rights and waterborne diseases to water pollution and scarcity. Underwriting Irland's films, performances, community actions, scrolls, archival objects, installations, and sculptures is the need to teach people about, and bring them together around, the importance of respecting and preserving water. Working with biologists, ecologists, and environmental groups, but also politicians, civil servants, architects, civil engineers, and musicians, Irland has been undertaking water art projects for over thirty years around the world, including in Europe, Africa, Southeast Asia, South America, Canada, and, of course, the United States. Her projects aimed at heightening awareness of waterborne diseases alone have taken her to Egypt, Ethiopia, India, and Nepal. The art outcomes of these outreach endeavors range from scrolls bearing greatly magnified depictions of deadly, albeit 'beautiful' pathogens, to her film Bilharzia 
Blues (2000), featuring musicians who tell the story of the disease caused by the parasite schistosomiasis in several languages.

Irland's work reflects the core notion of EcoArt that change comes about not only by fixing ecological problems, but also by altering the very way of thinking from which they emerge. The artist employs several strategies in her attempt to be a catalyst for this deeper, longer-term change: education, community building, reconnecting individuals with their sources of water, and integrating celebratory and ritualistic aspects into her art events as a way of framing water as sacred. Irland's art is therefore inherently ecological, although some work is more palpably or concretely so like, for instance, her building of rainwater harvesting systems. To paint an adequate picture of the range and multidimensionality of Irland's work I will discuss two projects on the Río Grande: the launching of Irland's ice books on the river in 2009; and the social art project that lasted from 1995 until 2000. It is important to note, that both these projects are part of larger and ongoing series, "Receding/Reseeding" and "Gathering of Waters" respectively, that involve the same work accomplished along other rivers and waterways: for example, the most recent "Receding/Reseeding" event was at the River Maas, which forms the border between Belgium and the Netherlands (2016), and the most recent "Gathering of Waters" took place on the Portneuf River, Idaho (2016).

First, however, we turn to the Río Grande, a river with an almost mythical appeal because of its importance in North American Native and Colonial history. The Río Grande or "Big River" is the "5th longest waterway in North America" (Penn 2001, 224). With a length of 1,885 miles or 3,034 kilometers, and possessing many tributaries, it constitutes one of the most important waterways of the southwest United States and northern Mexico, where it is known as the Río Bravo del Norte or "Furious River of the North". From its source in the San Juan mountains of southern Colorado, it flows through the states of New Mexico and Texas before reaching its mouth in the Gulf of Mexico. The Río Grande forms a natural border between the United States and Mexico, where it partially outlines the states of Chihuahua, Coahuila, Nuevo León, and Tamaulipas. The slew of twin cities along the river border reflect the tremendous economic disparity between the two countries. This disparity explains why the Río Grande, a relatively shallow river, now serves as a crossing point for innumerable Mexican migrants seeking a better life on its northern banks and beyond (Penn 2001, 226).

The Native Americans and even the early Hispanic settlers who established themselves as farmers along the Río Grande employed simple irrigation ditches called acequias in Spanish that had little impact on the river and its ecosystem (Phillips et al. 2011, 38). Damage to the river began with the American takeover of the region in the mid-19th century that saw modern technology and an exploitative commodification of nature penetrate the area. The authors of Reining in the Río Grande: People, Land, and Water (Phillips et al. 2011) convincingly argue that many of the ecological problems still afflicting the river today are to be traced back to the building of the railway system in the late 19th century that 
supported the industrialization of the Grand Río Basin. Deforestation, devastating to the river and its ecosystem, was not only caused by the sheer volume of wood needed for building the vast network of railway tracks, but also by "the timber barons" who cleared the forests, made their fortune and left, and by the "cattle barons" who sent in millions of animals and caused overgrazing (Phillips et al. 2011, 79). Wealth seeking newcomers looked down on subsistence farming; instead, they instituted large-scale farming made possible in the arid area only by building huge canals to divert water from the river.

The Río Grande responded to these pressures by oscillating between running dry or frequently flooding, both due, in fact, to aggradation, meaning the rise in the river bed that occurs when there is too great a load of eroded sediment, silt and soil in the water, caused here by the stripping of the vegetation that would normally capture the excess material. Huge dams were also built, and, if these reduced the sediment in the water, they caused new problems such as the waterlogging and salinization of fields. Technology was again employed to 'fix' the problems by, one, the creation of irrigation districts that concentrated on the "construction of massive levees, elaborate diversion works, and a network of drains" and, two, the complete reengineering of the river "straightening and channelizing it, even excavating it far below the water table to suck back the water lost by seepage from the aggraded original channel" (Phillips et al. 2011, 200). While the straightening of the Río Grande made water delivery downstream more efficient and prevented flooding, no one considered "the dry winding channels of its previous self-created course" or "the fish, the birds, the plants that had formerly depended on the myriad of habitat niches along the diverse meandering channels" Phillips et al. (2011, 139). In sum:

With each technological fix, the original Río Grande receded a step and so did its intrinsic ecological and aesthetic values. By the 1960s the straight, narrow Río Grande, confined between high banks and surrounded by towering levees and dense thickets of saltcedar, was seen by the citizens of Albuquerque only as a fit site to dump their refuse. Today, the general consensus is that reliance on technology went much too far. In line with river restoration efforts throughout the country, more jetty jacks are being removed with cranes, and levees are being relocated to expand wetlands.

(Phillips et al. 2011, 200)

The birth of the environmental movement has meant that dozens of restoration projects for the Río Grande and accompanying legislation have seen the light of day. These have had some positive impact on water quality and quantity, riparian biological diversity, endangered species, and native fauna and flora in the river basin. However, despite these successes, Phillips et al. $(2011,168)$ conclude that "real restoration has not been achieved". They explain:

Thousands of acres of riparian habitat remain under dense stands of nonnative shrubs. Efforts to restore the links between in-channel and overbank 
zones, using high flows to reroute the river, are greatly hindered by houses that have been built on the floodplain, restricting the high flows to fairly pitiful levels. Along most stretches of the river the riparian habitat is confined by levees to a narrow strip along its banks.

Restoration efforts are particularly difficult in the case of the Río Grande because the river straddles several states and two countries and has been at the center of a long history of conflicts over water allocation and competing interests and demands. Continued urbanization along the river places far too great a demand on the river's waters, and the already felt symptoms of climate change only add more uncertainty to its future. This short history of the Río Grande mirrors that of all other rivers whose ecosystems have also been adversely affected by industrialization, water overuse and the human impetus to engineer nature. Depicting the realities that ecological artists are courageously challenging, the story equally sets the context for Irland's social art projects along the fabled waterway.

The book is a recurring motif in Irland's work. The artist began by making books in wood to which she added natural elements. However, Irland's 'books of nature' came to be carved out of ice and floated down rivers. The whole series of frozen river water books is entitled "Receding/Reseeding" referring to the seeds, pods and grasses adorning the covers or pages of the books that are sent on a journey to replenish the river banks with native species. The title was born with the first ice book project in 2007 on Boulder Creek that was part of art critic and curator Lucy Lippard's groundbreaking show "Weather Report" about climate change held at the Boulder Museum for Contemporary Art in Colorado. As Irland explains, the impetus for the work was environmental: "I was inspired to create Tome I due to the fact that the Arapahoe Glacier is melting so fast, and it provides about $70 \%$ of Boulder's drinking water, so when it has disappeared, from where will the city obtain its water?" (Personal communication with the artist, June 10, 2016).

Landing where they will as the ice melts, the seeds hopefully take root along the river banks. Irland consults with specialists beforehand to identify the native species that would be the most beneficial in restoring the ecosystem of each river and its wetlands. If up until now, the artist has left it up to nature to place and plant the seeds, she intends to install monitoring systems on the seeds in the future to collect data and assess the scientific impact of the ice books. Irland describes the intended bio-remedial benefits of the "Receding/Reseeding" series' intended revegetation in these terms:

When an ecosystem is restored and the plants grow along the riverbanks, they give back to us by helping sequester carbon, mitigating floods and drought, pollinating other plants, dispersing seeds, holding the banks in place (slowing erosion), creating soil regeneration and preservation, acting as filters for pollutants and debris, supplying leaf-litter (for food and habitat), promoting aesthetic pleasure, and providing shelter/shade for riverside organisms, including humans. 
In the case of the Río Grande books' launch at Albuquerque, New Mexico in June 2009, what Irland calls "the ecological language" or "riparian text" of the ice sculptures was composed of Fremont cottonwood seeds (populus fremontii), desert willow (chilopsis linearis) seeds and seed pods, lemonade berry (rhus trilobata), and riparian grasses. Moore (2013, 54), in an article on Irland's work, makes the parallel between seed and text. She writes:

A seed is a conveyance system for information. It is words taken wing - words written in the language of adenine, cytosine, guanine, thymine, ancient instructions clasped between hard covers, everything needed to carry a story to a new place where it can take root. Long before writers figured it out, seedbearing plants had found a way to convey to the next generation wisdom accumulated over millions of years.

Irland produced eleven books. Ten were floated down the Río Grande, while the $300 \mathrm{lb}(136.1 \mathrm{~kg})$ ice book "Tome II", bearing cottonwood seeds, was simply set on the bank because it was the season for the latter to take root (Figure 12.1). Left to melt, it "recreated, in microcosm, the right conditions for cottonwood seeds to grow" (Irland n.d). The Río Grande, like so many other American rivers, had been straightened, preventing its yearly overflow on to the floodplain: cottonwood seeds would therefore land on dry ground, unable to sprout and grow. While the actual making of the ice sculptures is done in the artist's studio, the launching of the ice books is a social, participatory event, bringing together different communities concerned with their water source who would otherwise never meet. Among the eighty or so participants who attended the launch of the Río Grande ice books were "artists, farmers, acequia majordomos, college students, professors, hydrologists, Pueblo members, and hundreds of interested watershed citizens" (Irland n.d.). These meetings, in which participants exchange views on their river's fragile ecology and the importance of native species in restoring its watershed, aim at establishing common ground, facilitating future collaborations and reducing conflict over water rights and other pressing water issues related to the "Big River". This type of community building, inherent in much ecological art, is also vital to Irland who acknowledges that "it is the people with whom I work who keep me going" (Irland n.d.).

The ice books fufil all the criteria required to be labelled as EcoArt: they are site-specific ecological tools, they involve community building and education, and they try and recast the human relationship with the rest of nature. Like Watershed Sculpture's structures, the artefacts are temporary aesthetic objects and their production possesses a performative and participatory dimension related to performance art, and to what Joseph Beuys called "social sculpture" in which process, social relations, and politics intersect to effect change. The artist showcased her Río Grande ice books' project in a group exhibition at the socially committed Albuquerque 516 Arts Gallery that ran from August 1 to September 19, 2009, and in which she exhibited photographs of the books and their launch, projected a film on her ice book series, and displayed an actual ice book left to melt in 


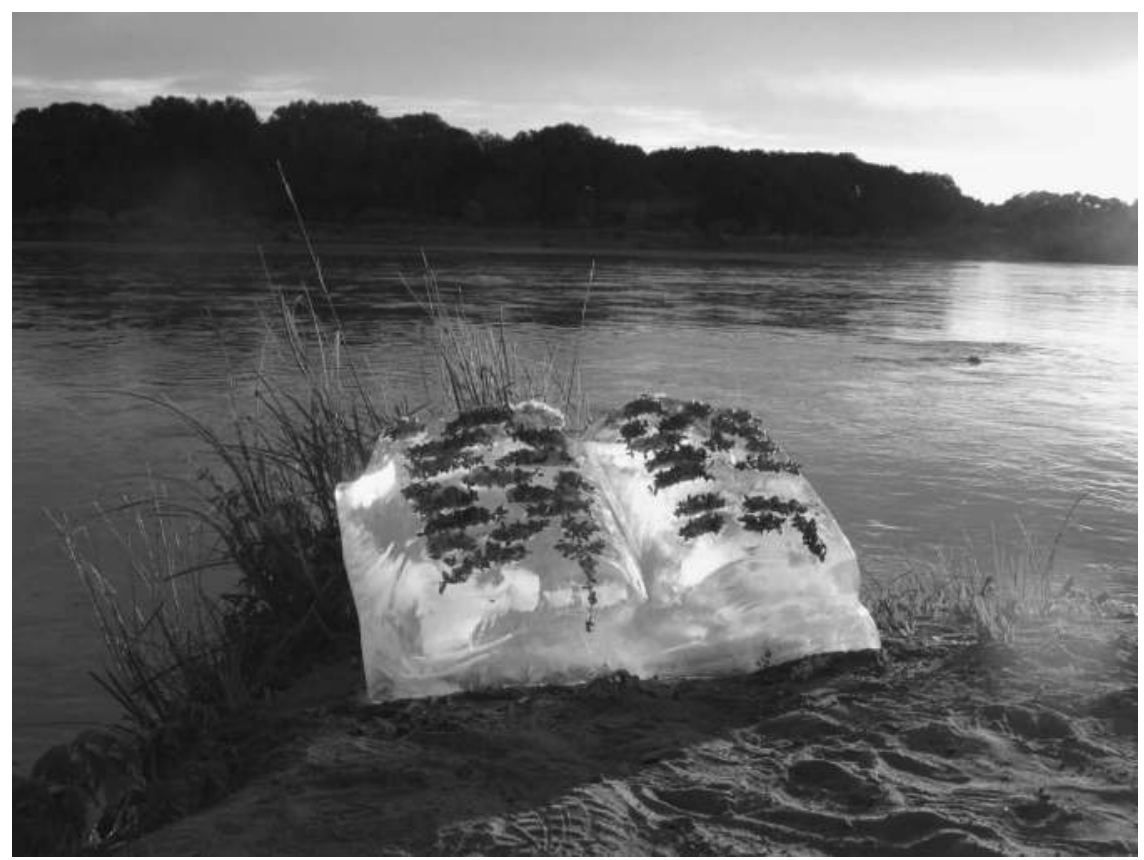

Figure 12.1 Basia Irland. Ice Book TOME II at Dusk. Frozen river water with Fremont cottonwood, 300 pounds, Río Grande, Colorado, 2009.

Source: Author's photo reproduced with the kind permission of the artist

a bucket where the dropped seeds would later sprout and then be returned to the river. Irland always takes full advantage of the art apparatus to communicate her message, most recently in her 2015-2016 solo retrospective show Reading the River, at the Museum de Domijnen in the Netherlands that recently published Reading the River: The Ecological Activist Art of Basia Irland (2017).

The best known of Irland's projects along the Río Grande is "Gathering of Waters", a five-year-long art project "in which people symbolically carried the waters of the Río Grande/Río Bravo from source to sea", something the river can intermittently no longer do on its own (Gerber 2003, 43). A canteen bottle known as the River Vessel was passed down the whole length of the river; at each stop a celebration would be held in which a little water would be added before being passed to the next community downstream (Figure 12.2). As Irland's documentary film on the project reveals, people carried the River Vessel in multiple ways: on foot or on horseback, by boat, raft or canoe, by car, truck or plane or, still yet, by hot air balloon. At the end of the journey at Boca Chica, a Zuni Pueblo woman handed the River Vessel to Irland waiting in the river. The artist held it up towards the sky as an act and sign of gratitude and respect, before 


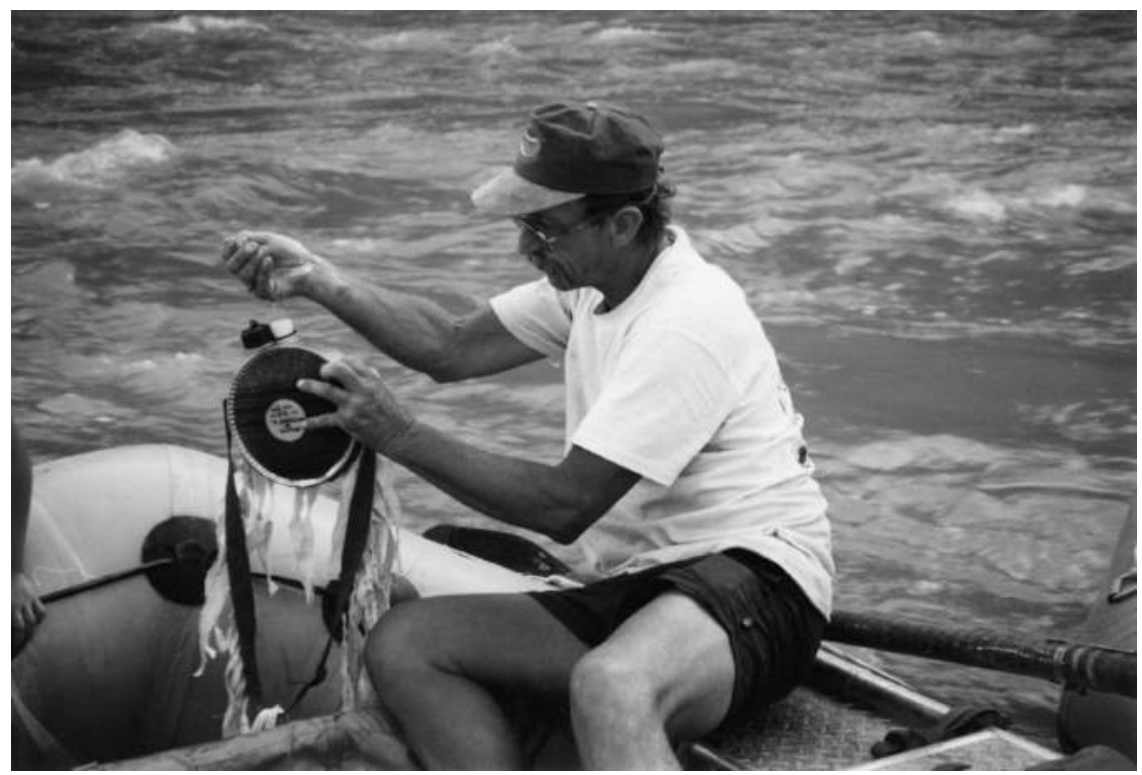

Figure 12.2 River guide adds water to the Canteen.

Source: Author's photo reproduced with the kind permission of the artist

ceremoniously pouring the water into the sea. Accompanying the canteen was a logbook in which participants, inevitably present at the river, would write down their thoughts. These confirm that a "Gathering of Waters" achieved its aim of reconnecting individuals and communities with their river and of raising appreciation of its plight. In her article on Irland, Lisa Gerber quotes several logbook entries that invoke blessings on the water or meditate on its meaning, for example, the one by Matt Schmaden who writes that "we are all connected by the life force of the River - by its nurturing and the legacy of its agelessness and its diverse peoples - and we must give it strength" (Gerber 2003, 48).

A "Gathering of Waters" cut through social, linguistic, cultural, racial, and economic barriers, bringing diverse people and communities together and creating lasting relationships to help save the Río Grande. As Irland says, the participants mirrored the river by "forming a kind of human river" (Irland n.d.). This is social sculpture at its best. While not art in the traditional sense, it is art in the transformative sense, namely a process with the potential of altering how we think about and relate to water. The project's success resides largely in the feelings the project instigated in people towards the river and the actions it spurred. Participants engaged in human creative expression and activity when they travelled with the River Vessel, held ceremonies or clean-up sessions, planted trees, wrote logbook entries, or read poems as did Irland when she crafted small clay 
canteens for all the project's participants or made her "Portable Repository", a backpack of ponderosa pine and recycled wood that serves as an archive of the project. In it, one finds maps in many languages, water samples from the Río Grande, hydrographs and photographs, a video about a "Gathering of Waters", as well as tiny cast silver sculptures of the endangered silvery minnow that once filled the Río Grande. In "Portable Repository", science and art again meet.

The work documents the project and provides useful information, but can also be exhibited as a kind of sculpture in art galleries and museums; "Portable Repository" is now, in fact, part of the Museum of New Mexico's permanent collection. Aesthetically and conceptually, the piece reflects important currents within contemporary art that posit art as open-ended, mobile, and interdisciplinary, rather than as an autonomous and hermetic object or field. In addition to performance art and social sculpture referred to earlier, "Portable Repository" evokes a branch of contemporary art, which American art critic Hal Foster describes as possessing an "archival impulse" that seeks to "make historical information, often lost or displaced, physically present" usually through installations incorporating found images and objects (Foster 2004, 4). In Irland's case one might replace the adjective 'historical' with 'geographical' or 'ecological'. The point is that this type of gathering of objects and/or data is an artistic strategy used by other contemporary artists. Finally, "Portable Repository", like the many other portable sculptures that document Irland's participatory art projects, is Irland's archival assemblage of found and manmade objects, and historical, geographical, and scientific data; a human scale installation whose very portability prevents its aesthetic reification. As a physical manifestation and witness of the project, the piece remediates the relationship between humans and rivers, respectful of and reciprocating the gift of water.

\section{Watershed Sculpture: living sculpture on the Truckee and Carson rivers, Nevada}

Daniel McCormick, half of the San Francisco-based Watershed Sculpture team, received his Bachelor's degree from the College of Environmental Design at the University of California, Berkeley. Prior to this, he studied sculpture at the University of California, Santa Barbara, including under James Turrell, known around the globe for his art installations produced using light, color, and space. Turrell left a deep and lasting impression on the young McCormick, not so much artistic as philosophical. His partner, Mary O'Brien, who studied studio art, environmental communications, and political science brings, like Daniel, additional skill sets needed for ecological interventions in which art and design, science, policy, and politics meet. Daniel and Mary had worked together in the field of bio-remedial art for decades before founding Watershed Sculpture in 2008. The two effectively met twenty-five years ago, when they were both involved in a restoration project of an urban creek in San Francisco. As the name reveals, Watershed Sculpture specifically broaches problems experienced by urban and rural compromised watersheds, elucidating why they prefer the expressions remedial 


\section{Valerie Behiery}

art or bio-remedial art over EcoArt, as these refer specifically to "works which restore or recover lands, waters, naturally occurring systems and habitats" (Carruthers 2006, 3).

Many of Watershed Sculpture's ecological interventions are characterized by large sculptures made of riparian materials that are woven together employing a basket weaving technique and then placed strategically on sites to abet problems of flow, floods, habitat, and sedimentation (Averett 2015). As the artists explain:

We are compelled by the idea of using sculpture in a way that will allow the damaged areas of a watershed to reestablish themselves. As it has evolved, our art has become focused on strategically congregating sculptural components made from riparian materials back into the watershed. They are intended to give advantage to the natural system, and after a period of time, as the restoration process is established, the artists' presence becomes less and less apparent.

(http://watershedsculpture.blogspot.com)

The works, functional and beautiful in their own right, also have zero negative impact on the environment, and evolve to aid in its recovery over time. The sculptures not only harmonize with the surrounding nature, but re-become nature, merging with the landscape out of which they were originally born. The humility of the structures contrasts with the hubris of much contemporary art and architecture and reflects the duo's ecocentric, rather than anthropocentric, worldview whose propagation and adoption many ecologists consider as the solution to our current environmental problems.

Like Turrell, McCormick and O'Brien deem that art must move beyond aesthetics and bring about change (Selz 2006, 235). The sculptures or interventions of the two artists who consider the watershed "a found object that is to be respected, even revered" focus exclusively on "restoring ecological balance" (Selz 2006, 235). They redefine art: no line here separates conservation or natural systems and art, thereby fully dissipating the traditional nature-culture divide. From this perspective, the art might be said to occur only once the handwrought structures have been transformed by the new growth covering them and become reintegrated into the site and its ecosystem. A critical shift has here taken place: instead of nature being transformed by humans to become culture, cultural manmade artefacts - albeit here made of natural material - are purposed to become nature. The duo feel no need to leave traces or marks of their individuality and then to equate this with art. Their ecocentric perspective that appears rooted in a systems-based thinking and approach, also rejects the dichotomy long upheld in science, philosophy, and art between subject and object or self and world. This vision of the world and of our place in it underwrites ecological art and philosophy, and is very much related to indigenous world views and therefore also to the contemporary indigenization of knowledge project that cannot, unfortunately, be broached here for reasons of length. For the artists, art and nature as well as perhaps art and the artists are neither separate, nor self-sufficient. Instead, they all 
form part of larger organic systems, thereby framing existence - whether of world, nature or self - as being produced through its connectivity and interaction with all else. Watershed Sculpture effectively embeds a post-anthropocentric philosophy in their art not only conceptually, but also physically and materially.

Daniel and Mary have worked on various urban and rural watersheds in the United States, mostly in California, but also in the states of Louisiana, North Carolina, and Nevada. The discussion will, however, here be restricted to "The Nature of Art" project (2014-2015) along Nevada's Truckee and Carson rivers. Part of an overall larger restoration effort, Watershed Sculpture's restorative structures were executed in collaboration with The Nature Conservancy of Nevada and the Nevada Museum of Art's Center for Art + Environment. The artists, with the help of hundreds of volunteers, produced and inserted structures at the McCarran Ranch Preserve on the Truckee River, and at the River Fork Ranch Preserve on its sister river, the Carson. These two rivers are linked by the Truckee Canal built as part of the Newlands Project just after the dawn of the 20th century (1902).

The Truckee River runs northeasterly from Lake Tahoe, California, to Pyramid Lake, Nevada, and traverses many landscapes on its 140 -mile $(225.3 \mathrm{~km})$ course from the Sierra Nevada Mountains to the Nevada desert. Its flow is essential to the communities along its banks, providing drinking water, generating hydropower, irrigating crops, while enabling fishing and other water sports, and maintaining a vital ecosystem for plants, fish, wildlife, and humans. However, echoing the history of the Río Grande, farming, logging, human engineering of the waterway, and unchecked urban growth and development have made it prone to droughts and flooding, affecting both the human and non-human communities it sustains. The Truckee's century-long history of damage and intervention has left its toll. The State of Nevada Division of Water Resources identifies the Truckee's major water-related issues as being water diversion (e.g. the Derby Dam for the Newlands Project), lack of upstream storage areas for periods of drought, the growing demand of water in the Reno-Sparks Metropolitan area, and problems relating to water quality, flow, and allocation (State of Nevada 2013).

The Nature Conservancy has restored four areas or properties along the Lower Truckee. Daniel and Mary's structures are part of the McCarran Ranch Preserve project near the city of Reno, whose restoration, still ongoing today, began in 2003. The problems witnessed at the McCarran Ranch Preserve, as elsewhere along the Truckee, stem mostly from work in the 1960s to straighten the channel as a method of flood control that caused the groundwater "to drop beyond the reach of riverside vegetation", and caused the "loss of approximately $90 \%$ of the riparian forest and as much as 70\% of bird species" when compared to 1900 levels (Nevada Nature Conservancy 2016a). Native fish population was also nearly decimated. The conservation team has undertaken many steps to restore the Truckee's ecosystem. It has reconnected the river to its floodplain to mitigate flood damage and lowered the floodplain while "slightly raising the river's bottom, and narrowing its width to re-create conditions that can support native vegetation" (Nevada Nature Conservancy 2016a). It has also reconstituted meanders 
to enable a natural flow pattern, and brought back native plants to cool the water and improve its quality as well as created riffles and pools to provide habitat for fish.

In spring 2014, after spending time researching the site and river, Daniel and Mary, in concert with Conservancy scientists, began conceiving, designing, and building four remedial sculptures for the McCarran Ranch Preserve, all made from tree cuttings found on site and installed in the river's riparian zones. The following descriptions of Watershed Sculpture's structures are fully based on my personal communication with the artists. The artists built the "Avian Habitat Resource Sculpture" (2015) after seeking advice from and discussing their designs with Elisabeth Ammon, an ornithologist and Executive Director of the Great Basin Bird Observatory whose expertise resides in the restoration of riparian habitats. The structure, made to attract both migrant and resident birds, such as Bewick's Wrens, House Wrens, and Yellow Warblers, is a five-foot sphere of woven cottonwood branches "wrapped with excelsior, coir and human hair" inside of which is staked a 12 -foot $(3.65 \mathrm{~m})$ perch made of fir and cottonwood (Pers comm 2016). The perch is vital because, as Ammon observes, wetlands are often lacking perches for birds that "like to sit up high and look down to observe insects and fish" (Averett 2015). In fact, while the artists were still crafting the avian habitat, a couple of House Wrens made their nest in the cavity at the top of the carved cottonwood log. The structure also offers habitat and nesting resources to other species: invertebrates, insects, and small reptiles like the Western Fence lizard. The fact that the presence of all these species is beneficial to birds only further underscores the interconnectedness inherent in all ecosystems.

"Multi-Systems Habitat Sampling" (dimensions are variable 2015) consists of three sculptures. First is a fascine, meaning a bundle of bound long sticks or branches used to strengthen embankments and prevent erosion. Made of red willow native only to a small area of Nevada that includes the McCarran Preserve, it has been inserted into the shore of a flood control pond where it provides home and shelter to several small species. Second, is an 'island' of cuttings fastened to the pond's bottom and possessing a perch used by Red-wing Blackbirds and Yellow-headed Blackbirds. Third is the "Log Indicator" sculpture, a partially buried, dead cottonwood tree "segmented in a Fibonacci sequence pattern". The artists carved a small cavity in the top of each section, filled it with a high nitrogen soil mixture to abet the process of decay and capped each one with a carved wooden knob. In addition to encouraging the tree's decomposition, the piece was designed to attract microorganisms, small invertebrates, insects such as nesting ground bees, reptiles like snakes, amphibians like frogs, and birds in an area of little growth.

The third work installed at the McCarran Ranch called "J-Hook Braided Log" (2015) is built in a reengineered, historic scour channel and joins the separate parts of a fallen cottonwood tree to act as a fascine that slows down flooding by guiding water overflow into the upland area of the floodplain. Filling with twigs and leaves, "J-Hook Braided Log" also traps silt and creates habitat. Daniel and Mary use here, as they often do in habitat-enhancing works for 
riparian zones, the technique of weaving live-staked Arroyo willow that will allow the willow to grow through and around the sculpture, thereby stabilizing the scour channel, preventing erosion and providing a home for birds - the Willow Flycatcher in particular - and small mammals and reptiles. Two cottonwood branch fascines positioned on opposite banks of a backwater make up the fourth structure on the Truckee River. "Was a Tree" (2015) was conceived to capture biodegradable materials and provide habitat and shelter for Wood Ducks and Western Pond Turtles and other reptiles. However, Daniel and Mary's description of the work reveals other functions of the piece and, more significantly, the necessity for ecological artists to understand each site's specific ecosystem and wildlife:

The walls and fascines are constructed so that they also provide the growing willow saplings shade and protection from browsing deer and foraging beaver. Parts of the sculpture in the water function as turtle crawls. Turtles inhabited the crawls immediately. In addition, the fascine and walls are designed for turtle nesting. Muskrats interact with the sculpture. Snakes use it to sun themselves.

(Pers comm 2016)

The most ambitious work undertaken as part of "The Nature of Art" project is, unhesitatingly, the "Flood Plain Wall" (2014) built for the River Fork Ranch, an 800 -acre (323.75 hectares) preserve on the Carson River, near Genoa, acquired by the Nature Conservancy of Nevada to protect wetland, meadow, and riparian habitats damaged directly by overgrazing and indirectly by the river's dredging (Nevada Nature Conservancy 2016b). However, since operating the ranch, the Conservancy has successfully restored or created almost 40 acres (16.1874 hectares) of habitat. The revegetation project supports the region's diverse wildlife - bald eagles, sandhill cranes, leopard frogs, monarch butterflies, and mule deer - prevents erosion of the river's banks, and filters pollutants from the water (Figure 12.3).

Rivers need a place to flood when their flow peaks. Floodplains decrease flooding of developed areas downstream, replenish groundwater aquifers and purify water naturally by collecting silt and pollutants. Their protection is central to the restoration project at River Fork Ranch that now safeguards 800 acres (323.75 hectares) of floodplain. McCormick and O'Brien designed and built "Flood Plain Wall" (2014) to rebuild the floodplain, stabilize banks, slow down floodwaters as well as revegetate the area; over a thousand willow stakes were planted in its making, thereby simultaneously creating a habitat. Set in a restored slough of the Carson, the work's two woven sections, a bifurcated piece $240 \mathrm{ft}$ (73.2 m) long, and a smaller $40 \mathrm{ft}(12.2 \mathrm{~m})$ structure, were specifically engineered "to create a willow stand of sufficient size to address the specific habitat requirements of the Willow Fly Catcher" (Pers comm, Mary O'Briend, 2016), but also to provide a home to the endangered Western Pond Turtle and other small reptiles or mammals. 


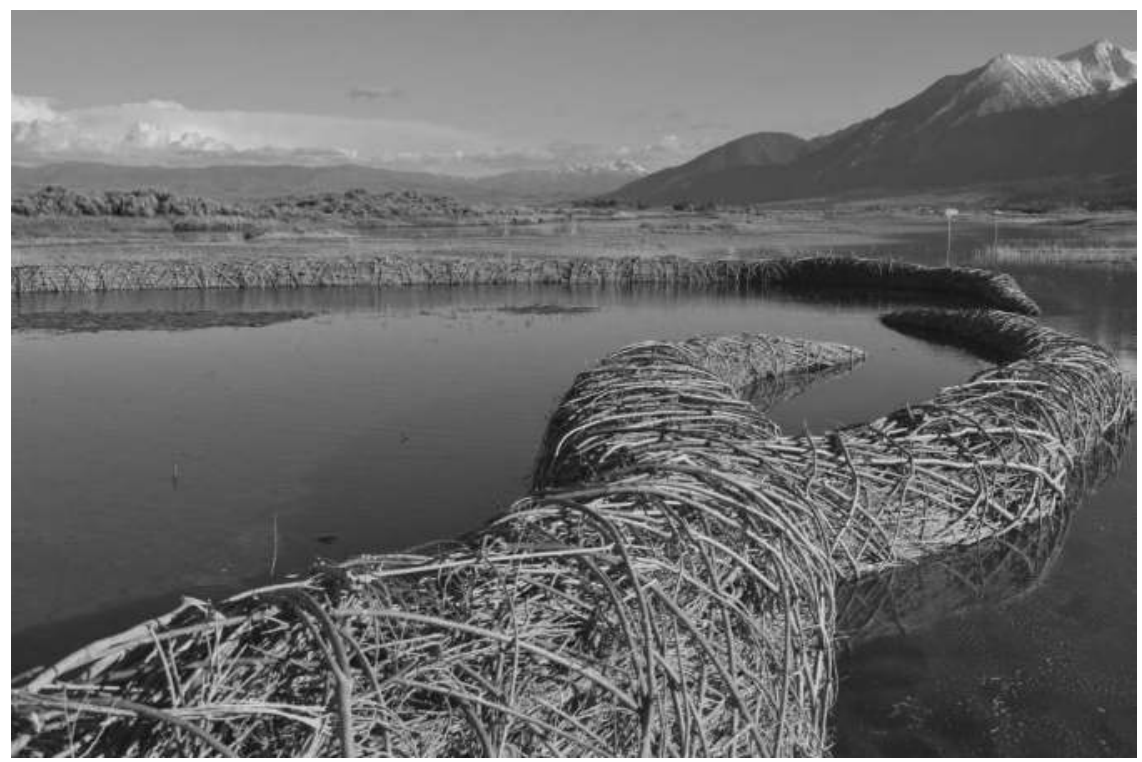

Figure 12.3 River Fork Ranch Flood Plain Wall.

Source: Author's photo reproduced with the kind consent of the artists

The sheer scale of the "Flood Plain Wall" demonstrates that it would be impossible for McCormick and O'Brien to weave their structures alone. Even if it were feasible, it would occlude the community involvement that both ecoartists and conservationists recognize as indispensable to the environmental movement. The artists depend on volunteers who not only build the sculptures, but also play a role in their upkeep and the examination of their progress. The structures for both the McCarran Ranch Preserve and the River Fork Ranch required hundreds of volunteers - businesspeople, activists, students, and other concerned citizens and thousands of hours. For the artists, this social, participatory aspect of the work is integral to its overall concept and aim. As Mary O'Brien states, "We consider the collaboration an ingredient of our art process, and we're pleased to become a part of the community in this way" (Pers comm 2016). The exhibition featuring "The Nature of Art" project held at the Center for Art + Environment at the Nevada Museum of Art in Reno, Nevada, from December 6, 2014 to April 5, 2015 enabled further outreach; over 47,000 people visited the show, confirming the still relatively untapped potential of the coupling of art and ecology.

"The Nature of Art" project shows that ecoartists are not masters in a studio isolated from the world, but rather are members of an interdisciplinary team for whom scientific research, data and knowledge of the terrain are of prime importance. The Nature Conservancy deems the endeavour a success; it has, in fact, asked Watershed Sculptures to produce an additional sculpture this year. The 
straightforward and efficient bio-remedial dimension of Daniel and Mary's sculptures constitutes its greatest asset, offering much hope in the light of current, calamitous climate prognostications and realities. The duo's woven structures prove that seemingly simple, low-tech solutions can have a profound beneficial effect on our rivers and ecosystems without causing, like technology, additional problems, as they equally make manifest the complex oneness of riparian ecosystems in which rivers, their wetlands, native flora and fauna, and human activity are completely intertwined. They also exemplify the benefits of the marriage of art and science in the cause of ecology. Bill Fox, Director of the Nevada Museum of Art's Center for Art + Environment, effectively considers their partnership with The Nature Conservancy as "a model for increasing the role of art in the world by integrating it into the work of environmental organizations" (Pers comm 2016).

\section{Conclusions}

The art examined in the present study provides a slice of what is encompassed by the category of ecological art as well as the kind of art projects initiated with the loving aim of protecting our rivers and, by extension, the myriad species including humans - that they sustain. EcoArt, often produced in conjunction with environmental scientists, can possess a bio-remedial component as seen in the case of Irland, but, more importantly, in the exemplary work undertaken by Watershed Sculpture.

Remedial art, espoused by a growing number of artists worldwide, proves that art can literally change the world for the better. Given the ecological crisis facing humanity, the need to demand our communities and governments, as well as the art apparatus, to facilitate and widely implement restorative art projects cannot be sufficiently stressed. However, if we are to successfully tackle current environmental challenges, humans also need to change. Sacha Kagan expresses this idea using a computer-based metaphor, "The global crisis of unsustainability is not only a crisis of the hardware of civilization, it is also a crisis of the software of minds" (Kagan 2012, 10). Framing art as a process and means to change human minds and habits elucidates the centrality of education, collaboration, and community building in Irland's and McCormick and O'Brien's work, as in that of ecoartists more generally. Akin to bioremediation, these three strategies necessarily involve real facts, figures and logistics. function and functionality are not necessarily direct, overt, or mechanical and, effectively, the pedagogical, collaborative, and communitarian aspects of ecological art are themselves rooted in deeper philosophical concerns seeking to transcend and transform the worldview and classification of knowledge propounded by modernity.

The art projects examined herein implicitly ascertain the need to widen the definition of art, both in terms of the types and number of practices it encompasses. This proposition initially appears in line with modernity in that modern and contemporary artists have been consistently pushing the parameters of what constitutes art; as French philosopher Jacques Rancière states, "Doing art means displacing art's borders, just as doing politics means displacing the borders of what 
is acknowledged as the political" (Rancière 2012, 149). But EcoArt is neither interested in redefining art for art's sake, nor striving to be avant-garde - perhaps already an impossibility - a very concept invented by modernism. If it stretches the parameters of what constitutes art, it is solely for the aim of drawing attention to fragile ecologies and the problematic philosophy and practices at their root.

The varied practices of ecological art all aim to recast the relationship between humans and the rest of nature by moving beyond the modern utilitarian and mechanistic worldview that reduces nature "to dead matter in motion" and "a system of inert parts to be externally controlled" (Mpanya 2011, 136). Irland, and McCormick and O'Brien all make art that is intended to deconstruct the ideologically constructed divisive wall between the human and non-human worlds, and to actually see the world through the eyes of (non-human) nature. In each project discussed, the artist is not asking 'Who am I?', but rather, 'Who is the river, and what does she need and want?' In postcolonial terminology, one would say that the artists are giving voice to the minoritized or subaltern subject of nature. The artists manage, however, to move beyond deconstruction and critique and propose a truly post-modern worldview in which the world or, indeed, the universe is posited as an irreducible whole, akin to the late scientist's David Bohm's theory of "unbroken wholeness" (Mpanya 2011, 139).

The holistic worldview promulgated by ecological art explains its capacity to point the way forward, conveying not only the interconnectivity of the human and non-human worlds, long understood in both indigenous and pre-modern worldviews, but also the inseparable bonds among art, science, epistemology, politics, social organization, and the natural environment. The three custodians of the rivers - Irland, McCormick, and O'Brien - have already understood this and their art, akin to rivers and all other natural systems, ask us to transcend an anthropocentric worldview to experience, instead, oneness and harmony with the perpetual movement and ever-unfolding present of the world and its nourishing, life-giving waters. They corroborate Kagan, who argues that art is not just a medium, but instead constitutes "the active process of interdependences between different dimensions of human crisis that draws us into the search for pathways to a post-fossil fuel age, and on to a new era of human development based on an aesthetics of sustainability" (Kagan 2012, 7). Whether that new era ushers in depends, of course, not on art but on us, the human agents who make it and appreciate its message.

\section{References}

Averett, N. 2015. "Art That Walks in the World." Resilience, 8 June.

Carruthers, B. 2006. Mapping the Terrain of Contemporary Ecoart Practice and Collaboration: Art in Ecology-a Think Tank on Arts and Sustainability. Vancouver: (commissioned by) UNESCO.

Foster, H. 2004. “An Archival Impulse.” October 110: 3-22.

Gerber, L. 2003. "The Nature of Water: Basia Irland Reveals the 'Is' and the 'Ought'." Ethics and Environment 8(1): 37-50, 203. 
Hartford, M. T. 2009. Mining Part III: Mountaintop Removal." In Encyclopedia of Environmental Ethics and Philosophy Volume 2, edited by J. Baird Callicott and Robert Frodeman, 66. Detroit: Macmillan Reference USA.

Heath, J. 2014. "Water, Water Everywhere: Lamentations, Celebrations and Healing Songs." In Water, Water Everywhere: Paean to a Vanishing Source, edited by J. H. Boulder, 5-17. Colorado: Baksun Books \& Arts.

Irland, B. n.d. www.basiairland.com/index.html.

Kagan, S. 2012. Towards Global (Environ)Mental Change: Transformative Art and Cultures of Sustainability. Berlin: Heinrich Böll Foundation.

McCormick, D., and O'Brien, M. n.d. Watershed Sculpture Blog. http://watershedsculpture. blogspot.com.

Moore, K. D. 2013. "Books of Ice." Orion Magazine, March-April, 53-59.

Nevada Nature Conservancy. 2016a. McCarran Ranch Preserve: A Healthy River for Wildlife and People. www.nature.org/ourinitiatives/regions/northamerica/unitedstates/nevada/ placesweprotect/mccarran-ranch-preserve.xml.

Nevada Nature Conservancy. 2016b. River Fork Ranch: Conservation for Future Generations. www.nature.org/ourinitiatives/regions/northamerica/unitedstates/nevada/ placesweprotect/river-fork-ranch.xml.

Penn, J. R. 2001. Rivers of the World: A Social, Geographical, and Environmental Sourcebook. Santa Barbara, CA: ABC-CLIO.

Phillips, F. M., Hall. G. E., and Black, M. E. 2011. Reigning in the Río Grande: People, Land, and Water. Albuquerque: University of Mexico.

Rancière, J. 2012. "The Paradoxes of Political Art." In Dissensus: On Politics and Aesthetics, edited and translated by Steve Corcoran, 134-151. London: Continuum.

Selz, P. 2006. Art of Engagement: Visual Politics in California and Beyond. Berkeley: University of California Press.

State of Nevada Division of Water Resources. 2013. Introduction (Truckee River WaterRelated Issues Section: A Chronologcal History of Lake Tahoe and the Truckee River and Water-Related Issues. http://water.nv.gov/mapping/chronologies/truckee/introduction. cfm.

Watershed Sculpture. 2014. History, Nevada Museum of Art. www.nevadaart.org/ exhibition/daniel-mccormick-mary-obrien-watershed-sculpture/. 


\title{
13 Hydrocitizenship
}

\section{Concepts and insights from the Lee Valley, UK}

\author{
Graeme Evans
}

\section{Introduction: hydrocitizenship and urban rivers}

Urban river systems represent one of the last vestiges of human-nature interaction. They are tangible sites for hybridity between nature and society (Latour 1993). In cities such as London, the rivers have been contained and engineered both to reduce the risk of flooding of urban settlements and infrastructure and to provide the conditions for commercial development and public access. The state of our rivers also reflects the global realities of population growth, urbanisation and related climate change, and global-local responses to this phenomenon such Millennium Development Goals, Sustainable Development, Local Agenda 21 and European Water Directives.

The increasing demand by citizens and environmental organizations for cleaner rivers, groundwater and coastal beaches has been evident for some time. This was recently reconfirmed by a poll of all $25 \mathrm{EU}$ countries (Eurobarometer 2012). When asked to list the five main environmental issues that Europeans are worried about, results for the EU25 showed that nearly half of the respondents were worried about "water pollution" (47\%), with individual ratings as high as $71 \%$. European Water Policy therefore seeks to clean polluted waters, and to ensure they are kept clean. In achieving these objectives, the roles of individuals and citizens' groups are seen to be crucial. The EU Water Framework Directive (WFD) was adopted in 2000 with the year 2015 as the target date for getting all European waters into 'good condition.' However, England \& Wales missed the 2015 "good status" target by some way, with $46 \%$ of water bodies failing to meet water quality standards by this date (HoC 2015). In fact, over $50 \%$ of European surface waters were forecast to fail to meet this standard by the due date (EEA 2012).

In the UK, population growth, the densification of land use and housing and the opening-up of former industrial waterfront areas has on the one hand increased our exposure to water, but on the other hand has created pressures on the water and sewage systems. Domestic pollution, road run off, storm surge and recreational water use have replaced what was heavy industry and dockland activity as reasons for pollution; but the legacy of those past disturbances remain in our contemporary waterscapes. Water and related urban ecosystems 
have therefore seen as objects to be 'rediscovered' and promoted to beneficiaries beyond those who have traditionally worked on rivers and canals. This physical, social and economic transformation has created a new type of steward and stakeholder base from what was formerly a small, largely closed group of local users and workers in the canals, reservoirs and transfer points along the river system. This has in turn generated a complex new governance and legislative system both to manage the water resource and the associated 'risks' of flooding, water quality, safety and conflicts between users (Nones 2016). Meanwhile, at a local level, communities have to respond to these external changes to large-scale waterfront regeneration as the river becomes a contested place for urban development, and to the prosaic operational responsibilities of access, maintenance, ownership and usage. This new relationship between stewards, stakeholders and residents and users of the river system has therefore created a need and space for a new form of river governance, represented here through the notion of 'hydrocitizenship.'

To analyse this concept, this chapter presents a critique of the Lea River Basin landscape, and human-nature inter-actions that have shaped it over the past fifty years. The Lee Valley has been the subject of in depth investigation as part of a research project entitled "Towards Hydrocitizenship," a three-year study of continuity and change in this river catchment. The study engaged communities and other stakeholders in relation to the urban water system. Within social-hydro relations, as in other contexts, citizenship can be understood in diverse, contradictory ways, including, for example, as a social contract, and an individual or moral responsibility which impacts on the practices of a community. There is a need to investigate and understand how particular socio-hydrological configurations (Swyngedouw 2009) are produced and how these contribute to potentially inequitable environmental conditions. Water issues generate specific and contentious forms of conflict within the eco-social fabric, which demand exposure and negotiation in any form of culture, and necessitate policy for addressing rights, sustainability and resilience. Hydrocitizenship is thus conceived as an enhanced awareness of, and sense of responsibility for, water as a vital, shared ecosocial resource. It implies ongoing processes of learning, negotiation and practice rather than a precisely defined/static position. In this sense hydrocitizenship is an important and underpinning subset of ecological citizenship (Dobson 2007). The challenges of developing (full) ecological citizenship are daunting, but hydrocitizenship is a relatively achievable step as 'water is everywhere' in political, cultural and ecological terms (Linton 2010), and an obvious medium of ecological and social connectivity, albeit in a complex, contested space of interconnected demands. Thus, hydrocitizenship has been developed as an interdisciplinary concept which seeks to investigate past, present and future water-society relationships in holistic, multi-issue, multi-site frameworks. It also seeks to engage directly with critical issues of global sustainability and environmental change in local/community settings by envisioning these 'macro' issues through the lenses of everyday relations and lived experience.

The hydrocitizenship project analysed here encompassed negotiating the complex governance arrangements and shifting relationships between new and 


\section{Graeme Evans}

established stewards and both incoming and incumbent resident communities. In the Lee Valley, new housing and migration (social, economic, leisure) has generated a human flow mimicking the flow of the river: a flow that is congruent with upstream-downstream relationships. Thus, this project required a multi-disciplinary approach to understand this historic and socially constructed landscape that has brought together social and environmental scientists with practising artists, attempting to work in collaboration with host communities, intermediaries and stakeholders; to co-design a grounded theory/heuristic framework.

\section{River governance in the Lee Valley}

The spatial and political complexity of river systems presents particular challenges for governance and issues of access, conservation and ownership. In the UK and in its devolved regions, a patchwork of government departments, agencies, water companies, river catchment partnerships and local authorities, alongside a host of voluntary organisations from environmental charities to recreational users and clubs, has been generated in response to such challenges. This includes privatised former public utilities which replaced the Water Boards in 1989; only the UK and France have their water companies in private ownership (Hall and Lobina 2008). A dominant concern is flood defence and reduction of risk from flooding; in urban river systems, particular emphasis is given to storm surge and other extreme events, and the management of waste and water quality. Organisations such as the Environment Agency and Internal Drainage Boards have statutory responsibility for water level management and flood mitigation, as well as a mandate for securing water quality in accordance with the EU Water Directive.

The River Lee and its tributaries, canals, reservoirs and riparian communities was one of four case study areas selected for the hydrocitizenship research project (the others being Bristol, Bradford/Shipley and Borth coast, Wales). Known as London's second river, the River Lee originates in the Chiltern Hills north of London and flows south where it meets the River Thames (Figure 13.1). The River Lee runs for 50 miles $(82 \mathrm{~km})$ and has tributaries such as the New River (an artificial waterway 20 miles $(32 \mathrm{~km}$ ) in length that was opened in 1613 to supply London with fresh drinking water), the Lee Navigation Canal (a further 28 miles [ $45 \mathrm{~km}[$ ), in addition to thirteen major reservoirs which continue to provide drinking water for the catchment area (over 500 square miles of flood plain). Several of these reservoirs are in the process of conversion to wetland nature reserves; these sites include visitor and education centres and pathways, allowing public access for purposes other than controlled use (e.g. for recreational fishing and birdwatching). As an indication of the river's amenity value and industrial past, over thirty pumping mills are located on the river, which today represent an important physical legacy and cultural heritage alongside a network of locks, bridges and other infrastructure.

For much of its upper reaches, the river runs through semi-rural and suburban residential areas, and then within or as a boundary to the Lee Valley Regional Park, a 10,000-acre, 26-mile-long linear park running through the 
northeast of London, Essex and Hertfordshire (Civic Trust 1964). This amenity is managed by the Lee Valley Regional Park Authority (LVRPA) and is made up of a diverse mix of countryside areas, urban green spaces, heritage sites, country parks, nature reserves and lakes and riverside trails, as well as sports centres for riding, boating, ice skating and cycling. In the lower reaches of the Valley is located the legacy from the London 2012 Summer Olympics, a site chosen for regional revitalisation in this otherwise nondescript inner suburb of east London. This place-making project seeks to transform the area into a new destination, and as a site for major new waterside housing

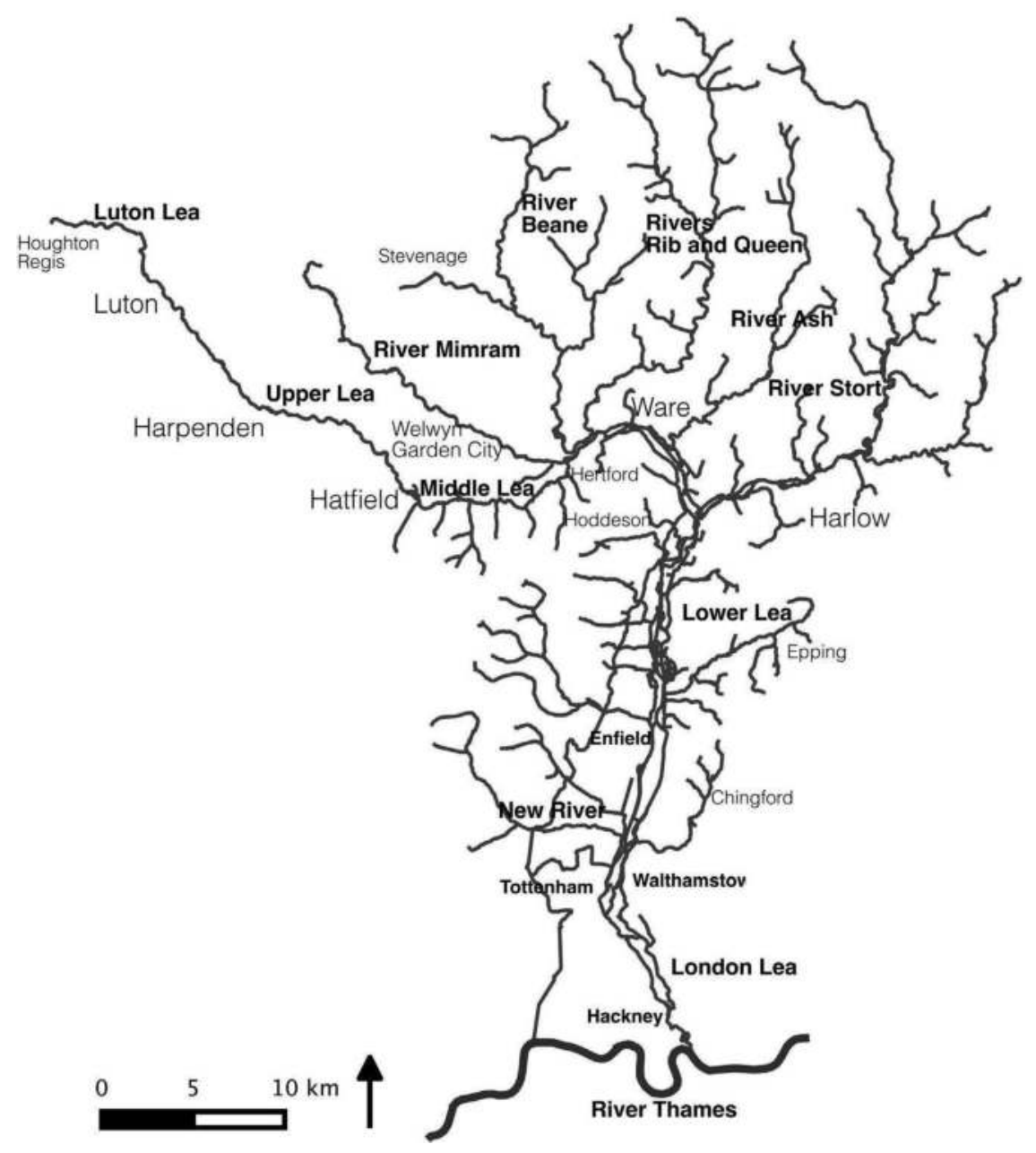

Figure 13.1 Lee Valley and neighbouring towns.

Source: the Author 
and associated retail, offices and a complex of educational/cultural facilities (Evans 2017). South of the Olympic park, the river's course is split, and it runs almost completely in man-made channels and canals that were originally created to power water mills, flowing through an area that was once a thriving industrial zone with a legacy of manufacturing and water engineering structures (Evans 2016). There is a high concentration of resident and practising artists around this area, which is the key for an annual arts festival and open studio events. These waterways also host a growing boat dweller population, some in marinas, but most in canal and riverside moorings. This catchment area is set to witness a five-fold population increase over the next $10-15$ years (Evans 2015a) as new urban villages are built and new communities are established, mostly on previously undeveloped waterfront land.

The expansive catchment of the Lee produces a spatiality that can be visualised firstly through maps. The extent of the watershed requires a scalar approach and 'zoning' for effective governance and for understanding how the river is perceived and experienced by various communities. This fragmentation of the river valley presents challenges for governance on the one hand, and on community responses and identities attaching to the river environment on the other. For example, where host communities are involved at the behest of water authorities, such involvement tends to be area and issue-specific (e.g. sustainable urban drainage, river clean-up, reed planting), with little consideration of mutual interactions ('upstream-downstream') between the "manifold characteristics and needs of the management of a river basin, so that when stakeholders are organised with dissimilar spatial references, water agencies may not be inclined to initiate and participate in multi-party stakeholder interactions" (Nones 2016, 1171). River systems and their governance present a multi-scalar challenge, which Lefebvre viewed through global, mixed and private levels of society, equated with the state, the urban and 'habiting' (or dwelling) (2003) in the 'politics of scale.' The state through national and local levels of government as well as supra-national (European Union) entities sets the legislative agenda, priorities, resource allocation and land use access conditions, and mediates goals such as National Ecosystems (NEA 2011) and environmental targets for water quality and habitat diversity. Urban authorities operationalise these policies and deliver local governance primarily in partnership with community and private organisations. An example in this case is the Lea River Catchment Partnership such as Thames 21 and the local Wildlife Trusts ${ }^{2}$ who are appointed by the government's Environment Agency to conform to the EU's Water Directive (Table 13.1). This catchmentbased approach encompasses engagement with local partners and users, including residents through local environmental improvements such as the installation of Sustainable urban waters Drainage ( $\mathrm{SuDs}$ ) schemes, reed bed planting and environmental education with schools (e.g. installing water butts and waterside planting).

The roles and relationships between stewards of the river environment and stakeholder organisations is summarised in Table 13.1. In some cases, stewardship and stakeholder characteristics are one and the same but as the governance system becomes more distant from the water ecosystem these roles divide and can come into conflict with one another. Responsibilities such as access, health and 
Table 13.1 Stewards and stakeholders in the Lee River system.

\begin{tabular}{|c|c|}
\hline Interest Group & Level-Stewardship and Stakeholding \\
\hline European Union (EU) DG & $\begin{array}{l}\text { European - Water Framework Directive } \\
\text { (WFD): water quality standards; } \\
\text { Integrated Coastal Zone Management } \\
\text { (ICZM) }\end{array}$ \\
\hline Environment Agency (EA) & $\begin{array}{l}\text { National - flood risk/defence, air \& water } \\
\text { quality }\end{array}$ \\
\hline Internal Drainage Boards (IDBs) & $\begin{array}{l}\text { Regional - storm water management, } \\
\text { watercourse maintenance and } \\
\text { improvement, adoption of Sustainable } \\
\text { Drainage Systems (SuDs) }\end{array}$ \\
\hline Canals \& Rivers Trust (C\&RT) & $\begin{array}{l}\text { National - canal access, safety, } \\
\text { maintenance; canal usage, visitor } \\
\text { management, boat usage, moorings }\end{array}$ \\
\hline $\begin{array}{l}\text { Lee Valley Regional Park Authority } \\
\text { (LVRPA) }\end{array}$ & $\begin{array}{l}\text { Regional - park/landscape and visitor } \\
\text { management, marina management, } \\
\text { leisure facility operator, planning (land- } \\
\text { use) authority, governance (33 London } \\
\text { Boroughs/riparian Counties) }\end{array}$ \\
\hline Love the Lea/Thames 21 & $\begin{array}{l}\text { Regional - conservation e.g. reed planting, } \\
\text { clean-up, SUDS } \\
\text { Catchment Partner (Lower Lee), Education/ } \\
\text { schools programme }\end{array}$ \\
\hline $\begin{array}{l}\text { Water Authorities, e.g. Thames Water } \\
\text { Authority }\end{array}$ & $\begin{array}{l}\text { Water quality, management and supply } \\
\text { Regional - visitor access and promotion }\end{array}$ \\
\hline $\begin{array}{l}\text { London Legacy Development Corporation } \\
\text { (LLDC) }\end{array}$ & $\begin{array}{l}\text { Regional - Olympic Park/zone and } \\
\text { waterways, facility and visitor/events } \\
\text { management; Planning authority, land } \\
\text { development, land/riverscaping }\end{array}$ \\
\hline $\begin{array}{l}\text { Wildlife Trusts (e.g. London, Herts \& } \\
\text { Middlesex) }\end{array}$ & $\begin{array}{l}\text { Local - public access to nature/reserves } \\
\text { (Walthamstow Wetlands, Woodberry } \\
\text { Wetlands); water heritage interpretation; } \\
\text { wildlife conservation and education }\end{array}$ \\
\hline Local authorities & $\begin{array}{l}\text { Local - local governance (via elected ward } \\
\text { councillors); Planning authority, housing, } \\
\text { recreation, access, revenue, licensing }\end{array}$ \\
\hline $\begin{array}{l}\text { Other landowners (e.g. property, farmers, } \\
\text { utility companies) }\end{array}$ & $\begin{array}{l}\text { Local - maintenance/management, access } \\
\text { (restricted) } \\
\text { Land values, protection, safety } \\
\text { Housing and property development }\end{array}$ \\
\hline Anglers/Fishermen & $\begin{array}{l}\text { Local - fish stocks and health, conservation } \\
\text { recreational amenity and competition } \\
\text { (e.g. Walthamstow Reservoirs Anglers } \\
\text { Club) }\end{array}$ \\
\hline Canoe/Rowing Clubs & $\begin{array}{l}\text { Local - river access and quality; recreational } \\
\text { amenity and competition (e.g. Lee Valley } \\
\text { Rowing Club) }\end{array}$ \\
\hline Boat dwellers & $\begin{array}{l}\text { Local - river access, flow, water quality } \\
\text { (also source of pollution, e.g. waste water, } \\
\text { litter); alternative housing, recreational } \\
\text { amenity, social network (Springfield } \\
\text { Leisure Cruiser Club Marina) }\end{array}$ \\
\hline
\end{tabular}


Table 13.1 (Continued).

\begin{tabular}{lc}
\hline Interest Group & Level - Stewardship and Stakeholding \\
\hline Birdwatchers & Local - nature conservation, ecosystem \\
& service; recreational amenity and \\
& competition (Wetlands Reserves) \\
\hline
\end{tabular}

Source: the Author

safety and flood prevention are also scalar, through national, regional and local levels of interest and control.

A key role of the governance of river and water management is balancing and resolving conflicts between the needs and interests of different user groups. At a meta-level this is encapsulated in the tenets of sustainable development which necessitates policy changes and greater coherence between sectors, requiring: "integration of objectives where possible; and making trade-offs between objectives where integration is not possible" (Dalal-Clayton and Bass 2002, 7). The current development of the Lee Valley and river system project is based on this concept. However, conflicts of interest occur on the ground between different user groups, for instance between anglers, birdwatchers and canoeists and walkers. While anglers and birdwatchers would need a quiet environment, canoeists and walkers may disturb or frighten fish and birdlife. In addition, birds of prey such as herons and cormorants can compete with anglers for their catch. The opening up of waterside areas and the creation of 'reserves' for visitors and educational/observational research clearly presents a challenge to the previously exclusive access granted to groups such as anglers and birdwatchers. For example, Walthamstow Reservoirs (owned by Thames Water as a commissioned water supply), a place currently undergoing transformation into an accessible wetland for visitors, was previously a fishing ground. Not surprisingly, the Anglers Club members see no benefit in opening access and interpretation of these water assets for a wider public.

Managing these reserves, which falls under the mandate of local Wildlife Trusts, also necessitates direct intervention to maintain ecosystem biodiversity. Biodiversity and ecosystems are closely related; the concepts of diversity and variability are important for managing each of them. There are many ways of considering 'diversity,' such as the number and abundance of species, their distribution in an area, and different types of interaction pathways. For example, planting reed beds, removing invasive plants, breeding fish stocks for the reservoir and culling Canada Geese and virile crayfish ${ }^{3}$ are all considered direct interventions that are helpful for the diversity of the local biota.

Currently a particularly problematic conflict is intensifying around resident canal boat dwellers and the Canals \& Rivers Trust (C\&RT - see Table 13.1). The Trust's policy has shifted towards recreational use of the canals and waterways, including revenue-generating activities that take the focus away from a residential community of boaters. With few permanent moorings, an increasing number of boats move from temporary mooring to temporary mooring to comply 
with C\&RT rules that seek to enforce shorter stays to restrict peripatetic waterborne living. Families with children at local schools and accessing work locally are effectively forced off the space of their dwelling (i.e. the river-as-home). This situation is exacerbated by population growth in these waterfront areas, the unaffordability of housing in London in general and in these waterside locations in particular, which is increasingly more expensive to rent or buy. ${ }^{4}$ Privatisation of moorings also exploits excess demand and is detrimental to this lifestyle. The focus on the visitor economy is therefore at odds with a section of traditional 'stewards' and river users - for example, in Hackney Wick, located in the lower Lee, the local E20 Fishing Trust has been displaced by the C\&RT who evicted this angling group to acquire their premises (to be used as a visitor centre). Ironically the Canal \& Rivers Trust promotional programme and narrative is titled Humans of the Waterways. ${ }^{5}$

This mediation between state-professional-community has created a hierarchical governance system with a complex system of many licences, permissions and barriers. Direct action and access to the river is increasingly difficult unless conducted through the relevant agencies, which makes it difficult for locals or user communities to engage with these waterways. Through the hydrocitizenship concept, expectations are that awareness of the value of ecosystems and urban nature and greater citizen responsibility and governmentality will arise out of this form of inclusive engagement. In addition, resilience in the face of climate change, improved access and recognition of amenity values (or 'cultural ecosystems values'; NEA 2011) are also expected outcomes.

\section{Social production of river space}

A particularly helpful conceptual framework for understanding the construction of space in the context of the Lee Valley watershed can be derived from Lefebvre's triad with respect to the river's governance, perceptions and the scales at which these operate. Firstly, conceived space can be characterised by the representations through which dominant groups define space - specifically the spatial representations which urban designers and scientists employ. Here representations of space "are tied to the relations of production and to the 'order' which those relations impose, and hence to knowledge, to signs, to codes, and to 'frontal' relations" (Lefebvre 1991, 33). They also refer to "conceptualized space, the space of scientists, planners, technocratic subdividers and social engineers, and of a certain type of artist with a scientific bent - all of whom identify what is lived and what is perceived with what is conceived" (Lefebvre 1991, 38).

Here, urban planners, landscape architects, environmental scientists, water engineers and 'environmental' artists (including writers, poets) dominate the discourse and imagery, and both the interpretation and design of the waterways. This includes the important role that landscape architects and designers have in river walkways and in parkland design and selective interpretation. In a study of the new Olympic Park which abuts the River Lee and Navigation canal, Snaith (2014) found that landscape traits such as presence of natural plants, semi-natural 
or pastoral landscapes and wilder or picturesque characteristics such as perennial flower plantings, meadows, marshland nature reserves were strongly preferred by people claiming white British ethnicity, but such traits were not seen as important by 'non-white' British groups (the majority of the population in the lower Lee riparian boroughs). Other key representations of river space as conceived and 'represented' by scientists and planners are described in binary terms such as safe/unsafe, accessible/inaccessible, and through flood risk maps which designate areas according to different chances of flooding based on statistical probability of inundation. While such maps claim scientific objectivity, they rely on crude modelling and timelines ( 1 in 100 years, 1 in 1000 years) and they do not reflect lived experience and knowledge from 'below' (i.e. those who have the most direct experience of extreme natural events over time are not consulted for map-making). This highlights Forsyth's point that "environmental explanation needs to incorporate the views and experiences of people living in (effected) zones to be both biophysically accurate and socially relevant" (Snaith 2014, 147).

Secondly, perceived space embraces the idea of social practice; in this sense space is a social product. Spatial practice refers to the production and reproduction of spatial relations between objects and products, including ecosystems services (human "benefits" from nature - NEA 2011). It also ensures continuity and some degree of cohesion: "in terms of social space, and of each member of a given society's relationship to that space, this cohesion implies a guaranteed level of competence and a specific level of performance" (NEA 2011, 33). This is consonant with the notion of governmentality. This dispersed form of power (Foucault 1991) seeks to "shape, guide or affect (our) conduct ... to act on the conduct of conduct" (Gordon 1991, 2), thereby influencing the actions of others through processes which encourage self-regulation. Behaviour towards the river - what is permitted, who can (or cannot) access and for what activities - is therefore not just a question of governance, but is a 'governmental' process based on formal rules. This implies a degree of permission and compliance which may not be generally held by, or be within the reach of, most individuals. In our case, river-based stewards hold local knowledge and status, whilst incumbent riparian residents possess both a historic and symbolic association with the river, which may be based on family/historic activity (i.e. work), type of access or skills. To others, 'outsiders,' including new urban settlers and visitors, this hydro-relationship is more vicarious and amenity/property based - reflected in the idea of ecosystems services and its underlying economic (cost-benefit) value system (NEA 2011).

Thirdly, lived space encompasses the spatial representations which 'ordinary' people make in living their lives, the mental constructs with which they approach the physical world. In this case, such representational spaces refer to space lived directly "through its associated images and symbols and hence the space of 'inhabitants' and 'users'" (Lefebvre 1991, 39). This is also bound up with the perceived and conceived notions of this river space, which have tended to bring negative associations (e.g. fear of crime, pollution) and images of an unsafe, unwelcoming watercourse reinforced through historical associations, oral history and media, but one that still forms a strong symbolic and physical bond with its 
constituents who may also have experienced it at other times through pleasant if prosaic interactions (e.g. child and dog walking), and special events. This is reflected in the perceptions and experiences expressed by participants in cultural mapping exercises carried out along the river (see next section). This area of the Lower Lee Valley, once a neglected marshland then a neglected industrial zone and dump for the city's waste, is currently gentrifying at a rapid pace. New residents and recreational visitors to this "edgy" enclave that stimulated artists sit uncomfortably amongst social housing and elderly community residents. It is the lived experience and day-to-day relationship with the river that stands to suffer most from wholesale regeneration of the waterfront through place-making and intensification of land and space usage.

\section{Analysing the Lee Valley as a lived river space of hydrocitizens}

In our study, productions of space were assessed through documentary and discourse analysis of land use plans, policies and governance systems, primarily through regional (meso-level) urban authorities and professionals who carry the main state-led responsibilities. The project 'conceived' this urban water space through visual and technical representations of its usage, development potential and access; issues such as flood mitigation, land use planning/zoning, economic development and regeneration, water and environmental quality, recreation, heritage and nature conservation were all analysed for this purpose. Communication of plans and policies relies heavily on maps (including digital data analysis) at varying scales, and the use of visuals ('artist impressions,' graphics, photos), technical specifications and quantitative data and forecasts. To provide an alternative and a more qualitative and experiential view of the valley landscape, a series of connected walks were undertaken, providing a visual and textual narrative of the different sections and features of the river and its environs (Read 2015). Stakeholder analysis was done with administrative agencies and with local organisations (Table 13.1). Participatory-GIS (Geographic Information System: GIS-P) method was used to capture spatial characteristics of the valley, to gain insight to the perceptions, usage and aspirations of different communities along the river, as well as to map citizen-science installations, festival events and walking narratives of the river itself.

A first step testing out the relationship between the lived space of outside users and that of the riparian residents employed cultural mapping (Evans 2015b) with participatory GIS (GIS-P) to capture perspectives based on cultural ecosystem values of the local. GIS was helpful to analyse responses from communities that were 'hard to reach,' and from those less able to access or comprehend 2D designs, maps or access ICT facilities. In view of its spatial data analytical and visual capability, GIS-P is particularly applicable to the design of urban environments, including transport and mobility, wayfinding, crime and community safety, the design of open space and in capturing and presenting scenarios around a range of environmental scenarios such as flood risk and pollution (Cinderby et al. 2006). 


\section{Graeme Evans}

Perspectives on local cultural ecosystems were collected initially from a meeting with residents and ward councillors held in a canal-side location in Hackney Wick, and were later analysed to derive local community values (Ryan 2011). These exercises were repeated in different locations (e.g. marshes, wetlands), reflecting different user and geographic characteristics. The following categories and from the Millennium Ecosystem Assessment (2005), and Plieninger et al. 2013) were adopted for analysis:

- Use: sense of place, activities, recreation;

- Aesthetics: aesthetic values, spiritual values, inspiration;

- Cultural Use: recreation, social relations, cultural heritage values, knowledgel educational systems;

- Problems: accessibility, safety, unpleasant; and

- Community Cohesion: diversity, involvement.

Participants (Figure 13.2) were asked to identify recreational uses, cultural uses and problem areas. A set of socio-demographic questions was also asked regarding gender, age, home postcode and familiarity with the study area; the responses to those questions could be matched with comments and marks annotated on the map. After the workshop, the data was transferred to a database and entered onto

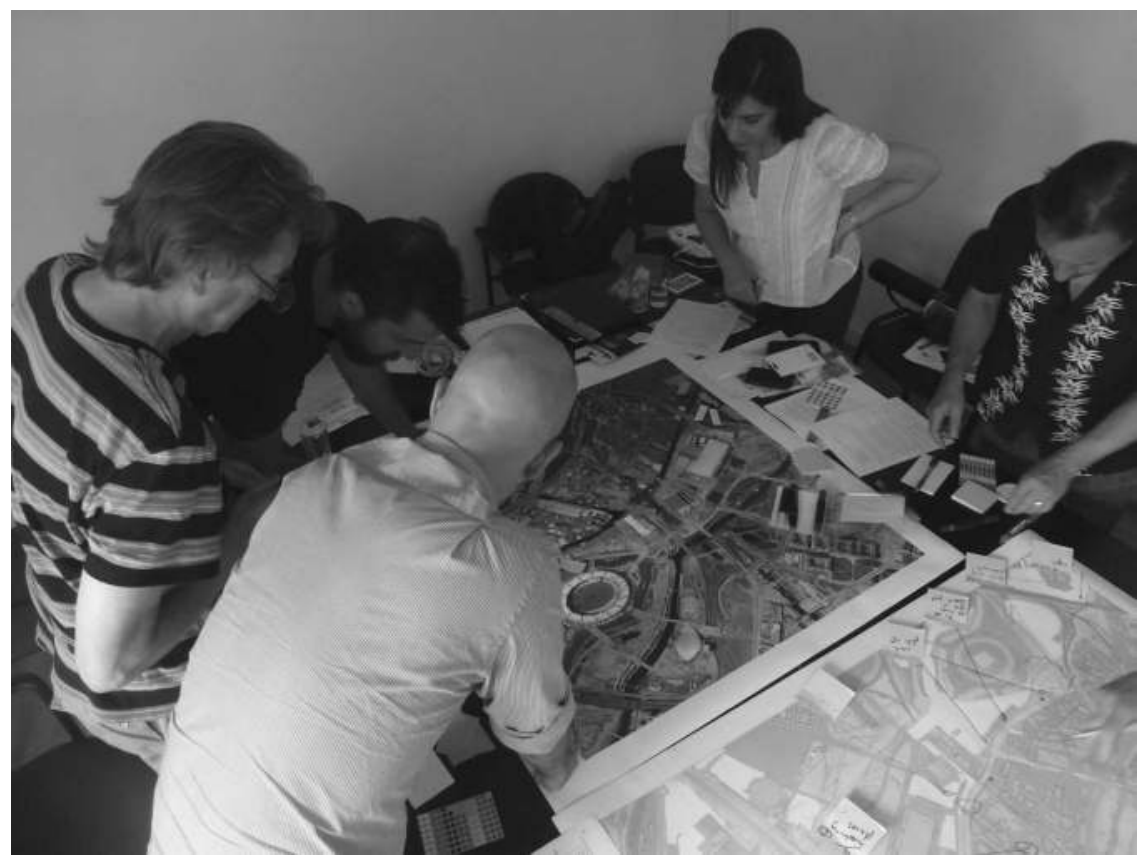

Figure 13.2a-c Cultural ecosystem mapping, Hackney Wick, lower Lee Valley.

Source: the Author 

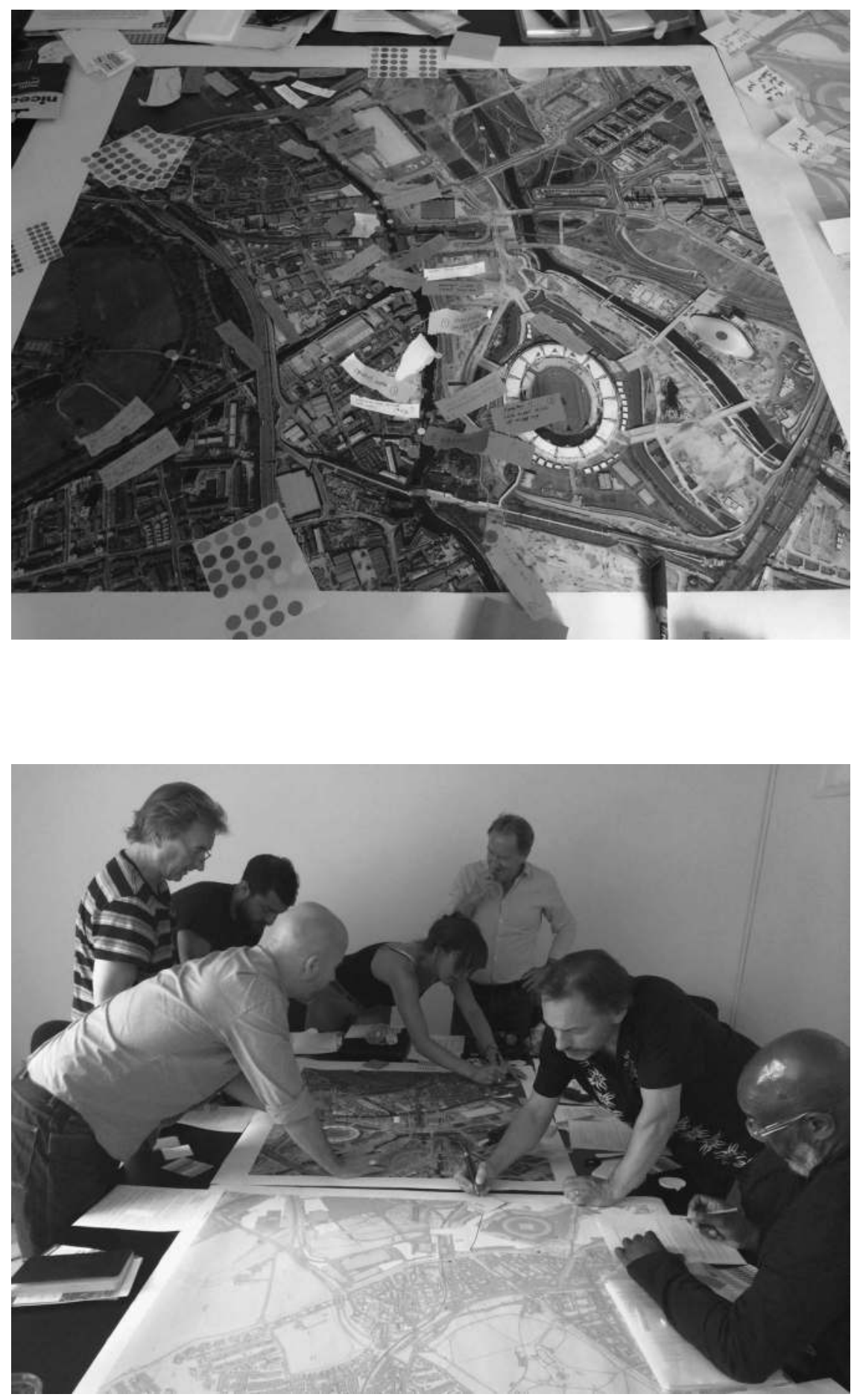


\section{Graeme Evans}

GIS. One benefit of this cultural mapping is that primary data and visualisations can be layered with other data such as environmental, demographic and land use; allowing analysis of correlations, convergence/divergence between lived experience and formal, scientific conceptions, and representations of space. It also provides an opportunity for subsequent iterations to be compared and merged to produce a cumulative picture (see www.leevalley.org).

The most common use of the canal/river was walking along and sitting by it. Walking around the wetland area, Victoria Park and Wick Field was also mentioned as one of the specific activities that participants enjoy doing. The Queen Elizabeth Park was opened in April 2014 and several changes and new landscaping were identified. However, Hackney Wick locals did not 'connect' to the east of the canal and there were not many reports of them using the facilities there. Anecdotal evidence suggests that there is a marked (and historic) spatial divide between the west and east neighbourhoods adjoining the Lee river/canal (and new Park), despite newly created bridges and walkways. This divide is both territorial and a reflection of safety issues (e.g. fear of crime, vandalism, falling into the water). Thus, the divide generated by River Lee is both physical and symbolic, despite efforts to create links across it.

Aesthetic values were most commonly mentioned with the places the participants enjoy most, such as watching the lock/gates, walking/sitting at the woodland and cycling along the marshes. The main problems that were mentioned around the canal/river were of rubbish and safety. Participants felt unsafe along the canal at night as there were several mugging incidents in this area. Scariness was also ascribed to certain areas. These incidents and threats also overlap with the places that people enjoy during the daytime (walking/cycling/sitting), clearly exhibiting that individual river features and locations contain multiple and contradictory meanings, depending on the respondent and other circumstantial conditions. Participants also highlighted accessibility issues for the bridges on the canal, and the presence of algae on the canal during the summer. Some of the spiritual and inspirational values were affected by the changes in the area, for instance 'relaxing the by canal' was stressed as having a spiritual value - except for the (increasing number of) passing cyclists. Other spiritual values mentioned were 'watching sunsets during the summer' over the canal and 'walking under the open skies over the park.'

There are several heritage assets in this area that mainly arise from its industrial background. Old Ford Locks dating from 1865, with walls of Kentish ragstone along the west bank of the River Lee, was referred to by participants as the 'ghost of industrial past.' Queens Yard was also highlighted - a cluster of buildings from different periods providing public access to the canal frontage. Crate Brewery was a local company which produces craft beer in the area and the adjoining café was mentioned as the most popular destination for participants, who visited those locations both to socialise with their friends and meet new people by the canal. The landscape of this former industrial area increasingly reflects the changing economy and the livelihoods which are supported by the improved transport connections and regeneration of the waterfronts - cultural and creative industries with associated café culture, entertainment and events which visitors 

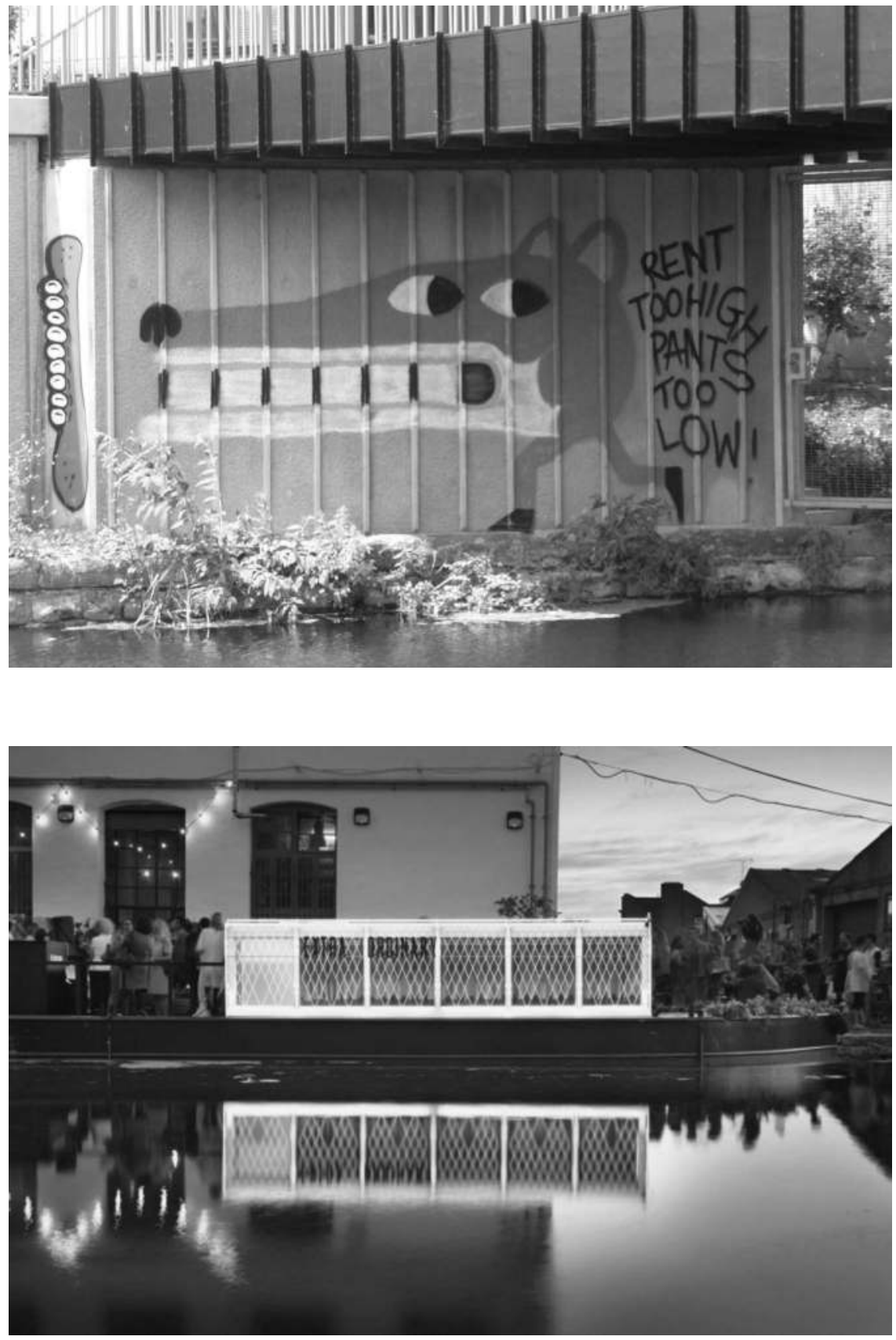

Figure 13.3a-b Graffiti and floating cinema, Hackney Wick, lower Lee Valley.

Source: the Author 


\section{Graeme Evans}

clearly value (longer established residents less so). Such change has led to makeover and in some cases removal of heritage buildings and infrastructure. At the same time, the conditions which attracted artists and alternative lifestyle (such as canal boat dwellers) are changing, leading to the loss of artist workspaces and studios, live-work accommodation and affordable housing (Figure 13.3). The river in one sense is a benign backdrop to this gentrification process, but then it also plays host to floating cinemas, cafes and pleasure boats, and the culvertisation and clean-up has removed its natural character.

\section{Conclusion: an emerging hydrocitizenship}

How does the lived river space of the Lee shape responses to this environment and help form a consciousness of river governance? The dominant narrative, as with urban development more generally, is through spatial 'zoning' and largescale masterplans which attempt to categorise the river's various separate functions such as industry, recreation, heritage, flood mitigation and environmental quality. Specific interventions can vary according to land-use types (semi-rural, suburban, to urban and industrial areas), with greater intensity of engagement and impact evident in the more urban parts of the catchment. Governance and initial attempts at hydrocitizenship tend to follow these spatially determined functions, and are largely single issue and risk-based (Nones 2016). At this stage, the river is still not represented as an integrated and fluid whole. Perceived key roles are conservation volunteering, greater environmental awareness and personal actions (e.g. waste disposal, recycling, water usage), as well as engagement with the water amenity through a more explicit visitor economy - exploiting the 'willingness to pay,' rather than free access and use.

Thus, the spatially conceived river valley is managed through river catchment partnerships that administer environmental improvements, education and promotional programmes, but do not challenge the underlying ownership or access powers. This results in confusion and contradictions over who has and should take responsibility for different aspects of the river - from rubbish collection on the river/banks, lighting, recreational and commercial usage and access, to heritage interpretation and conservation (natural and cultural, e.g. buildings). The everyday river experience aims to remedy this problem and address this hierarchical patchwork through bringing residual and dispersed local knowledge into play; notably, knowledge of established river dwellers (boaters, workers, local landowners - past and present) and residents whose memories transcend the decades of industrialisation-deindustrialisation and rediscovery of the waterfronts, are deemed particularly important for perceiving the river as an organic whole. Of course, such knowledge is augmented by perceptions of new settlers, artists and community groups who adopt this river heritage as their own. As a local resident put it: "I have been travelling all over the world, many times. It's not that I am everywhere, but everywhere is inside of me." This is true of the Lee Valley. We base our individual discoveries on the idea that both the place and we ourselves are new, or renewed by the dialogue between place and ourselves. It 
is not a general Lee Valley but my Lee Valley (Sinclair 2010, 23); and this is the first meaningful step in a more personalised form of citizen governance, i.e. that of 'hydrocitizenship.'

In terms of citizen engagement in supposedly consultative processes such as the European Water Directive and Catchment Partnerships (Nones 2016), local stakeholders are generally not engaged in the decision-making or (master) planning processes from the outset; resulting in controversial decisions and public opposition, which can foster negative consequences for freshwater ecosystems. As Raymond Williams argued: "to achieve (cultural) growth, varying elements must be equally available and new and unfamiliar things must be offered steadily over a long period to make general change" (Williams 1961, 365). It is these gradual and sustained partnerships between the stewards and local communities that is likely to have a lasting effect on our attitude to rediscovered urban water landscapes, as opposed to grand schemes such as apartment blocks, cultural and educational institutions, heritage centres, new parks and festivals and destination strategies that are prone to be influenced by vested interests, risking both a commodification of the river and a distancing from the river ecology. This is particularly important as tension and divergence between the stewards and stakeholders in the governance of the river is becoming more apparent as public agencies move towards a visitor-based and economic rationale and a 'risk-averse' mindset, exploiting or closing off the river environment as a valorised amenity rather than a public good.

This study also highlighted the need to conduct citizen-based research as a 'process' and through participatory and innovative methods. As our rivers are increasingly shaped by human movements and material flows, which in turn are influenced by those rivers, a discursive space created by a reflective research process like the one described in this chapter is equally important for generating a sense of hydrocitizenship, as are specific practices and programs that facilitate responsible and thoughtful engagement with some of the few natural ecosystems left in the city.

\section{Notes}

1 Hydrocitizenship has been funded (2014-2017) as part of the UK Arts \& Humanities Research Council (AHRC) Connected Communities research programme www. hydrocitizenship.com with the Lee Valley one of four area-based case studies (www. leevalley.org) led by a team from Middlesex and Brighton Universities.

2 http://www.riverleacatchment.org.uk/ The Catchment Based Approach (CaBA) embeds collaborative working at a river catchment scale to deliver improvements to water environments. Community partnerships, bringing local knowledge and expertise, are active in each of the 100 Water Framework Directive catchments across England. Organisations engaged with CaBA include NGOs, Water Companies, Local Authorities, Government Agencies, Landowners, Angling Clubs, Farmer Representative Bodies, Academia and Local Businesses.

3 The UK's only native 'white clawed' crayfish was wiped out along the River Lee after an invasion of the signal crayfish in the 1980s and the associated spread of crayfish plague. 


\section{Graeme Evans}

4 In 2015, the number of 'continuous cruisers' on London's waterways increased by a third over the previous year, with over 5,000 boats without a permanent mooring.

5 Canal Rivers Trust https://canalrivertrust.org.uk/humans-of-the-waterways?utm_ source $=$ Canal $\% 20$ River $\% 20$ Trust\&utm_medium $=$ email\&utm_campaign $=$ 1271503_Solus-Great-Nature-Watch-110716\&utm_content $=$ HOTW\%20 header\&dm_i=2GFS,R93J,4MMWIE,1VPU4,1.

\section{References}

Cinderby, S., Forrester, J., and Owen, A. 2006. A Personal History of Participatory Geographic Information Systems in the UK Context: Successes and Failures and Their Implications for Good Practice. Royal Geographical Society Annual Conference, London, August-September.

Civic Trust. 1964. A Lea Valley Regional Park. London: Civic Trust.

Dalal-Clayton, B., and Bass, S. 2002. Sustainable Development Strategies: A Resource Book. London: Earthscan.

Dobson, A. 2007. "Environmental Citizenship: Towards Sustainable Development." Sustainable Development 15(5): 276-285.

EA. 2005. Preparing for Climate Change Impacts on Freshwater Ecosystems: Literature Review and Proposal Methodology. Science Report: SC030300/PR. London: Environment Agency.

EEA. 2012. More Than Half of EU Surface Waters Below 'good' Ecological Status. Brussels: European Environment Agency. www.eea.europa.eu/highlights/more-than-half-of-eu.

Eurobarometer. 2012. Attitudes of Europeans Towards Water-Related Issues. Flash Barometer 344. Brussels: Director General of the Environment.

Evans, G. L. 2015a. "Designing Legacy and the Legacy of Design: London 2012 and the Regeneration Games." Architectural Research Quarterly 18(4): 353-366.

Evans, G. L. 2015b. "Cultural Mapping and Planning for Sustainable Communities." In Cultural Mapping as Cultural Inquiry, edited by C. Duxbury, 45-68. London: Routledge.

Evans, G. L. 2016. "The Lee Valley: An Industrial River System and Heritage Landscape.” In Patrimoni e Paesaggi Costruiti Dall'acqua, edited by M. Vanor, 90-101. Milan: Mim Edizioni Srl.

Evans, G. L. 2017. "From Albertopolis to Olympicopolis - Back to the Future?" VEAA Journal 8: 1-15.

Forsyth, T. 2001. "Critical Realism and Political Ecology." In After Postmodernism: Critical Realism? edited by A. Stainer and G. Lopez, 146-154. London: Athlone Press.

Foucault, M. 1991. "Governmentality." In The Foucault Effect: Studies in Governmentality, edited by G. Burchell, C. Gordon, and P. Miller, 87-104. London: Harvester Wheatsheaf.

Gordon, C. 1991. "Governmental Rationality: An Introduction." In The Foucault Effect: Studies in Governmentality, edited by G. Burchell, C. Gordon, and P. Miller, 1-52. London: Harvester Wheatsheaf.

Hall, D., and Lobina, E. 2008. Water in Europe. Public Services International Research Unit (PSIRU). London: University of Greenwich.

HoC. 2015. Water Framework Directive: Achieving Good Status of Water Bodies. Briefing Paper CBP 7246, 27 November. London: House of Commons Library.

Latour, B. 1993. We Have Never Been Modern. Cambridge, MA: Harvard University Press.

Lefebvre, H. 1991. The Production of Space. Translated by D. Nicholson-Smith. Oxford: Blackwell. 
Lefebvre, H. 2003. The Urban Revolution. Minneapolis: University of Minneapolis Press Linton, J. 2010. What Is Water? The History of a Modern Abstraction. Vancouver: UBC Press.

Millennium Ecosystem Assessment. 2005. Ecosystems and Human Well-Being: Synthesis. Washington, DC: Island Press.

NEA. 2011. National Ecosystems Assessment. London: DEFRA.

Nones, M. 2016. "Is Public Participation an Added Value for River Basin Management?" European Planning Studies 24(6): 1159-1174.

Plieninger, T., Dijks, S., Oteros-Rozas, E., and Bieling, C. 2013. "Assessing, Mapping, and Quantifying Cultural Ecosystem Services at Community Level." Land Use Policy 33: 118-129.

Read, S. 2015. Walking Narratives of the River Lee. Lee Valley Hydrocitizenship. London: Middlesex University.

Ryan, R. L. 2011. "The Social Landscape of Planning: Integrating Social and Perceptual Research With Spatial Planning Information." Landscape and Urban Planning 100: 361-363.

Sinclair, I. 2010. "Water Walks." In Towards Re-Enchantment: Place and Its Meanings, edited by G. Evans and D. Robson, 13-28. London: Artevents.

Snaith, B. 2014. Why the Olympic Park Is a Successful Multi-Cultural Landscape. London: Landscape Institute, 7 May.

Swyngedouw, E. 2009. "The Political Economy and Political Ecology of the Hydro-Social Cycle." Journal of Contemporary Water Research 8 Education 142(1): 56-60.

Williams, R. 1961. The Long Revolution. London: Pelican. 


\title{
14 River Tourism
}

\author{
Malcolm Cooper
}

\section{Introduction}

In a previous book on river tourism, the author recognized that rivers have a multitude of uses, not all of them compatible with their appropriation as tourism resources (Prideaux et al. 2009). Rivers can be used as the boundaries for municipal, regional, and national political entities, while at the same time provide water supplies, waste water carrying capacity (less now but still apparent), a means of transport, and have a religious connection (again, less now but still apparent in countries like India), a cultural and historical connection, and often a background scenic value for communities and travelers alike (Cole 2007). Given all these attributes, it is not surprising that rivers have occupied an important place in human history (Lloyd 2002; Stanley et al. 2003; Cerveny and Cerveny 2006). They provided the water and fertile alluvial plains that sustained the first human settlements, and in so doing assisted the accumulation of wealth based on agriculture and trade. The great civilizations of the past developed (Grzymski 1993; Rice 1999) on the banks of the Indus, Nile, Tigris, Euphrates, Mekong, Rhine, Danube, Yangzi, and Yellow Rivers, and in the 21st century rivers continue to be closely associated with cities. However, another association has recently emerged; they are now a major tourism resource (Arlt and Gequn 2009; Cooper and Prideaux 2009).

In both rural and urban settings rivers appeal to communities because they retain much of their natural capital value while offering opportunities for swimming, fishing, boating and other forms of recreation. In the riverscapes of today tourists find opportunities for water-centered recreational activities, as well as enjoyment of the urban-river cultural landscapes that have emerged over the years. Rivers also provide opportunities for recreational cruising. However, rivers are also sensitive to human intervention, and in many riverine systems the ecosystems they support are showing considerable stress from irrigation, catchment deforestation, pollution, dam construction, and other types of intervention. Rivers as a major tourism resource provide spectacular settings, recreational opportunities, waterfront landscapes, but this complicates their use as a means of transport, and as an essential source of water for human consumption.

The world's great rivers have long intrigued travelers; Herodotus, describing a journey to Egypt in 450 BCE writes that when the Nile overflows "the whole 
of Egypt becomes a sea, and only the towns stick out above the surface of the water. When this happens, people use boats right in the middle of the land and not just along the course of the river. Anyone going from Naucratis to Memphis sails right by the pyramids" (Carson 1994, 22). In this regard, Hulme and Youngs (2002), Prideaux and Lohmann (2009), and Lloyd 2002 suggest that writing and travel have always been intimately connected, especially through experiences involving rivers. While the traveler's tale is a form of fiction, it is also a form of travel marketing as old as travel itself. Rivers have thus been considered as having an equally important place with sea voyages and overland travel as the setting for travel in ancient times, and from a tourism perspective, travel writing has been the marketing mechanism that fired the imagination of readers into concrete action as travelers. Many of the themes associated with travel writing in the modern era can be found in the earlier writings of Ibn Battuta and Marco Polo (Hulme and Youngs 2002). Their accounts of the events and attractions (and repulsions!) encountered fascinated readers in the later Middle Ages and Renaissance eras in Europe and throughout the Middle East, offering a different form of travel narrative to those of the pilgrimages and stories of warfare that had dominated earlier writing. Even later, such writing also provided an impetus to the exploration (and exploitation) of the rivers that they had encountered (Popescu 1991; Winchester 1996).

The use of such writings for the purposes of mass tourism in the 20th and 21 st centuries has thus been important, but required also the toning down of the more 'unsafe' aspects of adventure in the river basin context (Prideaux and Lohman 2009). For example, Borthwick (2002) describes travels on the Amazon as a more restrained journey, of the type more likely to be encountered by the average tourist rather than the explorative exploits of writers of the past. Similarly, other major rivers like the Yangtze River of China have proved as equally fascinating for travel writers at least since the Tang Dynasty (8th century), and up to the modern era (Winchester 1996; Hessler 2001). The logical outcome of this requirement though is that many of the writings on river as tourism resources are designed more for promotional purposes. Thus, Shaw (2007) provides a travel guide of the Yangtze river from Chongqing to Wuhan that is written not to evoke the spirit of adventure and recount personal adventure as are the accounts of Winchester and Hessler or the ancient writers, but as a 'how to do it' guide to creating a personal adventure (Prideaux and Lohmann 2009).

In the modern era, this approach is contained in the presentation of much of the information on the Nile Valley, for example, as an important tourism resource for Egypt, or in the information provided on the cruises along the Amazon, Volga, Danube, and Mississippi that support large day and overnight river tourism industries. In addition, tourism icons created by fluvial geomorphological processes have become major national and international attractions, including places like the Grand Canyon (Colorado River), Victoria (Zambesi River), and Niagara Falls, the iconic harbors of Rio and Sydney, and the many other similar attractions. The myriad of rivers that exist on this planet are capable of hosting recreation possibilities ranging from fishing to canoeing, and draw visitors from nearby or far localities. Surprisingly however, little research has been undertaken 


\section{Malcolm Cooper}

into the patterns of use that have emerged from the extensive role of rivers in the tourism industry, or into the impact of this situation on the social life of host riverine communities.

One of the regions that has seen a continual rise in river tourism, and in the documentation of this in relation to its social impact as well as its environmental impact is Europe (Erfurt-Cooper 2009). The interest in travel along European waterways has, for example, revived a form of passenger transport that began at least two millennia ago (Steinbach 1995; Baranowski and Furlough 2001). Europe's waterways have a long history of having been utilized to transport freight and people from one settlement or country to another (Davies 1998; Erfurt-Cooper 2009). The favorable geography and climate of much of Europe is the basis of an extensive network of natural waterways which, over time, have been connected by additional but artificial waterways, the canals. Many European countries including France have built canals to connect local river basins, while others, including Germany and Russia, have focused on the linking of their larger waterways to create a continent-wide system (Volga, Danube, Rhine). These extensive networks now support river tourism activity throughout Europe, particularly the long-distance cruising segment (Roberts and Simpson 1999; Erfurt-Cooper 2009). Elsewhere in Europe, cruising by canal and river boat can be found in most areas where there are suitable waterways. We should also note though, that river tourism is importantly land-based as well as water-based.

In many European cities, river banks are the preferred location for hotels and restaurants, primarily because the setting (ambiance) that a river provides can attract travelers and locals by providing them with an interesting view, and a relaxing setting for dining, accommodation, and other activities. Recreational parks and golf courses also make use of local streams where these are available to increase their attractiveness and profitability. Thus, over the last few decades, waterways have become more prominent as sites for recreation and leisure activities on both land and water. This in turn has resulted in an increased interest in taking time to explore rivers and their surrounding areas, even if it is only for a short time activity such as a sunset sailing, dinner cruise or walking along the banks. In many areas parks and open spaces beside the waterfront are being redeveloped to encourage heritage, nature-based, and ecotourism activity. There has also been a renewed interest in encouraging waterfront festivals and markets as activities that are able to generate extra income for local communities, in addition to water-based recreation. However, despite the beneficial economic effects of river tourism in terms of job creation, infrastructure provision, and stimulation of local businesses, there continues to be a lack of information that could be used to estimate the net economic and social contribution of river tourism activity. Because of this gap in data the current estimates of the contribution of river tourism to both host and tourist communities are vague, and fail to provide a reliable data set that can be used for comparison and analysis. The next section seeks to provide a list of components and their relationships so that informed discussion about benefits and costs in river tourism can be better carried out. 


\section{The human and ecological use of rivers}

It is useful to develop a classification of the uses of rivers and their associated lakes, canals, and water storages as a first step in identifying and discussing the impact of tourism on these resources. The need for a classificatory schema of this nature was made evident in the work of Prideaux et al. (2009), and has since become critical with the greater use of rivers as a tourism resource (attractions, transport corridors, the source of water for temporary visitors), in addition to their continuing functions in the environment of the host communities. In almost any region of the world it is possible to identify the inherent problems and conflicts between the major users of the water supplied by rivers, and this is equally if not more true of the impact of tourism on rivers. It is apparent that the unsustainable use of rivers for any form of use has the potential to degrade their ability to support all other forms of human activity, including tourism.
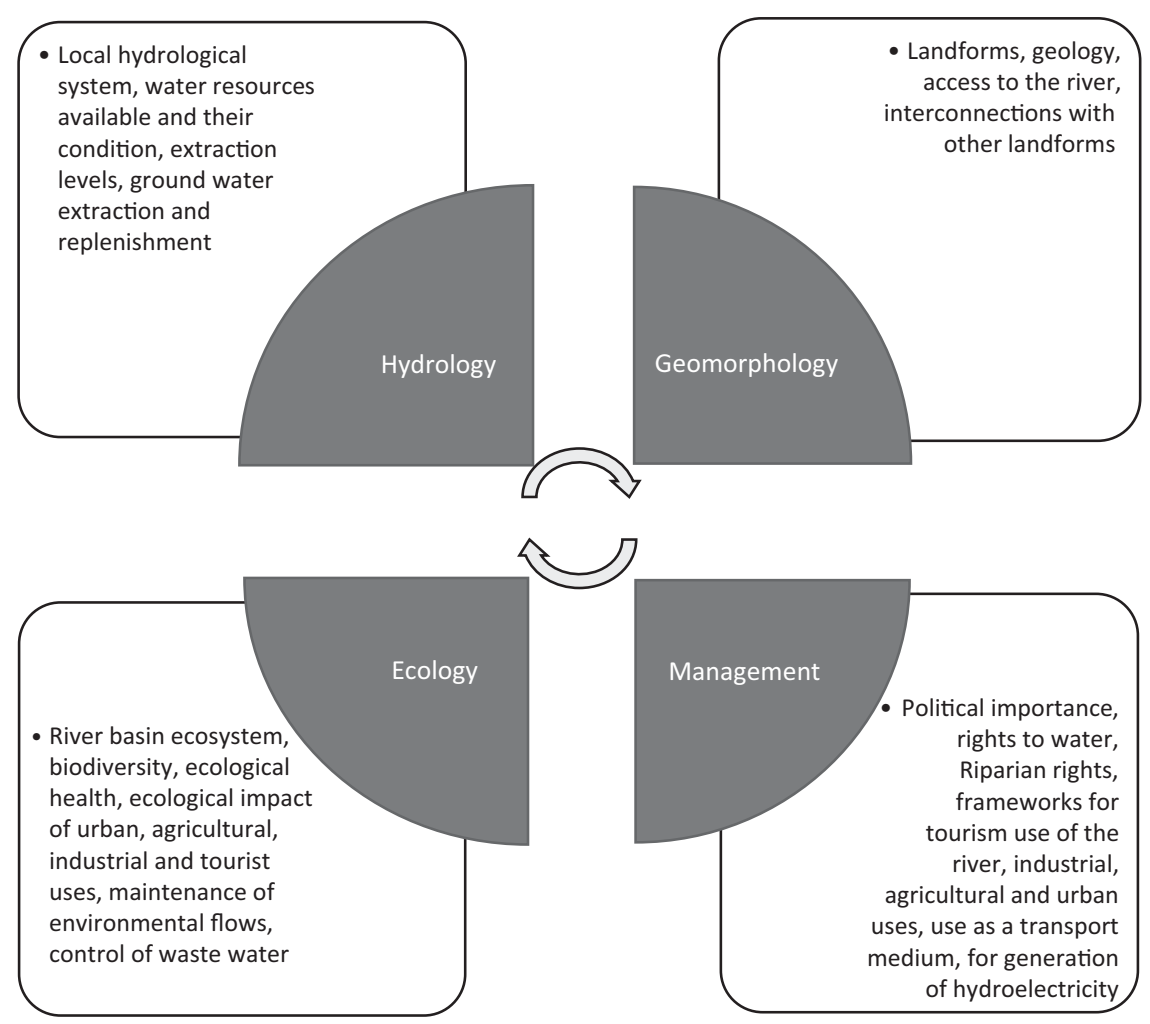

Figure 14.1 A simplified illustration of the range of factors that affect the ability of the tourism industry to use rivers for touristic purposes.

Source: the Author 


\section{Malcolm Cooper}

A very good example of this (Cooper 2017, Chapter 4 this volume) is found in Australia in the extensive harvesting of water from the Murray-Darling system to support irrigated agriculture, which has led to problems of increasing salinity and lower water levels in the river that have severe implications for the ecological health of the whole system. But in addition to this is the impact on those parts of the river and its surrounds, such as the towns up and down the river, on the lakes in the system, and on the exit area of the Coorong in South Australia (the Murray-Darling does not often flow to the sea in the 21st century) that support tourism. Use of the river for recreation and the additional demands of the existing (the major city of Adelaide in South Australia is the prime example) and increased population for supplies of drinking water and industrial/transport uses is heavily compromised as a result. More generally, the impacts of rapid population growth in many countries, the greater use of water for industrial and human purposes, increasing affluence, and the growth in recreation have combined to place

Table 14.1 The use of river systems for tourism and other industries.

\begin{tabular}{|c|c|}
\hline Framework for Role & Component \\
\hline Geographical & $\begin{array}{l}\text { Length, width, location and access, } \\
\text { navigability (including for adventure } \\
\text { tourism and sport), topographical features } \\
\text { along the course of the river }\end{array}$ \\
\hline Biological & $\begin{array}{l}\text { Ecosystems incorporating the river, changes } \\
\text { in ecosystem/species composition from } \\
\text { impacts on the river, fishing resources, } \\
\text { river health, existence of invasive species } \\
\text { (not indigenous to that river) }\end{array}$ \\
\hline Environmental condition & $\begin{array}{l}\text { Water quality, salinity, seasonality/flow, } \\
\text { urban stormwater runoff }\end{array}$ \\
\hline Riparian land uses & $\begin{array}{l}\text { Agriculture, urban, wilderness, recreation } \\
\text { (activities and places used for tourism, } \\
\text { including built and natural environments) }\end{array}$ \\
\hline $\begin{array}{l}\text { Industrial, urban, agricultural use of the } \\
\text { river water by riverine communities }\end{array}$ & $\begin{array}{l}\text { Irrigation, manufacturing/cooling uses, } \\
\text { sewerage disposal, human consumption } \\
\text { (direct and from storages), hydro } \\
\text { electricity generation }\end{array}$ \\
\hline Transportation use & $\begin{array}{l}\text { Industrial (for movement of goods), } \\
\text { commuting, tourism }\end{array}$ \\
\hline Recreational use & $\begin{array}{l}\text { Ability to support swimming, rafting/ } \\
\text { kayaking, boating, diving, fishing }\end{array}$ \\
\hline Political factors including borders & $\begin{array}{l}\text { Local, regional, national politics, riparian } \\
\text { conflict, borders, water use/storage } \\
\text { conflicts }\end{array}$ \\
\hline Management & $\begin{array}{l}\text { Legal frameworks, development and } \\
\text { environmental planning regulations, } \\
\text { resource allocation systems, transportation } \\
\text { regulations, river basin management } \\
\text { systems }\end{array}$ \\
\hline
\end{tabular}


enormous pressure on river systems throughout the world. Most of the world's great cities are built around or near rivers and depend on these systems for potable water, and for the support of agricultural activity and manufacturing industry, yet the same rivers or adjacent oceans are also often used for the disposal of human effluent and agricultural and industrial waste. This situation places great stress on river systems. Equally, even in remote regions such as the Yunnan province of China, or the upper Amazon Basin in Brazil, rivers are being subject to increasing use for tourism and other developmental purposes. Sustainability of rivers and river basins is therefore a major issue and the ability of tourism to compete with other river users will increasingly determine the extent to which rivers will continue to support tourism activities (Moscardo, Prideaux, and Laws 2006; Prideaux and Lohman 2009; Buckley 2009).

To create a basis for evaluating the role of rivers in the specific activity of tourism within the wider spectrum of uses, and the impact of this activity on rivers and riverine communities, Table 14.1 documents their significant direct and indirect roles, while Figure 14.1 attempts to identify the more important relationships between these roles. The important features of rivers in relation to their use for tourism (which is predicated on the much wider range of factors outlined in Table 14.1) developed in this chapter are based on an extensive review of the factors that may exert some influence on the tourist use of rivers, as well as the authors' own experience of the contribution of such rivers as the Nile, Murray-Darling, Rhine, Danube, and the Mekong. This review shows that individual river systems can support large tourism industries, but that there may also be considerable differences in the impact of many of the factors outlined in the table, some of which appear to overlap or have little relevance to tourism.

From the perspective of river tourism, factors that impact on one sector of a river may have significant though unanticipated consequences elsewhere along the river or in other parts of the hydrological cycle. For example, the clearing of forests in river catchments for agriculture may cause downstream flooding imperiling an archeological site or other area of tourist interest, or indeed the factors underlying climate change. Similarly, damming a river for hydroelectricity may lead to the drowning of significant areas of scenic beauty, such as occurred when the Three Gorges Dam on the Yangtze River in China became operational in 2011, or adversely impact the entire river basin downstream from the dam(s) as on the Mekong in relation to the series of dams constructed or being planned for the upper reaches of the river in China.

\section{The structure and components of river tourism}

The main components of river tourism are predicated on the nature and volume of the water a river carries; this can be used for bathing, canoeing, rafting, cruising, or simply just as an environment to contemplate or rest within. Even short periods near rivers can have a beneficial effect for some people, which explains why all tourist destinations offer water features as attractions if they have any rivers, canals, lakes, waterfalls, hot springs, or beaches. It also explains why if 
water is not available in a natural state but can be brought to a site at a reasonable cost, man-made landscaping will invariably include fountains, ponds, swimming pools, and/or artificial waterfalls to attract tourists, and may even include artificial watercourses. Nevertheless, the natural potential of rivers and lakes for tourism is invariably greater than the created versions, due to the oft-changing scenery (different natural and urban settings) and uses along their banks.

But this is not their only attraction. For example, Cooper and Prideaux (2009) showed that the religious value of the rivers of South Asia are equally important (to Hindu people the rivers in India are an essential part of their religious practices). Thus, for the international visitor they also provide a means of understanding the historical, cultural, and traditional practices of India, Pakistan, Nepal, and Bangladesh/Assam. Similarly, their value as a transportation medium is a combination of their ability to provide a means of moving goods between separate places, and their ability to move tourists from place to place. In this context, Erfurt-Cooper (2009) showed that rivers in Europe are valued for their use in leisure travel and their association with river bank activities, plus the heritage and cultural resources identified as important elsewhere, as much as for the scenic and cultural areas they traverse. In the European context, river tourists have an unparalleled opportunity to engage with local communities, go shopping and sightseeing, and be involved in any other activity on the banks of the river or canal that might suit them to enjoy during their holiday.

Rivers may also be boundaries between nations, and the management and sharing of water which crosses international borders is a matter of concern in relation to river tourism - because a river can be a natural resource that does not recognize national borders. Given the geography, demographics, and politics of human settlement in river basins such as that of the Mekong river for example (Laws and Sermone 2009), regional cooperation over the use and distribution of water is decisive for the health of the river system as well as for the sustainable development of river tourism. A basis for cooperation must be developed despite the often-lingering barriers of historical competition and conflict. However, it may be too simple a proposition to state that all that is needed for the emergence of significant river tourism on the Mekong and any other major river is a genuine dedication of the partner countries in its basin towards attaining this goal. For this to happen though, the tourism sector must be considered in the context of the local economic and geopolitical situation. All the physical and cultural attractions in the world cannot bring tourists to an area involved a situation of political conflict over the very resource that is required for tourism's continuation. This is seen most starkly in the Nile basin. The tourism resources of the riparian countries along the Nile largely stem from that river's long association with human settlement but, while the Nile valley is deserving of its reputation as the world's largest open-air museum, there are increasing conflicts over the allocation and use of its water (Cooper and Prideaux 2009).

River basins which do not cross national boundaries may still be affected by political and other divides. If we take for example the Mississippi River in the USA, it is possible to see that although a river may remain an important 
transportation corridor and source of water for agriculture and human consumption, its increasingly vital involvement in riverine tourism (based on cruises and gambling in the most part on the Mississippi) may be more important to local standards of living along its length (Timothy 2009). The recognition of this fact has led to several tourism and recreation corridors being delimited in recent years in major river systems such as the Mississippi river basin. The history of that river with its nostalgic elements (plantations, gambling, and steamboats) creates an important heritage product that focuses directly on the history of settlement of the river basin and the forms of socio-economic activity it supported in the past (amongst these was slavery). As a result, the value of heritage sites along the river, such as civil war Vicksburg, can be measured from a number of perspectives: as attractions that provide employment, as the iconic experience that underpins the sustainability of the regional tourism industry, as an educational experience that connects present generations with the past, as an activity that has encouraged local participation and maximized local benefits, and as a heritage site that preserves significant elements of the past. These considerations and situations are also found on major river systems such as the Volga and the Rhine-Danube in Europe, amongst others.

\section{The natural environment}

River ecology is also of special interest. Seasonally flooded wetlands along many rivers (for example the Tonle Sap system in the Mekong River basin) dominate the landscape and offer rare flora and fauna for the interest of tourists, and many have been designated as a protected natural area. For the river tourism industry, of special importance are the spectacular wetlands of the Danube Delta as it meets the Black Sea, or the Sunderbans in Bangladesh, said to be unique in the world, and increasingly important tourist destinations. At the other end of the scale, the Himalayan region, which generates and nurtures most of the rivers of North and South Asia, has equally important landscapes now being frequented by more and more adventure tourists. Often, the rivers of the region provide the only means of access and travel through these areas, a fact of increasing importance to both local communities and to tourists alike, and marketed strongly to the potential river tourist at the same time as the extreme tourism opportunities delivered by many of them in their headwaters.

\section{The impact of other uses}

Rivers and river basins have been developed in the past century beyond their natural systems to include dams for reservoirs, water intake systems for industry and agriculture, and as convenient sewers for waste products of human settlements. The impact of the resulting multiple-use riverine environment on river tourism must also be seen in the context of these other uses. And sadly, this does not make good reading. In this regard, a rather dark part of European and other regional river histories includes the abuse of natural freshwater by a range 


\section{Malcolm Cooper}

of industries and agriculture, topped off by pollution from municipalities. The rivers in Europe for example were used as a giant waste water disposal facility, flushing toxic waste from chemical and other factories, pesticides and herbicides from adjoining land use, as well as effluent from urban sewers downstream for some 200 years, before being very recently cleaned up. The more recent industrial development of China has also resulted in major pollution problems for earth, air, and water (Arlt and Gequn 2009), and swimming in the Yangzi River is not advisable. But perhaps more sadly, visitors coming for wildlife experiences to this river system are almost certainly too late. The population of one of the two major species indigenous to the river, the Chinese or Yangzi Alligator, is down to about 200 , placing it on the international list of highly endangered species. However, even with this status, it is still better off than the other species, the Yangzi River Dolphin which was last seen in 2004, and declared as 'functionally extinct' in 2007 (Arlt and Gequn 2009).

If we then add the religious use of the Ganges and associated river systems in India, the sheer size of the problems of inappropriate river use can be illustrated. The biggest culprit here is waste disposal. The Ganges is essentially toxic, especially in and around the religious center of Varanasi, where some 50 million pilgrims per year attempt to continue their religious observances tied to the river (bathing, drinking, and disposal of the dead) among the virtually untreated waste water flowing into the river.

\section{The politics and governance of river use}

For river tourism governance to be effective the following policy questions must be addressed:

1 Local tourism organizations and local water authorities must become part of an integrated system in respect of water resource management. Each has a vested interest in ensuring the availability of cheap, safe, and high-quality water for both locals and visitors, but they cannot do this in isolation from a comprehensive approach to river and river basin governance;

2 A basin-based approach to integrated water resource management would provide assistance to both water supply authorities and tourism authorities in the formulation of sound and comprehensive usage plans, as well as assisting governments to solve transboundary issues where these exist;

3 Understanding/clarifying the interface between levels of governance and uses for water is an urgent concern. Which ones take precedence? This is a critical question to settle in the case of the use of rivers for river-based tourism;

4 Documenting 'best practice' in river tourism in each region for proper dissemination to relevant parties and organizations is critical if this is to be achieved. There is no substitute for experience relating to the use of this resource, whether it be in white-water rafting or in waste water disposal; and

5 Finally, political will and commitment from local and national leaderships is a critical element for river basin-based governance and therefore river 
tourism. Basin-based governance critically needs leaders who can mobilize, harmonize, and sustain efforts towards sustainable integrated water resources management.

Many of these questions have of course been partially answered, as in addition to human heritage, rivers have traditionally been rich in natural heritage, particularly fish, bird life, and natural landscapes. Owing to these characteristics, many of the major rivers forming the core of river tourism worldwide are protected in various ways as public property, such as in municipal waterfront parks, nature preserves, wetlands, and National Parks. In addition, there seems to be occurring in some countries a renewed concentration on a cohesive regional approach to the use of rivers in tourism. This is not only limited to the more regulated use of the river; the German term, bootwandern (Erfurt-Cooper 2009), for example, refers to sharing of the modes of travel in a river basin that impact on the river, such as between the use of a boat and travelling on land beside the river. The boat provides accommodation during the night and a means of transporting the major part of personal luggage, sightseeing is done on the banks using local means of transport. Divided into parts in this way can mean that the total tourism system can be provided in a more efficient and less impactive way. The same principle works for bicycles and canoes which may be provided by a cruise company or be privately owned, offering the river tourist exercise on demand instead of inactivity on board, and the local communities along the river the opportunity to receive the tourist without having to provide a lot of extra capacity, thus reducing impact on the river from waste generated by urban activity.

The recent attention to more effective forms of river governance has focused on the issue of whether states that share this resource can cooperate effectively in its use and management. Makim (2002, 5), in discussing the Mekong region notes that "[t]here is now considerable evidence to suggest that, in matters of transboundary resource use, states are often able to establish and sustain collective action". This appears to be particularly true in the case of river tourism, as evidenced by the joint attempts by Pakistan and India, and Bangladesh and India to jointly develop river tourism (Cooper 2009). Each river basin however represents unique features and therefore must be managed differently, and it is essential that basin-wide plans be developed with as broad a participation of stakeholders as possible. A politically, socially, and scientifically based river basin plan would be a very potent tool for clarifying roles and expectations with stakeholders, and as a result should make governance of river tourism more effective and responsive.

Water resources management, development, and policy have evolved in a variety of ways from country to country (Waldron 2008). Water resources management and development is usually the responsibility of national or city authorities in many countries, who also have a central role in the development and marketing of tourism (Marzano et al. 2009). These authorities should therefore pay careful attention to their management in relation to tourism because this can affect all sectors of society, not just river tourists. Each country, developed or developing, must put together its own plan of action suitable for its hydrological conditions 
and needs, but incorporate river tourism wherever appropriate as a legitimate and important riverine system use. These plans for water management must not only be developed in theory: they should also be feasible and implementable. On the positive side though, river tourism may provide the impetus for otherwise parochial national and regional organizations to address such requirements speedily and more efficiently. In this regard, the increasing emphasis on River Councils as governance mechanisms for integrated water resources management has vast, and yet largely untapped, potential for achieving local ownership of sustainability goals and controlling river tourism.

\section{Conclusions}

At least since the beginnings of civilization, rivers have played a critical role in human survival, activities, and economics. Rivers have facilitated long- and short-distance travel, trade, hunting, and the growth of civilizations. They were also instrumental in supporting the transport requirements of the industrial and agricultural revolutions, while endowing recreational opportunities on later populations.

Several direct relationships between tourism and rivers have been identified in this discussion. First, rivers provide a wealth of attractions and aesthetic appeal for tourists, and provide a unique venue in which tourism can take place. In some parts of the world, the physical morphology created by fluvial systems result in amazing natural landscapes that draw visitors from all parts of the globe. Perhaps less impressive, but no less important, most rivers provide solitude, beauty, and interesting history that appeal to local recreationists, as well as tourists from further away. The second relationship is the use of rivers for transportation. Navigable rivers are valuable assets in any region or country for the transportation of raw materials and manufactured products. However, rivers are taking on an additional element of commerce and trade: that of transporting tourists on sightseeing cruises or more long distance as a major mode of tourist transportation. Third, rivers are an important resource for tourist destinations in three ways: they provide drinking and domestic water, they facilitate the development of intense tourism-oriented environments such as urban settlements, and they may be used to fill swimming pools! These are especially important considerations in arid regions (e.g. Las Vegas and the greater Phoenix/Scottsdale urban area of Arizona, USA), where residents are often required to sacrifice their own water use for the broader benefit of tourism. Finally, river water is necessary for many of the agricultural products and the electricity needed to sustain tourism in all regions of the world.

One question that has often not been adequately addressed in the small amount of previous writing on this topic is the sustainability of river tourism. As discussed earlier, further work needs to be done on prudent approaches to river tourism development (and their political status) to avert future problems in many regions. In specific areas and for specific forms of river tourism there may also be issues that will need to be addressed locally. For example, in sensitive environmental areas, there may need to be specific visitor number levels established 
and/or controls placed on tourism involving impacts on river-based indigenous populations.

In summary then, river systems are complex ecosystems that are influenced by many human activities, including tourism and recreation. The continued use by tourists of rivers must be monitored and well managed to be able to conserve the natural and cultural wealth of their ecosystems for present and future generations.

\section{References}

Arlt, W., and Gequn, F. 2009. "The Yangzi River Tourism Zone.” In River Tourism, edited by B. Prideaux and M. Cooper, 117-130. Wallingford, UK: CABI.

Baranowski, S., and Furlough, E. eds. 2001. Being Elsewhere: Tourism, Consumer Culture and Identity in Modern Europe and North America. Ann Arbor: University of Michigan Press.

Borthwick, J. 2002. Chasing Gauguin's Ghost: Tales of a Professional Tourist. South Melbourne: Lothian Books.

Buckley, R. 2009. "Parks and Tourism." PloS Biology 7(6): e1000143.

Carson, L. 1994. Travel in the Ancient World. Baltimore: John Hopkins University Press.

Cerveny, R., and Cerveny, N. 2006. "Egypt \& Water: Lifeline of a Civilization.” Weatherwise 59(6): 20-26.

Cole, J. 2007. Napoleon's Egypt: Invading the Middle East. New York: Palgrave Macmillan.

Cooper, M. 2017. The Murray-Darling Basin. Chapter 7 this volume.

Cooper, M., and Prideaux, B. 2009. River Tourism. London: CABI.

Davies, N. 1998. Europe: A History. London: Harper Perennial.

Erfurt-Cooper, P. 2009. "European Waterways as a Source of Leisure and Recreation." In River Tourism, edited by B. Prideaux and M. Cooper, 95-116. Wallingford, UK: CABI.

Grzymski, K. 1993. "Nubia: Rediscovering African Kingdoms." American Visions 8(5): 20-25.

Hessler, P. 2001. River Town: Two Years on the Yangtze. New York: Harper.

Hulme, P., and Youngs, T. 2002. "Introduction." In The Cambridge to Travel Writing, edited by P. Hulme and T. Youngs, 1-16. Cambridge: Cambridge University Press.

Laws, E., and Sermone, P. 2009. "The Mekong: Developing a New Tourism Region.” In River Tourism, edited by B. Prideaux and M. Cooper, 55-73. Wallingford, UK: CABI.

Lloyd, A. B. 2002. "Egypt." In Brill's Companion to Herodotus, edited by E. R. Bakker, I. de Jong, and H. van Wees, 415-436. Leiden: Brill.

Makim, A. 2002. "Resources for Security and Stability? The Politics of Regional Cooperation on the Mekong, 1957-2001." The Journal of Environment Development 11(1): 5-52.

Marzano, G., Laws, E., and Scott, N. 2009. "The River City? Conflicts in the Development of a Tourism Destination Brand for Brisbane." In River Tourism, edited by B. Prideaux and M. Cooper, 239-256. Wallingford, UK: CABI.

Moscardo, G., Prideaux, B., and Laws, E. 2006. "Researching and Managing Tourism and Hospitality Service: Challenges and Conclusions." In Managing Tourism and Hospitality Services, edited by B. Prideaux, G. Moscardo, and E. Laws. Wallingford, UK: CAB International.

Popescu, P. 1991. Amazon Beaming. London and Sydney: MacDonald.

Prideaux, B., and Lohmann, G. 2009. "The Amazon: A River Tourism Frontier.” In River Tourism, edited by B. Prideaux and M. Cooper, 147-164. Wallingford, UK: CABI.

Prideaux, B., Timothy, D., and Cooper, M. 2009. "Introducing River Tourism: Physical, Ecological and Human Aspects." In River Tourism, edited by B. Prideaux and M. Cooper, 1-22. Wallingford, UK: CABI. 


\section{Malcolm Cooper}

Rice, M. 1999. Who's Who in Ancient Egypt. London: Routledge.

Roberts, L., and Simpson, F. 1999. "Developing Partnership Approaches to Tourism in Central and Eastern Europe." Journal of Sustainable Tourism 7(Part 3 \& 4): 314-330.

Shaw, R. 2007. Three Georges of the Yangtze River Chongqing to Wuhan. Hong Kong: Odyssey Books.

Stanley, J-D., Krom, M. D., Cliff, R. A., and Woodward, J. C. 2003. "Short Contribution: Nile Flow Failure at the End of the Old Kingdom, Egypt: Strontium Isotopic and Petrologic Evidence." Geoarchaeology 18(3): 395-402.

Steinbach, J. 1995. "River Related Tourism in Europe - an Overview." GeoJournal 35(4): 443-458.

Timothy, D. J. 2009. "River-Based Tourism in the USA: Tourism and Recreation on the Colorado and Mississippi Rivers." In River Tourism, edited by B. Prideaux and M. Cooper, 41-54. Wallingford, UK: CABI.

Waldron, T. 2008. "Expertise in Water Loss Control Applied to Extreme Problems of Water Distribution Management." Water Science and Technology: Water Supply 8(1): 107-112. DOI:10.2166/ws.2008.031

Winchester, S. 1996. The River at the Center of the World. New York: Henry Holt. 


\section{Social landscape and environment}

\section{The Hérault River in Southern France}

Jeremy S. Eades

\section{Introduction}

This penultimate chapter of the book develops the theme of river basins adapting to the cultural, social and economic life of resident communities, including the new emphasis on the river from tourism (Chapter 14, this volume), through a discussion of the interaction of people and landscapes in the Hérault river basin in Southern France. The Hérault is one of the several major rivers in Southern France that flow from the Central Massif down to the Mediterranean Sea. On its $152 \mathrm{~km}$ journey, it passes through a range of distinct geographical zones, from river gorges in the hills, to alluvial plains towards the coast, before joining the sea at Grau d'Agde. In between, it flows first through spectacular limestone gorges, and then through alluvial plains where wine production predominates, and on the way, joins with around 20 major tributaries (Amiel 1998, 63-85), and many smaller streams. The confluences with each of these tributaries determined the sites from very early times of the major settlements along the Hérault, from Villerague and Ganges in the north, to Clermont l'Hérault, Pézenas and Agde in the south.

In all, the river basin covers around 2,500 $\mathrm{km}^{2}$ (Amiel 1998, 15), and includes some of France's most important wine-growing and tourism areas. The restructuring of the regional economy around tourism which took place between 1964 and 1979 (Ferras et al. 1979, 194-218) was a massive change of fortune after years of marginalization and neglect, but is only one of several such changes in the history of the river basin. The intent of this chapter is to describe the way in which water resources, geology and geography and economic and human factors have combined over the centuries to produce the river-based community system we see today, and have contributed to its cycles of poverty and prosperity.

\section{The river and its basin}

One of the most important physical facts about the Hérault river is the irregular nature of its flow. It rises at around 1,500 meters in the Aigoual massif, where the blockage of moist air from the Mediterranean can lead to intense rainfall (Amiel 1998, 23-28). Annually, that area receives near two meters of rain a year 


\section{Jeremy S. Eades}

(Ferras et al. appendices, map 18), but much of this can fall in just a few hours in intense storms. The rain pours into the surrounding river valleys, and the speed of the flow is accelerated by the rapid drop in altitude in these valleys. For instance, while the Hérault rises at 1,500 meters, its altitude at Villerague, only about $10 \mathrm{~km}$ away as the crow flies, is less than 400 meters, and by Ganges, the next major settlement on the river, it has fallen to around 150 meters. The result is frequent flash flooding in the upper reaches of the river, and large-scale flooding of the alluvial plains further downstream (Amiel 1998, 83-99). The roads in the region are punctuated by signs warning motorists that they are potentially submersible, and many of the towns along the course of the river have areas officially considered "inondable". Also, bridges on the Hérault are often temporary, frequently swept away and rebuilt, only to be swept away again in the next major flood a few years later. Water and flood disasters are therefore major features of the physical and social history of the region.

The relationship between people and water also varies along different stretches of the river. In the upper reaches, where the rivers run through limestone gorges, the waters are crystal clear and a deep green-blue in color (Amiel 1998, 23-37). The gorges extend to the Pont de Diable, a massive bridge dating from the 11th century just north of Clermont l'Hérault and still in use: one of the few ancient structures to have withstood the ravages of the river. From here on the river broadens and meanders, fringed by reeds and trees and surrounded by vineyards that continue almost to almost uninterrupted as far as Agde (Amiel 1998, 39-53). The region has a long history of settlement, as is evident from the megaliths and impressive Greco-Roman remains found throughout. In ancient times, Agde was one of the main ports in the region, and, in the late 17th century, it also became the terminus for the Canal du Midi, the waterway constructed to link the Atlantic with the Mediterranean via Toulouse (Amiel 1998, 173-74). However, because of soil erosion further up the river, Agde has suffered from extensive silting over the years (Amiel 1998, 55-61). Despite occasional floods powerful enough to wash away the accumulated sand bars, the local people had to resort to dredging as far back as the 14th century to keep their port. Even after the construction of jetties, the port could only handle small vessels with a draft of less than two meters, so it gradually lost out to Narbonne and Sète which could handle much larger vessels. Agde is still used by pleasure craft and fishing boats the local market handles 800 tons of fish a year - but larger commercial vessels go elsewhere.

The history of the river valley records famous floods; grandes inondations are remembered for the damage caused to fields, mills and bridges along the river on an almost annual basis (Amiel 1998, 87-99). In recent years, floods and storms have deprived villages of water, blocked roads and railway lines with flood water, and washed down so much driftwood that this has endangered the fish stocks in places: between 1928 and 1979 alone, there were 80 serious floods along the river. Also, given the number of rivers cutting through the massif and across the coastal plains of southern France, bridges are of major importance for getting around. Many of the bridges across the Hérault are very old and of great historical interest 
(Amiel 1998, 174-79). Many were first constructed in Roman times, but have since been replaced or relocated several times.

A good example of the problems encountered over time is the history of bridge construction in Agde. There was an ancient bridge across the river there, but it collapsed in 1206, and was replaced by a ferry until 1678. This in turn was swept away by a flood in 1705 . The bridge was rebuilt, but only lasted until another flood in 1721. The next attempt at construction in 1722 was swept away the following year. Yet another, constructed in 1727, had to be repaired in 1765, and was destroyed in 1795 . For a while, the townspeople again had to make do with a ferry, later replaced by a pontoon, until the construction of a suspension bridge in 1828 that was replaced by a metal bridge in 1926. In 1964, this in turn had to be closed because the pillars had been damaged by the current. Temporary bridges have been used since, and the town still awaits a final solution.

\section{The riverine environment}

\section{Fishing and other uses of the water}

The local plants and animals also rely on the ebb and flow of the river. Of the $1,500 \mathrm{~km}$ of rivers in the Hérault system overall, about half are classified as first class fishing resources (Amiel 1998, 123-31). The main river can be divided into five zones, each with its own major species of fish, depending on the movement of the water, the oxygen available and the temperature. Levels of oxygen are highest in the upper reaches, where trout predominate. Further downstream, as the river bed changes from rocks to pebbles and gravel, grayling take over. As the river widens, the trout and grayling populations decline and catfish, perch, pike and roach become common. Further on still, bream predominate, until the river reaches the sea and salt-water species like sea bass and flatfish take over.

One of the main concerns of the river authorities is the impact of all this on fishing (Amiel 1998, 111-21). This has been popular on the river at least since Roman times, and was an important source of protein before the industrial and transport revolutions. Now it is mainly a leisure pursuit. Fishing is popular throughout France, with 2.3 million fishing permits issued annually, and some major species of fish and crustaceans have been imported from outside, including the rainbow trout and the American crayfish. The latter was introduced in the 1970s because of its resistance to diseases that were ravaging the native crayfish population at the time (Amiel 1998, 132). The French fish farming industry produces 40,000 tons of trout a year, the largest production in the world. There are several fish farms in the Hérault basin rearing mainly brown and rainbow trout fry, and these are released into the river annually in late September (Amiel 1998, 133-35).

Fishing in the river system has been heavily regulated over the years, initially to uphold the rights of the landowners, and later to maintain fish stocks, particularly of trout (Amiel 1998, 113-121). Like many of its tributaries, most of the Hérault is classified as a Category 1 river where fishermen can only use 


\section{Jeremy S. Eades}

single lines, nets with wide mesh to let through the smaller fish, and flies rather than maggots for bait. Maximum size limits are specified for each of the main species, and these vary between different parts of the river. Larger fish must be returned to the water. Fishing is only allowed from an hour before sunrise to half an hour after sunset. Catches of fish belonging to the salmon family (salmon, grayling, trout) are limited to 10 per person. The seasons for the main species are also laid down in detail. There are even regulations for crustaceans, mainly crayfish, both on the size that can be taken, and the kinds of nets that can be used.

The riverine environment is therefore the basis of much of the economy of the Hérault Valley, and the area is also well supplied with springs. Hot springs and spas have been popular since Roman times, and more recently they have moved into health and wellness tourism. They include Avène-les-Bains, specializing in skin care; Lunas, famous for treatment of eye diseases; and Lamalou-les-Bains, which specializes in treating rheumatism, particularly among old people. The Vitale spring has given rise to a major mineral water industry, producing three million bottles a month. The level of the water table throughout the region is continuously monitored to prevent over-exploitation, which can lead to seawater intrusion and other forms of pollution. Overall coordination is provided by the agencies of the Rhône-Méditerranée-Corse region (one of six such regions in France) which administers the water resources of 30 départements and a total area of 130,000 km (Amiel 1998, 148). The main uses are for drinking water and irrigation, but other uses include power generation and fish farming. The agencies are also responsible for the management of the network of dams, reservoirs, canals, public fountains and the rest of the infrastructure created to provide water for the main communities in the region, particularly during the late 19th century.

The largest fresh-water resource in the region is the Lac du Salagou, created by damming the Lergue and the Salagou tributaries of the Herrault and completed in 1968 (Amiel 1998, 168-70). The aims were to increase the water available for irrigation and control the violence of the annual floods. The dam is 62 meters high, 357 meters long and 7 meters wide. The fish population is extensive, and the lake has become a Mecca for fishermen. However, there have recently been increasing problems with the spread of an invasive pond weed which originated in Southern Africa and probably entered the lake via the runoff from an ornamental pond. This is already affecting swimming and fishing in some parts of the lake around the village of Octan (as reported in Midi Libre during June 2013). Clearing the weeds does little good because the plants on the surface have already deposited seeds on the lake floor which will germinate the following year. At the time of writing, it is not clear how to deal with the problem if it worsens in the future - short of draining the entire lake.

\section{Forests and agriculture}

One of the most interesting features of the ecology supported by the Hérault basin in the last century has been the extension of the forested areas; these have tripled since the 19th century (Roque 2012, 5). Historically though, the extent of 
the forests has varied in inverse proportion to the size of the population. During the Roman period (to $500 \mathrm{CE}$ ), the prosperity of the region and the consequent population growth meant that many areas of forest were cleared for agriculture (Roque 2012, 15-16). With the collapse of the Roman empire and the decline in population, the forests began to take over again. The rise of the Frankish empire under Charlemagne led to another period of population increase and prosperity, and to the extension of agriculture at the expense of the forests once more. There were ups and downs in the Middle Ages, as the region was subjected to a succession of wars, including the Albigensian Crusade against the Cathars, and the Hundred Years' War against the English. There were also epidemics, the most serious being the Black Death in 1348 (Roque 2012, 19-22). However, once the religious wars which followed the Reformation were over and the monarchy reestablished in the 17th century, both the population and economy activity began to grow once more. In 1730, there was an official ban on creating new vineyards to protect the remaining forests, but it was impossible to enforce. Much of timber cut down was turned into charcoal, lighter and easier to transport over long distances than fuelwood, and wood was important for the manufacture of glass (as fuel and ash), furniture, bricks and tiles, ironwork, pottery, tanning, meat processing, baking and construction (Roque 2012, 23-4).

Offsetting these demands was an increasing realization that the condition of the forests in Languedoc affected much more than the local communities that lived there. Some of the key work was carried out by George Fabre (1844-1911), an energetic and visionary civil servant with a talent for both administration and research on deforestation (Roque 2012, 107-9; Amiel 1998, 19, 23). He showed that the silting of the port of Bordeaux could ultimately be traced to soil erosion near the source of the Garonne in the Cevenne, the region in which the Hérault and other major rivers also rise. As a result, the tide began once again to turn, the numbers of forests controlled by local communities and the state began to increase and the acreage of forest started to expand, with different species predominating in different zones of the Hérault basin (Amiel 1998, 16-20). Between 1,000 and 1,500 meters, beech trees are dominant, replanted to reverse the deforestation in the Aigoual massif and the rest of the Cevenne. From 500 to 1,000 meters, the main species are deciduous oak on acid soils and white oak on chalky soils. In the lower reaches of the river, major species include the evergreen oak, which grows on all types of soil, and the maritime pine, planted originally to provide timber for the mines.

The main cultivated crops in the catchment are grapevines and olives. These were also often grown in the hillier areas, on terraces constructed on the sides of the valleys. First introduced by Greek colonists from Phocea around 600 BCE, olive trees have survived despite periodic severe frosts and forest fires. As recently as 1956, Clermont l'Herault was the only cooperative in the region in which olives survived winter frosts (Amiel 1998, 17). In the hills, agricultural production declined as the population moved out, and the regional park in Upper Languedoc now appears to be unspoiled and unpopulated wilderness. Nevertheless, quick inspection of the overgrown hillsides often reveals the presence of older stone walled terraces, long since abandoned. 


\section{Jeremy S. Eades}

Finally, along the banks of the river is the distinctive type of vegetation known in French as "ripisylve" or river bank forest (Amiel 1998, 21). This consists of plants that thrive in humid conditions, including trees such as poplars, willows, ashes and aldars, and climbing plants such as clematis and honeysuckle. The dense vegetation is also home to many species of birds. Thus the present distribution of forests in the Herault basin is the result of a number of factors: climate, terrain and the availability of water which together determine which species will grow where; the rise and fall of industries due to changes in climate, disease or market demand; demand for energy for local industries, which at first led to deforestation, and then to the planting of specific species for use as fuel or construction materials and, finally, state-led efforts at reforestation in the 20th century and the establishment of national and regional parks. The next section deals in more detail with the development of industry in the region, and particularly the use of the rivers to generate the power necessary to drive them.

\section{Industry in the Hérault}

Mention has already been made of some of the industries that flourished in the Hérault valley from ancient times, including mining, agriculture and textiles. One of the earliest of these was gold production, panning for gold dust washed down the river from the Aigoual massif. The name Hérault itself probably originates from the Latin word aureus, meaning golden (Amiel 1998, 20). There are also deposits of lead and tin in the area, which gave rise to both local mining industries and a demand for wood and charcoal to fuel them. The mines have mostly disappeared, though the memory of them is sometimes preserved in place names. A good example is the town of Ganges, located about $38 \mathrm{~km}$ from the source of the river, at $186 \mathrm{~m}$ above sea level, with a population of 3,300. Its name in Roman times was Aganticum, derived from the Latin word for treasure, a reference to the production of iron, lead, silver and gold in the vicinity. As mining declined in the 18th century, Ganges became a major center of silk production. However, since the collapse of the textile industry, it is now perhaps best known as a center for river tourism. Other industries such as glass or ceramics survive elsewhere in the work of local artisans, such as the potters of Saint-Jean-de-Fos.

The reason for the appearance of textile and other industries in the first place was the availability of water power, generated by the mills whose remains are still to be seen along the course of the river (De Cooman 2004). Many of them are very old, dating from between the period between the 11th and 13th centuries. Generally, they were built along with weirs or barrages used to contain the river water, while some of water passing through a specially constructed channel powered the mill wheels. One of the reasons why so many have survived to the present day, if only as ruins or shells, is that they were heavily fortified (De Cooman 2004, 10-11): the goods stored there, the income they produced and their strategic locations on river crossings meant that they were important targets in times of war or civil upheaval. They were therefore built so that they were difficult to access and easy to defend. At first, most of the mills were used for milling 
grain, but later they were put to other uses. By using cams, the millowners could turn rotary motion into horizonal or vertical movement back and forth, so that the mills could be used to make textiles, leather or metalwork (De Cooman 2004, 12-13). With the invention of the dynamo in the late 19th century, many of the mills were converted to electricity generation, which could be used to power the surrounding villages.

The mill in the riverside village of Bélarga was one of those converted to the production of electricity. This mill is from the 13th century, and formed part of the village fortifications (Palouzié-Guedar 1992, 30; De Cooman 2004, 73-4). It was used until the 19th century to produce flour, bringing in a substantial income for successive owners, who also controlled the river crossing across the weir. Even while other mills were being converted to electricity generation, Bélarga continued to be used for the trade in grain. If anything, this had received a boost after 1865 as farmers affected by the Phylloxera epidemic in the wine industry moved back to grain production. However, the industrial revolution was creating other problems for the mill owners, as a court case launched by the owner of the Belarga mill showed.

In 1882, the mill and the château at Belarga were acquired by a certain Jules Maistre, an entrepreneur from Villeneuvette. He hoped that the mill would remain a good source of revenue, but he was disappointed as the strength of the current in the river steadily declined, reducing the amount of energy available for grinding. Maistre suspected that part of the reason might be the construction of a railway bridge across the river between Campagnan and Paulhan, downstream from the Bélarga mill. In 1886, he launched legal proceedings against the Midi railway company, arguing that the construction of the bridge arches had slowed down the current and harmed his business. Initially, the case was thrown out by the court. He appealed to the departmental prefect, and this time he was more successful. In his deposition, he argued that through construction and improvements, he had been able to develop his enterprise and increase his turnover through agreements with agents in Marseille and Toulouse at a time when some of the local farmers were turning from wine to grape cultivation. However, because of the lack of power from the river, he sought the advice of consultant engineers. They told him that the reasons for the sluggish flow were the curvature of the river banks, the orientation of the river passage at Bélarga and, last but not least, the construction of the railway bridge down river. Rocks had been placed in the river meters away from the mill to protect the pillars of the bridge. This had slowed down the flow of water. If the falloff in river water continued, he claimed, the mill would soon be fit only for storing hay.

For whatever reason, this time the court agreed with him rather than the railway company. It cancelled the earlier decision and awarded him damages of 10,000 francs, paid with interest. However, soon the Bélarga mill was converted to generate electricity, just like the mills in other villages on the river, and by 1904 it was providing power to the neighboring villages of Paulhan, Aspiran, Campagnan and Plaissan. Soon after this it seems to have been badly damaged by another major flood, possibly in 1908; supposedly the last time that the water 
inundated the entire village and rose as high as the steps of the mayor's office. The mill building now survives as a ruin with substantial walls but no roof, like many of the other mills which once made the river valley prosperous. Thanks to the weir, the area around the mill has become a popular beach, with fishing, swimming and picnics during the summer months.

Finally, as the older villagers have died, the old and often derelict houses in the village have been bought and gentrified by outsiders as retirement or second homes which they often rent to tourists. Meanwhile the younger people in the village have built new modern houses on the outskirts of the village, often more cheaply than renovating the older housing stock.

\section{Economic revival of the river communities: wine and tourism}

In recent years, the socio-economic fortunes of the Longuedoc region, and of the Herault River valley within it, have begun to change, thanks to the revival of two ancient industries: wine and tourism. Along with the olive, wine production was introduced to Languedoc by the ancient Greeks, while Gallia Narbonensis, the Roman colony in this area, was known for the quality of its wines. However, with the collapse of the Roman empire, both the population of the region and wine production went into decline. With the centralization of the French State once more after 1200, the foundation of the port of Sète in 1666 and the completion of the Canal du Midi in 1681, wine production started to expand once more. Wine production increased in other areas as well with the arrival of the railways in 1853, particularly in the alluvial plains of the Hérault. However, the new prosperity was short lived. Bumper harvests led quickly to a fall in the price of wine, and production was also hit by a series of epidemics affecting the vines, the worst of which was a blight caused by an aphid, the grape phylloxera, which probably originated in America (Ferré 1997). The vineyards of Gard were the first to be hit, in 1869 , and the disease spread to Hérault and Aude in 1878. As the producers worked out how to deal with the problem - the solution was to graft the vines onto American root stocks which were immune to the disease - imports of wine surged, and so did the artificial production of wine using beet sugar, acids, coloring and dried grapes imported from elsewhere (Ferré 1997).

A ban on false and imported wines became the main rallying cry in the protests accompanying the crises in the wine industry of the region throughout the 20th century (Juge 1999). These protests were most vocal in the area to the west of the Hérault river where in some communities more than $75 \%$ of the agricultural land was devoted to vines (Ferré 1997). In addition, the distribution of land remained unequal. It was divided between a small number of large-scale producers with over 20 hectares, and many small producers with less than 5 hectares. The impact of a fall in wine prices on the small-scale producers and their families could be disastrous, and both poverty and unemployment spread rapidly. The most serious protests took place in the periods 1904-07 (Ferré 1997) and the 1970s (Juge 1999). They took the form of mass processions and demonstrations, together with 
blockades of roads and railways by activists to prevent the importation of wine from elsewhere (Ferré 1997, 12-15).

In the longer term, one of the solutions to the problems of small-scale producers was the formation of caves cooperatives, cooperative production facilities to which local farmers could bring their grapes for processing into wine (Brouwer et al. 2008; Gavignaud-Fontaine et al. 2009). These still operate in many riverside communities, where the cave cooperative is often the largest building in the community. For the most part, they produce cheap table wines of reasonable quality using the river water, mostly sold and consumed locally. However, starting in the 1970s, individual producers also started to make efforts to reduce production and improve both quality and income quality by planting better grape varieties which produced stronger wines (initially Carignan, Grenache and Cinsault; later Cabernet, Merlot, Chardonnay and Sauvignon) and by branding the wines using appellations that placed restrictions both on the amount that could be produced and the varieties that could be used.

\section{Tourism}

The other major boost to the riverine economy in the last few decades has come from tourism. This is a complex market with distinct sectors, many of which are ultimately dependent on the geography of the river system. To start with, the upper reaches of the river, with its sparse population and spectacular local scenery, is an area made for eco-tourism, including camping, hiking and climbing in the valleys, caving (Amiel 1998, 153-58), swimming, canoeing and kayaking (Amiel 1998, 137-39) on the river, or simply driving along the roads of the national and regional parks with their precipitous drops and hairpin bends.

Further downstream, from Clermont l'Hérault south, the main objects of tourism are the circulades of the fortified villages (Palouzié-Guedar 1992), the old churches, Roman remains, cathedrals and other historic buildings of the large cities and the pleasant river landscapes between them, whether used for fishing, boating, swimming or basking in the sun. This is where much of the wine production is concentrated, and where much of the marketing of wine direct from the producer takes place. There are frequent signs by the side of the road advertising degustation et vente, tasting and sales of wine. Some of the smaller vineyards distribute most of their production in this way, while others sell through supermarkets as well.

A recent phenomenon in both the mountain and riverside agricultural villages has been the considerable gentrification and purchases of property as second homes by outsiders, often from other countries (De Cooman 2004) This, together with the rising birthrate in France, means that the river villages are once again taking on a more prosperous look, and the decay of the exterior of many buildings has been reversed, with new paint and plaster increasingly common. In one such settlement, Bélarga, the houses on the imposing quayside overlooking the river, including the Château, have undergone a facelift over the last few years. 


\section{Jeremy S. Eades}

However, only one of them belongs to a Frenchman, and even he is an architect from the north rather than a local.

The state as a tourism promoter began to take an interest in the river in the mid-1950s, particularly in 1956 when severe frosts nearly wiped out the olive crops and badly affected the vines (Klemm 1996; Juge 1999). This climate impact had a long-term impact on the regional economy, as some of the landowners along the coast began to sell off their land (Brouwer et al. 2008). There were also worries that the established tourist resorts of Provence to the east were reaching saturation, and opening new coastline to tourism was an obvious option, given the increasing popularity of beach tourism. The strategy was to create integrated tourism destinations within the catchment, some of them from scratch, including Cap d'Agde at the mouth of the river, and to more than doubling the existing tourism capacity of the region from 250,000 to 600,000 beds (Klemm 1996). A second aim was to attract new customers, both from within France and the foreign market in which France was losing out to its Mediterranean competitors. A third aim was to create a model of planned tourism development to avoid the problems of piecemeal development, land speculation and disruption of the local economies. Some of the local marshes were to be drained (without much thought towards ecosystem values, even for ecotourism), while others were to be opened to the sea to create yachting marinas (again with the potential to disrupt ecosystem values being neglected in favor of facility production).

Despite the master planning and supposed central control (that nevertheless often neglected water and nutrient regulation and ecosystem supporting habitats in favor of tourist development; Brouwer et al. 2008), there were also major problems with construction, as developers started then abandoned building sites across the catchment when they realized they were unlikely to be profitable, resulting in poorly integrated facilities and pressure on the river environment. Other problems were the seasonal nature of the tourism economy, with most of the activity concentrated in the summer months of July and August, and the failure of the new resorts to attract permanent populations of local people to look after them. However, despite these problems, the tourists began to flock in, increasing at a rate of around 10\% a year, from 500,000 in 1964 to 1.8 million in 1977 .

One of the locations in the Herault river basin where this happened is the commune of Agde near the mouth of the river, with a permanent population of around 22,000. It is made up of four distinct parts: the old town of Agde itself, with the cathedral from which bishops used to rule the surrounding region; the Grau d'Agde to the east of the mouth of the Hérault river; Tamarissière on the opposite bank of the river (the site of woodlands originally planted to help combat silting and erosion, and whose clearance is thus indicative of the "regardless of impact" approach taken to overlay settlement for touristic purposes on the riverine environment); and Cap d'Agde, the modern holiday resort, with villas, beaches and a reputation for colorful night life based on the clothing optional Quartier Naturiste. With 11 beaches, accommodation for around 200,000, and 15 million overnight stays a year, Agde is now one of the largest and most popular holiday resorts in France. It has also tried to arrange events to bring in the tourists 
outside the summer months, including tennis and chess championships and an annual boat show on the river.

\section{Conclusions}

The issue posed at the start of this chapter was that of the way in which geographic, economic and human factors have combined to produce cycles of poverty and prosperity within a major river basin. As we have seen, the geographic endowment of the river basin is complex: on the one hand, it is rich in natural resources such as beautiful scenery in the north and agricultural lands in the south, and it is on these resources that the current major industries of tourism and wine making are based. On the other, its other resources such as minerals are no longer as important as they once were, while the forests, once heavily exploited as sources of energy and raw materials, are undergoing a period of recovery and expansion (Roque 2012). Like the forests and the population, the wine industry has expanded and contracted over the centuries, and currently is enjoying both a reduction in area and an improvement in quality, with the introduction of new grape varieties, fermentation technologies and branding strategies. However, like their predecessors, these major industries may not be as secure as they seem because of the other feature of the fluvial history of the region: the unpredictability of its climate and the flow regimes of its major river.

I have argued in this chapter that it is this unpredictability that has regularly had a devastating effect on the economy and ecosystems of the region. Even though the climate of Languedoc is usually seen as benign, with high temperatures in the summer and sunshine throughout much of the year, it is capable of both savage storms and severe frosts, and both can have a devastating effect on the vines and olives which have been the mainstay of agriculture over the centuries. Storms in the hills combined with the topography of the river valley have regularly produced devastating floods downstream, and even the most robust buildings such as mills and bridges have been unable to withstand them. While some, like the Pont du Diable, the foundations of which are constructed on rock several meters above the level of the river, have been able to survive: but most of the others have not been so lucky.

There are two other sets of unpredictabilities as well. The first is epidemics, in both humans and plants, which have also devastated the region from time to time. For example, Languedoc has at times suffered from the typical problems of a mono-crop economy, and when this has failed, as in 1907 or 1975, the result is massive hardship and political militancy. As we have seen in this chapter, successive phases of agricultural growth in the Hérault river basin were abruptly terminated by a series of epidemics in the chestnut, silk and wine industries, which have dominated the local economy in turn over the years. The second is the issue of the region's integration with the global and national economy. Languedoc has never been an independent political entity. It used to be part of the Roman empire, and after that empire collapsed, it sat uneasily on the boundary between the emerging countries of France and Spain, being invaded from time to time by 


\section{Jeremy S. Eades}

Visigoths, Muslims, Franks, English, Catholics and the forces of the new French state. With the industrial revolution, the region became more vulnerable to shifts in the global economy, as was clear with the opening of the Suez Canal and its impact on the Languedoc textile industry, thanks to imports of silk from China and Japan.

However, it is the combination of global forces and the French State that has, in the last few decades, come to the river's aid in reviving and restructuring the regional economy and society. The wine industry has taken off in the global market in a way that was difficult to foresee: new grapes, technologies and markets have all been successfully exploited, resulting in a quality product very different from the one that local people used to buy at low prices in five liter plastic cans a generation ago. Languedoc wines are now taken seriously in the world wine market, and their rising prices, even within the region, reflect this. However, economic diversification has also meant that many landowners treat wine production as a part-time rather than a full-time occupation, and are no longer plunged into poverty and misery as soon as there is a good harvest (from the consequent overproduction, and its concomitant fall in prices). Nevertheless, those in fulltime wine production tend to now be more knowledgeable and skilled in producing for an international market than were their predecessors, and they have the capital and marketing skills to succeed in this market. Many of the vineyards, like La Baume, have been bought up by major national and international conglomerates, so that they now reach a global market. The combination of global demand, production and marketing skills and initiative in searching out new methods and new markets have been the crucial factors in this transformation.

In the latest reincarnation of tourism, it was the French state that took the lead. The interministerial mission of the 1960s faced the national problem of how to improve France's balance of payments and compete more effectively in the increasingly international business of tourism. The natural resources of the Languedoc were ripe for (re)exploitation for tourism, and contained many elements of what the international market wanted (Klemm 1996; Brouwer et al. 2008). The state played an important role in this process by allowing the industry to take off through seeing the development of the south of the country holistically, and supplying a massive amount of infrastructural assistance. There were some bonuses along the way: although creating the largest naturist community in Europe was almost certainly not part of the original plan for the redevelopment of the Cap d'Agde (Velton 2003), a combination of local initiative and official flexibility made it possible to develop and exploit this new niche market in the tourism industry. However, as I have noted, a lot of this was carried out without much thought towards the ecosystem values of the river basin, even towards those environments required for ecotourism in the lower reaches of the river when facilities such as yachting marinas were constructed with their potential to disrupt ecosystem values being disregarded in favor of the facilities thought to be required for tourism.

Finally, Norman Foster's phenomenal Viaduc du Millau is thus not just a recently built and quick way to get across the Tarn River by a bridge, but also a tourist 
destination in its own right, as people make a special trip there to soak in the view, take photos and buy the produits de pays on sale at the tourist center. Even the apartment blocks in the Quartier Naturiste in the Cap d'Agde are now seen as pieces of architectural heritage to be designated and preserved. Meanwhile, villages like Belarga in the upper valley are being restored as tourists and second home owners move in from other parts of France and further afield. The Hérault river valley has once again become a cosmopolitan region with global connections - rather as it was at the height of the Roman empire - and, in the process, is better able to deal with the uncertainties and risks which the geography and the nature of the river have subjected it to in the past.

\section{References}

Amiel, J. 1998. L'Hérault: Fleuve Méditerranéen. Montpellier: Les Presses du Languedoc. Brouwer, F., van Rheenen, T., Dhillion, S. S., \& Elgersma, A. M. 2008. Sustainable Land Management: Strategies to Cope With the Marginalisation of Agriculture. Cheltenham: Edward Elgar.

De Cooman, M. 2004. Les Moulins de l'Hérault de Ganges à Agde. Esperon: Editions Etudes et Communications.

Ferras, R., Picheral, H., and Vielzeuf, B. 1979. Atlas et géographie du Languedoc et Roussillon. Paris: Flammarion.

Ferré, G. 1997. 1907 La Guerre du Vin: Chronque d'une désobeissance civique dans le Midi. Portet-sur Garonne: Edition Loubatières.

Gavignaud-Fontaine, G., Vayssettes, J-L., Sauget, J-M., Wienin, M., Normand, S., Rodriguez, L., and Touzard, J. M. 2009. Caves Coopératives en Languedoc Roussillon. Lyon: Editions Lieux Dits.

Juge, J-P. 1999. Guerriers du vin: Une saga occitane. Portet-sur Garonne: Edition Loubatières. Klemm, M. 1996. "Languedoc Roussilon: Adapting the Strategy." Tourism Management 17(2): 133-139.

Palouzié-Guedar, H. 1992. Gignac: Un canton de la moyenne valée d l'Hérault. Montpellier: Association pour la Connaissance du Patrimoine du Languedoc Roussillon.

Roque, J-L. 2012. L'Hérault et ses forêts: Une histoire d'hommes. Sète: Nouvelles Presses du Languedoc.

Velton, R. 2003. The Naked Truth About Cap d'Agde. San Rafael, CA: Scarlett, Oh! Publishing. 


\title{
16 Concluding remarks and the way forward
}

\author{
Shamik Chakraborty, Abhik Chakraborty, \\ and Malcolm Cooper
}

\section{Introduction}

This book has focused on the importance of rivers by seeking a range of cultural, economic and natural environmental discourses from a select group of commentators highly qualified to draw the connections we desired when first planning this project. Aspects such as their description by artists, their expression in landscapes, community perceptions of rivers as one of the physical sources of water for a myriad of uses including leisure (tourism) activities, indigenous and customary practices, transport, drinking water, and so on. No one aspect is more important than any of the others, but all these approaches combine to understand a river's existence in society, and how a society chooses to use (or misuse) a river. Here, we identify five key points that emerge from this volume as key messages to any society that lives with rivers. These five aspects are not independent of each other, and they are five subsets of the same thinking: integrating rivers and society.

But, before discussing those five key points, a question arises: What makes this summary chapter necessary, for whom, and why? We would first like to clarify these below and then go on to carry out the actual synthesis. The first point is that rivers represent fundamental geomorphological (physical) processes that are as ancient as the formation of the land itself, and as social as being the location of some of the biggest, densest, and most complex societies on the planet. The former (wild nature in the rivers) never loses itself totally even in the most urbanized areas (think about the underlying rock strata in the most advanced urban conglomeration, or the flood events that can jeopardize the urban systems). It is more often the society which loses the river. However, a river is merely 'altered' to a different state by anthropogenic activities, and nature can come back in a relatively short time when the human component is not present (Weisman 2007). Thus, rivers represent - perhaps more strongly than any other landform features - the stark contrast between wild nature and the 'taming' effect of human communities. This is also true because rivers are, as noted earlier, a 'fundamental' landscape feature. In general, all over the world we have seen the increasing conversion of river basins from forested or wild areas to less bio-diverse, monoculture food or cash crop plantations and urbanized areas, and less and less direct interaction of human communities with the riverine landscapes. 
Being a fundamental landscape feature, rivers also represent a fundamental 'function' of the landscape. In many cases landscapes (and societies) based on rivers come into being, evolve and are eroded and are re-established in a different form. Unfortunately, the functions of rivers have generally been 'compromised' since historical times (Wohl 2005), and the accumulation of these compromises have degraded river systems in general all over the world. There are very few rivers that now run wild, contributing to lower diversity in the ecosystems and societies within their landscapes. This has led to a worldwide decoupling of both systems. The fact that this has occurred despite great progress in science and technology makes us think that science and technology alone may not have the answer or capacity to restore or conserve rivers and their societies, and it is here in this book that we look for other potential approaches to their restoration and conservation.

A part of this approach for any river basin may lie in the society using it, and how it chooses to live with the river. A viable way to look for these methods may be capturing the different perceptions and experiences of humans that are centered on a river and its resources, and see what components decouple the two systems. It is here that the system ceases to maintain itself as a socioecological system. This chapter is therefore a synthesis of the different pathways that a society can reconsider, replicate, or continue to maintain the ecosystem for the conservation of rivers and their functions; that is, avoiding the decoupling effect. This chapter is for anyone who loves his/her river, and the scientists and policymakers who are interested in restoring or conserving rivers in a holistic manner.

\section{Rivers and society are coupled systems and must be understood through culture}

It is their interactions over space and time and over hierarchical levels that make rivers immensely complex contributors to landscapes on the planet (Ward 1997). This is particularly so after considering the role of humans with their economic and socio-cultural attributes in these processes. Our societies play a vital role in defining the state of riverine environments and their functioning, but while doing so often fail to accept and cope with the dynamic, nonlinear, but vital functions of rivers (viz. changes in river regime, river course, floods, droughts, the importance of wetlands and the sea/land interface at their mouths, and so on), eliminating their ecological interaction within the landscape (see Chapter 2, this volume). This does not allow the system to be 'coupled' i.e. evolve with mutual interactions between these systems. The benefit of having coupled systems is that they are robust and can shape society and ecology - incorporating its nonlinearity and complexity - with examination, observation, interpretation, and other cognitive processes (Berkes et al. 2003). With these, rivers have a capacity to self-organize without intent (Levin 1998) that leads to the adaptability of the overall system. Incorporating such non-linearity and complexity in resource governance is a main characteristic of complex adaptive systems (CAS), and acts 
as a main factor in the successful joining together of social and ecological systems in river basins.

One such way of 'coupling' systems would be to allow riverine environments and their ecological boundaries the freedom they need to preserve the holistic nature of the system. There are arguments that river basins should be conserved and used sustainably, and that economies within river basins should be developed and operated within the environmental limits of river systems (Molle et al. 2007). In accordance with this approach, there are remarkable recent examples of rivers given rights as human beings: at first in New Zealand after 140 years of effort by indigenous Maori tribes (The Guardian 2017b), and followed by the replication of such laws in the Ganges Basin (The Guardian 2017a); the latter being one of the most complex socio-ecological riverine landscapes on the planet.

However, our understanding how society should fit sustainably within a river's natural cycle is still largely lacking. Landscape ecologists rarely take whole rivers within their studies and the connection between terrestrial ecology and aquatic ecology has not been fully elucidated (Wiens 2002). Although there have been steps to include riverine landscape degradation as an important parameter in Europe and North America, landscape ecology-based managements have not been generally adopted (Jungwirth et al. 2002). A landscape approach, therefore, needs to incorporate important parameters that include ecological connectivity (Amoros and Roux 1988), serial discontinuity (Ward and Stanford 1995), the concept of ecotone (Naiman and Decamps 1990), the flood pulse ecosystem concept (Tockner et al. 2000), and the concept of historical land use (Wohl 2005). It is here that understanding the function of rivers through culture demands that we include coupled system thinking into river basin management while attending to these concepts. This also shapes our understanding through the landscape (a product of human influences and culture), and thus incorporates the cultural point of view as a fundamental component of the river system.

\section{Capturing interactions between rivers and society and the disciplines which studies them as subsets of the whole ecological system of rivers}

Several chapters in this volume (particularly Chapters 2, 4, 5, and 6) suggest that it is difficult for rivers and society to simply coexist as a cohesive entity, as the two are often treated as separate systems. This is particularly so in highly industrialized and urbanized societies, or societies that are water stressed due to biogeographic conditions (Chapters 4, 6, 7, and 15). Capturing the essence of human-river interactions are vital for addressing the needs of societies to live alongside rivers without losing the well-being of both; critical analysis and appreciation of interactions may create pathways to that end. Capturing the multiplicity of the places, processes, and practices through the meanings people attach to their rivers and riverscapes is a way to include these interactions (Chapter 8). Indigenous practices internalize natural systems with their complex adaptive mechanisms such as flood and epidemics (Chapter 9) in communities as a result 
of the eco-centric and sacred viewpoints shared by those societies. However, such perceptions may also prevent intervention, which may be socially justified but environmentally/or ecologically unsafe.

Indigenous and local knowledge systems are thus vital features that hold many river systems together, keeping the use values of the landscapes in front of human communities for a long time, and this is possible because they do not necessarily see the wilder landscapes as a part of the human managed system. This is a vital feature of SESs and river systems. In addition, indigenous and local knowledge systems are themselves continuously evolving by adaptive processes (Berkes 2012), and are passed on to the next generation through cultural interaction with the environment through indigenous and local knowledge (ILK) that deals with the relationship between living beings and their surrounding environments. Without such knowledge, conservation programs may support only that part of the ecosystem that is measured, seen, and/or scientifically proven, but not the other part that is unknown without such cultural interpretations. Thus, the loss (or revival) of indigenous communities, living for thousands of years alongside the river in their culture, can be important tools for scientific evaluation, and therefore for understanding the health of riverine ecosystems (Chapter 9).

\section{Interactions that conserve}

Interactions that conserve include pre-existing, traditional systems for riverine resource uses (Chapters 5 and 9) are important because they are time-tested methods of riverine resource use practiced through cultural interaction with a river, and thus have higher resilience compared to modern high input resource use systems. Pre-existing resource use systems often use lesser inputs and less intensive but diverse use of landscapes, making the system more sustainable (Heckenberger et al. 2007). Modern use of the riverine landscapes cannot match their technology, which are sophisticated and linked with their environments. But indigenous lifestyles and technology are extremely rare as the dominant management mechanisms in the 21 st century, leading to lower and lower resilience due to projectoriented river basin developments, or agricultural practices that increasingly remove the wild and diverse landscapes. These facts are evidenced in some of the case studies in this volume: for example, the case of building of the Garrison Dam that disconnected traditional societies of Mandan, Hidatsa, and Arikara people from their landscapes (Chapter 9), and the erosion of traditional agriculture in the Zayandeh-Rud River in Central Iran (Chapter 5). Formal arrangements that take a longer timescale into account can be better equipped to address ecological sustainability (Chapter 3). However, they might disregard social sustainability aspects even as they uphold concepts of ecological sustainability.

Including all stakeholders to create policy relevant knowledge is another important factor in the task of capturing interactions to bring sustainability in river systems by bringing their landscape value judgments. It is also related to actual and complete information, as it is the stakeholders who would choose how 
to use the landscape and not the planners and policy makers or researchers who may be inclined to apply management interventions that are removed from the real-world scenario. For instance: creating protected areas by taking the local and indigenous people out of the landscape may result in social-ecological decoupling, and alienation of the landscape-based knowledge the community has. This may make us lose valuable interactions that conserve a river's ecological functions.

\section{Interactions that degrade}

These interactions include bureaucratic and top down approaches of river basin management (Chapter 3). Major decisions in river basin management lie often with government authorities (Chapters 7 and 13), whose decisions may be clogged by a less adaptive bureaucratic mechanism that falters where economic returns are low (but environmental returns are high; Chapters 8 and 11). Worse still is the interaction of industries that see regulation of activities as inappropriate (and the industry regulators as irrelevant). Treating river systems through utilitarian western thinking and related analytical methods 'de-couples' them from the everyday lives in basin society, creating another bottleneck for sustainability of rivers (Chapter 8). Moreover, 'risk' based river basin management intervention can gain traction from flood related uncertainties and risks, but comes at the expense of diversity and spatial heterogeneity in a river system, a point exemplified by the case of the Danube basin (Chapter 2).

Furthermore, socio-economic interactions can also degrade a river's key ecological areas (and thereby also degrading its functions), alternative industries like tourism can also degrade it to a significant extent through large-scale land conversions (Chapter 15). Thus, policies and new interventions need careful planning.

\section{Conservation of riverine landscapes outside formally protected areas}

Conservation of the total riverine landscape therefore should be a priority; conservation should not be limited to protected areas (if any). This approach would include rivers in the urban areas. If grounded, it can partly answer some of the most pressing sustainability issues of our generation: city growth within the limits of natural boundaries given by the planets ecosystems. It may be akin to rethinking our behavior and lifestyles; putting us back in connection to the riverine ecosystems with the help of "skills, sensitiveness and orientations" based on longterm experiences with the environment (Ingold 2000, 25). Tapping the informal knowledge base from the community level is a possible solution pathway to this end (Berkes et al. 2000). Cultural attributes and pre-existing systems can provide better options in grounding sustainable land/resource use. However, one problem is that these 'cultural' attributes and interactions are themselves contested, and this is one of the main reasons why a system, in spite of retaining signs of sustainability, can lapse into a degraded state due to endogenous problems (i.e. problematic/unsustainable land use options from the local community itself). Most of 
our case studies (see, for example, Chapters 4, 5, 6, 7, 8, 12, and 15) imply this position (i.e. conservation of rivers outside protected areas as a necessity). Thus, while recent international policy based on theories such as ecosystem services may work, strategic interventions with monetary values centered around utilitarian notions of the riverine resources may only result in increase in wealth or well-being that is measured with certain quantitative estimates at the expense of landscape diversity.

\section{New thinking for the governance of rivers}

The 'new' governance incorporates the ecosystem of rivers into basin governance, policy, and decision-making. One of the difficult issues is the modification of river catchments through linking for better water security at the expense of ecological health of the river, in many cases the exact consequences are unknown. Governance of water resources to drought proof the basin of the Orange River in South Africa exemplifies this issue (Chapter 3 ). These situations are particularly grave when considering the situation of frequent droughts and unreliable rainfall patterns which climate change and overuse can bring (see also Chapter 4 on the Murray-Darling Basin of Australia).

New adaptation strategies are thus highly required in urban regions that incorporate frugal innovations with appropriate, accessible, and affordable solutions. Frugal innovations are more important in the case of urban areas of the developing world to reduce the pressure of growing urban population on the water consumption, which ultimately affect the river basins and ground water (Chapter 6). New methods to understand rivers and its interactions with the society are also called for, and bringing art and artists in the management agenda is a viable way to reduce the utilitarian thinking that often make nature an objective to be controlled (Chapter 12). Ecological art thus can be a new genre in the science of river basin ecosystems and make the discipline more holistic by moving beyond an anthropocentric viewpoint that dominates river basins.

Changing governance systems with personalized form of governance and catchment partnerships can be another viable tool. This is exemplified by the Lee River case (Chapter 13 Evans). Riverscapes must be 'rediscovered' by society, prioritizing local interaction and everyday experiences for a long-term effect on river ecology. This can also help avoid the commodification of river resources and prevent decoupling from the river ecology (Chapter 14).

\section{Monitoring rivers in diverse ways for (new) river basin livelihoods}

Livelihoods that do not see 'management' as external interventions can regain the lost sustainability of river systems. Again, this can be done by an integrated approach where 'strategic' management is minimized as much as possible (be it for restoration and conservation based activities such as in-stream biodiversity conservation, or more growth-based, adverse interventions such as building 


\section{Shamik Chakraborty et al.}

dams for irrigation and hydroelectricity). Stewardship and monitoring through diverse processes can recapture the dynamic nature of rivers and their associated societies. Thus, diversity can be utilized for sustainability of river based tourism (Chapter 14), connection of everyday life and cultural connections to the river (Chapters 8,10 , and 13), for conserving the pre-existing traditional land uses (Chapter 9), and for the sustainability of water related policies (Chapters 3 and 6).

\section{The way forward: gaps that remain}

In the post 1990s we have seen several international agreements based on societyenvironment relationships emerge, and the importance of cultural interactions has come under scrutiny. But cultural interactions are not grounded to the desired extent; there are but a handful of key references. Grounding such aspects may require a long-term agenda that may go past time frames that research projects, policy interventions, grants, and other financial and complementary capital inputs required as a norm. Thus, this book is a very important collection of longer-term views on the connections between rivers and society. In addition, the following points are always worth remembering for a wider, and more personalized, perception of rivers at the same time:

- Bring forward biodiversity as a main indicator for river conservation and restoration, even in urban areas. This may also be brought to light through the diversity of landscapes, and the diversity of lifestyles that are connected to that biodiversity; and

- Highlight the 'my river' (own heritage) point of view - rather than restoring rivers and conserving them for the common good, an approach that has the propensity to create top-down management intervention. Adaptive capacity should be perceived and nurtured at a personal scale, and this can be aided by personalized and vernacular representations of the river.

With these two points in mind we close this volume with the hope that it provides a discursive space for understanding and incorporating rivers into our society in a more holistic and effective way.

\section{References}

Amoros, C., and Roux, A. L. 1988. "Interaction Between Water Bodies Within the Flood Plains of Large Rivers: Function and Development of Connectivity." In Connectivity in Landscape Ecology, edited by K. F. Schreiber. Munstersche Geographische Arbeiten 29: $125-130$.

Berkes, F. 2012. Sacred Ecology. 3rd ed. New York: Routledge.

Berkes, F., Colding, J., and Folkes, C. 2000. "Rediscovery of Traditional Ecological Knowledge as Adaptive Management." Ecological Applications 10: 1251-1262.

Berkes, F., Colding, J., and Folkes, C. 2003. Navigating Social-Eecological Systems: Building Resilience for Complexity and Change. Cambridge: Cambridge University Press. 
The Guardian. 2017a. "Ganges and Yamuna Rivers Granted Same Legal Rights as Human Beings.” The Guardian. www.theguardian.com/world/2017/mar/21/ganges-and-yamunarivers-granted-same-legal-rights-as-human-beings.

The Guardian. 2017b. "New Zealand River Granted Same Legal Rights as Human Beings." The Guardian. www.theguardian.com/world/2017/mar/16/new-zealand-rivergranted-same-legal-rights-as-human-being.

Heckenberger, M. J., Russell, J. C., Toney, J. R., and Schmidt, M. J. 2007. "The Legacy of Cultural Landscapes in the Brazilian Amazon: Implications for Biodiversity.” Philosophical Transactions of the Royal Society B 362(1478): 197-208. DOI:10.1098/rstb.2006.1979

Ingold, T. 2000. The Perception of the Environment: Essays on Livelihood, Dwelling and Skill. London: Routledge.

Jungwirth, M., Muhar, S., and Schmutz, S. 2002. "Re-Establishing and Assessing Ecological Integrity in Riverine Landscapes.” Freshwater Biology 47: 867-887.

Levin, S. A. 1998. "Ecosystems and the Biosphere as Complex Adaptive Systems." Ecosystems 1: 431-436.

Molle, F., Wester, P., Hirsch, P., Jensen, J. R., Murray-Rust, H., Paranjpye, V., Pollard, S., and van der Zaag, P. 2007. River Basin Development and Management. www.iwmi. cgiar.org/assessment/Water\%20for\%20Food\%20Water\%20for\%20Life/Chapters/ Chapter\%2016\%20River\%20Basins.pdf.

Naiman, R. J., and Decamps, H. eds. 1990. The Ecology and Management of Aquatic Terrestrial Ecotones. Paris: UNESCO and Carnforth, UK: Parthenon.

Tockner, K., Malard, F., and Ward, J. V. 2000. "An Extension of the Flood Pulse Concept." Hydrological Processes 14: 2861-2883.

Ward, J. V. 1997. "An Expansive Perspective of Riverine Landscapes: Pattern and Process Across Scales.” Gaia 6: 52-60. DOI:10.14512/gaia.6.1.6

Ward, J. V., and Stanford, J. A. 1995. "The Serial Discontinuity Concept: Extending the Model to Floodplain Rivers." Regulated Rivers: Research and Management 10: 159-168.

Weisman, A. 2007. The World Without Us. New York: St. Martin's Press.

Wiens, J. A. 2002. "Riverine Landscapes: Taking Landscape Ecology Into the Water." Freshwater Biology 47: 501-515.

Wohl, E. 2005. "Compromised Rivers: Understanding Historical Human Impacts on Rivers in the Context of Restoration." Ecology and Society 10(2): 2. 


\section{Index}

Amazon 11-12

Anthropocene 3-4, 22, 181-182

art, redefinition 194

art custodians of our rivers 184-201

Avian Habitat Resource Sculpture 196

Biwako-Yodogawa watershed 13-17

capturing interactions between rivers and society $248-250$

Chadegan Reservoir dam project 66-67

changes to water supply systems 27-46

changing river landscape 5-6

Chennai 77-92; adaptation strategies 88-89; Adyar River 82-83; augmenting water sources 83-84; awareness, information and communication relating to water quality 87 ;

Buckingham Canal and its influence 83; Coovum River 81-82; desalination 84; ground water sources 84 ; hydrological cycle 80; increase in maximum temperature 88; Kotalaiyar River 81; Krishna River Project 84; population growth, water demand and supply gaps 85 ; recommendations for policy change 89; river system 77-79; rivers 81-83; rivers and water supply status $85-87$; rivers traversing 78 ; storage of water in jars 86; supply adaptation strategies 77-92; surface water bodies 81-83; variables in water resource management 79-80; Veeranam Project 83-84; water demand 78; water quality $86-87$; water resource management 79-80; water resources 84 ; water supply shortage 78-79; water supply system 81-84 Chennai Metropolitan Development Authority 79

climate change, realities of 185
Clutha River 117-133; 'the big river' 123; cultural landscape 127-130; and flooding 125; The Golden River 124-125; influence of 125; language of vernacular riverine landscape 126-127; Maori discourses 124; people, place and rivers 130-131; personal placescapes 130; vernacular landscape in practice 123-125; vernacular practices making river places $127-130$

Common Oriental Clam 19

Complex Adaptive Systems 9-10

Congo 12

conservation of riverine landscapes outside formally protected areas 250-251 contemporary ecological debate 181 controlling rivers $2-4$

dam projects 2

dams 2, 5-6, 11-12, 15-16, 21-22, $97-110,128,131,135,138,225-227$. 236, 252

De Beer 175, 177-180

Den Briel Meuse 178

drought management using stream flow analyses 37-38

drought proofing 27-46; actual seven-year performance of storage system compared to expected 38; calculation of risk of failure and reliability 37 ; critical period for storage system 35 ; example of simple inter-basin transfer, Bloemfontein Area of South Africa 43; hydrological background 28-36; hydrology and resource system analyses 39; 41; inter-basin transfers of water 31-32; methodology used in South Africa 27-46; modelling water resource system as starting point 39; out of kilter algorithm 42; rainfall 29-30; reservoir 
yields for different record lengths 36 ; streamflow 31-34; typical 2-basin water resource system 31 ; water likely to be available in future 32-34; yield and reliability calculations 36 ; yield assessment 34-36

\section{EcoArt 184-185}

encountering a river $1-2$

Europoort 177

\section{"Flood Plain Wall" 197-198}

flow 1, 39, 42-43, 104, 223; and motion 1, 160, 200; and sustenance, equilibrium 1 , $5,10,22$, see also river, rivers

Fort Berthold reservation 135-138

from control to comprehension 2-4

Garrison Dam 136-137

Gavkhouni wetland 64-66; importance of 64-65; and pollution 65; requirement inflow 66

governance of rivers, new thinking 251

Hérault River 233-245; agriculture 236-238; Bélarga 239-240; bridge construction in Agde 235; caves cooperatives 241; cultivated crops 237; cycles of poverty and prosperity 243; economic revival of river communities 240-243; fishing 235-236; floods 234-235; forests 236-238; French State; and 244; global forces 244; hot springs 236; industry 238-240; irregular nature of flow 233-234; Lac du Salagou 236; mills 238-240; mining 238; relationship between people and water 234; "ripisylve" 238; riverine environment 235-240; second homes 241-242; social landscape and environment 233-245; state as tourism promoter 242; tourism 241-243; tourist development 242-243; unpredictabilities 243-244; Viaduc du Millau 244-245; wine production 240-241

hydraulic civilizations 2

hydrocitizenship 202-219; and urban rivers 202-204

indigenous and local knowledge systems 249

industrialization 11

interactions: that conserve 249-250; that degrade 250

inter-basin transfers of water 31-32
Irland, Basia 186-193; book as recurring motif 189-191; core notion of EcoArt 187; "Gathering of Waters" 187, 191-193; ice books 189-191; "Portable Repository" 193

Japan, socioecological degradation 13-14 "J-Hook Braided Log" 196-197

Katsura River Basin 17

Kawakami Dam 16-17

Kizu River Watershed 14; artificial structures 16

\section{Land Art 184}

landscape: cultural geographical bearings 117-120; ecology 248; idea of 117-120

Landtong, green stage in the harbour $179-180$

Lee Valley 202-219; aesthetic values 214; analyzing as lived river space of hydrocitizens 211-216; biodiversity and ecosystems 208; and Canals and Rivers Trust 208-209; catchment 206; conceived space 209; conflict between user and groups 208; cultural mapping 211, 212, 213; emerging hydrocitizenship 216-217; graffiti and floating cinema 215; heritage assets 214; lived space 210-211; most common use 214; neighbouring towns 205; perceived space 210; river governance in 204-209; social production of river space 209-211; spatiality 206; stakeholders 207-208; stewards 207-208

Lee Valley Regional Park 204-205

long term agenda 252

Los Angeles River 150-168; annual clean up 156; aridity of climate; and 153; Chinatown 161-166; conceptual end 150; conceptual timeline 157-158; confluence with Rio Hondo 162; concrete channel 156; controlling 155-157; diversion 154; end of 150-168; fictional treatments 158-159; lifeforms 152-153; Little Portion 157; lower section 151-152; mouth of 151; paradox; and 167; paradoxical end of the line 157; power of water; and 160; Rupert Hughes on 159; sign at end 153; study in paradox; as 152; waste, accumulation of 160-161; water source; as 154

loss of spatial heterogeneity 11 
McCormick; Daniel 193-199

Missouri River 134-149; The Big Muddy 134; cultural cohesion of indigenous peoples; and 137-138; and cultural resilience 145-146; Flood Control Act 1944 134-135; fracking boom at Fort Berthold 143-144; indigenous language speakers 139-140; language restoration through media 141; life in traditional villages 136; oil and gas production 143-145; restoration ecology of culture 138-143; restoration ecology of indigenous culture and language 134-149; restoration of healing rituals and ceremonies 141-143; restoration of language and story 138-143; stories and indigenous peoples 140-141; taming of 136-137; water protectors at Standing Rock 1444-145

monitoring rivers in diverse ways for new river basin livelihoods 251-152

"Multi-Systems Habitat Sampling" 196

Murray-Darling System 47-59; adaptive plan 53; climate variability 49-50; community as stakeholders 53-54; conditions of water resources 50-51; connectivity 49; controversial water policy 53; Federation Drought 47; geography 48-49; geology 48-49; governance, plans and reality 52-53; groundwater 50-51; heritage 54-56; hydrology 48-49; long-term annual inflow and water use 52; management of water resources 47-59; surface water 50; tourism, recreation and sustainability 54; users of basin water resources 51-52

\section{Old Testament 174}

out of kilter algorithm 42

potable water, shortage of 77

rainfall 29-30; and climate change 29; indicative single mass plot 30 ; records 29; reducing rainfall record 30

Rhine-Meuse delta 169-183; De Jacobsladder (Jacob's Ladder, novel) 169-176; nature conservation 179; protection of native species $178-179$

Rio Grande 186-193; damage to 187-188; flooding 188; importance of 187 ; restoration projects $188-189$; running dry 188 river: as system or entity $4-5$; cultures 3 ; and economic development 2, 19, 211; management 5-6; motion of 1; see also river tourism; rivers; specific entries of individual rivers

River Fork Ranch 197-198

river tourism 6; 220-232; appeal to communities 220; components 225-227; direct relationships 230; Europe 222; evaluation 225; impact of other uses 227-228; major attractions 221-222; natural environment 227; policy questions 228-230; and political conflict 226-227; politics and governance of river use 228-230; range of factors affecting 223; religious value of rivers 226; rivers as boundaries 226; structure 225-227; and travelers 220-221; unsafe aspects of adventure 221; use of river systems 224

rivers: and communities $27-46$; as an entity 4-5; and biodiversity 3, 65, 179, 208, 223, 252; as complex adaptive systems 4, 9-26, 248; as fundamental function of landscape 247; fundamental geomorphological processes 246: human and ecological use 223-225; imaginary power in western culture 170; informal knowledge base 250; landscape and place 117, 248; and my river 252; metaphorical resonance 186; re-engineer to natural state 1 ; and responsible governance $6,45,56,68,141,217,236$, 250-251; and society as coupled systems 246-248; and society debate revisited 1-8; as socioecological landscapes 9-26; as vernacular landscapes 117-133

riverscape 4-5, 120

Rotterdam: expansion of harbour 176; Green Agreement 179

Sao Francisco River 93-116; changing river flows 104; 105; control of flow 99-101; dams, effect 103; drought 201202015 101-105; and droughts 95-96; electric supply sector; and 99; extreme temporal and climatic events; effects of 10105; hydropower 96-97; hydropower stations 100; instruments for irrigation 98; purposes during colonial times 94; users 96-98; uses 96-98; vulnerability 110; watershed 95; see also Velho Chico

SES 10-11 
Shahrestan Bridge 73

Sobradinho reservoir, percentage of water volume available 102

social scientists, role of 3

socioecological landscape, multiple changes $21-22$

streamflow 31-34; naturalized 32-34

summer, obvious object for anthropomorphism 172

sweetfish 20

Takatsu River Watershed 17-21; disturbance 21; gentle image 18; sweetfish 20

Taki River Basin 15

textual potamology 150

transboundary cooperation 6, 228-229

Truckee and Carson rivers, living sculpture on 193-199

Truckee River 195

TVA 2

urban river, hydrocitizenship and 202-204

Velho Chico 93-116; assessing public participation 105-106; Catholic Church; and 106-107; civil society against Inter-basin water transfer project 108; and Dom Helder Camara 109; ecosystems 93; federal and state support 105; geography and demographic characteristics 93; and hunger strikes 107; management of water resources 110-111; National Water Policy 1997
100; new approach to water resources governance 109-110; Padre Cicero; and 108-109; public participation 106-109; stakeholders of management discourses 98-99; traditional forms of participation, citizens initiated 106-109; Transposicao 107; see also Sao Francisco River

vernacular landscapes 2, 6, 117, 119-123, 131

water likely to be available in future 32-34

watershed sculpture 193-199

Wetlands 5-6, 49-54, 137, 152-153, 186, 188-189, 199, 212, 227-229, 247 see also Gavkhouni wetland

Yodo River Basin 13-17

Zayandeh/Gavkhouni drainage basin 61

Zayandeh-Rud 60-76; agriculture and 67-68; climatic background 61-63; and climate changes 60; general geology 61-62; geological formations and their effects 62; geophysical background 61-63; and industry 68-69; integrated water catchment management 71-72; rainfall 63; regional climate 62-63; social and political environment 71-72; and tourism 72-73; urban use 69-70; wastewater treatment 70-71; water and wastewater pricing 70; water management $66-72$; water resources 63-64 